NBSIR 77-1274

\title{
Retrofitting an Existing Wood Frame Residence for Energy Conservation--an Experimental Study
}

D. M. Burch

C. M. Hunt

Thermal Engineering Section Center for Building Technology Institute for Applied Technology National Bureau of Standards

Washington, D.C. 20234

July 1977

Final Report

Prepared for

Federal Energy Administration

100

$-456$

Washington, D.C. 20461 


\section{RETROFITTING AN EXISTING WOOD \\ FRAME RESIDENCE FOR ENERGY \\ CONSERVATION--AN EXPERIMENTAL STUDY}
D. M. Burch
C. M. Hunt

Thermal Engineering Section Center for Building Technology Institute for Applied Technology National Bureau of Standards

Washington, D.C. 20234

\section{Sponsored by:}

The Federal Energy Administration

12th and Pennsylvania, N.W.

Washington, D.C. 20461

\section{July 1977}

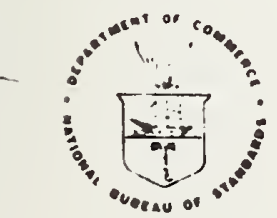

U.S. DEPARTMENT OF COMMERCE, Juanita M. Kreps, Secretary Dr. Sidney Harman, Under Secrotary Jordan J. Baruch. Assistent Secrotary for Science and Technology NATIONAL BUREAU OF STANDARDS. Emest Ambler. Acting Director 
RETROFITTING AN EXISTING WOOD-FRAME RESIDENCE FOR ENERGY CONSERVATION--

An Experimental Study

by

D. M. Burch and C. M. Hunt

ABSTRACT

A wood-frame residence having only limited insulation in the attic was retrofitted in three stages to reduce its energy requirements for heating and cooling. The three retrofit stages comprised: reducing air leaks; adding storm windows; and installing insulation in the floor, ceiling, and walls. The house was extensively instrumented to evaluate energy savings and other performance factors. An economic model was used to evaluate the cost effectiveness of the retrofit options and the number of years to pay back their initial investment.

The walls of the test house were insulated with three different types of insulating material: fibrous glass wool, cellulosic fiber, and urea-formaldehyde foam. The thermal performance of these three insulating materials was measured and compared, both in the field and laboratory.

"Recommended good practices" for moisture protection were applied when insulation was installed in the test house. The effectiveness of these measures in preventing damaging moisture accumulation in crawl spaces and attics was evaluated.

Finally, thermographic surveys were performed before and after the retrofit! Based on the results of these surveys, criteria for distinguishing between insulated and uninsulated wood-frame cavity walls were presented.

Key words: Air infiltration; condensation in buildings; energy conservation; energy measurements; fuel-savings; heat-loss reduction; insulation properties; residential heat loss; retrofitting houses; thermal conductivity; thermal insulation; thermography. 
CONTENTS

$\underline{\text { Page }}$

ABSTRACT

EXECUTIVE SUMMARY

1. INTRODUCTION

2. DESCRIPTION OF TEST HOUSE

3. ENERGY-CONSERVATION MODIFICATIONS PERFORMED ON THE TEST HOUSE

3.1 Measures Taken to Reduce Heating and Cooling Energy Requirements

3.2 Protective Measures for Preventing Moisture Accumulation in the Attic and Crawl Space

4. HEAT-TRANSFER PROPERTIES

5. AIR-INFILTRATION MEASUREMENTS

5.1 Theory

5.2 Measurement Technique

5.3 Results and Analysis

5.4 Conclusions

6. ENERGY MEASUREMENTS

6.1 Experimental Plan

6.2 Instrumentation and Measurement Technique

6.3 Winter Energy Measurements

6.4 Summer Energy Measurements

6.5 Conclusions

7. ECONOMIC ANALYSIS

7.1 Theory

7.2 Results 
8. COMPARISON OF THE THERMAL PERFORMANCE OF THREE INSULATING MATERIALS

8.1 Guarded-Hot-Plate Measurements

8.2 Full-Scale Laboratory Wall Tests

8.3 Heat Transmission and Moisture Measurements in Retrofitted Wall Sections of the Test House

8.4 Other Performance Properties of Insulation

8.5 Summary of Results

9. EFFECTIVENESS OF RECOMMENDED "GOOD PRACTICE" MEASURES FOR PREVENTING MOISTURE ACCUMULATION

9.1 Experimental Plan

9.2 Experimental Results

9.3 Conclusions

REFERENCES

NOMENCLATURE

CONVERSION TABLE

ACKNOWLEDGMENTS

APPENDIX A.

Description of the Third Stage of the Retrofit

A-1

APPENDIX B Location of Heat Leaks in Residences Using Infrared Thermography

APPENDIX C. Location of Air-Leakge Paths in a Residence Using Pyrotechnic Smoke 
1. Photograph of the test house.

2. Typical cross-section of the house after retrofitting.

3. Floor plan of the test house.

4. Caulking compound being applied to foundation sill.

5. Storm window being installed.

6. A photograph of the south side of the test house showing the awnings.

7. Apparatus used to measure air-leakage rates for the test house.

8. Pre-retrofit air-infiltration correlation.

9. Post-retrofit air-infiltration correlation.

10. Schematic diagram of furnace system showing the location of measuring transducers.

11. Photograph of the weather station.

12. Floor plan of test house showing location of temperature sensors.

13. Measured heating loads for the unoccupled test house after various stages of the retrofit.

14. Energy-release rates for equipment, lighting, and occupancy.

15. Heating-load correlations for the occupied test house after various stages of the retrofit.

16. Heating degree days as a function of outdoor balance temperature for Washington, D.C.

17. Pre- and post-retrofit winter crawl-space temperatures.

18. Pre- and post-retrofit winter attic temperatures. 56

19. Pre- and post-retrofit sensible cooling loads. 59

20. Pre- and post-retrofit latent cooling loads. 
21. Pre- and post-retrofit summer indoor relative humidities. 61

22. Pre- and post-retrofit daily-average summer crawl-space 63 temperatures.

23. Pre- and post-retrofit daily-average summer basement 64 tempera tures.

24. Pre- and post-retrofit daily-average summer attic

temperatures.

25. Construction details of laboratory test wall.

26. Location of measurement transducers on laboratory test wall.

27. Photograph of exterior surface of laboratory test wall showing buckling and warping of the wood siding.

28. Elevation view of wall section of the test house showing measuring station.

29. The effect of mean wall temperature on the thermal conductance of the three separate wall sections.

30. Floor plan of the test house showing location of humidity sensors and places where moisture content samples were cored out.

31. Variation of indoor relative humidity and relative humidities of embedded sensors.

32. Water blister at exterior surface of $U-F$ wall section.

33. Percent linear shrinkage of urea-formaldehyde foam as a function of elapsed time.

\section{TABLES}

1. Description of Exterior Building Elements Before the Retrofit (Inside-to-Outside).

2. Thermal Conductivities of Building Components.

3. Areas and Pre-Retrofit Thermal Transmittances for Building Components. 
4. Thermal Transmittances for Retrofitted Building Components.

5. Pre-Retrofit Air-Infiltration Measurements.

6. Air-Infiltration Rates After Stage 1 of the Retrofit.

7. Air-Infiltration Rates After Stage 2 of the Retrofit.

8. Air-Infiltration Rates After Stage 3 of the Retrofit.

9. Effect of Attic Ventilation on Air Infiltration.

10. Summer Air-Infiltration Rates.

11. Calculation of Annual Heating Loads.

12. Comparison of Reductions in Heat-Loss Rate to

Reductions in Annual Heating Load.

13. Pre-Retrofit Steady-State Winter Heat-Loss Calculations.

14. Post-Retrofit Steady-State Winter Heat-Loss Calculations.

15. Daily-Average Heat-Transfer Rates, Btu/h.

16. Cost Estimate for Energy Conservation Options.

17. Heating System Efficiencies and Fuel Costs Used for Sample Calculations.

18. Winter Heating Energy Cost and Savings, Dollars.

19. Pay-Back Periods for Energy-Conservation Options.

20. Thermal Conductivities of Three Insulating Materials Measured in the Guarded-Hot-Plate Apparatus.

21. Experimental Results of Ful1-Scale Laboratory Wall Tests After Two-Month Exposure.

22. Temperature Coefficients $(\alpha)$ for the Thermal Conductivity Values.

23. Comparison of Measured and Predicted Thermal Conductance Values at Wall Sections Insulated with Loose-Fill Materials. 


\section{TABLES}

$\underline{\text { Page }}$

24. Winter Moisture Contents of Material Samples Removed from Cellulose Wall Sections.

25. Winter Moisture Contents of Material Samples Taken from the Glass-Fiber Wall Section.

26. Winter Moisture Contents of Material Samples Taken from U-F Wall Section.

27. Summer Moisture Contents of Material Samples Removed from Cellulose Wall Section.

28. Summer Moisture Contents of Material Samples Taken from the Glass-Fiber Wall Section.

29. Summer Moisture Contents of Material Samples Taken from the U-F Wall Section.

30. Measured Linear Shrinkage of In Situ U-F Foam of the Test House. 

A wood-frame residence having only limited insulation in the attic was retrofitted in three stages to reduce its energy requirements for space heating and space cooling. The three stages were: reducing air leaks; adding storm windows; and installing insulation in the floor, ceiling, and walls. The house was extensively instrumented to evaluate energy savings and other performance factors.

Techniques used to reduce air-leakage rates did not produce measurable reductions in heating energy requirement. This was attributed to the fact that the test house was of tight construction in its original state. The addition of storm windows reduced heating energy requirement by 25.2 percent. The installation of insulation in the walls, ceiling, and floor reduced heating energy consumption by an additional 33.3 percent. The total reduction in heating energy requirement achieved by all stages of the retrofit was found to be 58.5 percent.

Measurements of dally average cooling loads before and after the retrofit indicated that the retrofit was not effective in reducing the cooling energy requirement for this particular test house under the particular conditions tested. Post-retrofit latent loads were found to be somewhat less than corresponding pre-retrofit values, whereas postretrofit sensible cooling loads were found to be slightly higher than corresponding pre-retrofit values. An explanation is given in the following:

As part of the third stage of the retrofit, a plastic-sheeting vapor barrier was installed over the bare earth of the crawl space and insulation with a vapor barrier was installed in the floor over the crawl space. These measures were effective in reducing vapor flow to the living space and caused a substantial reduction in indoor relative humidity during the summer. Lower moisture levels within the living space after the retrofit resulted in lower latent loads. Prior to the retrofit, there was no insulation in the floor over the crawl space, and heat loss through the floor provided natural summer cooling for the house. The insulation placed in the floor over the crawl space precluded much of the natural cooling provided by heat loss through the floor and more than offset the benefits derived from additional ceiling insulation. The roof overhung the south wall of the test house and provided significant shading of the windows from solar radiation, thereby precluding much of the benefit to be derived from awnings. The effect of storm windows and wall insulation was small due to the fact that daytime reductions in heat gain were offset by nighttime reductions in natural cooling of the test house since the windows were kept closed at all times. The applicability of these findings on summer cooling to similar houses is discussed in the text. 
An economic analysis was performed to evaluate the relative merits of the energy conservation measures. Since the retrofit did not provide reductions in the cooling energy requirement for this particuiar test house, the effect of reduction in the summer energy requirement was not included in the economic analysis. Sealing air leaks was not found to be cost effective, since this process produced no measurable reduction in the winter energy requirement. For this set of retrofit experiments, storm windows were found to be more cost effective than installing insulation, since they required significantly fewer years to pay back their initial investment.

A second objective of the study was to compare the thermal performance of three insulating materials commonly used to retrofit the exterfor walls of residential buildings. The three materials selected for study were cellulosic fiber, fibrous-glass wool, and urea-formaldehyde (U-F) foam. The comparisons consisted of thermal conductivity measurements using the guarded-hot-plate apparatus, heat-loss and moisture measurements performed on a full-scale test wall which was exposed to simulated winter conditions in the laboratory, and heat-loss and moisture measurements on wall sections of the test house.

Thermal conductivity measurements were performed on specimens of the three materials in accordance with the guarded-hot-plate standard method of test given in ASTM C 177-71. Each specimen was prepared so that its density was approximately equal to the typical density of the insulation material when $i t$ is blown into cavity walls. The thermal resistance (R-value) for all three materials was found to be good. The thermal resistance (R-value) for the U-F foam was found to be 17 and 19 percent higher than the values for cellulosic fiber or fibrous glass wool, respectively.

In the laboratory, a full-scale $(8 \times 8 \mathrm{ft}(2.44 \times 2.44 \mathrm{~m}))$ test wa11, similar in construction to the walls of the test house, was exposed to approximately a $5^{\circ} \mathrm{F}\left(-15^{\circ} \mathrm{C}\right)$ winter condition for a two-month period. The interior surface of the wall was maintained at approximately $75^{\circ} \mathrm{F}\left(23.9^{\circ} \mathrm{C}\right)$ and 45 percent $\mathrm{rh}$. Different sections of the test wall were insulated with the three insulating materials. Heat-loss rates and moisture contents of the insulations were measured at the separate sections of the test wall. Measured heat-loss rates agreed within approximately 10 percent of corresponding predicted values determined by the series-resistance method, even though a significant amount of moisture had accumulated within each of the insulating materials.

The three insulating materials were also installed in 14-foot ( $4.3 \mathrm{~m}$ ) wall sections of a test house. Measured thermal conductances of the separate wall sections were observed to decrease as the mean temperature of the insulation was reduced. Thus, the thermal resistance of the wall sections increased when the outdoor air temperature became lower. Measured conductances of the wall sections insulated with cellulosic fiber and fibrous-glass wool agreed with corresponding values predicted by the series-resistance method. In the case of the U-F wall section, measured conductances of this wall section were observed to be 
higher than corresponding predicted values determined by the seriesresistance method. The higher thermal conductances observed at the U-F wall section were attributed to the presence of a fissure (void space) in line with the measuring station, and the possible presence of a portion of the water originally contained in the foam.

After the winter season, in the third week of April, 76 days after insulation was blown in the walls of the test house, samples of the wood siding, sheathing, and insulation materials were cored out at various locations of the separate wall sections. The moisture contents of these samples were determined using an oven-drying technique.

The moisture contents of the wood siding and sheathing at wall sections of the test house insulated with the loose-fill materials ranged from 12 to 15 percent. The average moisture contents of the wood siding and sheathing at the U-F wall section of the test house were found to be 23.2 and 33.4 percent, respectively. These values are considerably higher than corresponding values measured at the other wall sections, and may be accounted for as follows:

The U-F foam had a wet density of $2.51 \mathrm{~b} / \mathrm{ft}^{3}\left(40.1 \mathrm{Kg} / \mathrm{m}^{3}\right)$. After the $U_{-} F$ foam had cured in the wall cavity, its dry density was 0.7 $1 \mathrm{~b} / \mathrm{ft}^{3}\left(11.21 \mathrm{Kg} / \mathrm{m}^{3}\right)$. The difference in these densities is due to the water originally contained in the foam, which represents the introduction into the wall cavity of approximately $0.47 \mathrm{lb}$ of water for each square foot of exterior wall surface $\left(2.29 \mathrm{Kg} / \mathrm{m}^{2}\right)$. The foregoing results suggest that much of water originally contained in the foam had migrated from the U-F foam into the sheathing and wood siding and was unable to penetrate the oil-base paint system applied to the exterior surface. An oil-base paint film has a comparatively low permeability to water vapor and functions somewhat as a vapor barrier. At the end of the winter season, some blistering of the oil-base paint system at the U-F wall section was observed.

It should be pointed out that if a more permeable paint system had been applied to the exterior surface the original moisture of the U-F foam might have passed through the construction and escaped to the outside environment. The heat of the following summer was effective in driving out most of the accumulated moisture.

Other performance properties of the insulations that were investigated included shrinkage and fissures of the U-F foam and settling of the loose-fill materials.

Approximately three months after the foam was installed in the test house, the U-F wall section was opened up, and the foam was examined for shrinkage and fissures. Several fissures were observed. The linear shrinkage was measured and found to be approximately 2.6 percent. Fifteen, twenty, and twenty-six months after the installation of the foam, the U-F wall section was again opened up and the linear shrinkage was found to be $5.6,7.3$, and 8.1 percent, respectively. In this time 
period, the rate of shrinkage was observed to occur at approximately a constant rate irrespective of the age of the foam; very little leveling of $f$ in the rate of shrinkage was observed. Aside from the shrinkage, the foam appeared to be in good condition after 26 months. No new measurements of conductance were made.

In the case of walls insulated with loose-fill materials, no settling of the materials was observed over an 18-month period. In the case of the ceiling, gradual settling of the cellulose fiber insulation occurred during the first 25 days following the installation of the material, after which settling took place at a reduced rate. At the end of 25 days, the loose-fill material had settled $3 / 4$ inch $(1.91 \mathrm{~cm})$ out of an initial fill of 6 inches $(15.24 \mathrm{~cm})$. Eighteen months after the installation, the total measured settling was $1-1 / 2$ inch $(3.82 \mathrm{~cm})$ out of an initial fill of 6 inches $(15.24 \mathrm{~cm})$, or 25 percent. The bag count for the cellulose insulation indicated that the cellulose installed had been initially applied in the ceiling at too light a density.

A third objective of this study was to observe the effectiveness of "recommended good practice" measures for preventing moisture accumulation. During the third stage of the retrofit, attic ventilation in the amount of one square foot of ventilation opening for every 300 square feet of ceiling was provided for the test house, in accordance with FHA requirements. Also, the existing ceiling insulation was equipped with a vapor barrier facing downward. The combination of these two protective measures was effective in keeping the attic dry during the winter.

In the case of the crawl space, a vapor-barrier ground cover was placed over the bare earth of the crawl space, and crawl-space ventilation openings consistent with ASHRAE recommendations were provided. These protective measures were found to be effective in keeping the moisture content of wood parts of the floor during the summer below 19 percent. Usually summer moisture problems, such as wood rot, begin to occur when the moisture content approaches the fiber saturation point $(30 \%)$. Thus, the protective measures were effective in keeping the summer moisture content of the wood parts of the floor at a satisfactory level.

As part of this study, a thermographic survey was performed before and after the retrofit of the test house. Thermography was shown to be an effective technique for distinguishing between insulated and uninsulated wood-frame cavity walls.

The authors consider the following findings to be significant:

1. Energy conservation actions which reduce the thermal transmittance of the envelope of a building provide reductions in heating energy requirements not only by reducing heat-loss rates but also by lowering the outdoor balance temperature for the building. When the outdoor balance temperature is reduced, there will exist a larger 
number of heating hours for which the internal heat (from lights, equipment, and people) can provide the required heating energy instead of the heating plant.

2. Retrofit measures to reduce the air leakage of a well-built house may not be effective in saving significant amounts of energy. The installation of storm windows to a home may not produce a reduction in air infiltration when the existing windows are equipped with good weatherstripping.

3. The installation of storm windows and insulation in the walls, floors, and ceiling of a frame house produce significant reductions in the energy requirements for heating, but by themselves may not reduce the energy requirement for cooling significantly, especially if the daily average indoor-outdoor temperature difference is small during the summer. Combining night ventilation with daytime air conditioning would probably increase the energy conservation benefits during the summer for a retrofitted house.

4. The benefit of insulating the floor of a house over a crawl space should be evaluated on an annual basis, not on a seasonal basis, The winter benefits of floor insulation are likely to be partly offset by reduced heat loss to the crawl space during the summer.

5. Water-mixed foam insulation should not be introduced into wall cavities of existing buildings unless adequate provision is made for the escape of the moisture. An incorrectly placed vapor barrier may inhibit the escape of the moisture, resulting in moisture damage to the building. For this particular test house, an oil-base paint system was applied to the exterior surface of the test house, which restricted the escape of the moisture originally contained in the foam. Paint blistering was shown to result. Similar results would be expected with other vaporimpervious coatings on films.

6. Cellulosic fiber, fibrous glass wool, and urea-formaldehyde foam were found to have good insulating properties. With regard to other performance properties of the insulating materials, at 18 months, no settling was observed for either of the dry loose-fill materials installed in the walls of the test house. For the U-F foam, several fissures were observed after the foam had cured. Also, linear shrinkage of the foam was observed to occur at a constant rate. At 26 months, the total amount of observed linear shrinkage was more than eight percent.

7. When cellulosic fiber is applied at too low a density to ceilings, substantial settling may occur. 
RETROFITTING AN EXISTING WOOD-FRAME RESIDENCE FOR ENERGY CONSERVATION--

An Experimental Study

by

D. M. Burch and C. M. Hunt

\section{INTRODUCTION}

This study was carried out under the sponsorship of the Federal Energy Administration to provide technical information that could be used in future broad-scale energy-conservation programs for existing buildings.

Many residences in this country were constructed during times when energy was cheap and plentiful. During these times, there was little incentive to employ energy-conserving construction practices, and as a result homes were built to minimize initial building costs. Thus, many of the present, homes of this country are essentially uninsulated (i.e., single-pane windows, little or no weatherstripping, and little or no insulation in the walls, ceiling, and floor).

Approximately 11.7 percent of the nation's energy is used for space heating and cooling of residential buildings [1]*. Estimates for the potential energy savings from improving the thermal performance of existing homes range from 20 to 60 percent.

In an earlier study [2] Anderson exposed to winter conditions four test houses located in St. Paul, Minnesota. The construction of the four houses was identical except for the amount of insulation. The first house was uninsulated; the second, third, and fourth houses were insulated with blanket insulation throughout in thicknesses of 0.9 $(R-3.6), 1.7(R-6.8)$, and 2.3 inches $(R-9.2)$, respectively. The savines in measured fuel consumption for the second, third, and fourth hoises were $27.2,31.3$, and 32.2 percent, respectively. In a recent study [3] Degelman and Lewis showed that upgrading the thermal resistance of the ceiling Insulation from $\mathrm{R}-13$ to $\mathrm{R}-19$, installing storm windows, and adding weatherstripping to a house located in Canton, Ohio, produced a 34-percent reduction in energy requirements for space heating and cooling.

This report presents the results of a retrofit study. The objectives of this study were: (a) to quantify the winter heating and summer cooling energy savings achieved by retrofitting an existing residence having limited insulation; (b) to compare the thermal performance of

* Numbers in brackets refer to literature references cited at the end of the text. 
three different types of insulating materials commonly used to insulate existing cavity walls; and (c) to evaluate the effectiveness of "recommended good practices" measures [4] for preventing damaging moisture accumulation in attics and crawl spaces. An economic model is presented and the cost effectiveness of the retrofit options and the number of years required to pay back their initial investment is calculated.

Although it is anticipated that significant energy savings are possible by applying more insulation, adding storm windows, and by sealing the cracks around the doors and windows, very few empirical case studies are available to assess the actual benefit of such a retrofit. In the present study, energy measurements were performed on an actual residence before and after energy conservation measures were implemented, thereby providing substantive data on the energy savings achieved by the energy conservation measures.

Three insulating materials commonly used to retrofit existing residential walls for improving their insulating properties are fibrous glass wool, cellulosic fiber, and urea-formaldehyde (U-F) foam. When measured in the laboratory with a guarded hot-plate apparatus, all three of these materials are shown to have good insulating properties. However, when they are blown into the walls of a residence, their effective insulating properties may be reduced by certain factors. For example, loose-fill materials blown into wall cavities sometimes settle, if the materials are installed at too low a density. In the case of U-F foam, if the material is not prepared properly, excessive shrinkage may occur, producing fissures and void spaces where the insulation pulls away from the studs. The present study examines these factors in a typical woodframe house.

Reference [4] recommends "good practice" measures for reducing moisture accumulation in attics and crawl spaces. These measures include proper ventilation and the inclusion of a vapor barrier on the warm-side of installed insulation. For crawl spaces, a vapor-impervious ground cover is also recommended. These protective measures were implemented in a typical wood-frame house and their effectiveness was examined.

For geographic locations having cold winters, winter moisture accumulation in exterior walls sometimes poses a serious problem. Moisture accumulation in the siding and sheathing of exterior walls may cause paint failure, and in serious cases may actually cause warping and/or buckling of wood siding. In the winter, occupant-related activities inside a residence release as much as 25 pounds $(11.3 \mathrm{Kg}$ ) of water per day [5]. A portion of this water will permeate through the exterior walls when no vapor barrier is present. The effect of adding thermal insulation to walls is to reduce the temperature of the siding and sheathing, thereby increasing the likelihood of condensation. Water vapor can also enter the wall from the inside through cracks along the baseboard and around the electrical receptacles. Another source of moisture accumulation in exterior walls is rain penetration through 
cracks in the construction. The present study examines moisture accumulation in retrofitted side walls.

Thermography has been shown to be an effective tool for locating and identifying heat leaks in bulldings [6]. There has been much recent interest in establishing criteria which would make it possible to use thermography as a survey tool to distinguish insulated walls from uninsulated walls. In the present study, the feasibility of using thermography as such a survey tool is demonstrated.

\section{DESCRIPTION OF TEST HOUSE}

The test house selected for the present study was a wood-frame rambler, built in the early 1950's and located in suburban Washington, D.C., adjacent to the Nationa 1 Bureau of $\mathrm{Standards.} \mathrm{It} \mathrm{is} \mathrm{sometimes}$ referred to as the Bowman House, a name derived from the former owner. A photograph of the Bowman House is shown in figure 1. This house, having a floor area of $2054 \mathrm{ft}^{2}\left(191.8 \mathrm{~m}^{2}\right)$ excluding the unheated basement floor area, is somewhat larger than typical bouses in this country, which range between 1200 to $1500 \mathrm{ft}^{2}$ (111 to $139 \mathrm{~m}^{2}$ ). The west side of the test house ( $r$ ight side as shown in figure 1) contains the living quarters (living room, dining room, foyer, kitchen, and study) and is built over a basement, whereas the east side contains the sleeping quarters and is built over a crawl space.

The house in its original state was typical of many houses having limited insulation. The walls and floor were without thermal insulation, while the ceiling had $3-1 / 2$ inches $(8.9 \mathrm{~cm})$ of glass-fiber blanket-type insulation laid on top of the ceiling between the joists. A kraft-paper vapor barrier on the backside of the insulation was placed so that it faced the ceiling below.

The house initially had single-pane windows with the exception of a large picture window in the living room which contained insulating glass. Good weatherstripping had been installed around the doors and windows, and the construction of the house was tight to begin with. The window area is 16 percent of the wall area and 11 percent of the floor area.

The quality of construction of the house indicated that it had been constructed by skilled carpenters. A description of the floor, ceiling, roof and exterior walls of the test house prior to the retrofit is given in table 1. A cross-section of the house after retrofitting is given in figure 2. The walls of the house were constructed without fire stops, and diagonal wind braces were used at the corners of the house. A floor plan of the house is shown in figure 3.

The original heating plant, consisting of an oil-fired forced-air furnace system was used for the pre-retrofit heating energy measurements. This furnace had an output capacity of $120,000 \mathrm{Btu} / \mathrm{h}(35,100 \mathrm{~W})$ and its efficiency was measured and found to vary between 52 and 58 


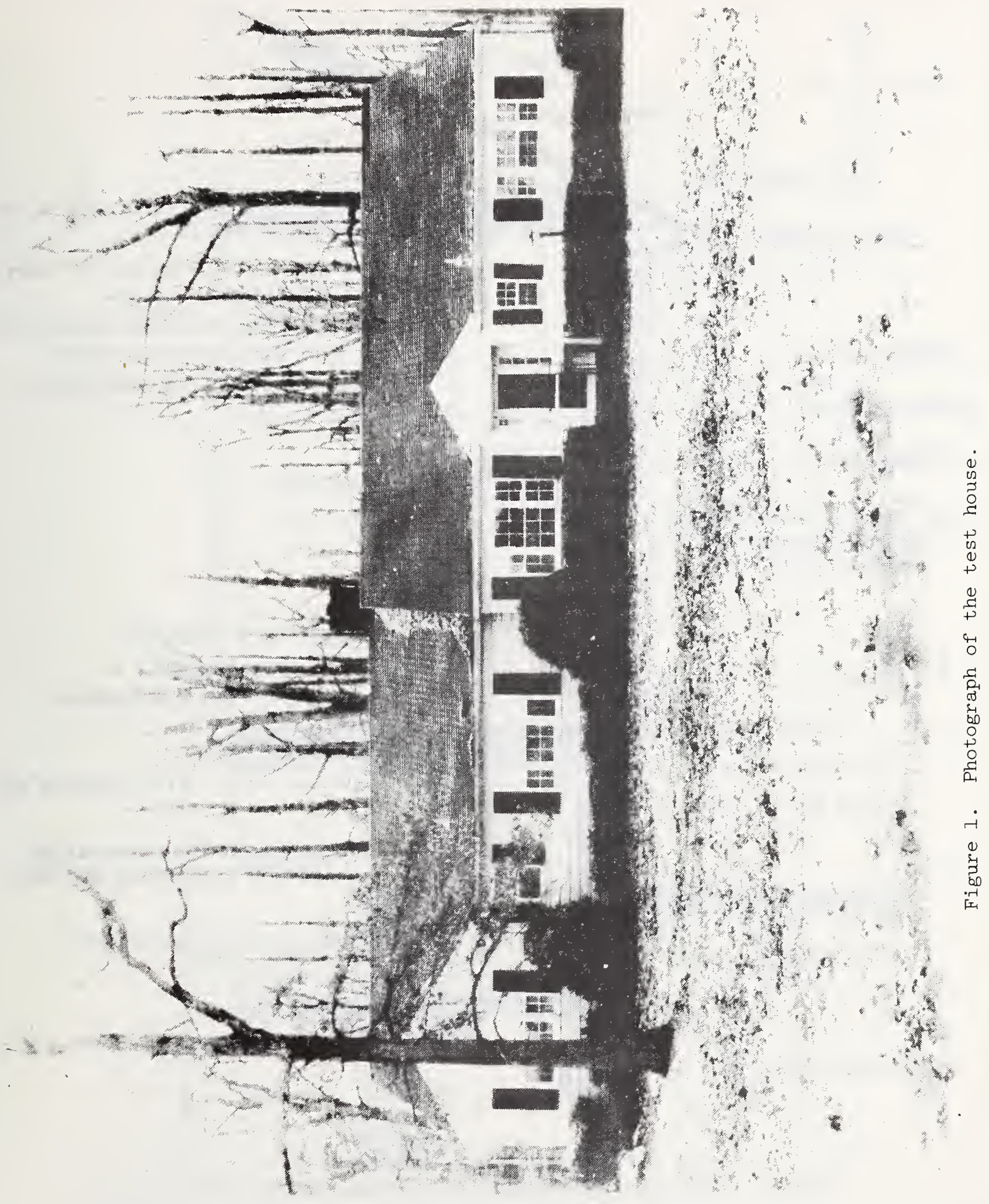




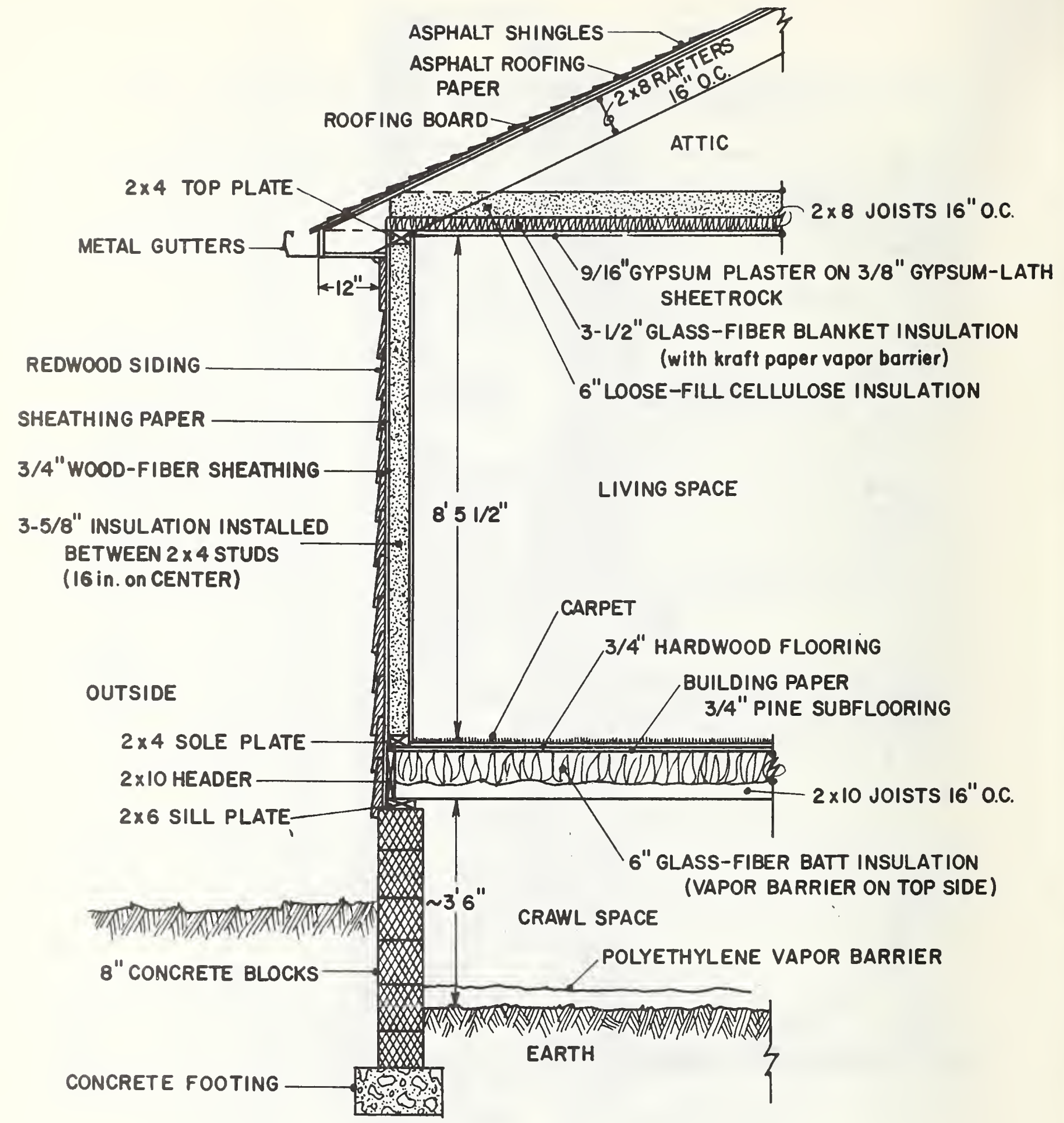

Figure 2. Typical cross-section of the house after retrofitting. 

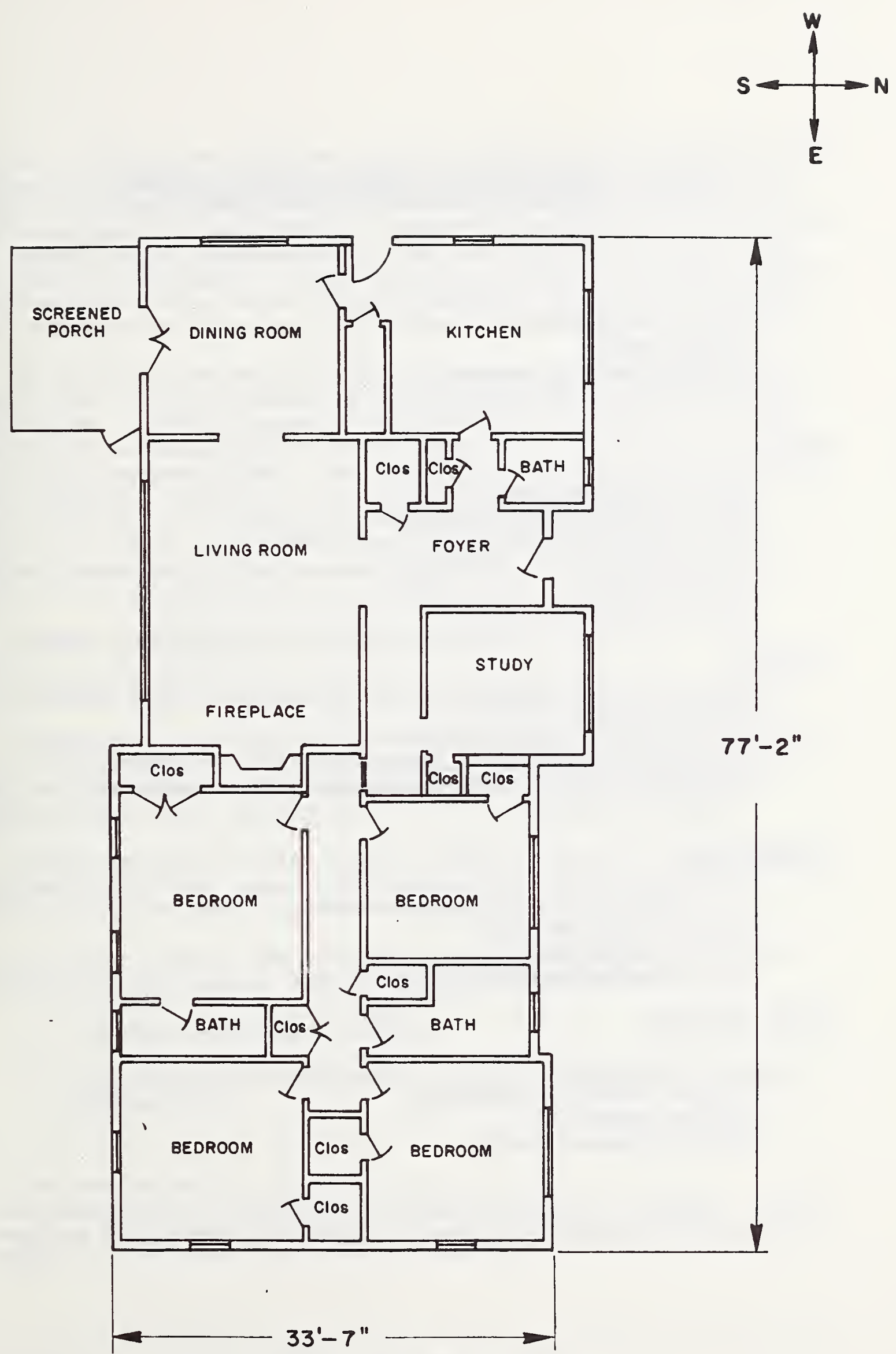

Figure 3. Floor plan of the test house. 
Table 1. DESCRIPTION OF EXTERIOR BUILDING ELEMENTS

BEFORE THE RETROFIT (INSIDE-TO-OUTSIDF)

Floor

3/4-inch hardwood (oak) floor

building paper

3/4-inch pine subf looring

$2 \times 10$ wood joists placed 16 in. on center

$\underline{\text { Wa } 11}$

9/16-inch gypsum.plaster

3/8-inch gypsum-lath sheetrock

$2 \times 4$ wood studs place 16 in. on center

3/4-inch wood-fiber sheathing

sheathing paper

7/16-inch redwood siding

\section{Ceiling}

9/16-inch gypsum plaster

3/8-inch gypsum-lath sheetrock

$2 \times 8$ wood joists (with 3 1/2-inch glass-fiber blanket insulation with a draft-paper vapor barrier installed between the joists)

\section{Sloping Roof}

$2 \times 8$ rafters placed 16 in. on center

3/4-inch wood sheathing

asphalt roofing paper

1/8-inch asphalt shingles

\section{Attic End Wa 11s}

$2 \times 4$ wood studs

3/4-inch wood-fiber sheathing

sheathing paper

7/16-inch redwood siding 
percent. Warm air was delivered into two separate supply branches which delivered air to room registers in the west and east sides of the test house. The rooms, except the bathrooms, were equipped with return air registers which were connected to a common return plenum for the furnace. The warm-air supply registers were located at the baseboard level on interior wall partitions, and the return registers were located at the same level on exterior walls. The air-delivery rate for the blower of the o1l furnace was measured and found to be $1450 \mathrm{ft} / \mathrm{min}(0.684 \mathrm{~m} / \mathrm{s})$.

After the pre-retrofit heating energy measurements, the oil-fired furnace was replaced with a 5-ton (i.e., 60,000 Btu/h) air-to-air heatpump system. The duct system of the house was not changed. The heatpump system was equipped with three stages of electric-strip heaters for providing supplemental heat. The capacity of the electric-strip heaters was intentionally sized to satisfy the design heating load for the

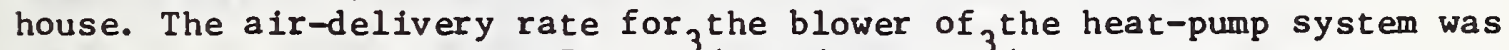
measured and found to be $1770 \mathrm{ft}^{3} / \mathrm{min}(0.835 \mathrm{~m} / \mathrm{s})$. In a separate series of measurements the seasonal coefficient of performance of the heat pump was found to be 1.74 for heating [7].

\section{ENERGY-CONSERVATION MODIFICATIONS PERFORMED ON THE TEST HOUSE}

\subsection{Measures Taken to Reduce Heating and Cooling Energy Requirements}

Immediately following the pre-retrofit winter heating measurements, 3-1/2 inch glassfiber blanket insulation was installed under the basement ceiling.* This insulation was present during the pre-retrofit summer cooling energy measurements.

During the second winter season, energy-conservation masures were performed on the test house in three stages to permit the separate energy savings for each stage to be quantified.

The first stage of the retrofit consisted of reducing air leaks. Specific measures taken to seal air leaks are listed below:

a. Fireplace damper was repaired.

b. A spring-activated damper for the kitchen ventilation-exhaust was installed.

* This insulation was installed as a sound-absorbing treatment. It was required for programs unrelated to the present energy conservation study. 
c. Caulking compound was applied to cracks around the warm-air supply ducts where they penetrated the inside walls. Corresponding cracks around the air return ducts were not caulked, since air leakage through these cracks was considered to be much less significant than air leakage through the cracks of the supply ducts.

d. Improved weatherstripping was installed under exterior doors.

e. A board was inserted into a large crack between exterior siding and foundation wall (foundation sill) followed by the application of a caulking compound (see figure 4).

f. Inside and outside surfaces of exterior walls were repainted. A latex-paint system was applied to the interior surfaces and an oil-base paint system to the exterior surfaces.

g. Wall-to-wall carpet was installed, except for the kitchen, the two rear bedrooms, and the bathrooms.

h. All window panes were reputtied. In addition, the intersections between the window frames and the house were caulked at various locations as needed.

i. Weatherstripping was installed around the door to the attic.

The air leaks associated with items $a$ and $b$ above were identified from a smoke test described in appendix $C$, and air leaks associated with items $d$ and $e$ were discovered during a thermographic survey described in appendix $B$. It would seem reasonable that if the combination of these measures were implemented significant reductions in air leakage rates for the test house should be produced.

The second stage of the retrofit consisted of the addition of woodsash storm windows (see figure 5). During the heating tests, considerable condensation developed on the inside surface of the storm pane. To permit this moisture to escape to the outside, two $1 / 8$-inch $(0.32 \mathrm{~cm})$ weep holes were drilled through the bottom rail of the storm windows. After the weep holes were drilled, the condensation disappeared.

The third stage of the retrofit consisted of applying insulation to the walls, ceiling, and the floor. Since NBS did not have the equipment or the trained personnel to blow loose-fill insulation into walls and over cellings, the third stage work was carried out under contract. As part of the third stage of the retrofit the following measures were performed: 6-inch $(15.2 \mathrm{~cm})$ glass-fiber batts (R-18.5)* were installed

* The R-values for the glass fiber blanket and cellulose insulation applied to the ceiling were taken from the manufacturer's literature. 


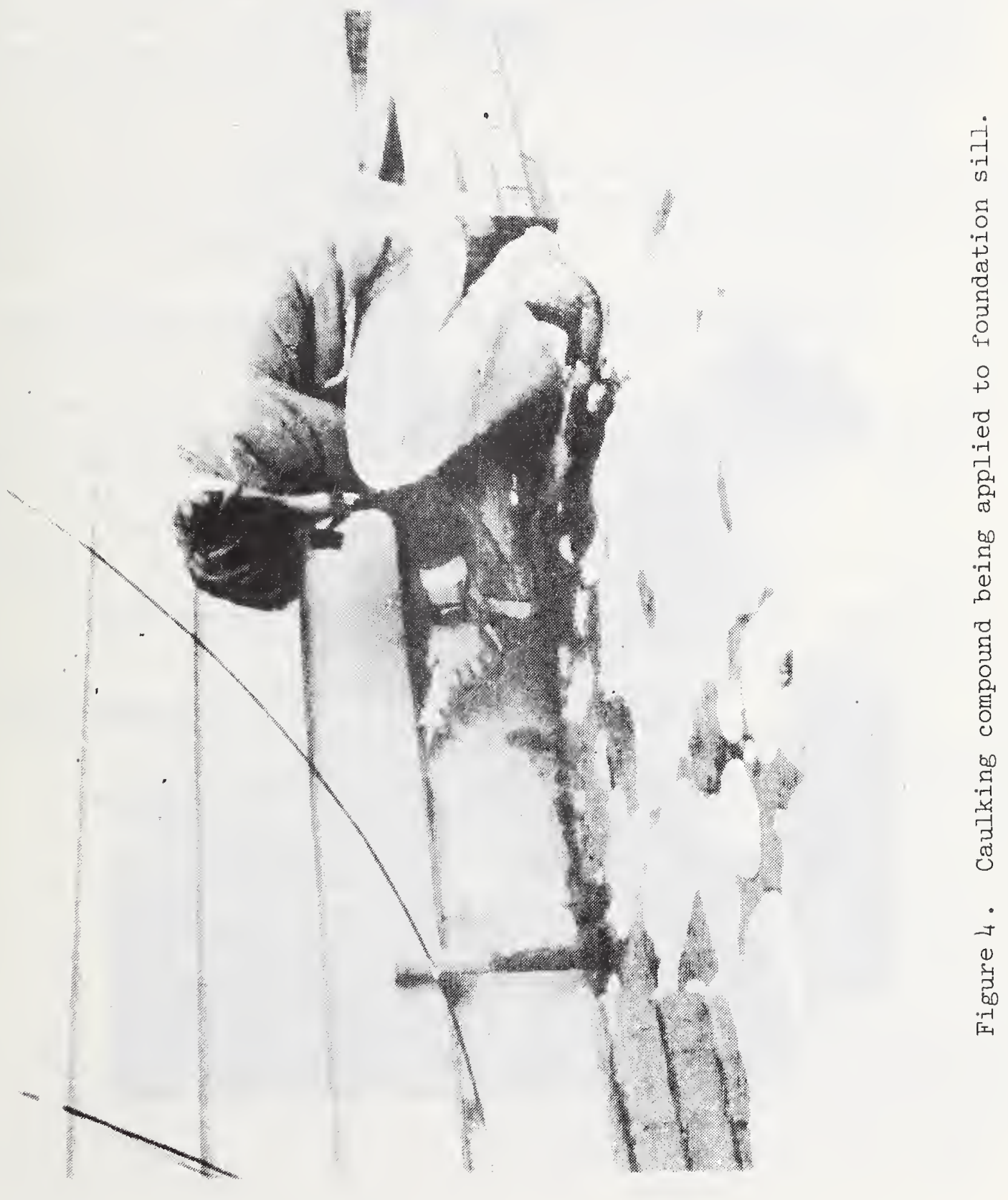




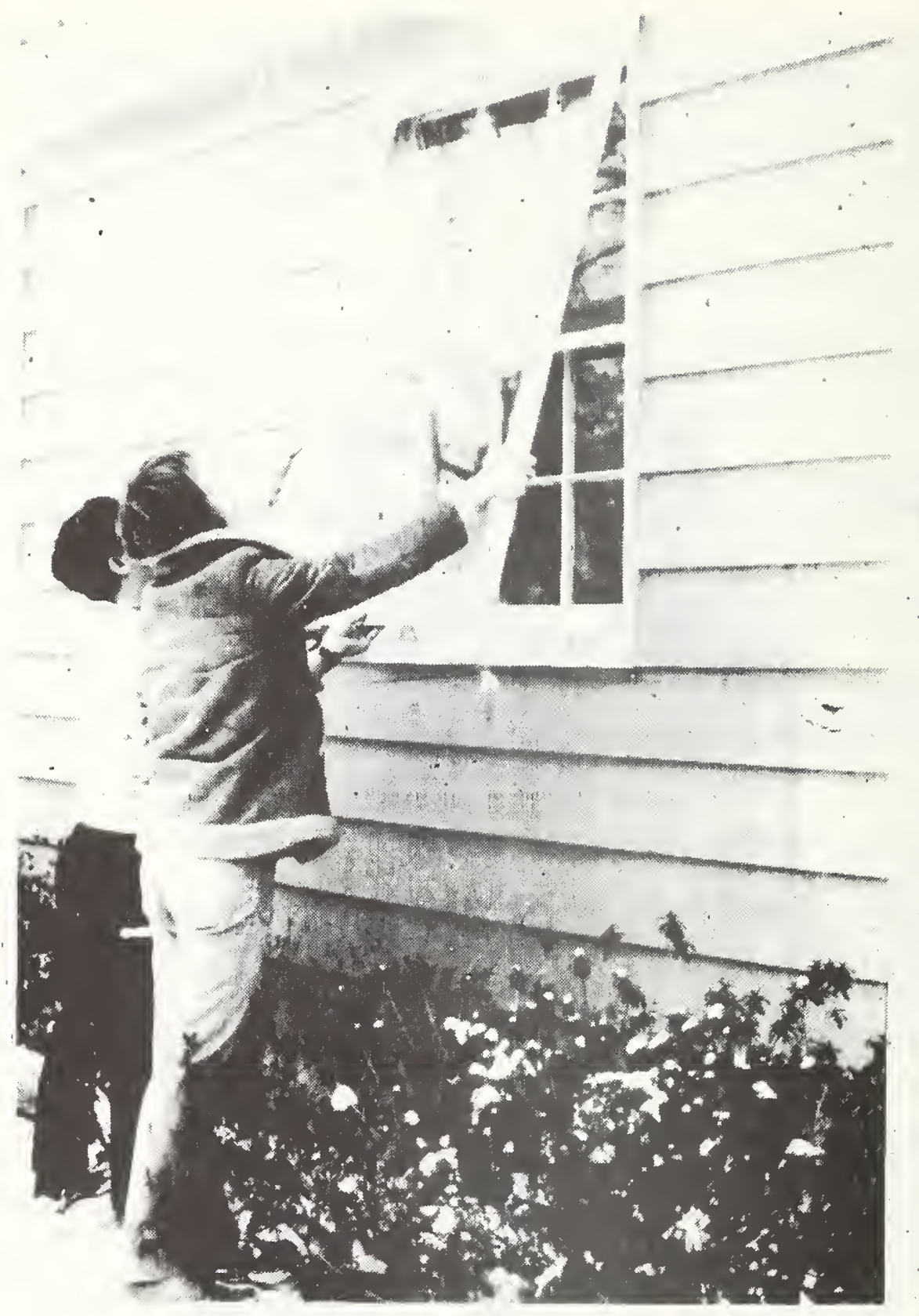

Figure 5. Storm window being installed. 
under the floor over the crawl space, insulation of three types was blown into the walls of the test house, and 6 -inches $(15.2 \mathrm{~cm})$ of 100 sefill cellulose $(R-20.8)$ were blown on top of the existing $3-1 / 2-i n c h$ $(8.89 \mathrm{~cm}) \mathrm{glass}-\mathrm{f}$ iber blanket $(\mathrm{R}-10.8)$ in the ceiling. Loose-fill glass fiber (R-13.7) was blown into one 14 -foot $(4.27 \mathrm{~m})$ wall section, and $U-F$ foam (R-14.4) was installed in a second $14-\mathrm{foot}(4.27 \mathrm{~m})$ wall section. The remainder of the walls of the test house were insulated with loosefill cellulose (R-12.6). A detailed description of the third stage of the retrofit is given in appendix $A$.

Before the post-retrofit summer cooling energy measurements, aluminum awnings were installed above the windows on the south side of the test house. A photograph of the south side of the test house after the awnings were installed is given in figure 6 .

\subsection{Protective Measures for Preventing Moisture Accumulation in the Attic and Crawl Space}

As part of the third stage of the retrofit, the following protective measures for preventing winter condensation on cold attic surfaces and summer condensation on cold crawl-space surfaces were in effect after stage 3 of the retrofit:

\section{Attic}

Ventilation area required in FHA Minimum Property ${ }_{2}$ Standards. (The net ventilation opening was $7.9 \mathrm{ft}^{2}\left(0.734 \mathrm{~m}^{2}\right)$. )

\section{Craw1 Space}

Ventilation area recommended in ASHRAE Guide. (The net ventilation opening was $\left.0.65 \mathrm{ft}^{2}\left(0.060 \mathrm{~m}^{2}\right).\right)$

- Polyethylene vapor barrier placed over the bare earth of the crawl space.

- Vapor barrier facing the floor present on the backside of the insulation.

Even though a vapor barrier on the backside of the ceiling insulation is not considered necessary for the Washington, D.C. area when adequate attic ventilatic. is provided, one was present nonetheless. It should also be pointed out that prior to the third stage of the retrofit the adjustable louvers of the ventilation openings at the ends of the attic were closed so that ventilation was limited to leakage under the eaves and through the shingles. These were opened as part of stage 3 of the retrofit to conform with attic ventilation requirements of FHA Minimum Property Standards. 


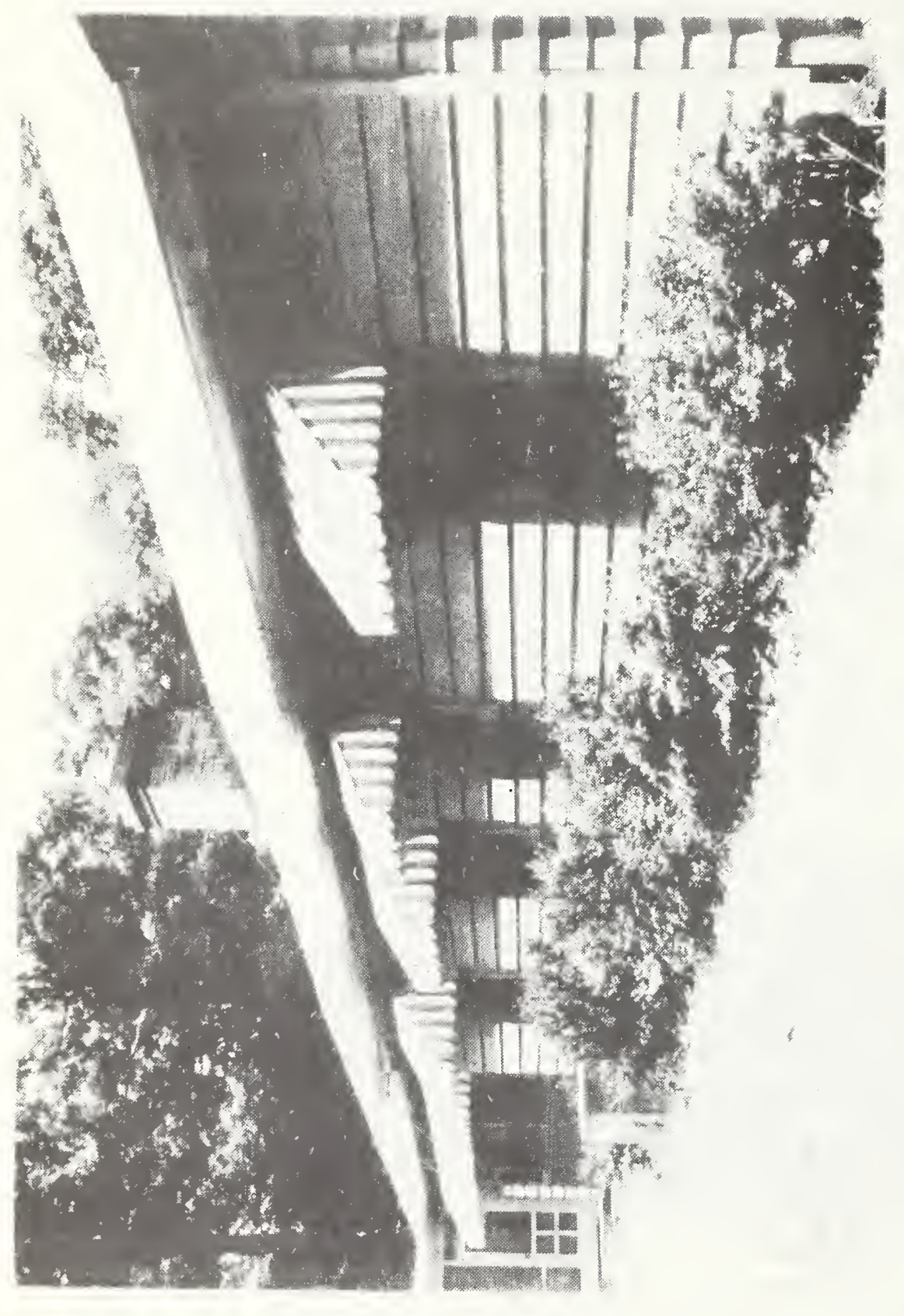

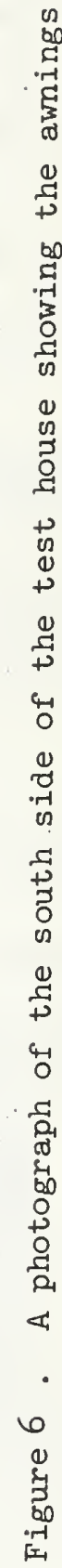




\section{HEAT-TRANSFER PROPERTIES}

The thermal conductivities of common building components needed for the heat-transfer analysis presented later in the report are given in table 2 .

Table 2. THERMAL CONDUCTIVITIES OF BUILDING COMPONENTS $[4,8,9,10]$

\begin{tabular}{ll} 
Building Component & $\begin{array}{l}\text { Conductivity } \\
\text { Btu/h.ft.F }\end{array}$ \\
\hline Hardwood (oak) floor & .10 \\
Pine subfloor & .07 \\
Wood structural members & .068 \\
Gypsum plaster & .28 \\
Gypsum-lath sheetrock & .12 \\
Wood-fiber sheathing & .032 \\
Redwood siding & .070 \\
Glass-fiber insulation & .027 \\
(blanket/batts) & $.022 *$ \\
Glass-fiber (loose-fill for walls) & .12 \\
Gypsum board & .023 \\
Loose-f ill cellulose & $.024 *$ \\
o celling & $.021 *$ \\
Urea-formaldehyde foam & \\
\hline
\end{tabular}

* Based upon NBS measurements discussed later in the report.

The areas used to compute heat flows through bullding components were the inside areas for each of the building components. These areas and their respective calculated pre-retrofit thermal transmittance values (U-values) are summarized in table 3. 
Table 3. AREAS AND PRE-RETROFIT THERMAL TRANSMITTANCES FOR BUILDING COMPONENTS

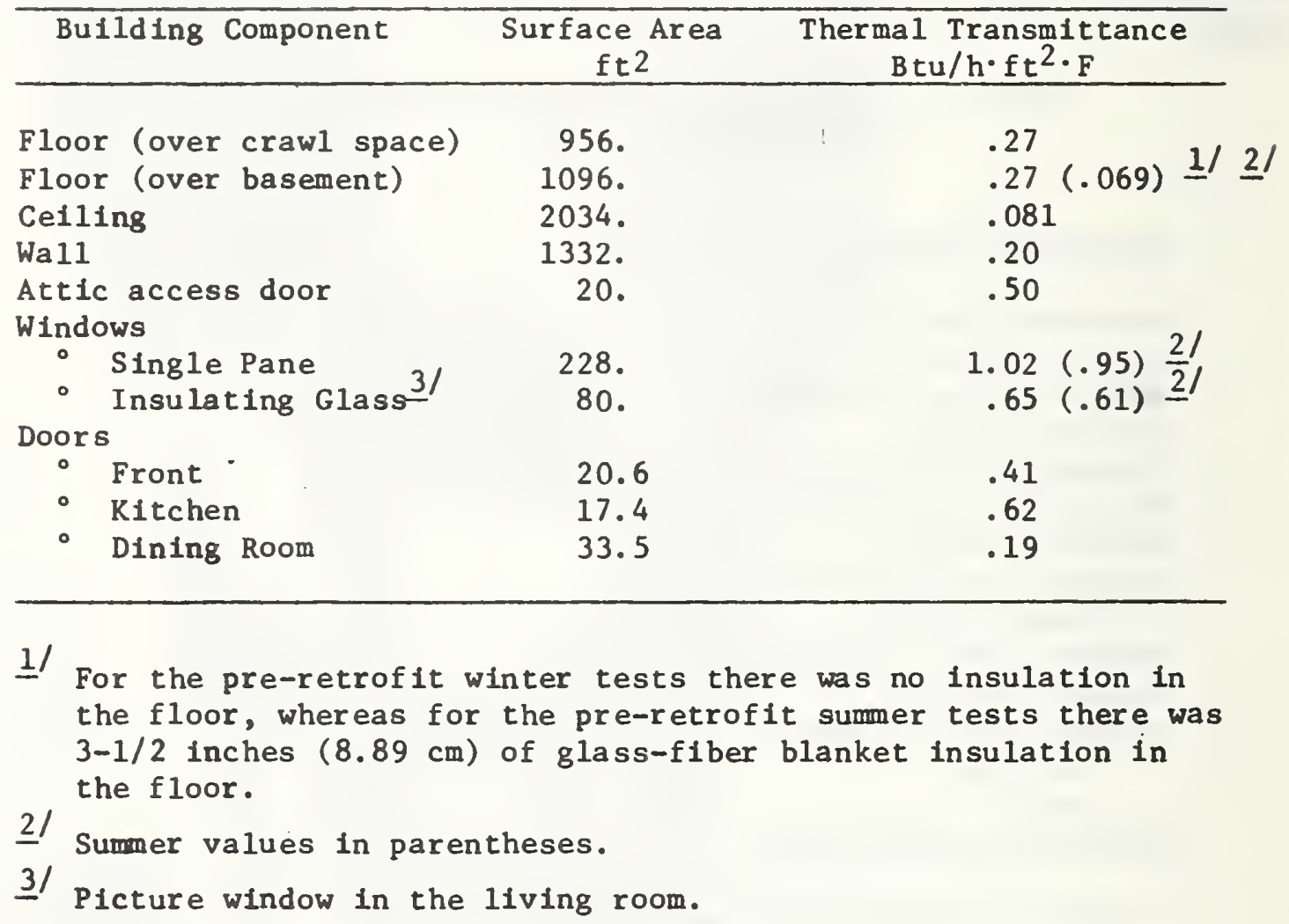

These thermal transmittance values for the walls, ceiling, and floor were calculated using the series-resistance method, or

$$
U=\frac{1}{1 / h_{1}+\sum_{n=1}^{N}\left(l_{n} / k_{n}\right)+1 / h_{0}}
$$

where $h_{1}, h_{0}=$ inside and outside surface heat-transfer coefficients, respectively, $\mathrm{Btu} / \mathrm{h} \cdot \mathrm{ft}{ }^{2} \cdot \mathrm{F}\left(\mathrm{W} / \mathrm{m}^{2} \cdot \mathrm{k}\right)$

$\ell=$ thickness of material, ft (m)

$\mathrm{k}=\mathrm{thermal}$ conductivity, $\mathrm{Btu} / \mathrm{h} \cdot \mathrm{ft} \cdot \mathrm{F}\left(\mathrm{W} / \mathrm{m}^{\cdot} \mathrm{k}\right)$

$U=$ thermal transmittance, $B t u / h \cdot f t^{2} \cdot F\left(W / m^{2} \cdot k\right)$

$N=$ number of layers in the building component 
Therma 1 bridges such as studs and joists were treated as parallel heatflow paths with no laterial heat flow between adjacent components. Heattransfer coefficients at the inside and outside surfaces were taken from Ref. [4].

Thermal transmittance values for retrofitted building components are given in table 4 .

Table 4. THERMAL TRANSMITTANCES FOR RETROFITTED BUILDING COMPONENTS

Building Components
Thermal Transmittances $\mathrm{Btu} / \mathrm{h} \cdot \mathrm{ft}^{2} \cdot \mathrm{F}$

\author{
Wall (insulated with cellulose) \\ Wall (insulated with glass fiber) \\ Wall (insulated with U-F foam) \\ Floor (over crawl space) \\ Floor (over basement) \\ Celling \\ Double-Pane Window
}

.069

.065

.063

.048

.069

$.035 \frac{21}{1 /}$

1/ The thermal transmittance values for the windows include the heat-transmission path through the wood sash.

2/ This thermal transmittance value is for the thickness originally installed in the ceiling. After 25 days the cellulose was observed to have settled 12.5 percent which produced approximately a five percent increase in the overall thermal transmittance of the celling.

\section{AIR-INFILTRATION MEASUREMENTS}

The purpose of the air-infiltration measurements was to investigate the effect of the three stages of the retrofit on the air-infiltration rates of the test house. Separate tests were carried out to investigate the effect of opening the attic ventilation louvers (which occurred during the third stage of the retrofit) on the air-infiltration rates for the test house. Summer air-infiltration measurements were performed on the house in its original condition and again after all the retrofit actions had been completed. 


\subsection{Theory}

To determine the rate of air exchange between the test house and its surroundings, the rate of disappearance of sulfur-hexafluoride $\left(\mathrm{SF}_{6}\right)$ tracer gas was measured. A small quantity of $\mathrm{SF}_{6}$ was released inside the test house, and the concentration decay rate was measured. The rate of change of concentration of tracer gas caused by infiltration was treated as a first-order process expressed by the equation:

$$
-\frac{\mathrm{dc}}{\mathrm{dt}}=\frac{\mathrm{v}}{\forall} \cdot \mathrm{c}
$$

where $v=$ rate at which air enters and leaves the enclosure, $f t^{3} / h\left(m^{3} / s\right)$

$$
\forall=\text { volume of the enclosure, } \mathrm{ft}^{3}\left(\mathrm{~m}^{3}\right)
$$$$
c=\text { concentration of tracer gas at time }(t) \text {. }
$$

Equation (2) may be expressed in the form

$$
\begin{aligned}
& c=c_{0} e^{-\frac{v}{\psi} \cdot t} \\
& I=\frac{v}{\psi}=\frac{1}{t} \cdot \ln \left(c_{0 / c}\right)
\end{aligned}
$$

where I denotes the number of volume changes per hour and $c_{0}$ is the initial concentration of tracer gas. The natural logarithm of the relative concentration, $\left(c / c_{0}\right)$ was plotted as a function of time. The air change rate (I) was taken as the negative slope of a least-squares fit line through the data points.

\subsection{Measurement Technique}

Sulfur-hexafluoride concentrations were measured with a gas chromatograph equipped with an electron-capture detector. A photograph of the measurement apparatus is shown in figure 7. Sampling and analysis were performed semi-automatically using a system which has been previously described [11]. The response of the instrument was logarithmic over the concentration range of 5 to $15 \mathrm{ppb}$ which was used.in the measurements. This may be expressed by the relationship:

$$
c=k \cdot \ln \left(\mathrm{J} / \mathrm{J}_{\mathrm{o}}\right)+\lambda
$$




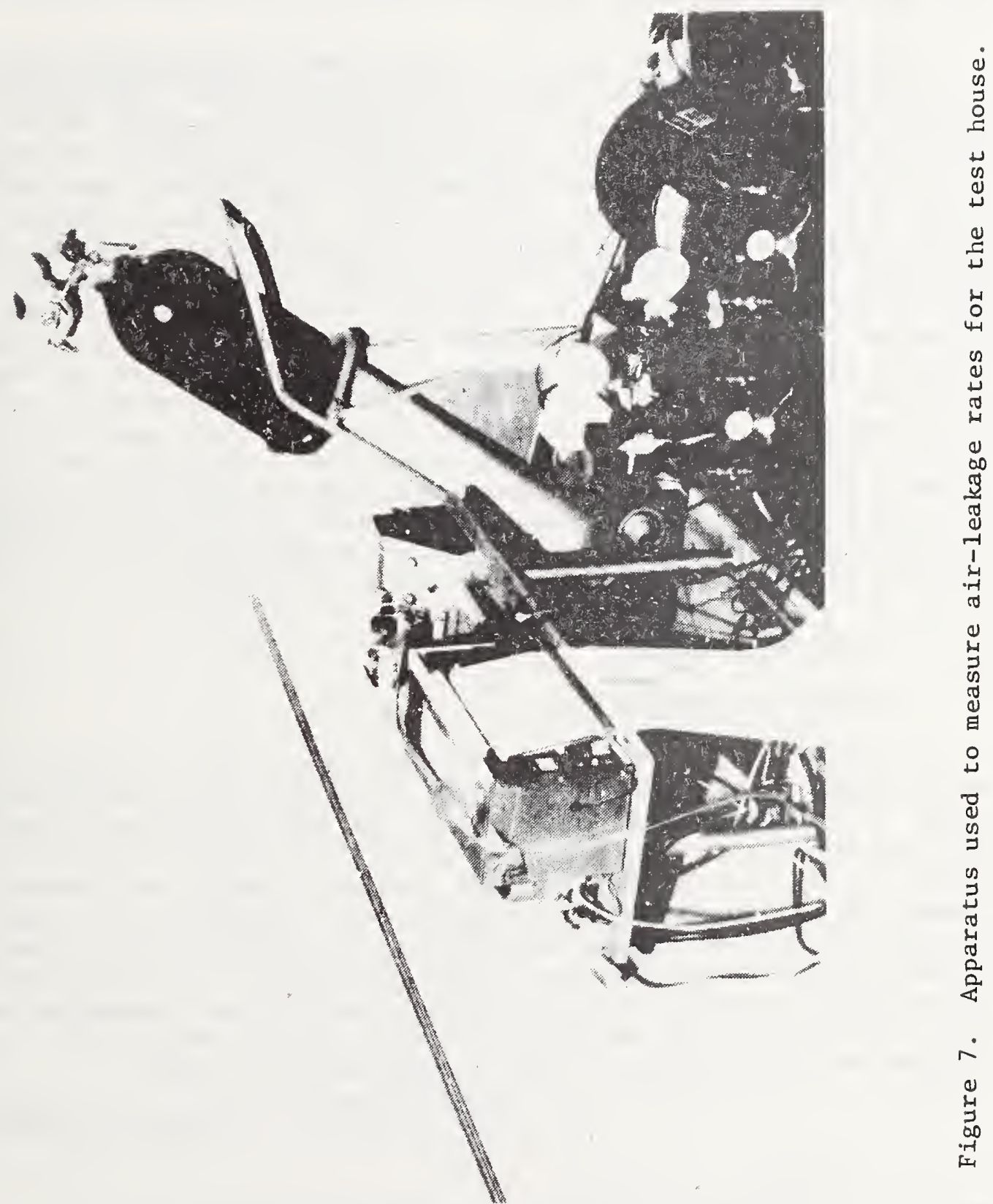


Here $c$ is the concentration of $\mathrm{SF}_{6}$ in $\mathrm{ppb}, \mathrm{J}_{0}$ is the standing current of the detector, and $J$ is the current with tracer in the detector (it is the trough of a chromatographic deflection), $k$ is a constant, and $\lambda$ is a snall extrapolated value of $\mathrm{c}$ at $\mathrm{J} / \mathrm{J}=0$. If $\lambda=0$, equation (4) has the form of Beer's law. The instrument was calibrated against reference mixtures of $\mathrm{SF}_{0}$ in air.

$\mathrm{SF}_{6}$ was introduced into the return plenum of the heating plant and distributed throughout the house. Samples were taken from the air distribution system every ten minutes (600 s) and analyzed for $\mathrm{SF}_{6}{ }^{\circ}$ In order to maintain good mixing, which is implicit in the use of eq. ( 3 ), the furnace fan was operated continuously. This is more than normal fan usage, but in addition to providing mixing, it eliminates random fan operation as a variable in infiltration measurements. Provision was also made to sample independently from different parts of the house. In the attic four equal length tygon tubes (1/8 in. $(0.32 \mathrm{~cm})$ ID) were connected to a sampling pump through a length of $1 / 4 \mathrm{in}$. $(0.64 \mathrm{~cm})$ ID tygon tubing and a solenoid valve. The sampling system has been described elsewhere [11]. A similar 4-point sampling network was used in the basement, and the first floor living space was sampled through a sampling network leading to the various rooms. A sampling tube also led to the crawl space, where occasional spot samples were taken. Infiltration rates were based on samples taken from the air-distribution system, but the independent sampling networks made it possible to check on vertical air movements between the three main parts of the house.

\subsection{Results and Analysis}

\subsubsection{Winter Air-Leakage Rates}

Winter air-leakage rates for the test house in its original state were measured over a wide range of outdoor temperatures and wind velocities. A summary of these pre-retrofit air infiltration measurements is given in table 5. In a previous study [12] in which air-infiltration rates were measured for a test house located inside an environmental chamber, it was found that in the absence of wind velocity, a good correlation existed between air-infiltration rates and the inside-tooutside temperature differences. Other studies $[12,13]$ have shown that for residences exposed to wind velocities as well as temperature differences, the rate of air infiltration (I) could be correlated with respect to these two driving forces with an equation of the form:

$$
I=a+b \cdot \Delta T+c \cdot V
$$

where $\Delta \mathrm{T}=$ inside-to-outside temperature difference, ${ }^{\circ} \mathrm{F}$

$\mathrm{V}=$ wind velocity, $\mathrm{mph}$

a, b, c = empirical constants. 
Table 5. PRE-RETROFIT AIR-INFILTRATION MEASUREMENTS

\begin{tabular}{|c|c|c|c|c|}
\hline$I_{\text {meas }}$ & $\begin{array}{l}I_{\text {calc }} \\
\text { (eq: 7) }\end{array}$ & $I_{\text {meas }}{ }^{-I}$ calc & $\begin{array}{l}\Delta \mathrm{T} \\
{ }^{\circ} \mathrm{F}\end{array}$ & $\underset{\mathrm{mph}}{\mathrm{V}}$ \\
\hline .22 & .19 & .03 & 1.0 & 4.7 \\
\hline .23 & .23 & 0 & 2.3 & 4.8 \\
\hline .20 & .28 & -.08 & 5.1 & 5.2 \\
\hline .42 & .39 & .03 & 6.0 & 11.5 \\
\hline .28 & .35 & -.07 & 7.4 & 7.5 \\
\hline .40 & .33 & .07 & 9.3 & 6.2 \\
\hline .43 & .41 & .02 & 9.5 & 10.0 \\
\hline .38 & .44 & -.06 & 10.7 & 11.0 \\
\hline .54 & .43 & .11 & 18.7 & 6.4 \\
\hline .44 & .45 & -.01 & 22.0 & 6.0 \\
\hline .53 & .48 & .05 & 22.5 & 7.5 \\
\hline .37 & .48 & -.11 & 24.5 & 6.5 \\
\hline
\end{tabular}

Average deviation $=\frac{I_{\text {meas }}-I_{\text {calc }}}{N}=0$

Standard deviation $=\sqrt{\frac{\sum_{i=1}^{N}\left(I_{\text {meas }}-I_{\text {calc }}\right)_{i}^{2}}{N-1}}$ 
A least-squares procedure was used to fit the pre-retrofit airinfiltration data to a correlating equation of the form given by eq. (5) The correlating equation and the corresponding root-mean-square deviation is:

$$
I=0.11+0.0100 \cdot \Delta \mathrm{T}+0.0196 \cdot \mathrm{V}, \delta=0.062
$$

The root-mean-square deviation $(\delta)$ is a parameter indicating the amount of scatter between the data points and their correlating equation.

The pre-retrofit air-infiltration rates were also fitted to a modified form of eq. (5) in which the temperature difference term $b \cdot \Delta T$ was changed to $b^{\prime} \cdot \Delta T^{1 / 2}$. The modified correlating equation, along with the root-mean-square deviation, is given in eq. (7).

$$
I=0.0506+0.0652 \cdot \Delta \mathrm{T}^{1 / 2}+0.0154 \cdot \mathrm{V}, \quad \delta=.061
$$

A plot of eq. (7) is given in figure 8. Under typical winter conditions, $\Delta \mathrm{T}=35^{\circ} \mathrm{F}\left(19.4^{\circ} \mathrm{C}\right)$ and $\mathrm{V}=7 \mathrm{mph}(3.1 \mathrm{~m} / \mathrm{s})$, the rate of air infiltration is roughly 0.5 air changes per hour. At design conditions, $\Delta \mathrm{T}=55^{\circ} \mathrm{F}$ $\left(30.6^{\circ} \mathrm{C}\right)$ and $V=15 \mathrm{mph}(6.71 \mathrm{~m} / \mathrm{s})$, the air-infiltration rate for the test house is 0.75 air changes per hour. These figures indicate that the test house in its original state had low air-leakage rates, due to good construction and good weatherstripping around the doors and windows.

The volumetric air-leakage rate per unit envelope area for the test house of the present study is $0.020 \mathrm{cfm} / \mathrm{ft}^{2}$ area $\left(1.02 \times 10^{-4} \mathrm{~m} / \mathrm{s} \cdot \mathrm{m}^{2}\right)$ at $\Delta \mathrm{T}=30^{\circ} \mathrm{F}\left(16.7^{\circ} \mathrm{C}\right)$ and $\mathrm{V}=0 \mathrm{mph}(0 . \mathrm{m} / \mathrm{s})$. The corresponding value for the townhouse studied in references $[12,15]$ is $0.022 \mathrm{cfm} / \mathrm{ft}^{2}$ $\left(1.12 \times 10^{-4} \mathrm{~m}^{3} / \mathrm{s} \cdot \mathrm{m}^{2}\right)$.

Winter air-infiltration rates were also determined after specific measures were taken to seal air leaks (see section 3.1). A summary of air-infiltration measurements after stage 1 of the retrofit is given in table 6. Calculated values were obtained from the pre-retrofit airinfiltration correlation (eq. 7) using measured temperatures and wind velocities. These provide an estimate of what the pre-retrofit infiltration would have been under the same weather conditions. The average difference between the measured and calculated infiltration rates was -0.08 air changes per hour, indicating that only a slight reduction in air infiltration had occurred. Since the statistical uncertainty in the data as indicated by the RMS deviation for the pre-retrofit air infiltration correlation is approximately $0.06 \mathrm{~h}^{-1}$, the calculated reduction of -0.08 air changes per hour shown in table 6 has low statistical significance. 


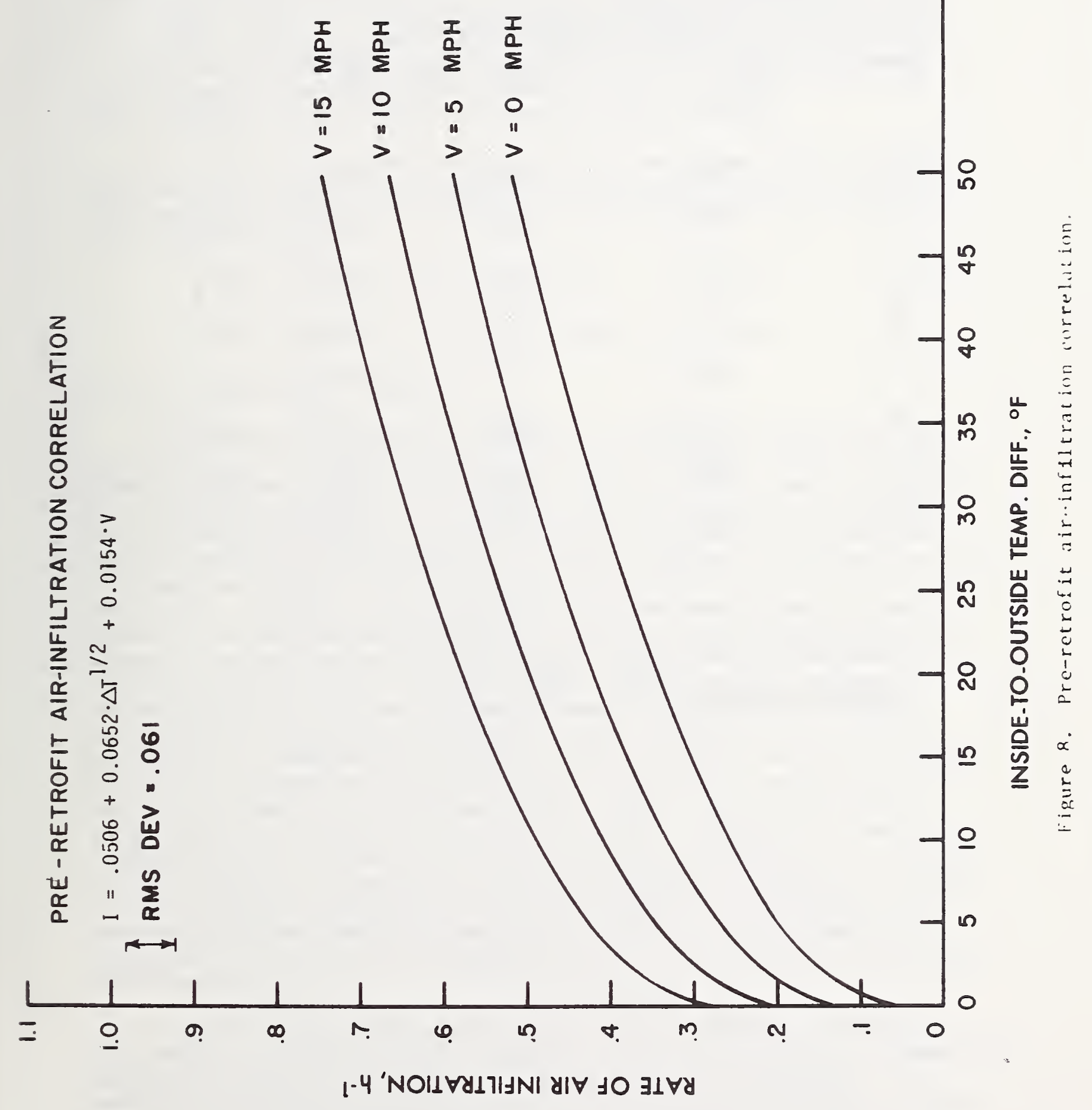


TABLE 0. AIR-INFILTRATION RATES AFTER STAGE 1 OF THE RETROFIT

Air-Infiltration Rate, $\mathrm{h}^{-1}$

\begin{tabular}{ccccc}
\hline$I_{\text {meas }}$ & $\begin{array}{c}I_{\text {calc }} \\
\text { (eq. } .7)\end{array}$ & $I_{\text {meas }}{ }^{-I_{\text {calc }}}$ & $\begin{array}{c}\Delta T \\
{ }^{\circ} \mathrm{F}\end{array}$ & $\begin{array}{c}\mathrm{V} \\
\mathrm{mph}\end{array}$ \\
.33 & .42 & -.09 & 20.4 & 4.3 \\
.37 & .47 & -.10 & 31.0 & 3.6 \\
.40 & .50 & -.10 & 31.0 & 5.5 \\
.39 & .45 & -.06 & 31.1 & 2.6 \\
.46 & .46 & 0 & 32.5 & 2.5 \\
.24 & .45 & -.21 & 33.0 & 1.8 \\
.55 & .46 & .09 & 33.5 & 2.0 \\
.28 & .46 & -.18 & 34.8 & 1.6
\end{tabular}

\footnotetext{
Average deviation, $I_{\text {meas }}-I_{\text {calc }}=-.08$

Standard deviation $\quad=.10$
} 
After the installation of storm windows (stage 2), no further reductions in the air-infiltration rates were observed. The results are shown in table 7. The average difference between the measured and preretrofit calculated infiltration rates was +0.04 air changes per hour, Indicating a slight increase in air infiltration had occurred over the pre-retrofit values. Since the statistical uncertainty in the data as indicated by the RMS deviation for the pre-retrofit air-infiltration correlation is greater than the observed change, it is possible that an actual change in air inflltration may not have occurred.

Air-infiltration measurements were also performed after the third stage of the retrofit. For purposes of calculating energy losses due to infiltration, new correlation equations were derived for post-retrofit data after stage 3:

$$
\begin{aligned}
& I=0.221+0.00916 \cdot \Delta \mathrm{T}+0.229 \cdot \mathrm{V}, \quad \delta=.064, \\
& I=0.0549+0.101 \cdot \Delta \mathrm{T}^{1 / 2}+0.0236 \cdot \mathrm{V}, \delta=.064
\end{aligned}
$$

Eq. (9) is plotted in figure 9.

After stage 3, a marginal systematic increase in infiltration over the pre-retrofit values was observed. This is shown in table 8 . The average increase of $+0.14 \mathrm{~h}^{-1}$, as indicated in table 8 , would correspond to an energy expenditure of less than 5 percent of the pre-retrofit heating loads for the test house. This is no greater than normal error in the energy measurement itself. However, there was no a priori reason to expect any increase in infiltration rate due to the addition of insulation. Therefore, this effect merits some examination to determine whether an actual increase occurred or whether it was a spurious effect arising from some systematic experimental error. It will be noticed in comparing tables 5 and 8 that the average inside-outside temperature difference during post-retrofit measurements was greater than the corresponding pre-retrofit conditions from which eq. (7) was derived. Therefore, in comparing pre-retrofit and post-retrofit air-infiltration rates, some extrapolation outside of the range of pre-retrofit data is required. However, if measurements after stage 3 are compared with those made after stage 1 and 2 , there is also a systematic increase in average infiltration rates. This latter comparison minimizes any extrapolation outside of the range of the data and also eliminates the effect of any procedural differences between pre-retrofit measurements and post-retrofit measurements a year later. Thus, it is concluded that the marginal increase in air-infiltration rate is real and not an experimental artifact.

As part of stage 3 of the retrofit, it was necessary to increase the amount of attic ventilation opening to comply with minimum recommended ventilation requirements of the FHA Minimum Property Standards. To evaluate the effect of increased attic ventilation, consecutive measurements of air leakage in the living space were carried out under the alternate conditions of ventilation louvers open and ventilation louvers closed. 
TABLE 7. AIR-INFILTRATION RATES AFTER STAGE 2 OF THE RETROFIT

Air-Infiltration Rate, $\mathrm{h}^{-1}$

\begin{tabular}{|c|c|c|c|c|}
\hline$I_{\text {meas }}$ & $\begin{array}{l}I_{\text {calc }} \\
(\text { eq. } 7)\end{array}$ & $I_{\text {meas }}-I_{\text {calc }}$ & $\begin{array}{l}\Delta \mathrm{T}^{\circ} \\
{ }^{\circ} \mathrm{F}\end{array}$ & $\begin{array}{c}\mathrm{V} \\
\mathrm{mph}\end{array}$ \\
\hline .43 & .43 & 0 & 27.1 & 2.5 \\
\hline .37 & .44 & -.07 & 28.1 & 2.6 \\
\hline .37 & .45 & -.08 & 29.3 & 3.0 \\
\hline .55 & .50 & +.05 & 32.9 & 5.0 \\
\hline .37 & .49 &.- .12 & 33.6 & 4.2 \\
\hline .64 & .48 & .16 & 35.2 & 2.6 \\
\hline .48 & .48 & 0 & 38.4 & 1.4 \\
\hline .53 &. .50 & .03 & 39.2 & 2.5 \\
\hline .48 & .50 & -.02 & 40.6 & 2.2 \\
\hline .54 & .55 & -.01 & 43.5 & 4.4 \\
\hline .80 & .55 & .25 & 43.7 & 4.4 \\
\hline .63 & .53 & .10 & 43.3 & 3.3 \\
\hline .45 & .53 & -.08 & 46.7 & 2.3 \\
\hline .60 & .53 & .07 & 46.8 & 2.0 \\
\hline .65 & .53 & .12 & 47.1 & 2.0 \\
\hline .68 & .56 & .12 & 50.5 & 3.0 \\
\hline .74 & .58 & .16 & 50.8 & 3.9 \\
\hline
\end{tabular}

Average deviation, $I_{\text {meas }}-I_{\text {calc }}=0.04$

Standard deviation

$=0.10$ 


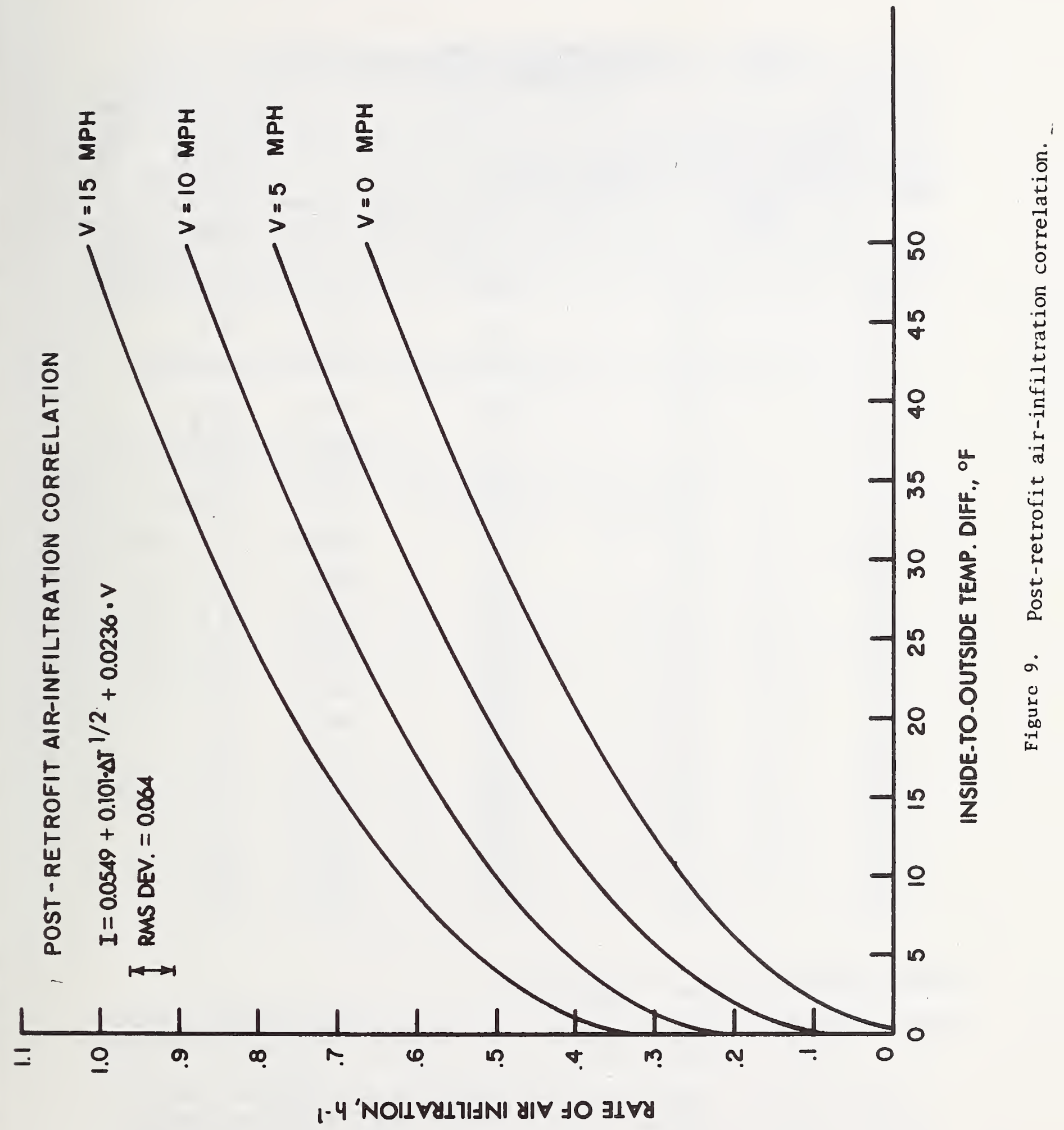


TABLE 8. AIR-INFILTRATION RATES AFTER STAGE 3 OF THE RETROFIT

\begin{tabular}{|c|c|c|c|c|}
\hline$I_{\text {meas }}$ & $\begin{array}{l}I_{\text {calc }} \\
(\text { eq. } 7)\end{array}$ & $I_{\text {meas }}{ }^{-I_{\text {calc }}}$ & $\begin{array}{l}\Delta \mathrm{T} \\
{ }^{\circ} \mathrm{F}\end{array}$ & $\begin{array}{r}\mathrm{V} \\
\mathrm{mph}\end{array}$ \\
\hline .52 & .42 & .10 & 19.5 & 5.5 \\
\hline .54 & .41 & .13 & 19.8 & 4.7 \\
\hline .63 & .52 & .11 & 23.3 & 9.9 \\
\hline .70 & $.5 i$ & .19 & 25.0 & 8.6 \\
\hline .59 & .43 & .16 & 25.9 & 2.8 \\
\hline .70 & .44 & .26 & 26.0 & 3.4 \\
\hline .45 & .41 & .04 & 26.0 & 1.6 \\
\hline . 39 & .42 & .03 & 26.4 & 2.3 \\
\hline .49 & .45 & .04 & 28.3 & 3.7 \\
\hline .64 & .45 & .19 & 31.6 & 2.4 \\
\hline .56 & .50 & .06 & 34.1 & 4.3 \\
\hline .69 & .48 & .21 & 37.6 & 1.8 \\
\hline .64 & .52 & .12 & 38.2 & 4.5 \\
\hline .70 & .55 & .15 & 39.3 & 6.0 \\
\hline .60 & .52 & .08 & 39.6 & 3.6 \\
\hline .75 & .57 & .18 & 40.0 & 7.1 \\
\hline .84 & .57 & .27 & 40.7 & 6.8 \\
\hline .74 & .60 & .14 & 41.1 & 8.3 \\
\hline
\end{tabular}

Average deviation, $I_{\text {meas }}-I_{\text {calc }}=0.14$

St.andard deviation $=0.07$ 
The results of these special air-infiltration tests are summarized in table 9. For these consecutive measurements, the effect of opening the attic ventilation louvers was to increase the rate of air infiltration for the occupied space of the test house by 0.01 air changes per hour. Since the random scattering of the data points as indicated by the RMS deviation of the post-retrofit air-infiltration correlation was $0.064 \mathrm{~h}^{-1}$, the measured increase in air-infiltration rate of 0.01 should not be regarded as statistically significant. Thus, these measurements indicate that closing the attic ventilation louvers produced no statistically significant reductions in the air-infiltration rates for the test house.

TABLE 9. EFFECT OF ATTIC VENTILATION ON AIR INFILTRATION. Air-Infiltration Rate, $\mathrm{h}^{-1}$

\begin{tabular}{|c|c|c|c|c|c|}
\hline \multicolumn{2}{|c|}{$I_{\text {meas }}$} & $I_{\text {calc }}($ eq 9) & $I_{\text {meas }}{ }^{-I}$ calc & $\Delta \mathrm{T}$ & V \\
\hline Open & Closed & & & ${ }^{\circ} \mathrm{F}$ & $\mathrm{mph}$ \\
\hline .70 & -- & .57 & .13 & 26.2 & 4.6 \\
\hline- & .56 & .53 & .03 & 22.9 & 4.3 \\
\hline .53 & -- & .53 & 0 & 23.8 & 3.7 \\
\hline-- & .56 & .50 & .06 & 21.8 & 3.4 \\
\hline .43 & -- & .46 & -.03 & 15.9 & 4.8 \\
\hline-- & .46 & .45 & .01 & 13.5 & 5.8 \\
\hline $.66 *$ & -- & .39 & .27 & 9.3 & 5.7 \\
\hline- & .30 & $\cdot 38$ & -.08 & 10.1 & 4.8 \\
\hline$\cdot 37$ & - & .38 & -.01 & 11.7 & 4.0 \\
\hline
\end{tabular}

Average deviation attic open $=+0.02$, standard deviation $=0.07$. Average deviation attic closed $=0.01$, standard deviation $=0.06$.

* Five door openings occurred during this measurement. It was therefore omitted from average. When included: average deviation $=0.07$, standard deviation $=0.13$. 
The preceding paragraphs presented the results of air-infiltration measurements before and after three stages of retrofit. The data have been analyzed to determine what differences were produced, whether the differences were significant, and their possible causes. From the point of view of the energy required to heat the house, it is concluded that any improvements obtained by retrofitting were not due to reduction in air leakage. Different conclusions might have been reached had the original house been more poorly constructed or had it been placed in a more exposed location under more severe weather conditions. As it was, the house was surrounded on all sides by trees and dense shrubbery near the house on the north side, which served somewhat as a windbreak.

In this connection, some wind-tunnel studies by Mattingly and Peters [16] are of interest. They measured the inside-outside pressure differences across different surfaces of a model cluster of townhouses, and from these results estimated the possible air-infiltration rates. When a model building or simulated trees were placed upwind from the townhouses, a marked reduction in pressure differences was obtained. This indicates that trees and other windbreaks may have a significant effect in reducing air leakage in homes.

\subsubsection{Summer Air-Infiltration}

Summer air-infiltration rates were measured for the test house in its original state, prior to the three stages of the retrofit. Summer air-infiltration rates were also measured after all the stages of the retrofit had been performed. The results of these measurements are shown in table 10 .

Comparing table 10 to tables 5 and 8 , it is seen that both the pre- and post-retrofit summer air-infiltration rates are in most cases lower than values measured in the winter. However, they were obtained under comparatively mild weather conditions for which the inside-tooutside temperature differences were much smaller than corresponding winter values. The differences between pre- and post-retrofit infiltration rates were small compared with the random variations in values themselves.

\section{TABLE 10. SUMMER AIR-INFILTRATION RATES}

\begin{tabular}{|c|c|c|}
\hline \multicolumn{3}{|c|}{ Pre-Retrofit } \\
\hline $\mathrm{h}^{-1}$ & $T_{0}-T_{i}$ & $\begin{array}{c}\mathrm{V} \\
\mathrm{mph}\end{array}$ \\
\hline .27 & 13.5 & 3.4 \\
\hline .44 & 12.6 & 3.0 \\
\hline .25 & -3.4 & 9.5 \\
\hline .21 & -3.3 & 6.9 \\
\hline .24 & -2.7 & 7.5 \\
\hline .29 & -3.1 & 7.1 \\
\hline
\end{tabular}

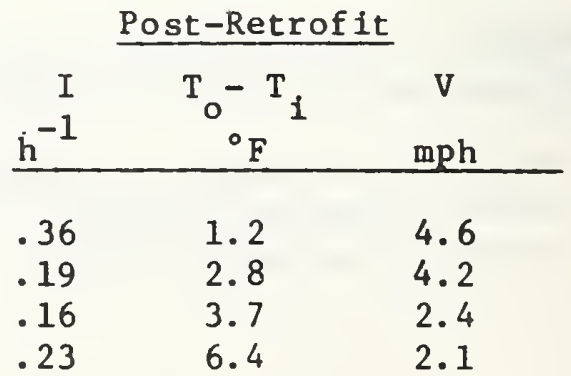


The small increase in winter air-infiltration rates which was observed after stage 3 of the retrofit was not observed for the summer. However, it should be noted that the temperature differences between the living space and the outside, as well as between the living space and the attic, were opposite to those prevailing in winter.

Separate measurements showed that air movement was predominantly upward from the living space into the attic under summer as well as winter conditions. In the summer, the temperature of the air in the attic is usually considerably warmer than the outdoor or indoor air. The warmer attic air is lighter than the surrounding air, and therefore has a tendency to rise and leak out of the ventilation openings at opposite ends of the attic. Air from the living space is apparently sucked into the attic to compensate for the outflow of air.

\subsection{Conclusions}

Air-infiltration measurements performed in the house in its original condition demonstrated that this particular house was of comparatively tight construction. Under typical winter conditions, the airinfiltration rate was approximately $1 / 2$ air change per hour subject to variations due to weather conditions.

After energy conservation actions were carried out to seal airleakage paths (stage 1 of the retrofit), air-infiltration measurements indicated only a small reduction in air-infiltration rates, comparable in magnitude with the normal statistical variation in the data. The minimal effectiveness of measures taken to seal air-leakage paths was attributed to the tightness of the original house.

The addition of storm windows produced no measured reductions in air-infiltration rates for the test house. This result was attributed to the good weatherstripping around the original window systems.

A surprising $f$ inding was that after insulation was added to the walls, ceiling, and crawl-space floor, the air-infiltration rates for the test house marginally increased. Separate measurements demonstrated that the observed increase in air infiltration probably was not due to opening the attic ventilation louvers which occurred during the third stage of the retrofit.

Summer air-infiltration rates were observed to be between 0.16 and 0.44 air changes per hour and were found to be approximately one-half of typical winter values. 


\section{ENERGY MEASUREMENTS}

In this section, the reductions in the energy required for space heating of the test house resulting from three stages of a retrofit are experimentally quantified. Winter heating loads for the test house were determined experimentally and compared with predicted values.

In addition, the reduction in the space-cooling energy requirement for the test house achieved by the combination of the retrofit actions was also experimentally investigated.

\subsection{Experimental Plan}

The experimental plan for quantifying the heating- and coolingenergy savings achieved by the retrofit was to measure first the winterheating (1973-1974) and summer-cooling (1974) loads for the test house In its original state under a range of outdoor climatic conditions. The only modifications performed on the test house prior to these investigations were those necessitated by neglect, such as the repair of a leaky roof.

During the following winter heating season (1974-1975), the test house was retrofitted in three stages. Winter heating loads for the unoccupled test hoise were measured after each stage of the retrofit, permitting the reductions in the heating load to he quantified after each stage.

During the following summer season (1975), awnings were instalj.ed over the windows on the south side of the test hollse. Cooling loads were measured and compared to pre-retrofit values.

The test house was unoccupied during testing, except for technical personnel needed to perform measurements. The only internall heat gains to the living space were a constant lighting load of 660 watts, the heat release from the equipment for measuring air infiltration (when it was operated), and the metabolic heat released by technical persnnnel. Heat. released by occupant-related activities has an appreciable effect on the heating loads of a residence. However, since internal heat gains due to occupancy would vary from one day to the next and would introduce uncertainties into the measurements, it was decided to first determine the heatjng load as a function of outdoor temperature for the unoccupied house. The heating- and cooling-energy requirements for an occupied test house would be obtained from a subsequent analysis.

\section{2 Instrumentatinn and Measurement Technique}

\subsubsection{Measurement of Heating and Cooling Loads}

The two branch supply duct systems feeding conditioned air to the east and west sides of the test house were insulated for both the preand post-retrofit energy measurements, so that duct losses would represent 
a small fraction of the heating and cooling loads. Since the duct losses were small, the heat delivered by the heating plant was assumed to be equivalent to the heat supplied to the first floor living space. Based on this assumption, the integrated heating or cooling load $(q)$ is given by the relation:

$$
q=\int_{0}^{P}\left(C_{p} \cdot \rho \cdot V \cdot A\right) \cdot \Delta T \cdot d t+W \cdot h_{f g}
$$

where

$$
\begin{aligned}
& C_{p}=\text { specific heat of air, Btu/lb*F }(\mathrm{J} / \mathrm{Kg} \cdot \mathrm{K}) \\
& \rho=\text { density of the air, } 1 \mathrm{~b} / \mathrm{ft}^{3}\left(\mathrm{Kg} / \mathrm{m}^{3}\right) \\
& \mathrm{V} \quad=\text { mean duct velocity, } \mathrm{ft} / \mathrm{min}(\mathrm{m} / \mathrm{s}) \\
& A=\text { cross sectional area of duct, } f t^{2}\left(m^{2}\right) \\
& \Delta \mathrm{T}=\text { temperature rise for space heating applications or temperature } \\
& t=t \text { ime, minutes } \\
& \mathrm{W}=\text { mass of water collected, } 1 \mathrm{~b}(\mathrm{Kg}) \\
& h_{f g}=\text { latent heat of vaporization of water, } B t u / 1 b^{\cdot} F\left(J / \mathrm{Kg}^{\circ} \mathrm{K}\right) \\
& P \quad=\text { period of time over which the blower operates. }
\end{aligned}
$$

The first and second terms represent the sensible and latent portions of the load, respectively. For residential heating application without humidification $(W=0)$, the latent term vanishes, since no water is removed or added to the structure by mechanical equipment. For most heating and cooling applications, the factor $\left(C_{p} \cdot \rho \cdot V \cdot A\right)$ may be considered to be constant and taken outside the integral. Thus, the time-varying heating or cooling load for a residence may be measured by integrating the temperature rise (or temperature drop) across the heating (or cooling) plant and multiplying this integrated value by the factor $\left(C_{p} \cdot \rho \cdot V \cdot A\right)$. This measurement of the heat delivered by a furnace system by integrating the temperature rise is similar to a technique used by Stricker [17].

It should be pointed out that the temperature difference $\Delta T$ is only integrated when the blower of the mechanical heating and cooling system is operating and delivering conditioned air to the living space. In the case of fuel-fired furnaces, a significant amount of thermal energy is stored in the heat exchanger. When the blower is off, hot air is delivered to the living space by buoyant forces. When heating loads 
were measured for the oll-fired furnace system, a cycle-by-cycle calculation for the gravity-force heating energy delivered to the house was included. This was accomplished by measuring air-delivery rate due to gravity force (using a hot wire anemometer) and the temperature difference between the supply and return (using a thermopile system) as a function of time. The calculation of heat delivered to the house due to buoyant forces is regarded as not of high accuracy.

In order to obtain meaningful duct velocity and temperature rise measurements, it is necessary that the measurements be made at a station in the duct having nearly uniform temperature profiles. A schematic diagram of the original oil-fired furnace system showing the location of the measurement transducers is shown in figure 10. Note that the airdelivery duct system has two major supply branches, one delivering conditioned air to rooms located over the basement, the other feeding the rooms located over the crawl space. For the pre-retrofit heatingenergy measurements, uniform temperature profiles were created in each major supply branch by installing louvered air-mixing devices which were constructed according to specifications given in reference [18]. The heating energy delivered during blower operation was measured separately for each of two major supply branches. The temperature rise across the return plenum and the basement supply duct was sensed with an 18-junction chromel-alumel thermopile. Nine of the junctions were arranged in an equally-spaced grid network and mounted in the return plenum. The other nine junctions were also arranged in an equallyspaced grid network and mounted in the basement supply branch located downstream from the louvered air-mixing devices. The temperature rise between the return plenum and the crawl-space supply branch was sensed with an identical thermopile system. The millivolt signal from each of the thermopiles was fed into micro-switching circuits which in turn were fed into analog integrators. When the blower of the furnacie system operated, the switching circuits applied the millivolt signal of the thermopiles to the integrators. When the blower stopped, the switching circuits applied a short-circuit across the integrators, thereby stopping the integration.

During the pre-retrofit heating-energy measurements, duct air velocities were measured at the approximate vicinity of the hot junctions of the thermopiles with a hot-wire anemometer that had been calibrated in a wind tunnel. In addition, the mass-flow rate was measured indirectly by using the electric heaters located in each supply branch and in the thermopile system.

After the pre-retrofit measurements, the oil furnace was replaced by a heat pump system, as part of a heat pump study [7]. The system was also equipped with supplemental electric-resistance heating elements. In the present study, only the electric-resistance heaters were used to heat the house. 


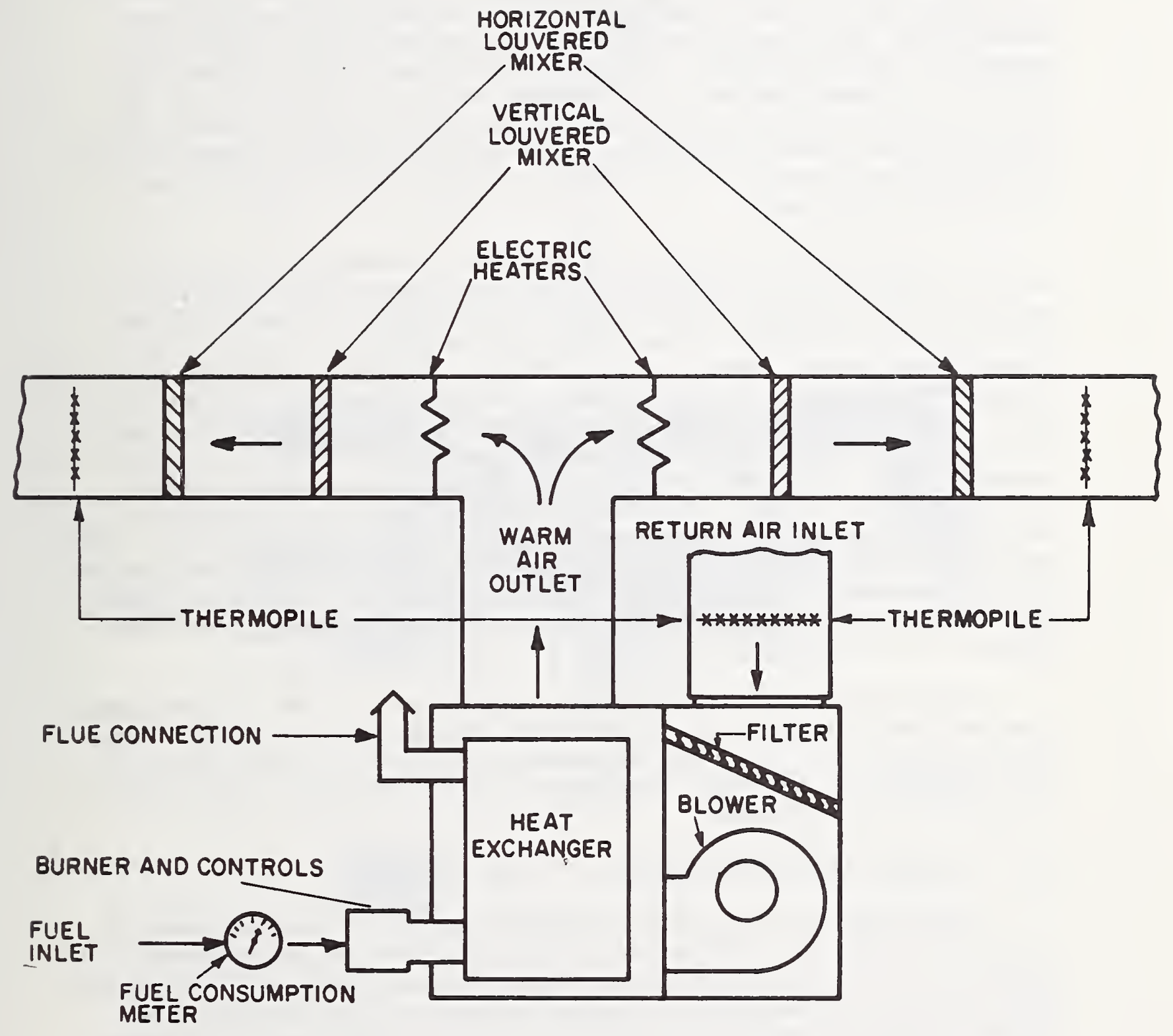

Figure 10. Schematic diagram of furnace system showing the location of measuring transducers. 
Smaller temperature differences would be developed across the heatpump system than the oll-fired furnace. It was therefore necessary to replace the 18-junction thermopiles on the oil-fired system with 36junction copper-constantan thermopiles in order to produce larger millivolt signals for operating the integrators. In addition, the louvered air-mixing devices were removed and air-flow measuring devices were installed in each supply branch upstream from the hot-junction grid network of the thermopiles. The air-velocity measuring devices consisted of a honey-comb air straightener, an array of pitot tubes for measuring the total pressure, and several static pressure ports. By measuring the pressure difference between the pitot-tube array and the static pressure ports, it is possible to monitor the velocity head of the moving air stream.

For the post-retrofit heating energy measurements, the electric energy supplied to the resistance heating elements and the blower was measured with watt-hour meters equipped with contact closure devices which produced a contact closure for each revolution of a disk inside the watthour meter. These contact closures were totalized, and the accumulated counts were printed out at hourly intervals. The electric heat supplied to the test house was equal to the electric energy supplied to the resistance heating elements and to the blower, less the jacket losses of the heat-pump system. Separate measurements demonstrated that the jacket losses were 8 percent of the total electric energy released by the resistance heating elements and the blower. The jacket loss was determined by taking the difference between the electric energy input to the resistance heating elements and the heating energy delivered to the house measured with the thermopile energy measurement system.

For the air conditioning tests, the condensate from the refrigeration coil was collected in a cylindrical tank located on an electronic weighing platform. The total condensate collected at hourly intervals was determined by feeding a DC voltage from the weighing platform into a data acquisition system.

\subsubsection{Outdoor Weather Parameters}

A photograph of the weather station used in the present study is shown in figure 11. This weather station was located approximately 60 ft $(18.3 \mathrm{~m})$ in front of and in line with the west end of the test house. This particular location was selected so that the wind direction and velocity sensors, mounted at the $18-\mathrm{ft}(5.5 \mathrm{~m})$ level, would be exposed to the prevailing winter northwest wind. Wind velocity was measured with a rotating-cup anemometer, and wind direction was measured with a wind-direction vane. The louvered enclosure shown in figure 11 contained a copper-constantan thermocouple for measuring outdoor temperature and a humidity sensing element which produced a millivolt signal proportional to relative humidity. During the pre-retrofit heating energy measurements, the total solar radiation incident on a horizontal surface was measured with a pyranometer mounted on top of the louvered 


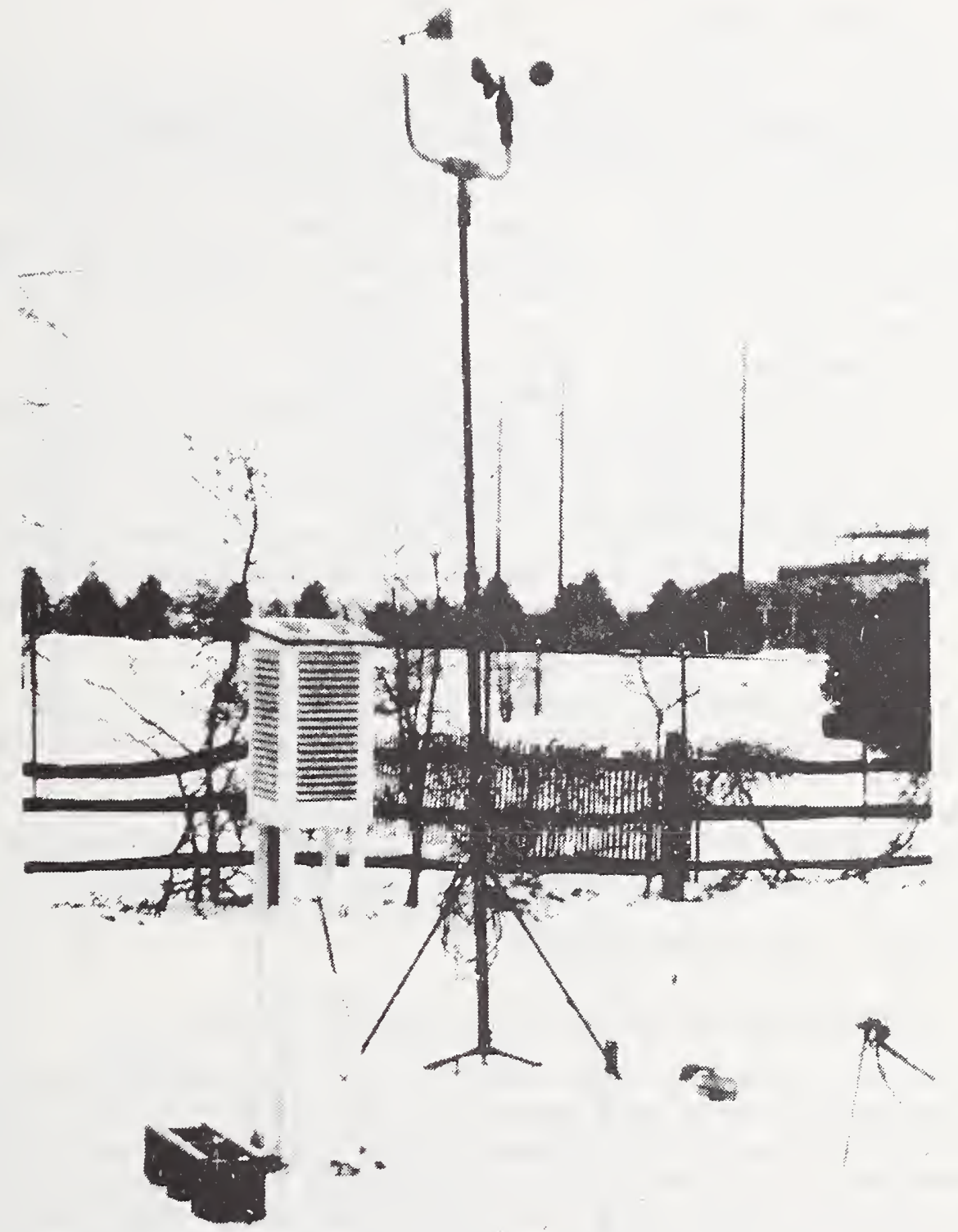

Figure 11. Photograph of the weather station. 
enclosure shown in figure 11. After the pre-retrofit heating energy measurements, the pyranometer was relocated on the roof of the test house. The outdoor ambient temperature was also measured with thermocouples installed on the north side of trees located behind the test house.

\subsubsection{Indoor Parameters}

Indoor air temperatures were measured using 24-gage copperconstantan thermocouples placed at the 4.5 ft $(1.37-\mathrm{m})$ level and in the center of each of the rooms of the house, except for the bathrooms. These thermocouple locations are depicted with the symbol "๑" on the floor plan of figure 12. In the living room two additional thermocouples were installed vertically in line with one at mid-height. One was placed 3 in $(7.62 \mathrm{~cm})$ above the floor and the other 3 in $(7.62 \mathrm{~cm})$ below the ceiling. Three attic air temperature thermocouples were located along the east-to-west center line of the attic, $1 \mathrm{ft}(0.305 \mathrm{~m})$ above the ceiling joists. These thermocouples were placed approximately $20 \mathrm{ft} .(6.10 \mathrm{~m})$ from the attic end walls and in the geometric center of the attic. Two basement air temperature thermocouples were placed along the broken line A-A (see figure 12), $1 \mathrm{ft}(0.305 \mathrm{~m}$ ) below the floor joists and approximately $10 \mathrm{ft}(3.05 \mathrm{~m})$ from the basement walls. In the crawl space, two thermocouples were placed along the broken line B-B (see figure 12), $1 \mathrm{ft}(0.305 \mathrm{~m})$ below the floor joists and approximately $10 \mathrm{ft}(3.05 \mathrm{~m})$ from the foundation walls.

A relative humidity sensor (the same type that was used in the weather station) was placed indoors in the center of the living room next to the mid-height thermocouple. For the post-retrofit measurements, identical relative humidity sensors were installed in the crawl space, basement, and the attic. In all cases, an ambient air temperature thermocouple was placed next to each humidity sensor.

\subsection{Winter Energy Measurements}

\subsubsection{Heating Loads for the Unoccupied Test House}

For the pre-and post-retrofit heating energy measurements, dailyaverage heating loads were determined for the unoccupied test house with corresponding daily average outdoor and indoor temperatures, dailyaverage wind velocities, and total incident solar radiation. The dailytotal heating loads for the unoccupied test house were taken to be equal to the sum of the heating energy delivered to the house by the furnace plus the constant lighting load and the energy released by airinfiltration equipment when it is operated. An average heating load for each day of test was calculated by dividing the daily-total heating load by $24-\mathrm{h} / \mathrm{day}$. 
LEGEND:

- temperature sensors
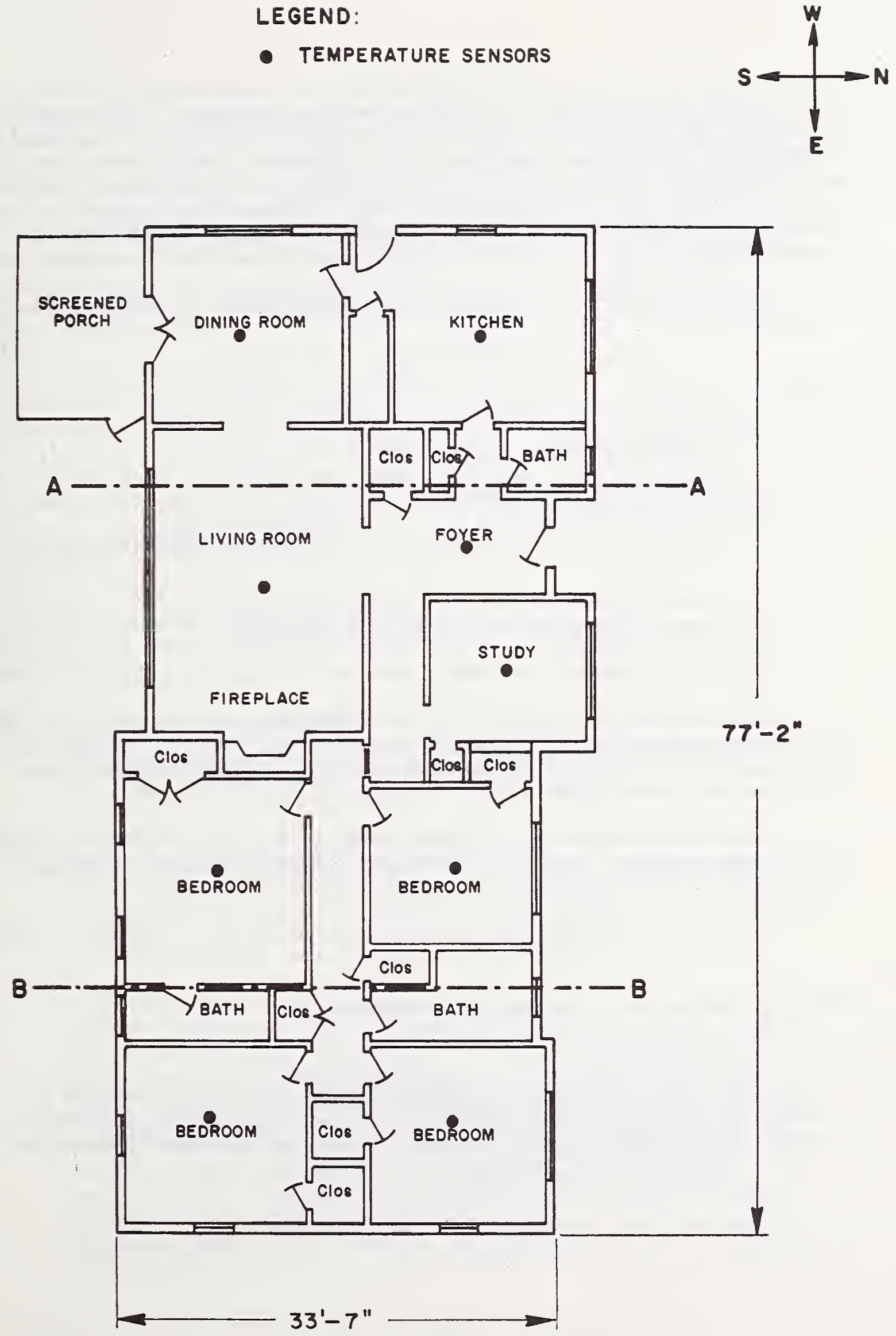

Figure 12. Floor plan of test house showing location of temperature sensors. 
The major portion of the heating load to the unoccupied house is due to heat loss through the exterior building envelope. The dominant driving force that governs this heat-loss rate is the inside-to-outside temperature difference. Another factor affecting the heat-loss rate is wind velocity. Since the wind velocity and indoor temperature* for each of the heating load measurements was not the same, it was necessary to normalize the measurements to equivalent wind velocities and indoor temperatures in order to obtain meaningful heating load correlations.

The heat-loss rate $\left(q_{I}\right)$ due to air infiltration is given by the relation:

$$
q_{I}=\rho \cdot C_{p} \cdot \forall \cdot I \cdot\left(T_{i}-T_{0}\right)
$$

where

$$
\begin{aligned}
\rho= & \text { density of air, } 1 \mathrm{~b} / \mathrm{ft}^{3}\left(\mathrm{Kg} / \mathrm{m}^{3}\right) \\
\forall= & \text { volume of a residence, } \mathrm{ft}^{3}\left(\mathrm{~m}^{3}\right) \\
I= & \text { rate of air infiltration as a function of wind velocity, } \\
& \mathrm{h}^{-1}\left(\mathrm{~s}^{-1}\right) \\
C_{\mathrm{p}}= & \text { specific heat of air, } \mathrm{Btu} / 1 \mathrm{~b} \cdot \mathrm{F}(\mathrm{J} / \mathrm{Kg} \cdot \mathrm{K}) \\
\mathrm{T}_{1}- & \mathrm{T}_{0}=\text { inside-to-outside temperature difference, } \mathrm{F}(\mathrm{K})
\end{aligned}
$$

The air-infiltration rate (I) is a function of wind velocity. The heat-loss rate $\left(q_{I}\right.$ ) may be adjusted from one wind velocity to another by using air-infiltration values from the pre- and post-retrofit airinfiltration correlations (eqs. (7) and (9)) in relation (11).

The heat-loss rate ( $q$ ) at one condition, $\left(T_{i}-T_{0}\right)$ may be adjusted to another condition, $\left(T_{1}^{\prime}-T_{0}\right)$ having a different indoor temperature $\left(T_{i}^{\prime}\right)$ by the relation

$$
q_{a}=q^{\prime} \cdot \frac{T_{i}^{\prime}-T_{0}}{T_{i}-T_{0}} .
$$

Here $q_{a}$ denotes the adjusted heat-loss rate.

\footnotetext{
For the winter heating energy measurements, an attempt was made to maintain constant indoor temperature throughout the test. However, small variations in indoor temperature were nonetheless observed to occur from one day to the next.
} 
Since the measured daily-average heating loads for the unoccupied test house are approximately equivalent to heat-loss rates, relations (11) and (12) were used to normalize the measured heating loads for the unoccupied test house to the average wind velocity $(4.2 \mathrm{mph}(1.88 \mathrm{~m} / \mathrm{s}))$ and average indoor temperature $\left(67.9^{\circ} \mathrm{F}\left(19.9^{\circ} \mathrm{C}\right)\right.$ ) of all the winter heating energy measurements. Normalized daily-average heating loads of the unoccupied house before and after the various stages of the retrofit are plotted as a function of daily-average outdoor air temperature in figure 13. The straight lines were obtained from a leastsquares procedure.

Measured heating loads before and after stage 1 of the retrofit are seen to be essentially correlated by the same straight line. These results suggest that measures taken to seal air leaks did not produce measurable reduction in the heating loads for the unoccupied test house. This finding is consistent with the results of the air-infiltration measurements which also showed that no statistically significant reduction in air infiltration occurred as a result of actions taken to seal major air-leakage paths.

Actually, there was a tendency for the heating loads after stage 1 to be slightly higher than corresponding pre-retrofit values. This result may have occurred as a result of one or a combination of the following factors:

- Elimination of heat gains from the chimney to the test house after the retrofit. After the pre-retrofit heating-energy measurements, the oil-fired furnace was replaced with a heatpump system.

Disturbance of ceiling insulation. As part of another study being conducted at the test house, speakers, microphones, and electrical outlets were installed in the celling. An attempt was made to preserve the integrity of the glass-fiber ceiling insulation, but some disturbance of the ceiling insulation may have occurred nonetheless.

- Lower crawl-space and basement temperatures. The jacket loss and the temperature of delivered air for the heat pump system which was installed after stage 1 of the retrofit were much less than for the oil-fired furnace. This resulted in lower crawl-space and basement temperatures. However, R-11 blanket insulation was added to the basement ceiling before stage 1 of the retrofit, which fortuitously maintained the postretrofit floor heat-loss rate at approximately the preretrofit level. Higher heat-loss rates and colder air leakage probably occurred through the floor over the crawl space after the heat-pump system was substituted for the oil-fired furnace system. 


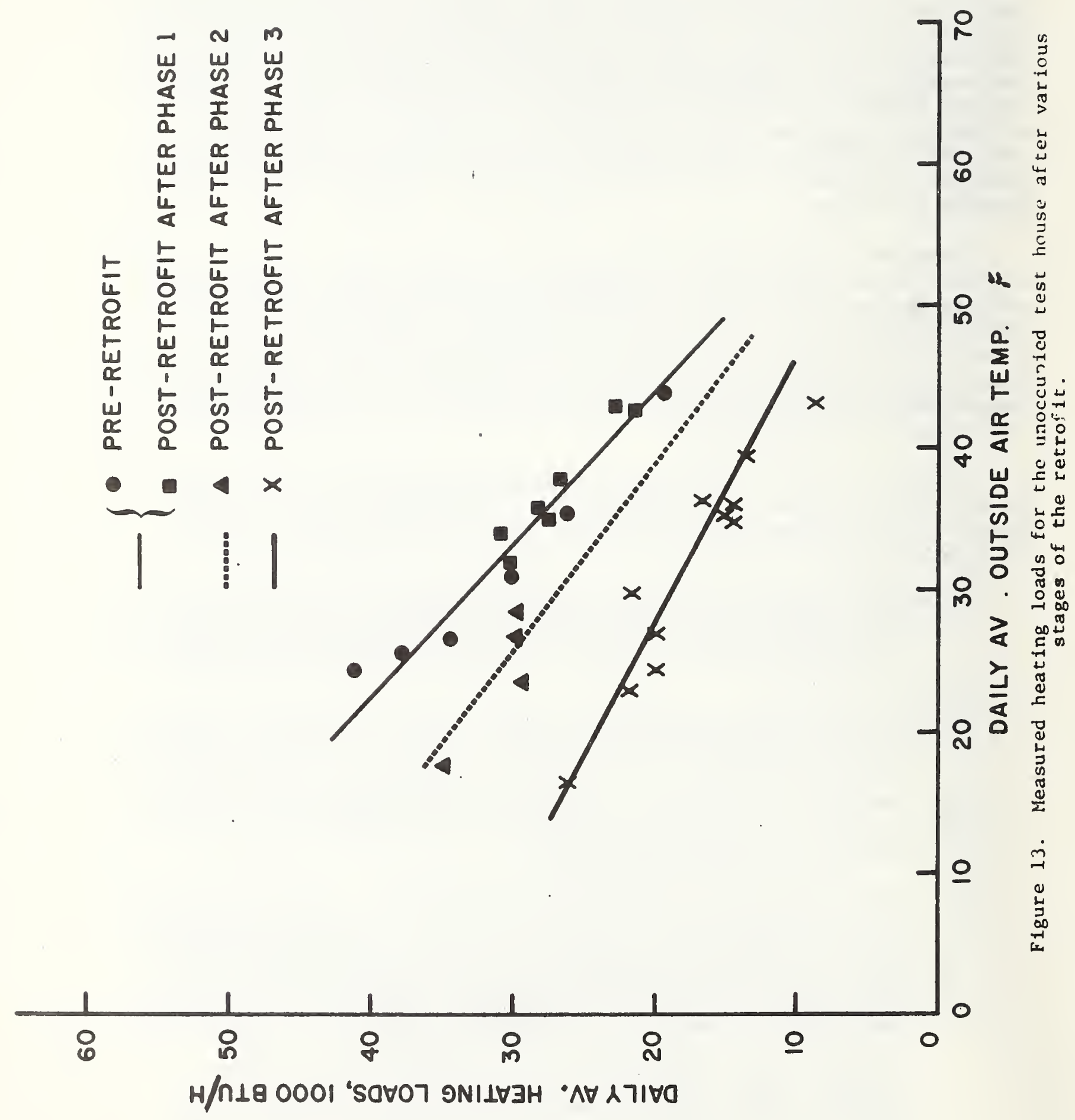




\subsubsection{Reduction in the Annual Space-Heating Energy Requirement}

The diurnal activities of a family occupying a house have a significant effect on its heating loads. The occupants and the operation of lighting and appliances release significant amounts of heat to the living space of a house.

In a previous study [15], an energy-release schedule for lighting, equipment, and occupants was presented. This occupancy schedule was devised for a six-member family living in a four-bedroom townhouse having a floor area of approximately $1200 \mathrm{ft}^{2}\left(111 \mathrm{~m}^{2}\right)$. Since the test house of the present study has roughly 71 percent more floor area, it was necessary to modify the townhouse occupancy schedule. It was assumed that the energy-release rates for lighting would be twice as large, whereas the energy-release rates for equipment would be 30 percent larger. The modified energy-release schedule for equipment, lighting, and occupants is plotted in figure 14. The dally-average heat-release rate for this schedule is $4,409 \mathrm{Btu} / \mathrm{h}(1,291 \mathrm{~W})$.

Over the conditions for which the house was tested, heat was always delivered by the heating plant during each hour of every test. If the test house had been occupied, the heat released by occupant-related activities would never have been sufficient to satisfy the heating load of the house over the conditions for which the house was tested. Therefore, the daily-average heating load for the test house, having an occupancy schedule of figure 14, would be equal to the heating load for the unoccupied test house (see figure 13), less the daily-average heatrelease rate for the occupancy schedule of figure 14 .

The foregoing procedure was applied to each of the daily-average heating loads of figure 13. The dally-average heating loads for an occupied test house are plotted in figure 15. A least-squares procedure was applied to the pre-retrofit and stage 1 data and the following correlating equation was obtained between heating load (q) expressed in $\mathrm{Btu} / \mathrm{h}$ and outdoor temperature $\left(\mathrm{T}_{0}\right)$ expressed in ${ }^{\circ} \mathrm{F}$ :

$$
q=-938 \cdot T_{0}+57,300 \quad \text { (pre-retrofit and stage } 1 \text { retrofit). }
$$

A similar procedure applied to the post-retrofit data yielded:

$$
\mathrm{q}=-532 \cdot \mathrm{T}_{\mathrm{o}}+30,000 \quad \text { (stage } 3 \text { retrofit). }
$$

Writing these equations in terms of the inside-to-outside temperature difference gives

$$
\begin{array}{ll}
q=938 \cdot\left(67.9-T_{0}\right)-6,380 & \text { (pre-retrofit) } \\
q=532 \cdot\left(67.9-T_{0}\right)-6,140 & \text { (stage } 3 \text { retrofit) } .
\end{array}
$$




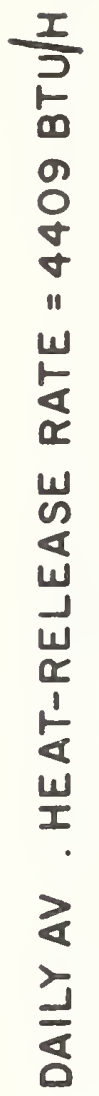

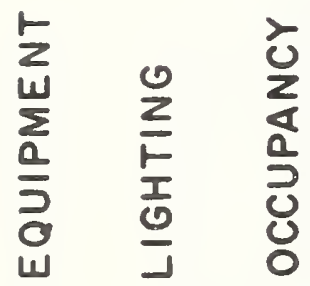

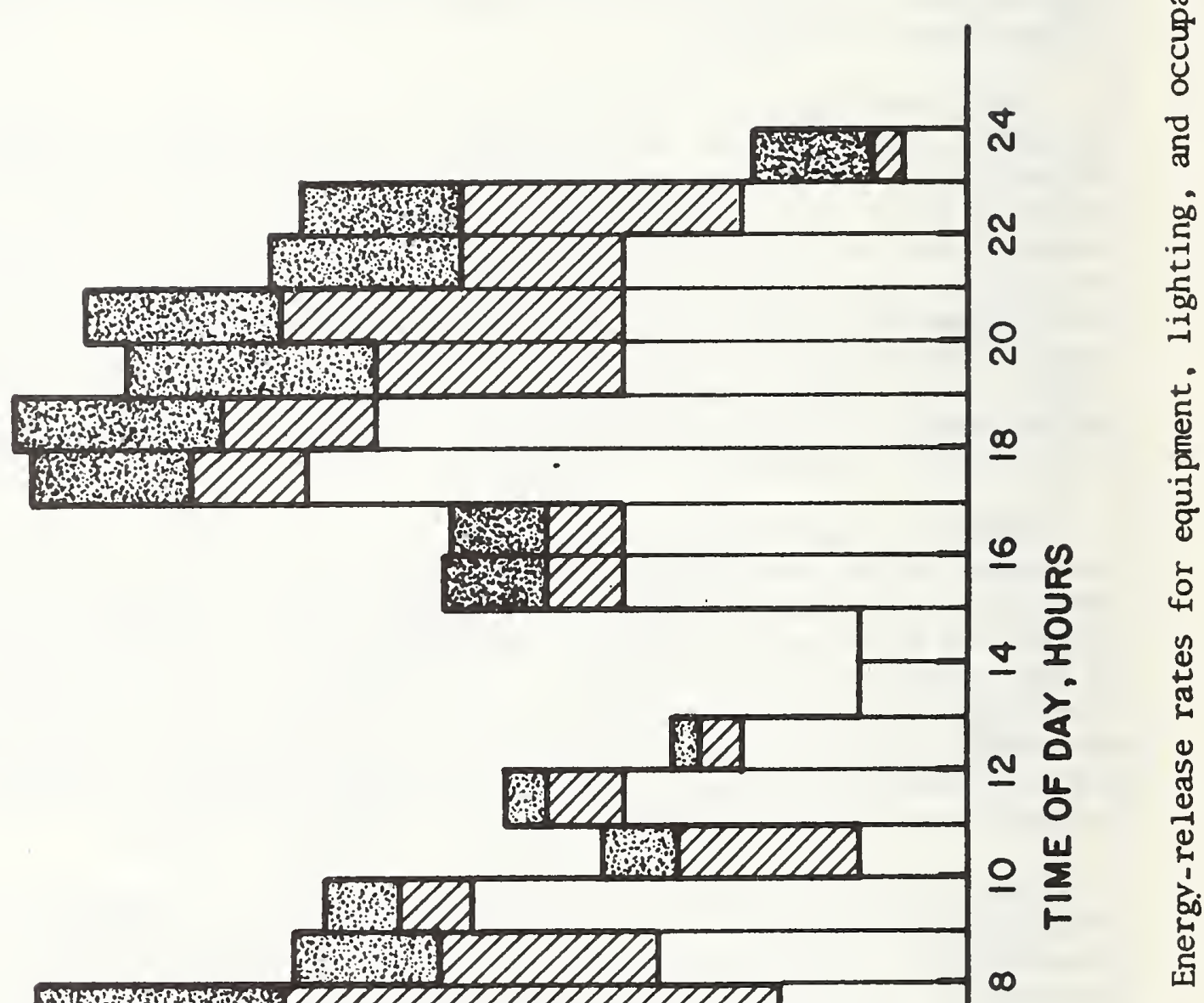

口图图
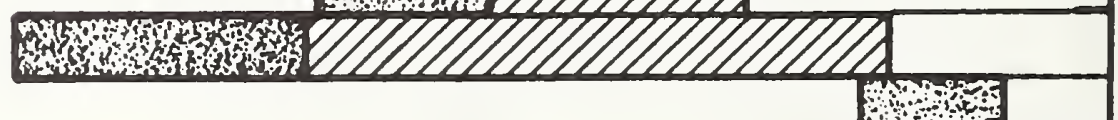

ปั.

จ

$\underset{\substack{\infty \\-1}}{\infty}$

j

(1)

3

เٔ

ญ

4

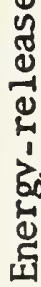

$\dot{7}$

崩

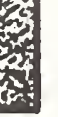

on

6

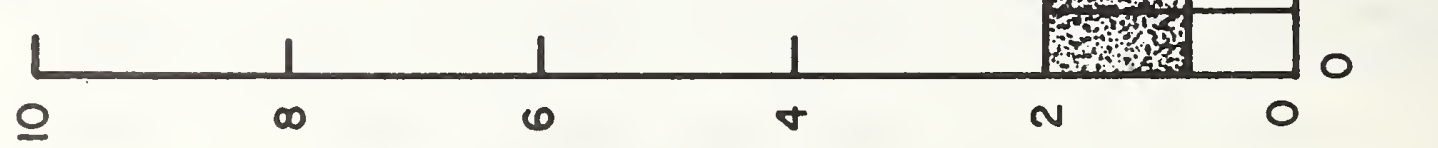

ก 180001 ' $\exists S \forall \exists 7 \exists \forall \perp \forall \exists H$ 


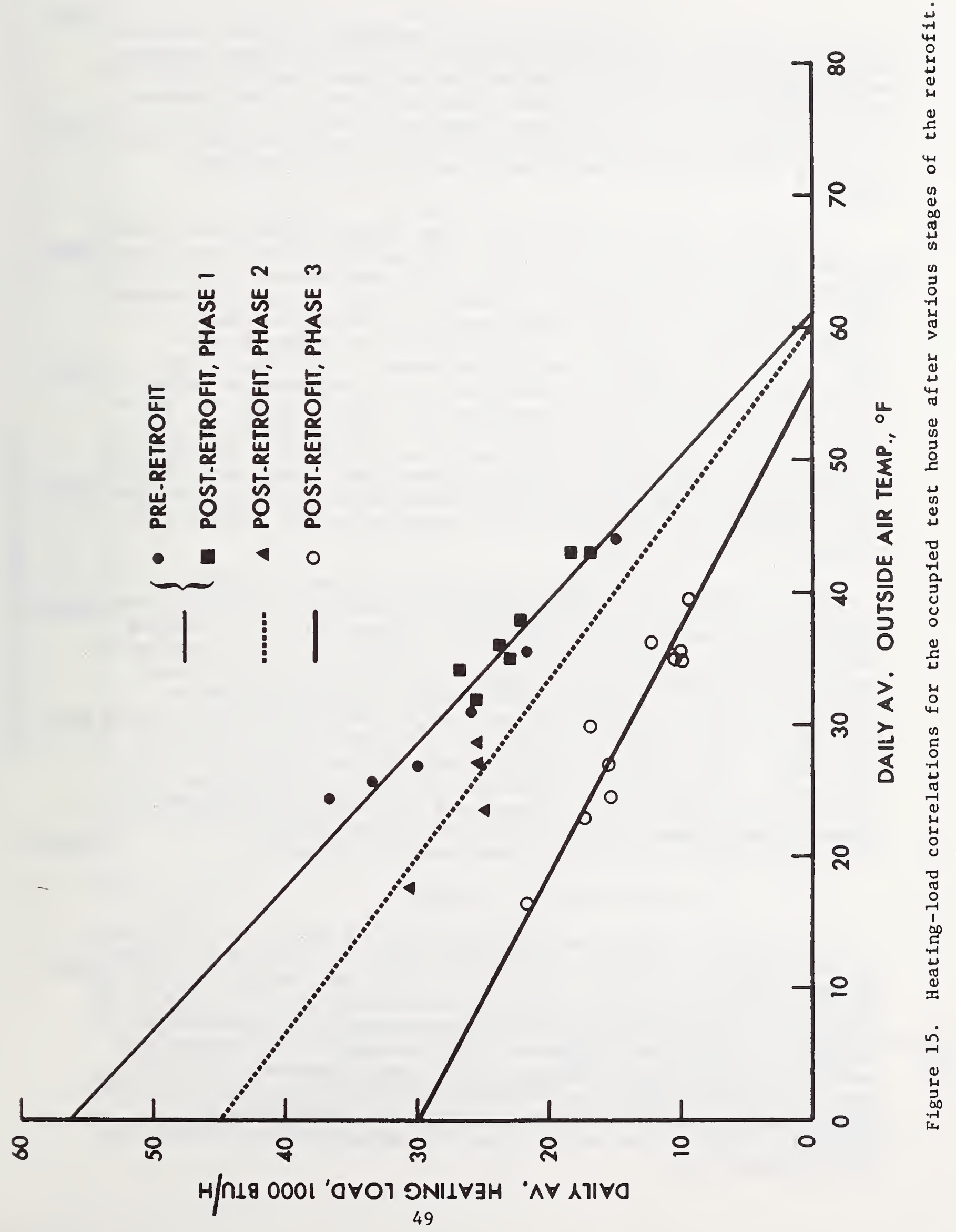


The first term in the foregoing equations represents the heat-loss rate from the test house. The second term represents daily-average internal heat-release from occupancy, lighting, and equipment, and heat gain from solar radiation through the windows. Recalling that the daily-average heat-release rate for the occupancy schedule is $4,409 \mathrm{Btu} / \mathrm{h}(1,291 \mathrm{~W})$, it is seen that the average solar load is calculated to be 1,971 (557 W) and $1,731 \mathrm{Btu} / \mathrm{h}(507 \mathrm{~W})$, respectively, which are not unreasonable figures.

The outdoor balance temperature is the outdoor temperature for which heating load for a house is zero. For this particular test house, the outdoor balance temperatures for the original and completely retrofitted house are found by setting eqs. (15) and (16) equal to zero and solving for $\mathrm{T}_{0^{\circ}}$. The outdnor balance temperatures for the occupied house were found to be $61.1^{\circ} \mathrm{F}\left(16.2^{\circ} \mathrm{C}\right)$ for the original house and $56.40^{\circ} \mathrm{F}$ $\left(13.6^{\circ} \mathrm{C}\right)$ for the completely retrofitted house. Performing a heat balance on the test house and making use of the heat-transfer properties of section 4, outdoor balance temperatures for the occupied test house before and after the retrofit are found to be $63.5^{\circ} \mathrm{F}\left(17.5^{\circ} \mathrm{C}\right)$ and $59.0^{\circ} \mathrm{F}\left(15.0^{\circ} \mathrm{C}\right)$ when solar radiation is not considered. The effect of including solar radiation in the steady-state heat balance would further reduce the calculated outdoor balance temperatures. Based on the foregoing considerations, the empirically determined outdoor balance temperatures are very plausible.

Since insufficient stage 2 experimental data were available to empirically determine the outdoor balance temperature, it was necessary to resort to a semi-empirical technique to obtain the stage 2 heating load correlation. The coefficient factor (938.) of eq. (15) represents the overall heat-transfer coefficient in $\mathrm{Btu} / \mathrm{h}^{\circ}{ }^{\circ} \mathrm{F}$ for the test house before the retrofit. Using the heat-transfer properties given in section 4, it was found that the addition of storm windows would reduce the overall heat-transfer coefficient of the test house by $119 \mathrm{Btu} / \mathrm{h} \cdot{ }^{\circ} \mathrm{F}$ $(62.7 \mathrm{~W} / \mathrm{K})$. The coefficient factor of eq. (15) was changed from 938 to 819 , and an outdoor balance temperature of $60.1^{\circ} \mathrm{F}\left(15.6^{\circ} \mathrm{C}\right)$ was calculated for the stage 2 data. Then using this empirically-determined outdoor balance temperature, the following correlating equation for the stage 2 data was obtained from a least-squares procedure:

$$
q=748\left(67.9-T_{0}\right)-5,851 \text {. }
$$

The number or annual heating degree days for Washington, D.C. given in reference [4] is 4,224. The value of 4,224 is based on an outdoor balance temperature of $65^{\circ} \mathrm{F}\left(18.3^{\circ} \mathrm{C}\right)$. The outdoor balance temperature for each of the correlating equations is different from $65^{\circ} \mathrm{F}\left(18.3^{\circ} \mathrm{C}\right)$. Therefore, to calculate the annual heating-energy requirement for each of the correlating equations, it is necessary to use the actual number of heating degree days for the reference temperature of that particular correlation. Heating degree days for Washington, D.C. (1957) are plotted versus outdoor balance (reference) temperatures in figure 16. These values were obtained by searching actual weather data for Washington, D.C. 


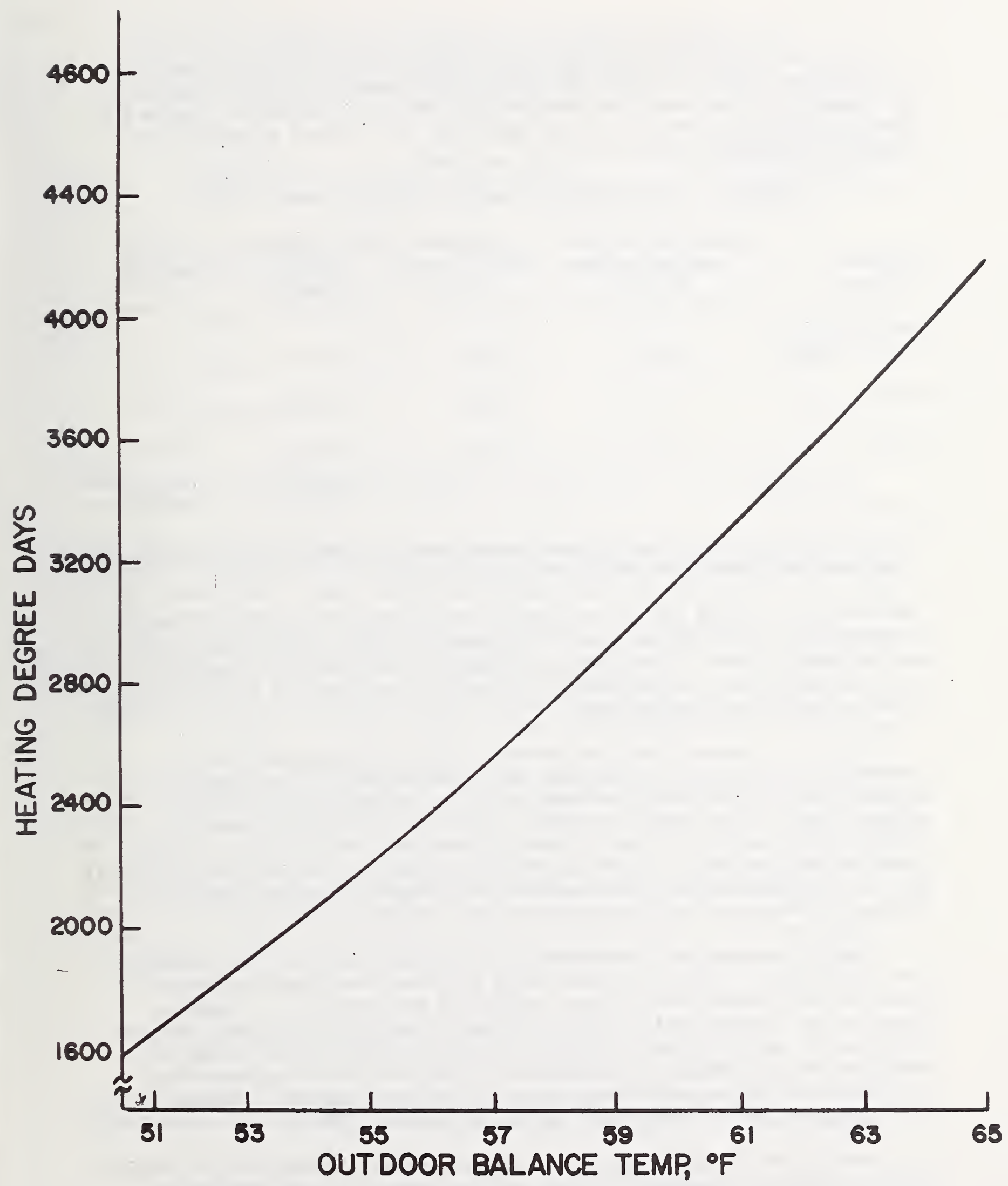

Figure 1h. Heating degree days as a function of outdoor balance temperature for Washington, D.C. 51 
The annual heating load for a residence is equal to the product of the adjusted degree days and the energy requirement for space heating per degree day (derived from the heating load correlations of figure 15). The calculation of annual heating loads for the various stages of the retrofit is shown in table 11 .

\section{TABLE 11. CALCULATION OF ANNUAL HEATING LOADS}

\begin{tabular}{lccccc}
$\begin{array}{c}\text { Retrofit } \\
\text { Stage }\end{array}$ & $\begin{array}{c}\text { Energy Requirement } \\
\text { per Degree Day } \\
\text { Btu/DD }\end{array}$ & $\begin{array}{c}\text { Adjusted } \\
\text { Degree Days* } \\
\text { DD }\end{array}$ & $\begin{array}{c}\text { Annual Heating } \\
\text { Load } \\
\text { Therms }\end{array}$ & $\begin{array}{c}\text { Energy } \\
\text { Savings } \\
\%\end{array}$ \\
\cline { 1 - 2 } $\begin{array}{l}\text { Pre-retrofit } \\
(\text { also Stage 1) }\end{array}$ & 22,501 & 3,350 & & 753.8 & 0 \\
Stage 2 & 17,945 & 3,140 & 563.5 & 25.2 \\
Stage 3 & 12,752 & 2,450 & & 312.4 & 33.3 \\
& & & TOTAL & 58.5
\end{tabular}

$\star$

Corresponding to the particular outdoor balance temperature of each of the heating load correlations of figure 15.

The reduction in the annual heating load resulting from the addition of storm windows was 25.2 percent. The installation of insulation in the walls, celling, and floor produced a further 33.3 percent reduction. The combination of all stages of the retrofit resulted in a 58.5 reduction in the annual heating load.

If it is assumed that the separate energy savings achieved by insulating the floor, ceiling, and walls for stage 3 of the retrof it are proportional to the predicted reductions in the heat-loss rates (see tables 13 and 14 of section 6.3.3), the percent savings in heating energy requirement are found to be 19.7 percent for the walls, 6.1 percent for celling, and 7.5 percent for the floor. It should be pointed out that if the celling had been uninsulated to begin with, the effect of adding insulation to that part would have been much greater.

The first terms of the heating load correlations for the occupled test house, eqs. (15), (16), and (17), represent the heat-loss rate from the test house after various stages of the retrof 1 . Comparing these terms for the various stages of the retrofit, it is seen that the addition of storm windows reduced the heat-loss rate by $20.3 \%$ and the addition of insulation to the walls, celling, and floor reduced the heat-loss rate by an additional $23.0 \%$. The total reduction in heat-loss rate achieved by all stages of the retrof 1 t was $43.3 \%$.

Reductions in heat-loss rate and corresponding reductions in annual heating loads are compared for the various stages of the retrofit in table 12 . 
TABLE 12. COMPARISON OF REDUCTIONS IN HEAT-LOSS RATE TO

REDUCTIONS IN ANNUAL HEATING LOAD

\begin{tabular}{l}
$\begin{array}{l}\text { Retrofit } \\
\text { Stage }\end{array}$ \\
\hline $\begin{array}{l}\text { Pre-retrofit } \\
\text { (and Stage 1) }\end{array}$ \\
Stage 2 \\
Stage 3 \\
Combination
\end{tabular}

\author{
Reduction in \\ Heat-Loss Rate \\ $\%$
}

0

20.3

23. 0

43.3
Reductions in Annual Heating Load $\%$

0

25.2

33.3

58.5

Reductions in annual heating loads are clearly seen to be larger than corresponding reductions in heat-loss rate.

Retrofit actions which reduce the thermal transmittance of the exterior envelope of a building provide reduction in annual heating loads by two mechanisms. They reduce the heat-loss rate and lower the outdoor balance temperature for a building. When the outdoor balance temperature is reduced, there will exist a larger number of heating hours for which the Internal heat (from lights, equipment, and people) can provide the required heating energy, instead of the heating plant. This result causes the number of heating-degree days to be essentially reduced, which in turn means reduced heating energy requirement for the bullding.

The foregoing results suggest that a "modifled" degree-day method which utilizes a variable outdoor balance temperature and adjusted degree days should be used to evaluate reductions in annual heating load provided by energy conservation modifications to the exter for envelope of a building. It will provide significantly more accurate results than the traditional base- 65 degree-day method. A difficulty in using a "modifled" degree-day method is that the outdoor balance temperature depends not only on the overali thermal transmittance of the building envelope but also on the amount of heat released from occupant-related activities which varies over a wide range from one family to the next.

\subsubsection{Comparison of Measured and Calculated Heat-Loss Rates}

The purpose of this section is to compare measured heat-loss rates to corresponding calculated values determined by a steady-state method. Since heated air was delivered only to the first-floor occupied space, 
:his region was used as the control volume for the heat balance. For these calculation:, measured temperatures for the crawl space (figure 17), attic space (figure 18) arld basement, at the average outdoor conditions for the data set, were used in the calculation of heat loss through the floor and ceiling.

The rates of heat transmission $\left(q_{c}\right)$ through the separate surfaces of the house were calculated using the steady-state relation:

$$
q_{c}=U \cdot A \cdot\left(T_{1}-T_{0}\right)
$$

where $U=$ thermal transmittance, $B t u / h \cdot \mathrm{ft}^{2} \cdot \mathrm{F}\left(\mathrm{W} / \mathrm{m}^{2} \cdot \mathrm{K}\right)$

$$
\begin{aligned}
& A=\text { surface area, } \mathrm{ft}^{2}\left(\mathrm{~m}^{2}\right) \\
& \mathrm{T}_{1}-\mathrm{T}_{0}={ }^{\mathrm{air}-\mathrm{o}-\mathrm{O}-\mathrm{ir}} \text { (emperature difference across the surface, } \\
& \left.{ }^{\circ} \mathrm{K}\right) .
\end{aligned}
$$

Heat loss due to air infiltration was calculated using eq. (11). For this calculation, the temperature of infiltrating air was taken to be at the temperature of outdoor air. Separate tracer-gas measurements showed that when tracer was released in the attic space, none would subsequently appear in the living space. However, some infiltration was found to occur from the crawl space to the living space. This latter infiltration process caused a portion of the infiltrating air to enter the test house at higher temperatures than the outdoor air. However, for the present analysis, the temperature of infiltrating air was taken to be at the temperature of the outdoor air.

Using eqs. (11) and (18) and making use of the heat-transfer properties given in section 4, pre- and post-retrofit air infiltration correlations (eqs. (7) and (9)), and measured crawl-space, basement, and attic temperatures, steady-state heat-loss calculations were performed for the house in its original state (table 13) and for the completely retrofitted house (table 14). For these calculations, the indoor and outdoor temperatures were taken to be equal to the mean values observed during the winter heating-energy measurements, namely, $\mathrm{T}_{1}=67.9^{\circ} \mathrm{F}\left(18.9^{\circ} \mathrm{C}\right)$, and $\mathrm{T}_{\mathrm{O}}=31.8^{\circ} \mathrm{F}\left(-0.1^{\circ} \mathrm{C}\right)$. The wind velocity was taken to be the mean value observed during the pre- and post-retrofit heating energy measurements (1.e., $V=7.9 \mathrm{mph}(3.5 \mathrm{~m} / \mathrm{s})$ and $V=3.5 \mathrm{mph}(1.6 \mathrm{~m} / \mathrm{s})$, respectively).

For the pre-retrofit steady-state heat-loss calculations, comparing the predicted heat-loss rate of $34,336 \mathrm{Btu} / \mathrm{h}(10,060 \mathrm{~W})$ from table 13 to the corresponding measured value of $33,900(9,933)$ (first term of eq. (15)), we see that the predicted value is only $436 \mathrm{Btu} / \mathrm{h}(128 \mathrm{~W})$, or 1.3 percent higher than the measured value. Also, for the postretrof it steady-state heat-loss calculation, comparing the predicted heat-loss rate of $20,993 \mathrm{Btu} / \mathrm{h}(6,151 \mathrm{~W})$ (from table 14 ), to the corresponding measured value of $19,205(5,627)$ (first term of eq. (16)), we see that the calculated value is only $1,788 \mathrm{Btu} / \mathrm{h}(524 \mathrm{~W})$ higher or 9.3 percent higher than the measured value. 


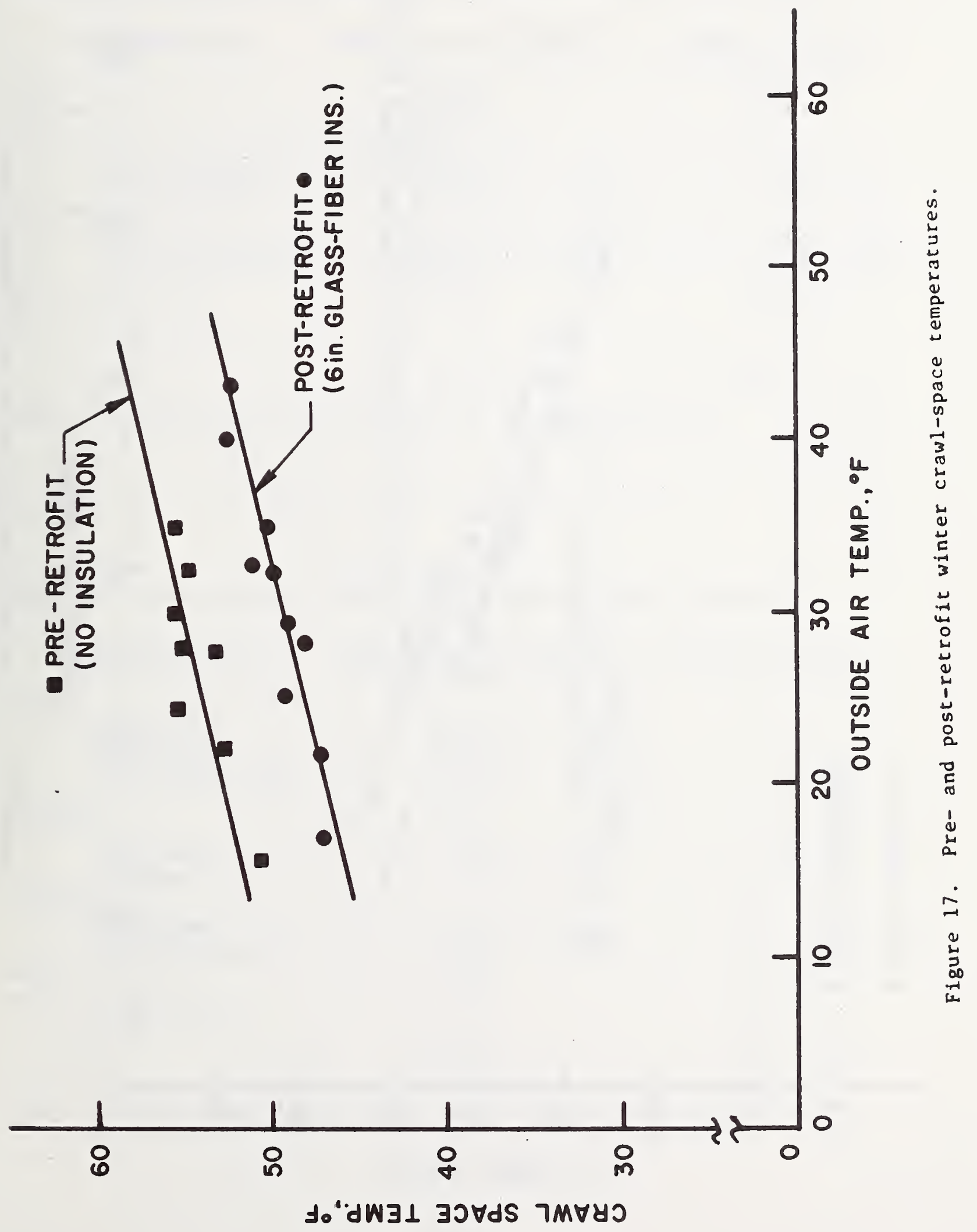




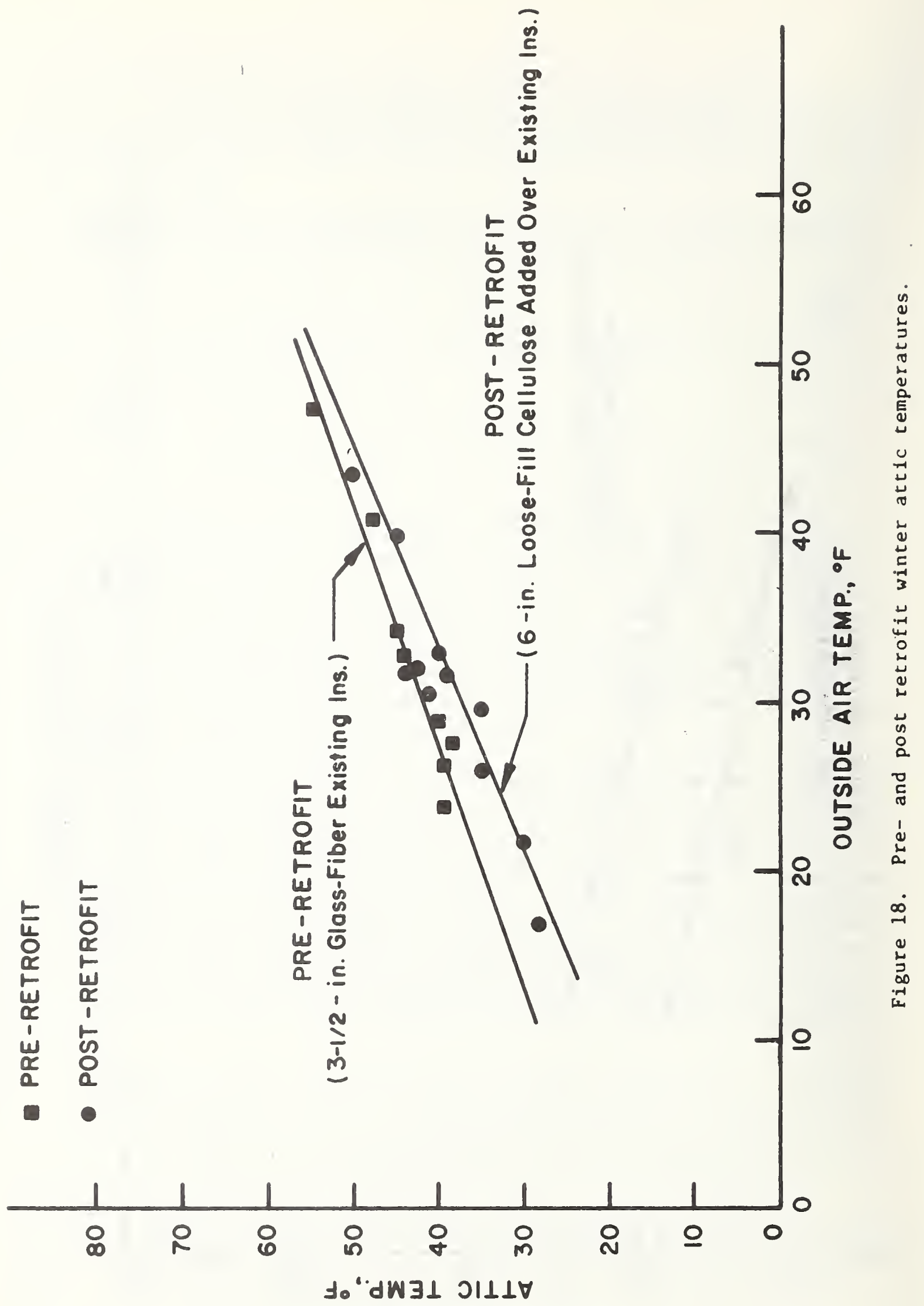


TABLE 13. PRE-RETROFIT STEADY-STATE WINTER HEAT-LOSS CALCULATIONS

\section{Heat-Loss Path}

Walls

Ceiling

Floor

- over crawl space

- over basement

Windows

- single pane

- insulating glass

Doors

Air Infiltration

$\left(I=0.51 \mathrm{~h}^{-I}\right)$ *

TOTAL
Heat-Loss Rate, Btu/h

9617.

4020 .

$\left.\begin{array}{r}3201 . \\ 292 .\end{array}\right\} \quad 3493$.

$\left.\begin{array}{l}8395 . \\ 1877 .\end{array}\right\} \quad 10,272$.

924 .

6010 .

34,336 .
Percent of Total

28.0

11.7

9.3

.9

$\left.\begin{array}{r}24.4 \\ 5.5\end{array}\right\}$

2. 7

17.5

100.

*Based on pre-retrof it air-infiltration correlation (eq. 7).

TABLE 14. POST-RETROFIT STEADY-STATE WINTER HEAT-LOSS CALCULATIONS

Heat-Loss Path

Wa 11 s

- cellulose

- glass fiber

- urea formaldehyde

Celling

Floor

- crawl space

- basement

Windows

- double pane

Doors insulating glass

Air Inf 11 tration $\left(I=0.65 \mathrm{~h}^{-1}\right)$ *

TOTAL
Heat-Loss Rate, Btu/h

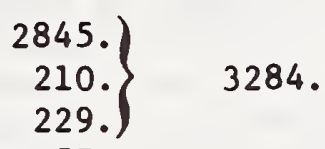

2057.

$\left.\begin{array}{l}844 . \\ 233 .\end{array}\right\} \quad 1077$

$\left.\begin{array}{l}4115 . \\ 1877 .\end{array}\right\} \quad 5992$.

924 .

7659 .

20,993 .
Percent of Total

15.6

9.8

4.0

1.1

28.5

4.4

36.5

100.

*Based upon post-retrofit air-infiltration correlation (eq. 9). 
The foregoing comparison of measured and calculated heat-loss rates for the test house supports the validity of the heating energy measurements.

\subsection{Summer Energy Mea surements}

\subsubsection{Measured Cooling Loads}

Both pre-retrofit and post-retrofit cooling loads were measured for the unoccupied test house. For these measurements, the only internal load inside the test house was a constant lighting load of $660 \mathrm{~W}$. The windows were kept closed throughout the measurements, therefore no benefit was realized from using cool night air for cooling. The daily-average indoor temperature averaged $73.3^{\circ} \mathrm{F}\left(22.9^{\circ} \mathrm{C}\right)$ for the preretrof 1 t measurements and $74.4^{\circ} \mathrm{F}\left(23.6^{\circ} \mathrm{C}\right)$ for the post-retrofit measurements.

The daily-average sensible and latent cooling loads for the preand post-retrofit measurements are plotted in figures 19 and 20. Note that the post-retrofit sensible loads (figure 19) tended to be slightly higher than the pre-retrofit sensible loads. For the case of latent loads (figure 20), the post-retrofit loads tended to be lower than corresponding pre-retrofit values. The benefit of reduced latent loads was offset by increased sensible loads, so that the retrofit is seen to have little or no effect on the total cooling loads for the test house.

\subsubsection{Analysis of Cooling Energy Measurements}

The reductions in latent load were attributed to a change in the relative huridity levels in the living space. As shown in figure 21 , the relative humidity in the first-floor living space was significantly reduced after the retrofit. The reduction in indoor relative humidity was attributed principally to the polyethylene film which was placed over the bare earth of the crawl space as part of the retrofit. The effect of this ground cover was to substantially reduce the moisture content of the crawl-space air. Separate tracer gas measurements showed that there was an exchange of air between the crawl space (and basement) and the living space when the air-delivery system of the heating plant was in operation. It was hypothesized that one mechanism by which crawl-space air infiltrated into the first-floor living space was through air leaks at the seams of the return-air ducts. In addition, the vapor barrier on the backside of the glass-fiber batts which were installed in the floor over the crawl-space may have reduced the permeation of water vapor through the floor.

The reduction in latent load $\left(\Delta q_{L}\right)$ may be estimated from the relation:

$$
\Delta \mathrm{q}_{\mathrm{L}}=\rho \cdot \psi \cdot \mathrm{I} \cdot \mathrm{h}_{\mathrm{fg}} \cdot \Delta w
$$




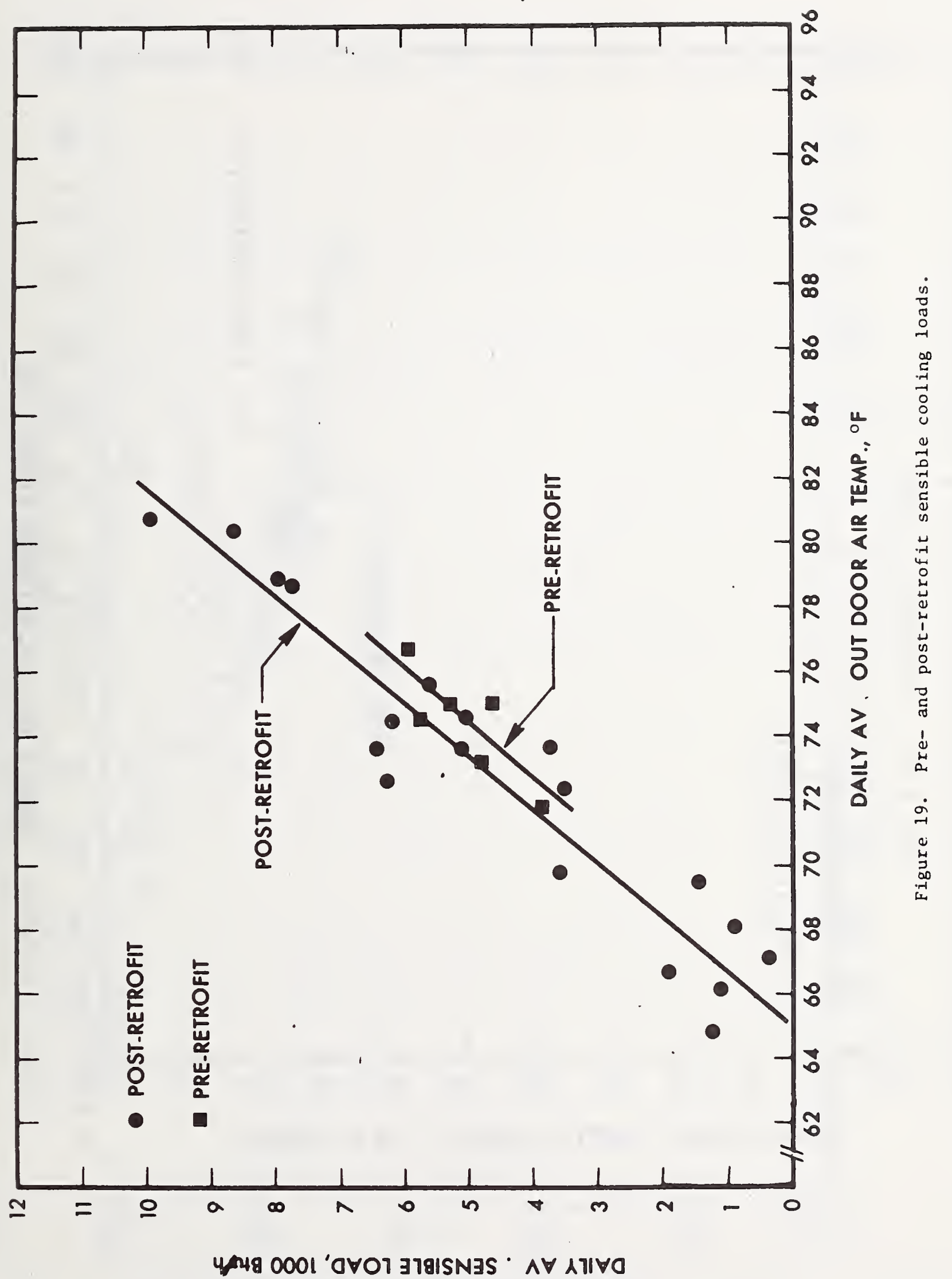




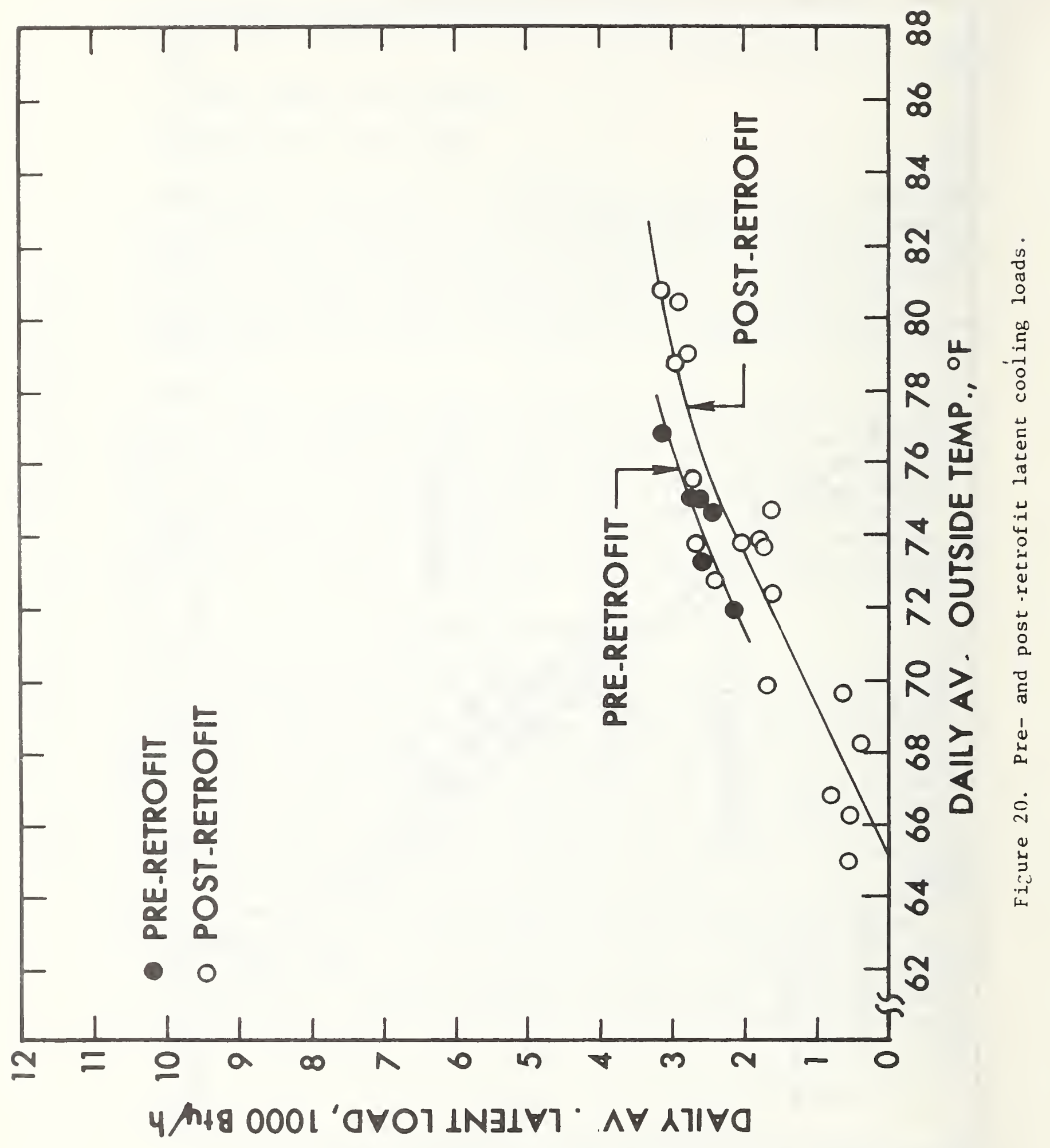




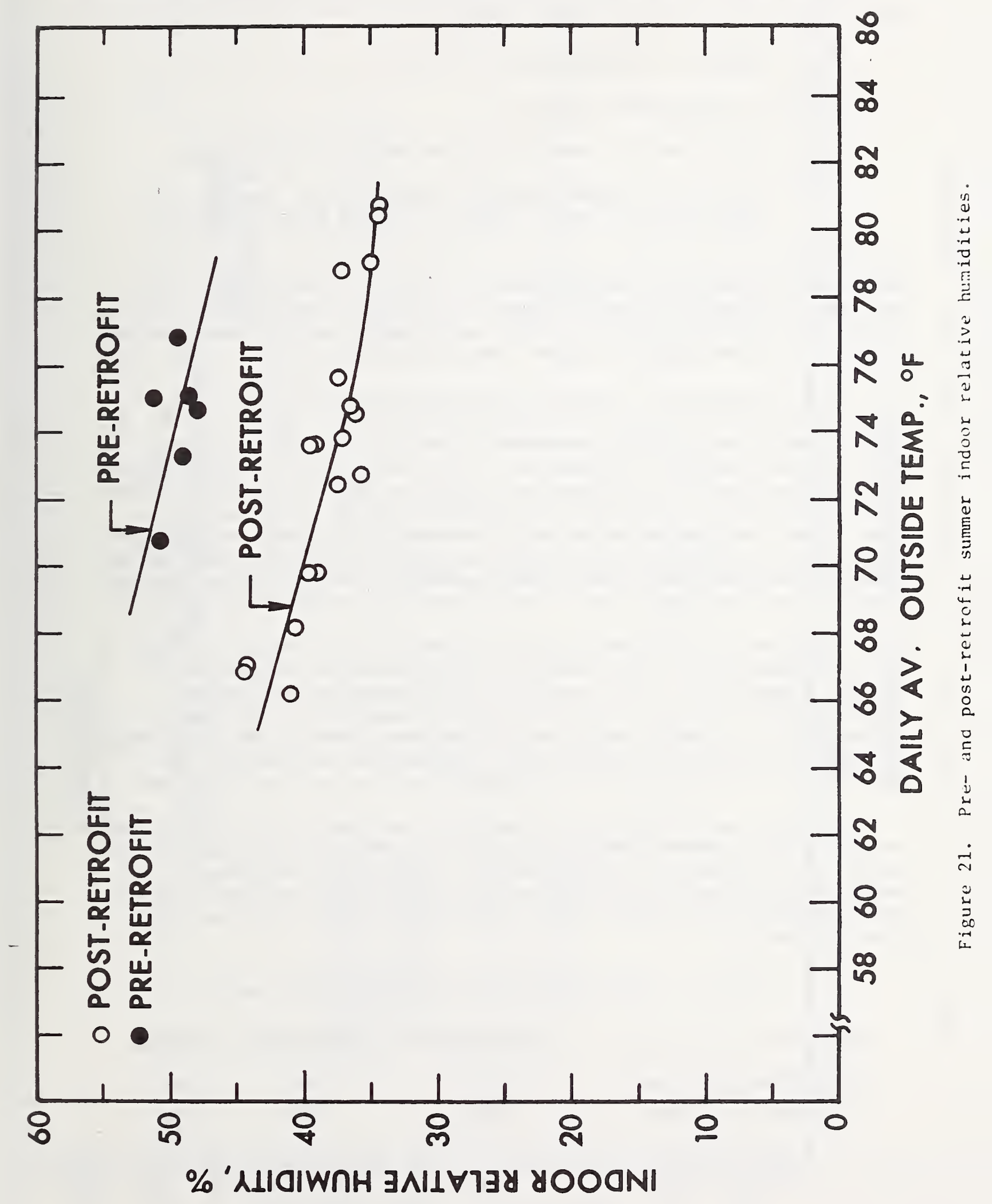


where $\rho=$ density of air, $1 \mathrm{~b} / \mathrm{ft}^{3}\left(\mathrm{Kg} / \mathrm{m}^{3}\right)$

$\psi=$ volume of the enclosure, $\mathrm{ft}^{3}\left(\mathrm{~m}^{3}\right)$

$I=$ air infiltration rate, $h^{-1}$

$\mathrm{h}_{\mathrm{fg}}=$ latent heat of vaporization for water, Btu/lb $\left(\mathrm{J} / \mathrm{Kg}_{\mathrm{g}}\right)$

$\Delta \omega=$ reduction in indoor humidity ratio between the pre- and post-retrofit cooling tests, $1 \mathrm{~b}(\mathrm{Kg}) \mathrm{H}_{2} 0$ per $1 \mathrm{~b}(\mathrm{Kg})$ air.

Taking the alr-infiltration rate for the house to be the mean of the summer alr-infiltration measurements $\left(I=0.26 \mathrm{~h}^{-1}\right)$ and making use of the relative humidity data of figure 2l, the reduction in latent load is found to be $745 \mathrm{Btu} / \mathrm{h}(218 \mathrm{~W})$. This approximates the difference between the pre- and post-retrofit latent load correlations shown in figure 20.

When comparing pre- and post-retrofit sensible cooling loads, it should be pointed out that the daily-average indoor temperature for the post-retrofit cooling-load measurements was $1.1^{\circ} \mathrm{F}\left(0.61^{\circ} \mathrm{C}\right)$ higher than the pre-retrofit measurements. If the post-retrofit measurements had been performed at an Indoor temperature of $73.3^{\circ} \mathrm{F}\left(22.9^{\circ} \mathrm{C}\right)$ instead of $74.4^{\circ} \mathrm{F}\left(23.6^{\circ} \mathrm{C}\right)$ then the post-retrof 1 t cooling loads would have been higher than the values actually measured. This would have caused the difference between the pre- and post-retrofit sensible loads to have been greater than the values actually measured. An analysis of the increase in sensible loads that occurred after the retrofit follows.

Comparisons of the pre- and post-retrofit dally average crawlspace, basement, and attic temperatures are glven in figures 22,23 , and 24, respectively. Note that both the crawl-space and basement temperatures are lower than the indoor air temperatures, so that the living space is always losing heat to the space below. The large amount of scatter in the dally-average attlc temperature correlations was attributed to differences in solar radiation from one day to the next.

The addition of thermal insulation in the floor over the crawl space reduced a prior sumer benef 1 t of heat loss from the living space to the crawl space, whereas the installation of additional insulation to the celling reduced heat gains through the celling. Pre- and post-retrofit daily-average heat-transfer rates through the ceiling and floor are given in table 15 .

TABLE 15. DAILY-AVERAGE HEAT-TRANSFER RATES, Btu/h

Component

Ceiling Heat-Gain Rate

Floor Heat-Loss Rate
Pre-retrofit Post-retrofit Change

1,451

861

590

1,518

615
903 


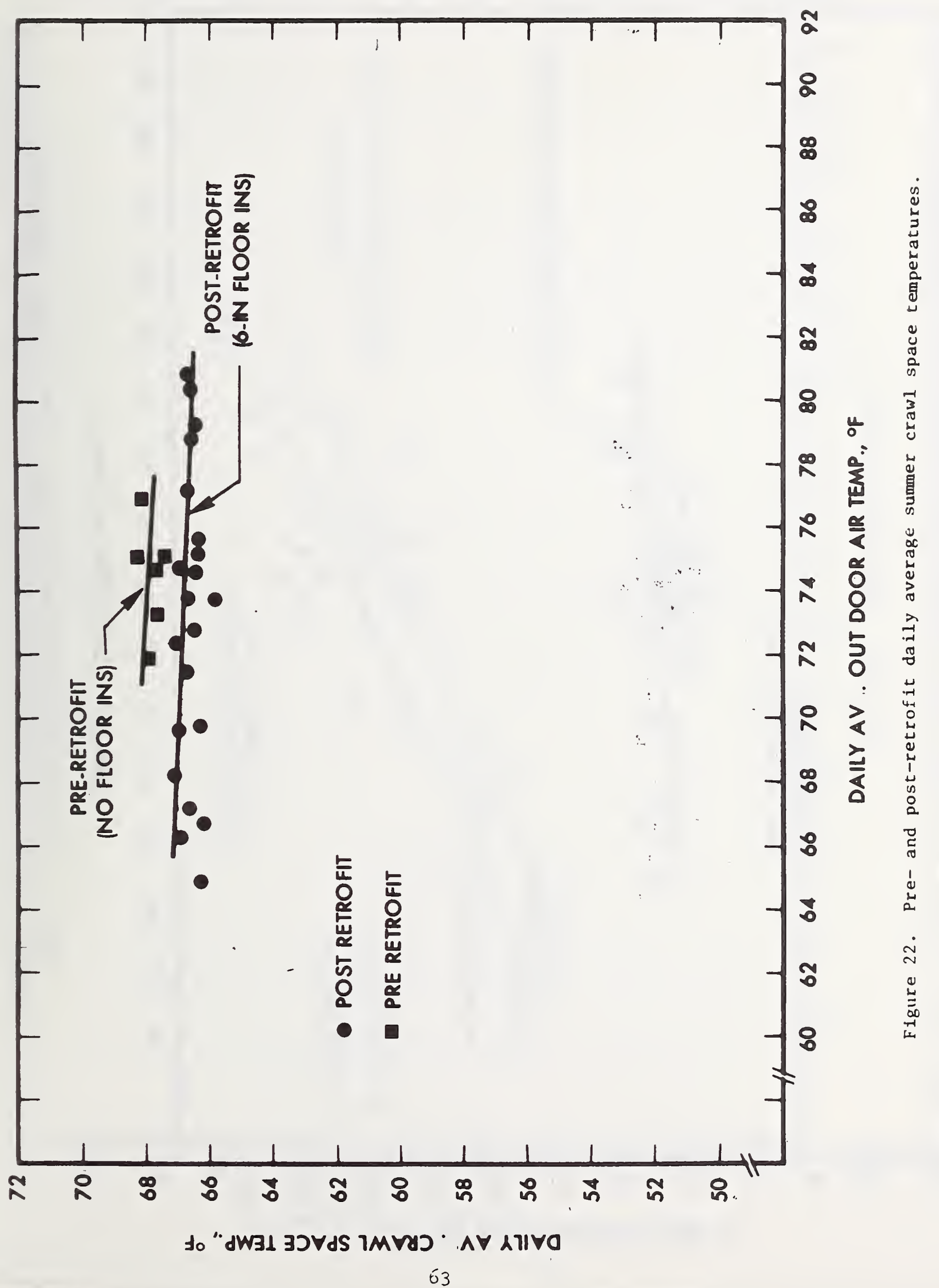




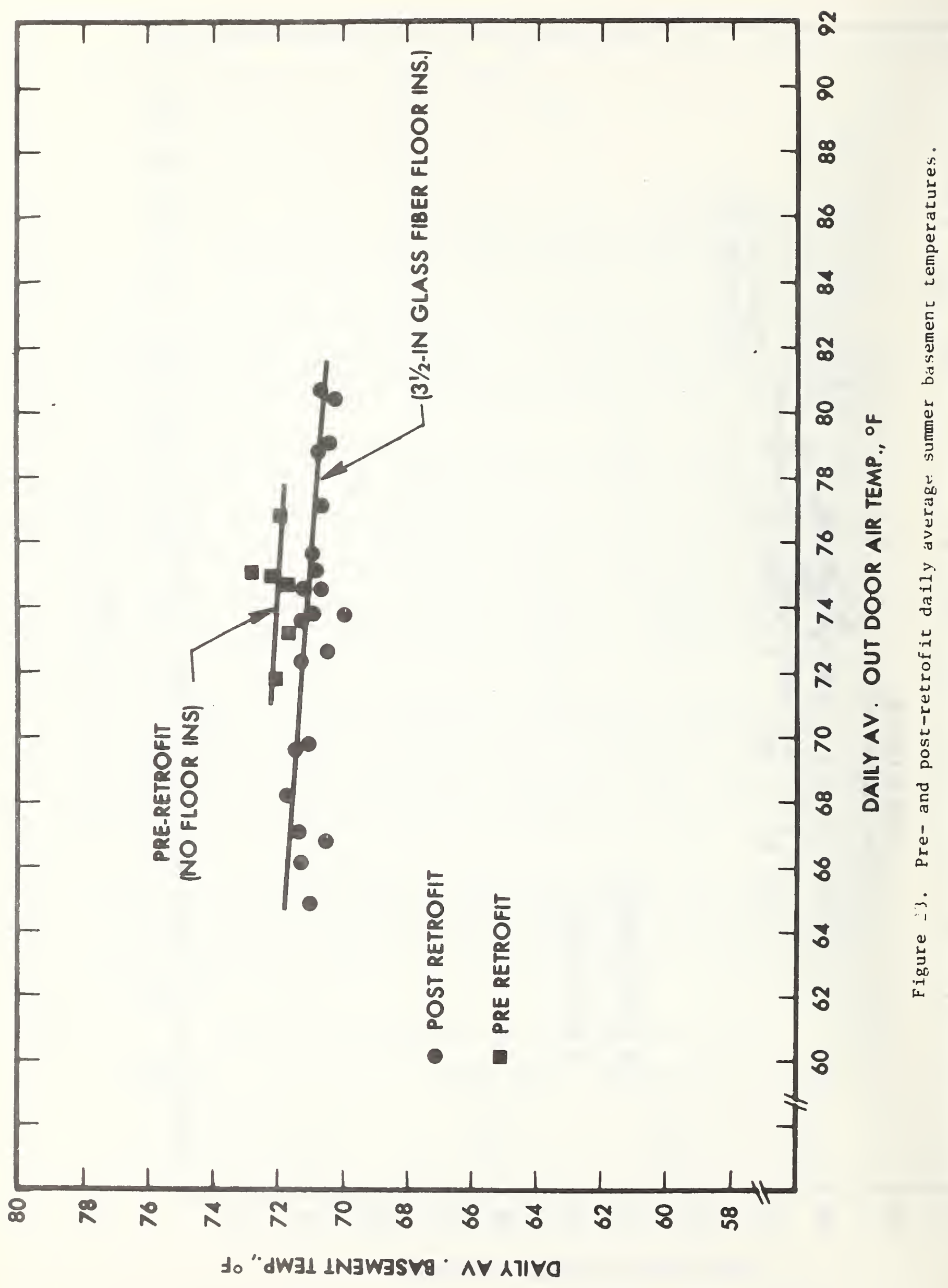




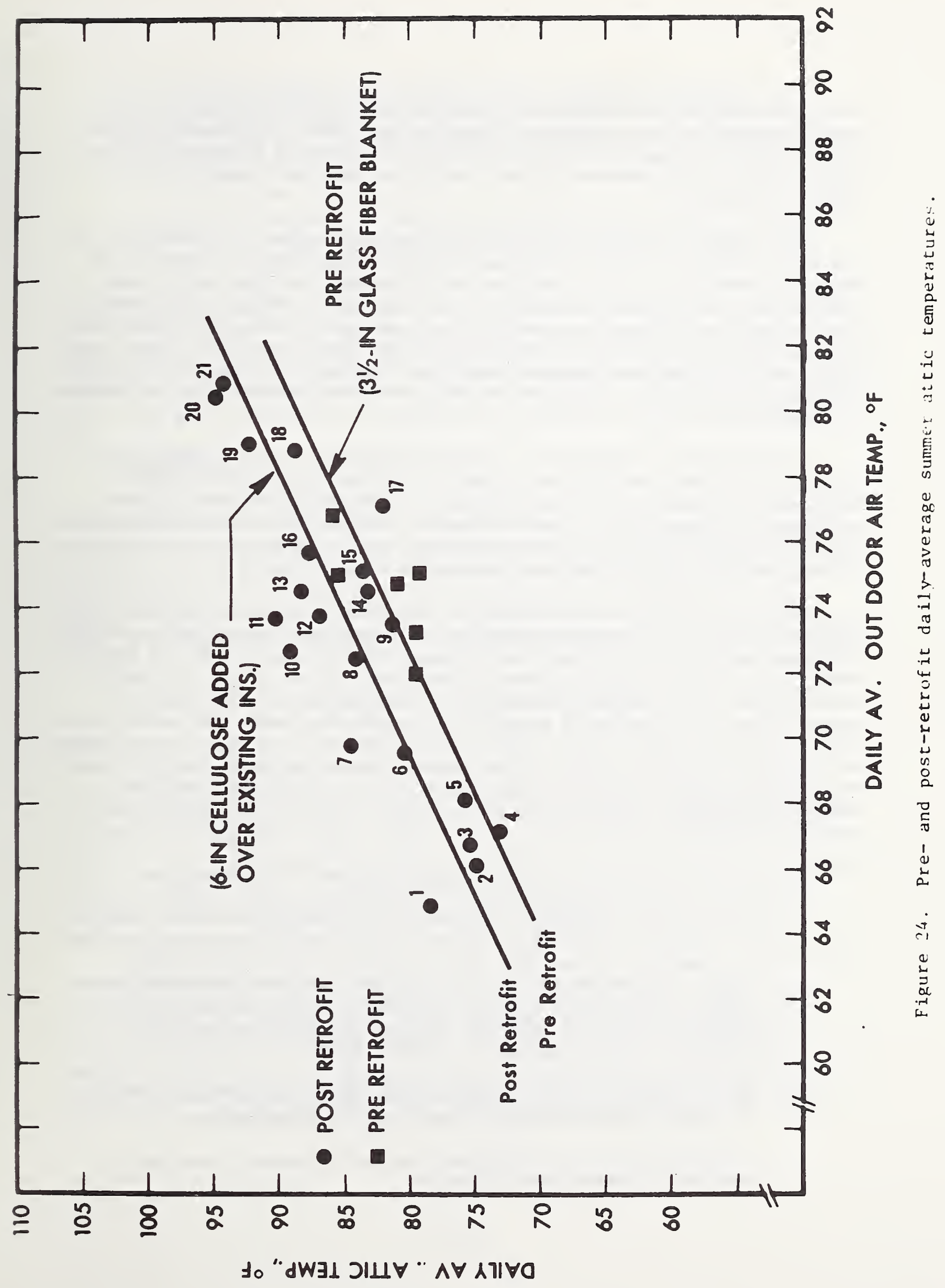


The foregolng dally-average heat-transfer rates were calculated using the steady-state heat conduction equation (eq. 19). For these calculatlons, da1ly-average crawl space (figure 22), basement (figure 23), and att1c (figure 24) temperature were used at an outdoor temperature of $73.3^{\circ} \mathrm{F}\left(22.9^{\circ} \mathrm{C}\right)$.

The results of table 15 show that the installation of insulation in the floor over the crawl space and additional insulation to the celling produced reduction in the heat-loss rate through the floor which more than offset the reduction in the rate of heat gain through the celling. The net effect of these two retrofit actions was to cause a net decrease in the dally-average rate of heat loss of $313 \mathrm{Btu} / \mathrm{h}(91.7 \mathrm{~W})$. This decrease $1 \mathrm{~s}$ of the same order of magnitude as the difference in cooling loads between the pre- and post-retrofit measured sensible cooling loads of figure 19 .

A qualitative evaluation of the effectiveness of the awning for reducing heat gain may be ascertained by considering the photograph of the installed awnings shown in figure 6. This photograph was taken at approximately noon time. The overhanging roof is seen to shade most of the area of each window on the south side of the test house. The add1tlonal shading derlved from the awnings is seen to be small.

Some qualitative understanding of the effect on the post-retrofit cooling loads of adding storm windows and insulation to the walls may be obtained by noting that the dally-average outdoor temperature was very nearly equal to the dally-average indoor temperature. Thus, the da1lyaverage heat gain through the window and the walls over the observed range of weather conditions should be approximately zero. In other words, the reductions in heat gain during the day are offset by reductions in natural cooling at night. Thus, storm windows and wall insulation would be expected to have a small effect in reducing summer cooling energy requirements for this particular test house and the conditions over which 1 t was tested.

The following factors unquestionably influenced the results.

1. At the test conditions over which the comparison of pre- and post-retrofit cooling loads was made, the dally-average outdoor alr temperature was very nearly equal to the dally-average indoor alr temperatures. If the tests had been conducted under warmer conditions for which no natural night cooling was possible, then the retrofit actions undoubtedly would have produced a net reduction in cooling loads.

2. The test house of the present study was surrounded by trees and recelved much shading from solar beam radiation.

3. The test house was unoccupled; the only internal load was a constant lighting load of $660 \mathrm{~W}$. 
4. The roof overhung the south wall of the test house and provided significant shading of the windows from solar radiation, thereby precluding much of the benef it that could be derlved from awnings.

5. Finally, the windows of the test house were not opened at night to take advantage of natural ventilation cooling of the house. Thus, the walls and windows were holding in heat which therefore had to be removed mechanically.

The foregoing analysis indicates that insulating the floor of a residence tends to increase the energy required for summer cooling, and that the summer benefit of wall insulation is probably related to the daily average temperature difference between indoors and outdoors during the cooling season. It also suggests that opening the windows at night would probably have been beneficial in reducing the energy required for cooling.

\subsection{Conclusions}

Energy conservation measures taken to reduce air-leakage rates did not produce measured reductions in heating-energy requirements. This was attributed to the fact that the test house was of tight construction to begin with. The addition of storm windows reduced heating-energy requirements by 25.2 percent. The installation of insulation to the walls, celling, and floor reduced the energy requirement for space heating by an additional 33.3 percent. The total reduction in heating energy achieved by all stages of the retrofit was found to be 58.5 percent.

The analysis of heating-energy requirements showed that energy conservation actions which reduce the thermal transmittance of the exterior envelope of a bullding provide reductions in annual heating loads by two mechanisms. They reduce the heat-loss rate and lower the outdoor balance temperature. When the outdoor balance temperature for a building is reduced, there will exist a larger number of heating hours for which the internal heat (from lights, equipment, and people) can provide the required heating energy instead of the heating plant. These results suggest that a "modified" degree-day method which utilizes a varlable outdoor balance temperature and adjusted degree days should be used to evaluate reductions in the annual heating load provided by energy conservation modifications to the exterior envelope of a building.

Measurements of daily-average cooling loads before and after the retrofit indlcated that the retrofit was not effective in reducing the cooling energy requirements for this particular test house under the particular conditions tested. The post-retrofit daily-average latent loads were found to be slightly less than corresponding pre-retrofit values, whereas the post-retrofit sensible daily-average cooling loads were found to be slightly higher than the pre-retrofit values. 
The reduction in latent loads was caused by lower humidity levels in the living space which were attributed to a polyethylene ground cover placed over the bare earth of the crawl space and a vapor barrier on the backside of the insulation installed in the floor over the crawl space.

The increase in sensible loads after the retrofit was attributed to the fact that the installation of insulation in the floor over the crawl space produced reductions in the heat loss through the floor which more than offset the reduction in heat gain through the ceiling due to additional insulation in the celling. The net effect of these two energy conservation actions was to cause a net increase in the sensible cooling load for the air conditioner. The effect of installing awnings over the south-facing windows was small due to the overhanging roof which provided significant shading of these windows from solar radiation, thereby precluding much of the benefit that could be derived from the awnings. The effect of storm windows and wall insulation was small, largely due to the fact that reductions in heat gain during warmer daytime hours were of $f-$ set by reductions in natural cooling of the test house during cooler nighttime hours.

Insulating a house and adding storm windows also tends to lower the summer balance temperature (above which mechanical cooling is needed) and therefore increase the number of hours during which cooling is required. However, most of this increase could be satisfied with a wholehouse fan instead of an air conditioner. The effects of floor and wall insulation on the summer cooling loads described above for this test house indicate that the benefits of various retrofit options may vary with climate and need to be analyzed on an annual basis rather than for winter and summer only.

\section{ECONOMIC ANALYSIS}

The purpose of this section is to present an economic model which may be used to evaluate the economic merit of various retrofit options. Since the retrofit on this particular test house did not provide reductions in cooling energy requirements, the effect of summer energy savings was not included in the economic analysis.

\subsection{Theory}

This economic analysis assumes that money would have to be borrowed at a prevailing interest rate to perform one or more of the retrofit options which were applied to the test house of the present study. of particular concern is the number of years required for the cumulative annual savings to pay back the initial investment. The net annual savings (AS) is related to the initial investment value (C) by the relation:

$$
C=\frac{1+P}{D-P}\left[1-\left(\frac{1+P}{1+D}\right)^{L}\right] \text {. AS for } p \neq D \text {. }
$$


When $P=D$, equation (20) is an indeterminant form. Applying the rule of L'Hospital, eq. (20) reduces to $C=L \cdot A S$. Here D denotes the discount rate* which was taken in the present analysis to be 10 percent, and $P$ is the annual rate of fuel price increase, which was taken to be 8 percent for ofl and electricity and 10 percent for gas. Solving for the pay-back period (L) we obtain:

$$
L=\frac{\log _{10}\left[1-\frac{C}{A S} \cdot \frac{D-P}{1+P}\right]}{\log _{10}\left(\frac{1+P}{1+D}\right)} \quad \text { for } P \neq D
$$

When $P=D$, eq. (21) is an indeterminant form. Applying the rule of L'Hospital, eq. (21) reduces to $L=C / A S$.

In estimating the cost for the specific energy conservation options, it was assumed that the homeowner would use his own labor to reduce major air leaks (stage 1 ), whereas he would pay an insulating contractor to install storm windows and to insulate the floor, ceiling, and walls. Cost estimates for the specific items of the retrofit are summarized in table 16. The figure of $\$ 780$ for storm windows is based on an installed cost of $\$ 30$ for a storm window up to 100 united inchest* and $\$ 0.60$ per each additional united inch. An important point that should be made is that some of the windows of the test house were considerably smaller than standard double-hung windows. Since the installed cost for a storm window up to 100 united inches is constant, the cost for installing storm windows for this test house was greater than for a house having standard double-hung windows. Thus the payback period for having storm windows installed on the test house of the present study will be longer than that for a house having standard-size double-hung windows.

The cost figure of $\$ 550$ for a 6 -inch $(15.24-\mathrm{cm})$ fill of $1008 \mathrm{e}-\mathrm{f} 111$ cellulose was based on $\$ 0.25$ per square foot installed. The figure used to estimate the cost of installing 6-inch $(15.24-\mathrm{cm})$ glass-fiber batts in the floor was $\$ 0.30$ per square foot of floor. And finally, the cost of installing loose-fill insulation into cavity walls was $\$ 0.60$ per square foot. These cost estimates were based on typical 1975 prices and were taken from reference [19]. The total cost for all items to retrofit the test house was $\$ 2840$.

* A discount rate is a factor used to convert cash flows occurring in different time periods to a common basis for comparison purposes.

** United inches $=$ the sum of the height and width of a storm window in inches. 
TABLE 16. COST ESTIMATE FOR ENERGY CONSERVATION OPTIONS

1. Stage 1 (Reducing Major Air Leaks)

$\$ 190.00$

2. Stage 2 (Storm Windows)

$\$ 780.00$

3. Stage 3 (Installation of Insulation in Walls, Ceiling, and Floor)

a. Ceiling

b. Floor over crawl space
- Insulation
- Polyethylene ground cover
- Pipe Insulation $\$ 80.00$

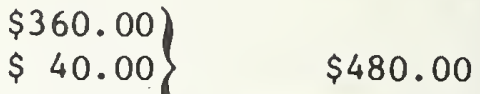
$\$ 840.00$

c. Wa 11

$\$ 550.00$

Total Cost of Retrofit

$\$ 2,840.00$

Since the monetary savings in fuel cost achieved by a retrofit depend upon the efficiency of the heating system and the cost of the fuel being used, a sample calculation was performed for four different types of heating systems. The assumed thermal efficiencies and fuel costs used for the four different heating systems are summarized in table 17.

TABLE 17. HEATING SYSTEM EFFICIENCIES AND FUEL COSTS USED FOR SAMPLE CALCULATIONS

\begin{tabular}{|c|c|c|c|}
\hline Heating System & $\begin{array}{l}\text { System Efficiency } \\
\text { (coefficient of } \\
\text { performance) } \\
\end{array}$ & $\begin{array}{r}\text { Fuel Cost } \\
\text { \$ per Therm } \\
\end{array}$ & $\begin{array}{c}\text { Cost per Therm in } \\
\text { conditioned space } \\
\$\end{array}$ \\
\hline $\begin{array}{l}\text { Gas-fired } \\
\text { forced a ir }\end{array}$ & 0.60 & 0.24 & 0.40 \\
\hline $\begin{array}{l}\text { Oil-fired } \\
\text { forced air }\end{array}$ & 0.55 & 0.26 & 0.47 \\
\hline $\begin{array}{l}\text { Electric } \\
\text { forced alr }\end{array}$ & $0.92 \star$ & 0.88 & 0.81 \\
\hline $\begin{array}{l}\text { Alr-to-air } \\
\text { heat pump }\end{array}$ & $1.74 \star \star$ & 0.88 & 0.51 \\
\hline $\begin{array}{l}\text { * An efficiency } \\
\text { to account fo }\end{array}$ & $\begin{array}{l}r \text { an electric heati } \\
\text { acket losses. }\end{array}$ & plant less $t$ & an unity was used \\
\hline
\end{tabular}


The foregoing system efficiencles (or coefficient of performance) are assumed typical seasonal values rather than steady-state values of ten cited by equipment manufacturers.

The winter heating-energy cost (HC) for the four separate heating systems may be calculated from the relation:

$$
\mathrm{HC}=\mathrm{HL} \cdot \mathrm{FC} / \mathrm{n}
$$

where HL = annual heating load in therms

$F C=$ fuel cost, $\$$ per therm

$n=$ efficiency of heating plant or coefficient of performance of cooling equipment.

\subsection{Results}

\subsubsection{Heating-Energy Costs}

Using the annual heating loads for the test house after various stages of the retrofit (table 11) and the cost per therm in the conditioned space (table 17), annual winter heating-energy costs were determined for four types of heating systems. The results are summarized in table 18 .

They show that the monetary savings achieved by the various energy conservation options are very sensitive to the fuel costs and the efficiency of the heating plant. Note from table 18 that the total annual dollar savings achieved by the retrofit for the gas, oil, electric and heatpump systems are $176.4,207.5,357.6$, and 225.1 , respectively.

\subsubsection{Pay-Back Periods}

The number of years to pay back the initial investment for the various energy conservation options for the four heating systems are summarized in table 19. These pay-back periods, with the exception of the payback periods for ceiling insulation, are consistent with values published in reference [20].

It is interesting to note that for this set of retrofit experiments, - storm windows were found to be more cost effective than installing insulation, requiring significantly fewer years to pay back their initial investment.

The payback perlods for installing additional ceiling insulation are longer than values cited in reference [20]. The longer payback perlods for celling insulation compared to reference [20] are probably due to the fact that the effect of winter solar gains on the roof 


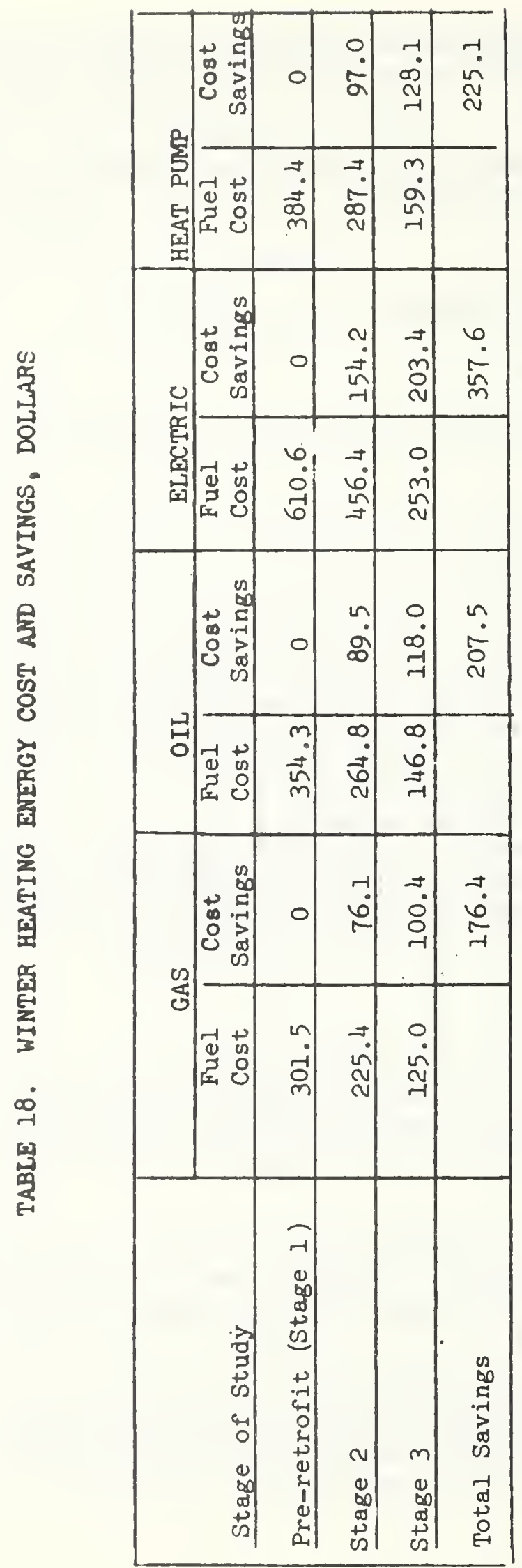


were not considered in that report. Also, the additional six inches inches of ceiling insulation installed equaled two inches more than the economically optimum amount cited in reference [20]. Using more than the economically optimum amount would cause the payback periods for the celling insulation to be longer.

\section{TABLE 19. PAY-BACK PERIODS FOR ENERGY-CONSERVATION OPTIONS}

Stage of

Retrof 1t

Stage 1

Stage 2

Stage 3

- wa 11

- ceiling

- floor

\begin{tabular}{ccccc}
\multicolumn{4}{c}{ Pay Back Period, Years } \\
Gas Heat & Oil Heat & Electric & Heat Pump \\
Infinite & Infinite & Infinite & Infinite \\
10.2 & 9.6 & 5.4 & 8.8 \\
17.4 & 17.5 & 9.5 & 15.9 \\
$(18.6) *$ & $(18.9) *$ & $(10.2) *$ & $(19.2) *$ \\
14.2 & 13.8 & 7.5 & 12.5 \\
29.9 & 34.8 & 17.4 & 31.1 \\
15.9 & 15.7 & 8.6 & 14.3 \\
$(19.3) *$ & $(22.1) *$ & $(11.8) *$ & $(20.0) *$
\end{tabular}

Combination of stages 1-3

16.1
15.9
8.7
14.5

* Includes cost of vapor-barrier ground cover and pipe insulation.

If the test house had been located in a geographic location having much colder winters, the pay-back periods would have been considerably shorter. Including the effect of the retrofit on sumer cooling loads in the economic analysis would have had the following effect on the payback periods. Reduced summer heat gains due to the installation of additional celling insulation would decrease the payback periods for the celling insulation. Reduced summer heat loss due to the insulation installed under the floor over the crawl space would increase the payback periods for the floor insulation.

It should be emphasized that the energy savings and payback periods depend upon heating-plant efficiency, energy cost, number of heating degree days, thermal characteristics of the house, discount rate, and the amount of annual fuel price increase. It was not the purpose of this section to present solutions for all possible varlations of the above parameters, but rather to present an economic model that could be used to evaluate the economic merits of energy conservation options. 


\subsection{Conclusions}

In retrospect, no money should have been spent on sealing air leaks, and perhaps less insulation should have been added to the ceiling. For this particular test house, paying to have storm windows installed was found to be more cost effective than having insulation installed, requiring significantly fewer years to pay back the initial investment.

8. COMPARISON OF THE THERMAL PERFORMANCE OF THREE INSULATING MATERIALS

This section describes laboratory and field measurements to compare the thermal performance of three different insulating materials commonly used to retrofit exterior cavity walls. The insulation materials selected for study included cellulosic fiber, fibrous-glass wool and urea-formaldehyde (U-F) foam. The thermal conductivities of the three materials were measured using a guarded-hot-plate apparatus. Heattransmission and moisture measurements were performed on a full-scale test wall that was exposed to simulated winter conditions in the laboratory. Similar measurements were also conducted on wall sections of a test house insulated with the three materials. Other performance properties such as shrinkage and settling were also investigated.

\subsection{Guarded-Hot-Plate Measurements}

Measurements of thermal conductivity and density were made on test specimens of the three different insulating materials in accordance with the guarded-hot-plate test method given in ASTM C 177-71. Each test specimen was prepared so that its density was approximately equal to the density as installed in the walls of the test house. The test specimens were intentionally not oven dried, but instead allowed to reach moisture equilibrium with respect to room air at $75^{\circ} \mathrm{F}\left(23.9^{\circ} \mathrm{C}\right)$ and 40 percent $r h$, so that the thermal conductivity measurements would be more representative of installed insulating materials.

Table 20 summarizes the thermal conductivity measurements. The measured values of thermal conductivity of cellulosic fiber are in close agreement with values reported by Tye [9]. Measured thermal conductivity values for fibrous glass wool are consistent with values measured by Bankvall [10] and values reported by ASHRAE [4]. The three materlals are seen to have good insulating properties as indicated by thermal conductivity measurements. The thermal conductivity of U-F foam is seen to be slightly lower than that of the other two materials.

It should be pointed out that differences in thermal conductivity may exist between the same type of insulating materials obtained from different manufacturers. For example, in the case of cellulose insulation, different manufacturing processes combined with various forms of newsprint material can lead to variations in coarseness and density of the material, which in turn may lead to differences in the thermal conductivity. 
TABLE 20. THERMAL CONDUCTIVITIES OF THREE INSULATING MATERIALS

MEASURED IN THE GUARDED-HOT-PLATE APPARATUS

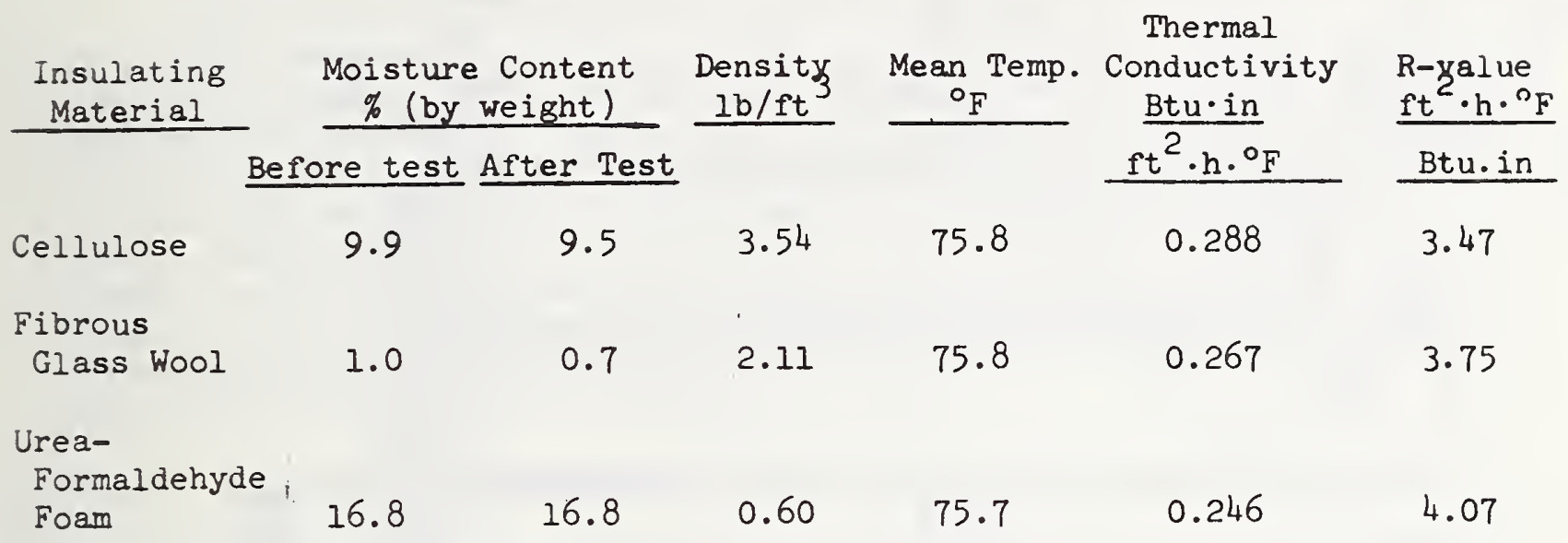

\subsection{Full-Scale Laboratory Wall Tests}

A full-scale laboratory test wall was exposed to a simulated winter condition on the exterior side and to typical indoor conditions at the inside surface for a two-month period. Different sections of the test wall were insulated with the three insulating materials. At the conclusion of the exposure period, measured thermal conductance values for the separate sections were compared with corresponding predicted values using the series-resistance method outlined in reference [4].

\subsubsection{Description of Test Specimen}

A test wall, $8 \mathrm{ft}$ high and $8 \mathrm{ft}$ wide $(2.44 \mathrm{~m}$ by $2.44 \mathrm{~m}$ ), similar in construction to the walls of the test house, was built in the laboratory. The construction details of this test wall are shown in figure 25 . It had six cavities between studs placed 16 in $(40.6 \mathrm{~cm})$ on center. As in the case of the test house, an oll-base paint system was applied to the exterior (cold-side) surface, and a latex paint system was applied to the interior (warm-side) surface.

-

As viewed from the inside surface, cellulose fiber was blown into the first two wall cavities on the left, fibrous glass wool into the two center cavities, and U-F foam into the remaining two cavities on the right. When the U-F foam was installed, the redwood siding was not attached to the wall for about a week, to permit some of the original water contained in the foam to excape through the comparatively permeable sheathing. The same procedures were used for installing each of the insulation materials into the laboratory test walls as were used for the wall sections of the test house. 


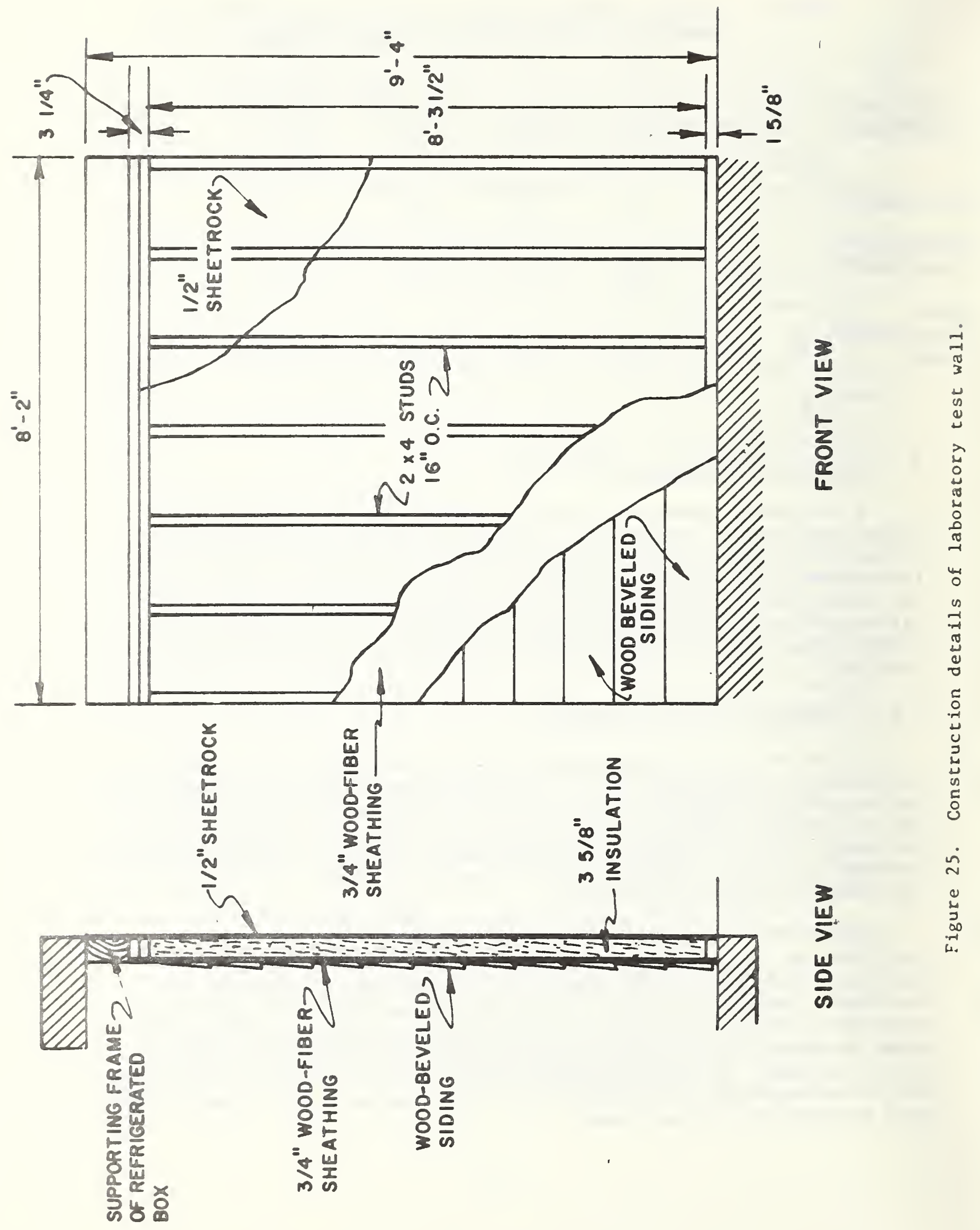




\subsubsection{Instrumentation}

Front and side views of the test wall showing the location of the humidity transducers are given in figure 26. Each pair of wall cavities insulated with different material was instrumented in a similar manner. Surface and ambient air temperatures were measured with 24-gage copperconstantan thermocouples. Heat-flow meters were spot-glued to the inside wall surface. They were connected in serles for each of the three insulated sections and the output signals were fed into an analog integrator for the purpose of averaging. The relative humidity at the inside surface was measured with a motorized psychrometer placed at the mid-height level. Thermocouples were embedded in the insulation at the top and bottom of the wall cavities.

\subsubsection{Experimental Procedure}

The experimental procedure was to install the laboratory test wall into a wall test apparatus which maintained the exterior side of the test wall at a temperature of $5+2^{\circ} \mathrm{F}\left(-15 \pm 1.1^{\circ} \mathrm{C}\right)$ and approximately $95 \%$ $r h$. The interfor side of the test wall was exposed to the laboratory environmental condition which was maintained at $75 \pm 3^{\circ} \mathrm{F}\left(23.9+1.7^{\circ} \mathrm{C}\right)$ and $45+3 \% \mathrm{rh}$. The wall test apparatus consisted of a ref rigerated enclosure, one side of which was open and fitted with a frame for supporting the laboratory test wall. The foregoing conditions were maintained for a two-month period. At the conclusion of the testing period, heat-flow rates were measured and samples of the insulating materials were cored out and their moisture contents were determined by comparing the wet weight of the samples with their corresponding dry weight after oven drying.

\subsubsection{Experimental Results}

The experimental results of the laboratory wall test are shown in table 21. The moisture contents at the end of the exposure period were found to be greater than corresponding winter values for the test house (see tables 24-26). This finding is not surprising, since the interior surface of the laboratory test wall was exposed to a substantially higher indoor relative humidity than the test house, and the exterior surface of the laboratory test wall was exposed to much colder outdoor conditions. The moisture contents were much greater at the bottom of the glass-fiber and U-F section, which may be due to colder temperatures within the insulation at the bottom of these sections. Also, note that the amount of accumulated moisture within the cellulose material is very nearly the same at the top and bottom of the wall section.

The measured thermal conductance values given in column 7 of table 21 were obtained by dividing the heat flow through the wall by the surfaceto-surface temperature difference. The predicted thermal conductance values of column 8 were obtained by the series-resistance method. The 


\section{LOCATION OF MEASURING SENSORS \\ - HUMIDITY \\ 口 INSIDE AMBIENT TEMPERATURE
$\triangle$ OUTSIDE "
10
- TEMPERATURE
O HEAT FLOW
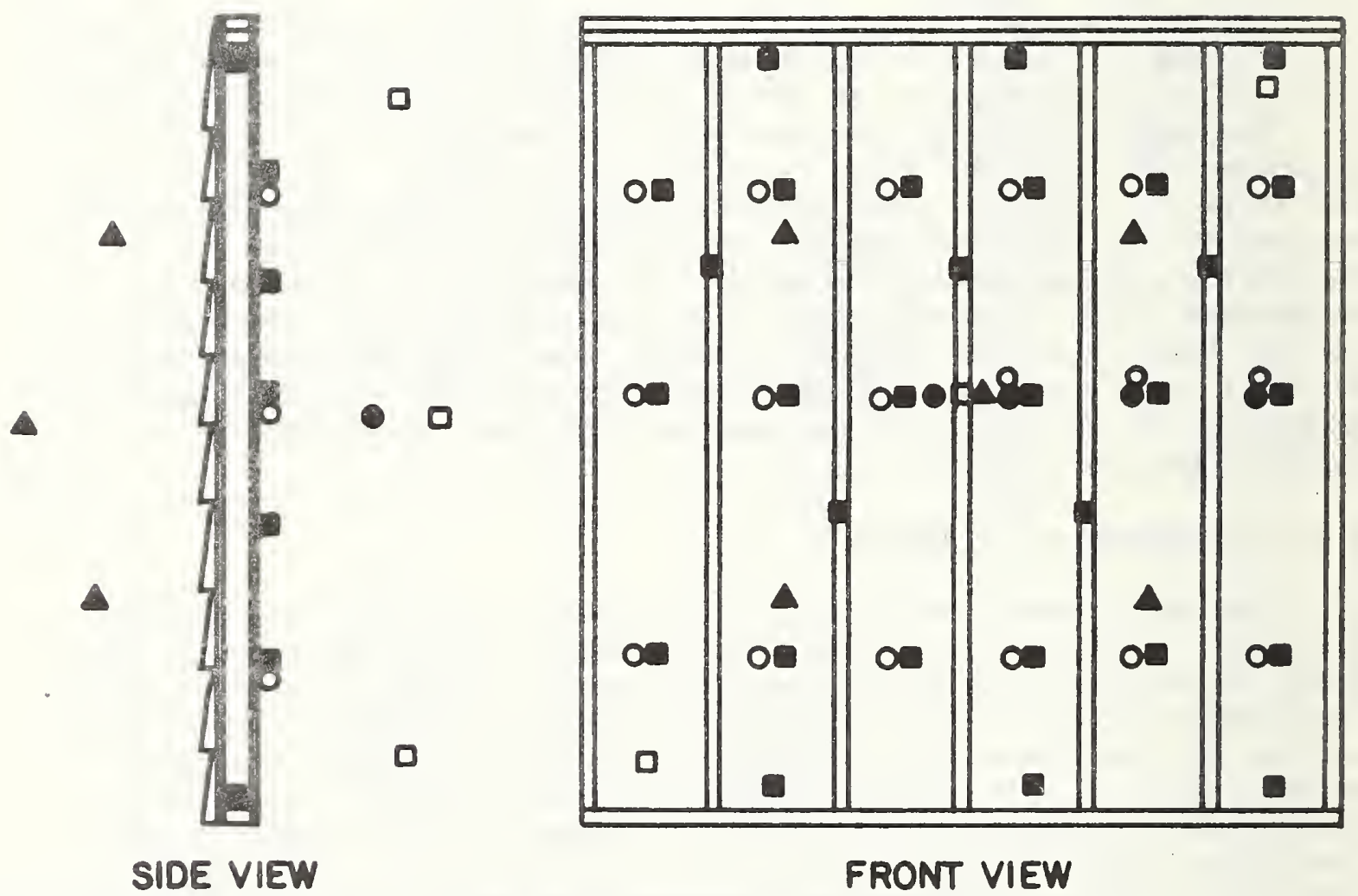

Figure 26. Location of measurement transducers on lavoratory test. wall. 
thermal conductivity ( $k$ ) for the insulating material used in the thermal conductance calculation was adjusted to the mean temperature of the insulation using the relation:

$$
k=k_{m}+\alpha \cdot \Delta T
$$

where $k_{m}=$ measured thermal conductivity at mean temperature of guarded-hot-plate measurement, $B t u \cdot i n / h \cdot f t^{2} \cdot{ }^{\circ} \mathrm{F}(\mathrm{W} / \mathrm{m} \cdot \mathrm{K})$ $\begin{aligned} \alpha= & \text { temperature coefficient of thermal conductivity, } \\ & B t u \cdot i n / h \cdot f t^{2} \cdot{ }^{\circ} \mathrm{F}^{2}\left(\mathrm{~W} / \mathrm{m} \cdot \mathrm{k}^{2}\right)\end{aligned}$

$\Delta \mathrm{T}=$ mean temperature of wall section minus the mean temperature of guarded-hot-plate measurement, ${ }^{\circ} F(K)$

The mean temperature of the insulation was approximately $76^{\circ} \mathrm{F}$ for the thermal conductivity measurements and approximately $40^{\circ} \mathrm{F}$ for the laboratory wall test. The temperature coefficients ( $\alpha$ ) for the thermal conductivity values are given in table 22 .

TABLE 21. EXPERIMENTAL RESULTS OF FULL-SCALE LABORATORY WALL TESTS AFTER TWO-MONTH EXPOSURE

Wall Insulation

Insulating Mean Temp.

Material $\frac{{ }^{\circ} F}{\text { Top. Bottom }}$
Moisture

Content $\frac{\% \text { (by weight) }}{\text { Top Bottom }}$ $1 \mathrm{~b} / \mathrm{ft}$

Cellulose 46

$36 \quad 4.4$

$18.6 \quad 17.4$

$34 \quad 1.7$

9.824 .3

0.7

$49.0 \quad 76.3$

U-F Foam

45

*

Thermal Condyctance

$\frac{\mathrm{Btu} / \mathrm{h} \cdot \mathrm{ft} \cdot \mathrm{O}_{\mathrm{F}}}{\text { Measured }} \quad \begin{gathered}\% \\ \text { Predicted }\end{gathered}$

$.065 \quad .063$

.062

10.1

.069

.051

.054

$-5.9$

- Data not available.

TABLE 22. TEMPERATURE COEFFICIENTS ( $\alpha$ ) FOR THE THERMAL CONDUCTIVITY VALUES

$\begin{array}{lccc}\text { Material } & \frac{\mathrm{Btu}^{\cdot} \mathrm{In} / \mathrm{h}^{\cdot} \mathrm{ft}^{\circ}{ }^{\circ} \mathrm{F}^{2}}{4.0 \times 10^{-4}} & \frac{\mathrm{W} / \mathrm{m}^{\circ} \mathrm{K}^{2}}{1.0 \times 10^{-4}} & \frac{\text { Reference }}{9} \\ \text { Cellulose } & 7.3 \times 10^{-4} & 1.9 \times 10^{-4} & 10 \\ \text { Glass fiber } & 6.3 \times 10^{-4} & 1.6 \times 10^{-4} & \begin{array}{c}\text { Manufacturer's } \\ \text { IIterature }\end{array}\end{array}$


Since the thermal conductivity measurements were performed on test specimens having approximately the same density as the installed material, it was not necessary to correct the thermal conductivity values for differences in density.

The measured thermal conductance values agree quite favorably with corresponding predicted values even though a large amount of moisture was present in the insulation materials, the percent difference being less than 10 percent. This was attributed to the fact that much of the moisture was concentrated in a thin layer of ice which was observed at the interface between the insulating material and sheathing. The bulk of the insulating material appeared to be comparatively dry.

After the two-month test period at an exterior temperature of $5^{\circ} \mathrm{F}$ $\left(-15.0^{\circ} \mathrm{C}\right)$, the refrigeration system was adjusted to maintain $36^{\circ} \mathrm{F}$

$\left(2.2^{\circ} \mathrm{C}\right)$ on the cold side. The $36^{\circ} \mathrm{F}\left(2.2^{\circ} \mathrm{C}\right)$ condition was maintained for 28 days, at the conclusion of which the refrigeration system was turned off and the test wall was allowed to come to thermal equilibrium with respect to ambient air at approximately $75^{\circ} \mathrm{F}\left(23.9^{\circ} \mathrm{C}\right)$. The floating condition was maintained for 33 days, after which significant buckling and warping of the wood siding was observed (see figure 27). The buckling and warping of the wood siding was attributed to high moisture content of the wood siding.

\subsection{Heat-Transmission and Moisture Measurements in Retrofitted Wall Sections of the Test House}

\subsubsection{Heat-Transmission Measurements}

The purpose of this section is to compare thermal conductance values measured in recrofitted wall sections of the test house with corresponding predicted values, using the series-resistance method.

\subsubsection{Instrumentation}

The heat-flow rates through wall sections of the test house insulated with the three types of insulating materials were measured with heatflow meters. The heat-flow meters were circular disks 2.0 in $(5.08 \mathrm{~cm})$ in diameter and 0.13 in $(0.33 \mathrm{~cm})$ thick, made of polyvinylchloride filler material, each having an embedded thermopile. Heat flux, upon passing through the wafer, caused a temperature difference to be developed across the wafer, which in turn caused a millivolt signal to be produced proportional to the heat-flow rate. At a station 4 feet above the bottom of the wall section, six heat-flow meters were spot-glued to the inside wall surface and equally spaced between adjacent wall studs, as shown in figure 28. The six heat-flow meters were series-connected and the output signal was fed into an analog integrator. The integration of the heatflow signal was necessary because instantaneous heat-flow rates were observed to possess large fluctuations due to the cyclic operation of the heating plant. The heat-flow measuring station also contained a 


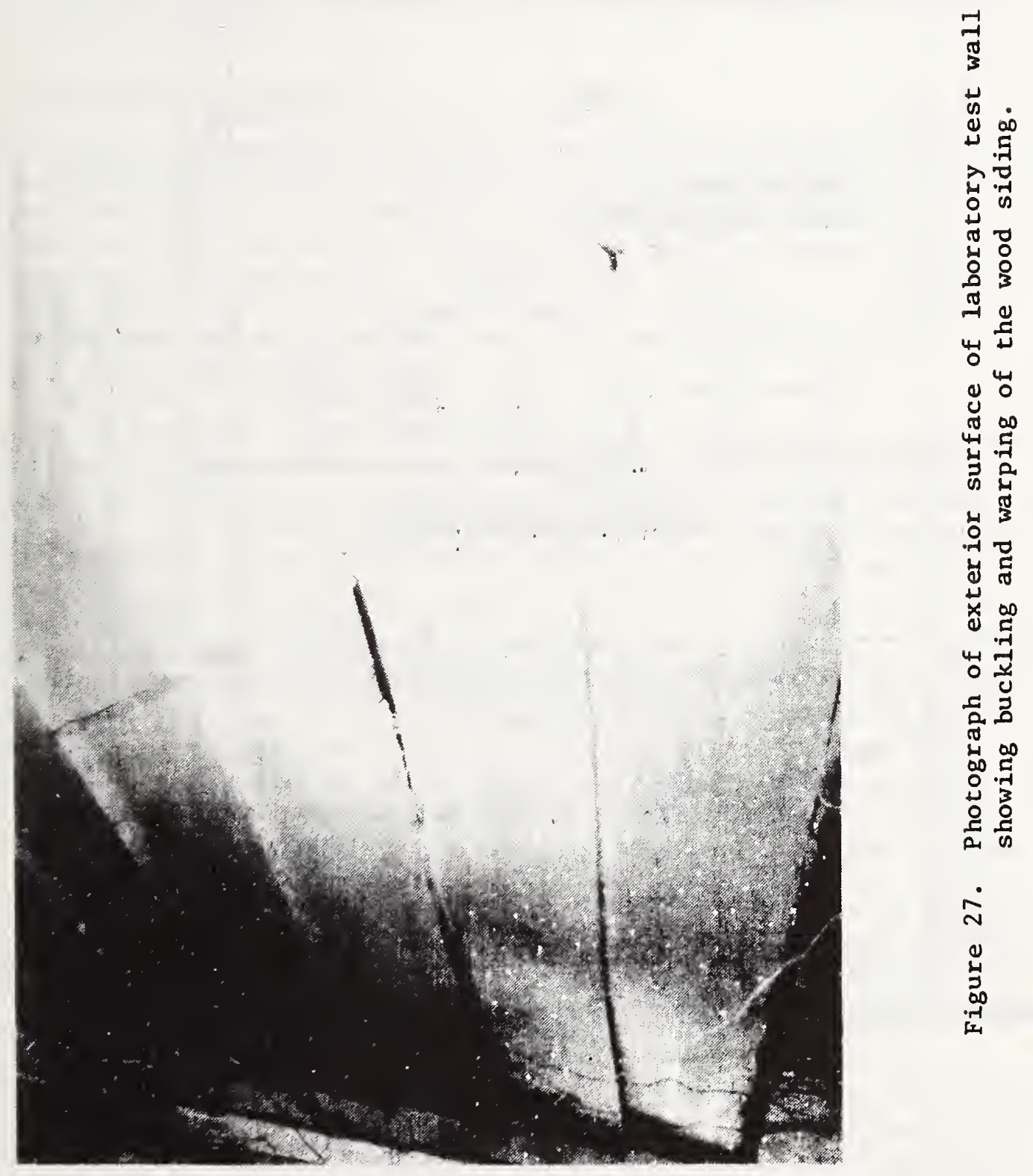




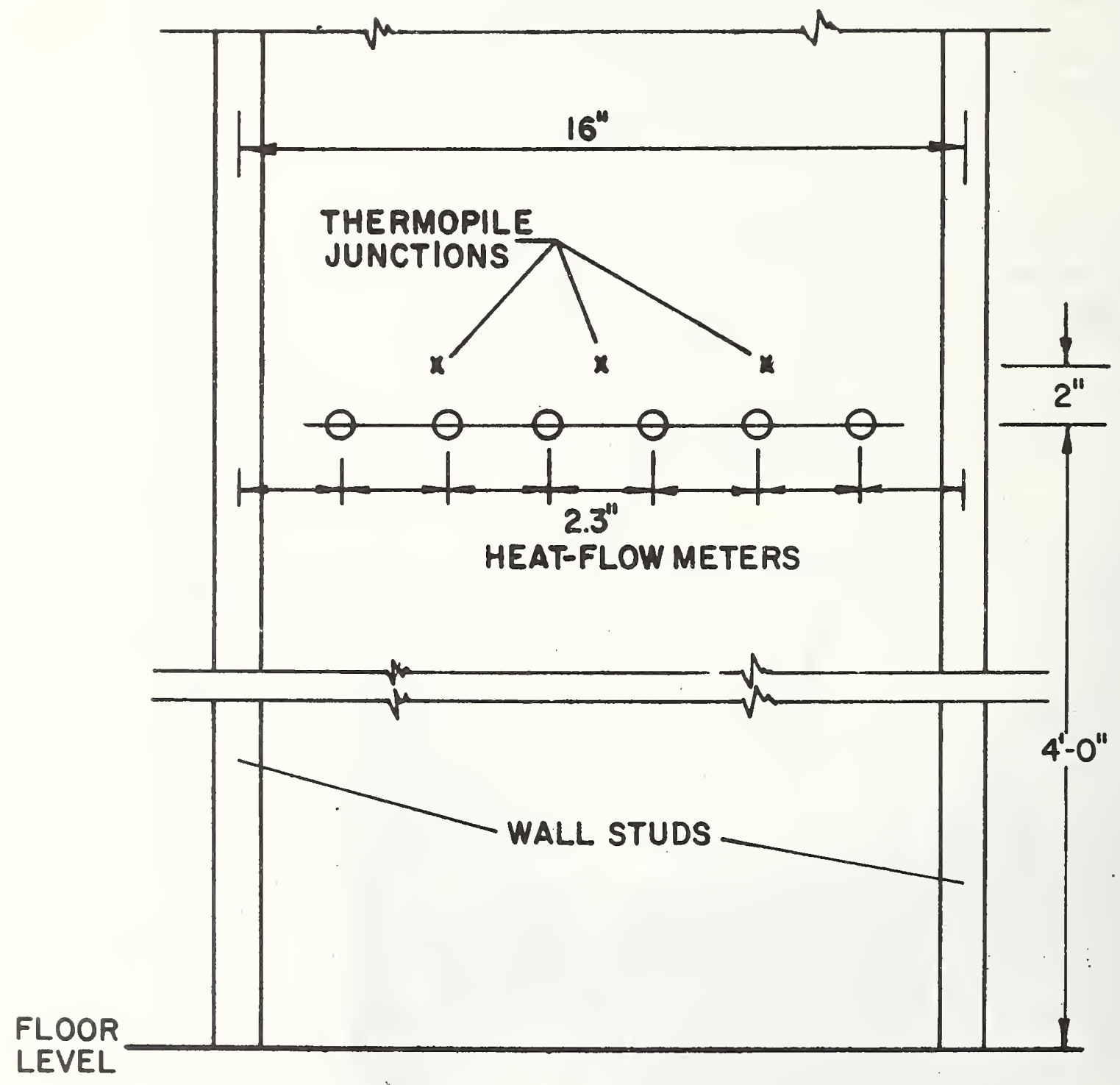

Figure 28. Elevation view of wall section of the test house showing heat-flow measuring station. 
6-junction thermopile for measuring the surface-to-surface temperature

difference. This thermopile was placed 2 in $(5.08 \mathrm{~cm}$ ) above the row of heat-flow meters, as shown in figure 28. Three copper-constantan thermocouple junctions were attached to the inside surface with aluminum adhesive tape. The other three junctions were attached at corresponding locations at the outside wall surface. This thermopile produced a millivolt signal proportional to the surface-to-surface temperature difference across the wall section. This millivolt signal was also fed into an analog integrator.

\subsubsection{Experimental Results}

The thermal conductances of the separate wall sections are plotted versus mean wall temperature in figure 29. The thermal conductance values were obtained by dividing the average heat-flow rate over a twelvehour nighttime period by the average surface-to-surface temperature difference over the same period. The mean wall temperature was taken to be the mean temperature between the inside and outside wall surfaces. The straight-line correlations were obtained from a least-squares procedure applied to the raw data.

It is interesting to note that the thermal conductances of all the wall sections decreased as the mean temperature of the insulation was reduced. This behavior is consistent with the fact that the thermal conductivity of all three materials decreased as the temperature of the material decreased. as indicated by eq. (23) and the temperature coefficients for thermal conductivity given in table 22 .

The thermal conductance of the $U-F$ wall section (see figure 29) is seen to be substantially higher than corresponding values of the other wall sections. This result is inconsistent with the findings of the guarded-hot-plate measurements (section 8.2) and the full-scale laboratory wall tests (section 8.3 ) which showed that U-F foam had somewhat better insulating properties than loose-fill glass fiber or cellulose. After the heat-loss measurements were performed, the inside wall surface at the measuring station of the $U-F$ wall section was removed in order to examine the $U-F$ material for shrinkage and fissures (void spaces where the foam had pulled apart). A cleavage, one inch in width, was observed directly in line with the heat-flow measuring station. The presence of this fissure undoubtedly contributed to the high measured thermal conductance values at the U-F wall section.

Another factor which could have contributed to the higher heat-loss rates observed through the $U-F$ wall section was the moisture content of the foam, although the data obtained on the wall specimen in the laboratory, and reported in table 21 , shows relatively good agreement between predicted thermal conductance and the thermal conductance measured in a specimen with 50-76\% moisture content. The heat-loss measurements were carried out approximately 45 days after the U-F foam had been installed. A humidity transducer installed between the foam and the wood-fiber sheathing indicated that a saturated condition existed there at the time 


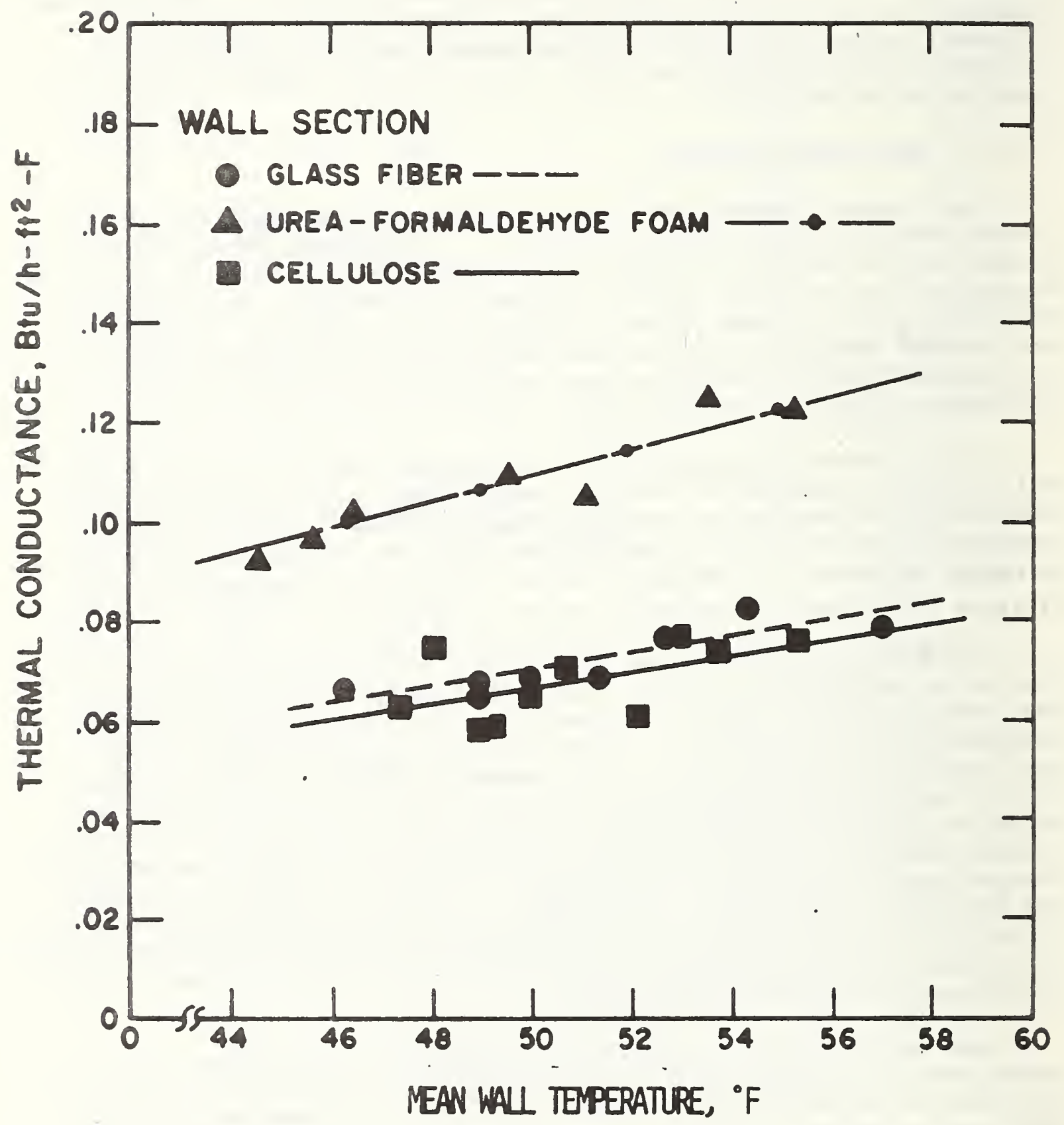

Figure 29. The effect of mean wall temperature on the thermal conductance of the three separate wall sections. 
of the heat-loss measurements (see figure 31, section 8.3.2.1). This result suggests that some of the original moisture contained in the foam was still present at the time of the heat-loss measurements.

In table 23, measured and corresponding predicted thermal conductance values for the cellulose and glass-fiber wall sections are compared. For the comparison, the insulation was taken to be at a mean temperature of $46^{\circ} \mathrm{F}\left(7.8^{\circ} \mathrm{C}\right)$. The predicted values were determined by applying the series-resistance method to the portion of the wall containing insulation. Since none of the heat-flow meters were placed over studs, the high conductance heat-flow path through the portion of the wall containing studs was not included in the calculation of conductances. The thermal conductivity of the insulating materials used in the thermal conductance calculations was adjusted to a mean insulation temperature of $46^{\circ} \mathrm{F}\left(7.8^{\circ} \mathrm{C}\right)$, using eq. (23) and the temperature coefficients of thermal conductivity given in table 22 .

TABLE 23. COMPARISON OF MEASURED AND PREDICTED THERMAL CONDUCTANCE VALUES AT WALL SECTIONS INSULATED WITH LOOSE-FILL MATERIALS

Wall Section

Cellulose

Glass-fiber
Thermal Conductance, $B t u / h \cdot f t^{2} \cdot F$ Measured Predicted .062 .056

From table 23, it can be seen that the measured thermal conductance of the cellulose wall section is slightly less than the predicted value, whereas the thermal conductance of the glass-fiber wall section is somewhat higher than the predicted value.

\subsubsection{Moisture Measurements}

Material samples of the wood siding, sheathing, and insulation were cored out at wall sections insulated with the three insulating materials at the end of the winter season. The moisture contents of these samples were determined using an oven-drying technique, and compared.

\subsubsection{Relative Humidities in Insulated Wall Cavities}

Ten days after the test house was insulated, small narrow-range humidity and temperature sensors were installed between the insulating material and the sheathing midway between the studs. The specific location of these humidity sensors is "denoted with the symbol " $M$ " on the floor plan in figure 30. The U-F foam and glass-fiber wall sections are indicated on figure 30 . Other parts of the wall were insulated with 


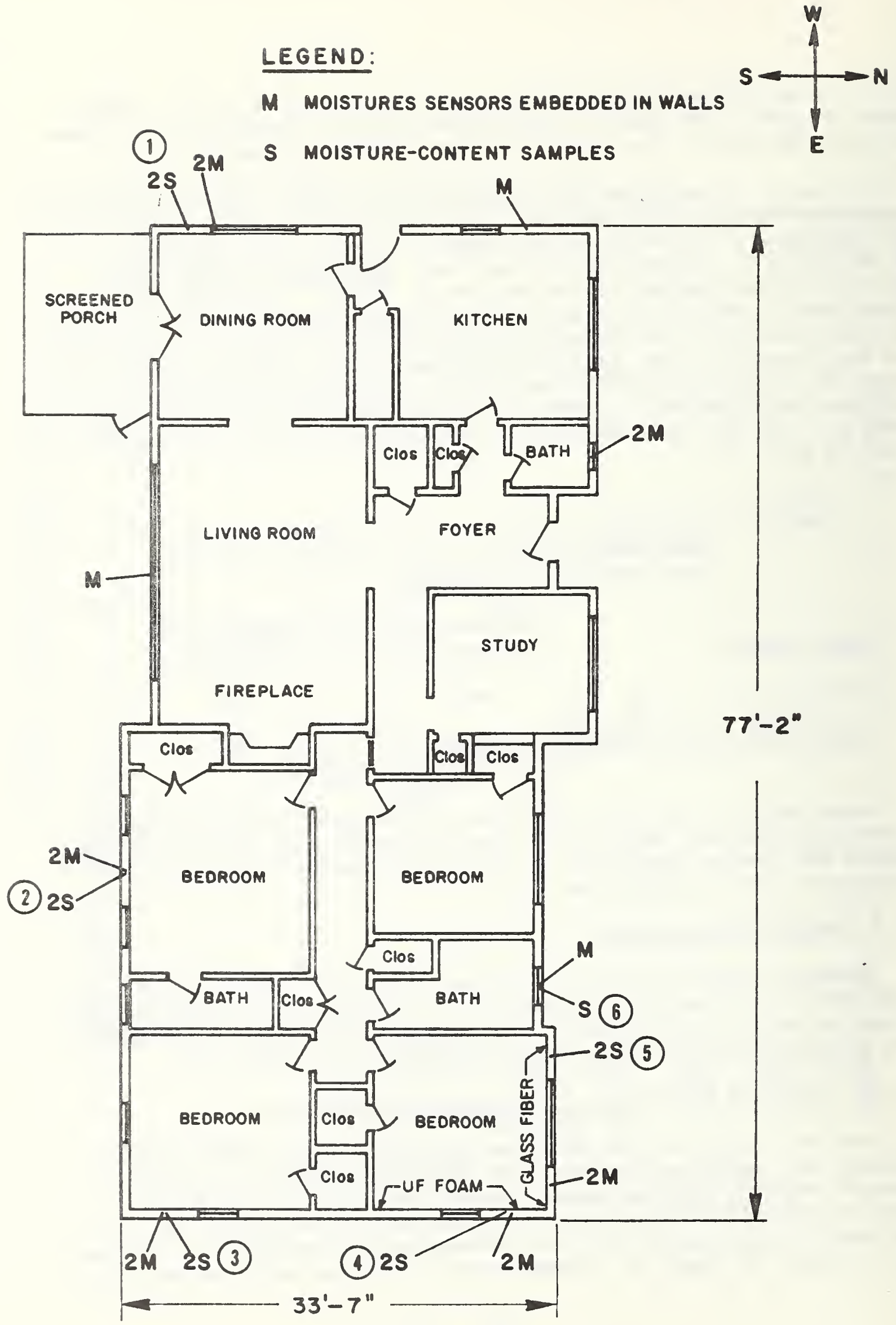

Figure 30. Floor plan of the test house showing location of humidity sensurs and nlaces where motsture content samples were cored nur. 
cellulose. At those locations where two sensors are indicated (denoted by the symbol " $2 \mathrm{M}^{\prime \prime}$ ), humidity sensors were installed approximately $1 \mathrm{ft}$ $(0.305 \mathrm{~m})$ below the ceiling level and $1 \mathrm{ft}(0.305 \mathrm{~m})$ above the floor level. At locations where only one sensor is indicated, the sensor was installed $1 \mathrm{ft}(0.305 \mathrm{~m})$ below the ceiling, except in the living room, where it was installed $1 \mathrm{ft}(0.305 \mathrm{~m})$ above the floor level. The installation procedure was to drill 1-inch $(2.54-\mathrm{cm})$ holes through the wood siding and sheathing, install the sensors, and replug the holes. These particular sensors responded to relative humidity only in the narrow range from 85 to 100 percent. Relative humidities less than 85 percent would not produce an instrument response.

A graph showing the varlation of relative humidities indicated by the embedded $\mathrm{rh}$ sensors is given in figure 31. Since the $\mathrm{rh}$ sensors were embedded at the interface between the sheathing and the insulation, they indicate the presence of moisture in both sheathing and insulation. The relative humidity at the interface between the U-F foam insulation and the sheathing remained at a saturated condition for approximately 40 days after the retrofit, at which time the relative humidity began to decrease slowly. The relative humidity at the interface between the glass-fiber insulation and the sheathing gradually increased, while relative humidities at the interface between the loose-fill cellulose and sheathing were not sufficient to produce an instrument response (i.e. less than 85 percent $r h$ ).

\subsubsection{Moisture Accumulation}

At the end of the winter heating season, in the third week of April (1975), 76 days after insulation was blown into the wa11s, $(2-1 / 4$ in $(5.72 \mathrm{~cm})$ diameter) circular samples of the wood siding, sheathing, and insulation were cored out at various locations. Locations where material samples were taken are shown on the floor plan of figure 30 . Where the symbol "2S" appears, samples were taken from the top of the wall approximately 1 foot $(0.35 \mathrm{~m})$ below the ceiling level and at the bottom approximately 1 foot $(0.305 \mathrm{~m})$ above the floor level. Where the symbol " $S$ " appears, samples were taken only at the top of the wall. Shortly after the samples were cored out, replacement circular pieces of sheathing and wood siding were installed using glue.

The experimental procedure was to place the samples in sealed jars immediately after they were removed. Shortly thereafter, these jars were weighed. The jars were subsequently unsealed and placed in an oven and heated to $212^{\circ} \mathrm{F}\left(100^{\circ} \mathrm{C}\right)$, with the exception of $\mathrm{U}-\mathrm{F}$ foam samples which were heated to $100^{\circ} \mathrm{F}\left(37.8^{\circ} \mathrm{C}\right)$. After the samples were oven dried, they were again weighed. The percent moisture content ( $\left.f_{m}\right)$ (by weight) was determined from the relation:

$$
\mathrm{f}_{m}=\frac{\mathrm{W}_{\mathrm{w}}-\mathrm{W}_{\mathrm{d}}}{\mathrm{W}_{\mathrm{d}}} \times 100
$$

where $W_{w}$ and $W_{d}$ are the wet and dry weights of the material, respectively. 
$\%$ "ALIJIWRH $3 \wedge 11 \nabla 7 \exists$ Y HOO:INI
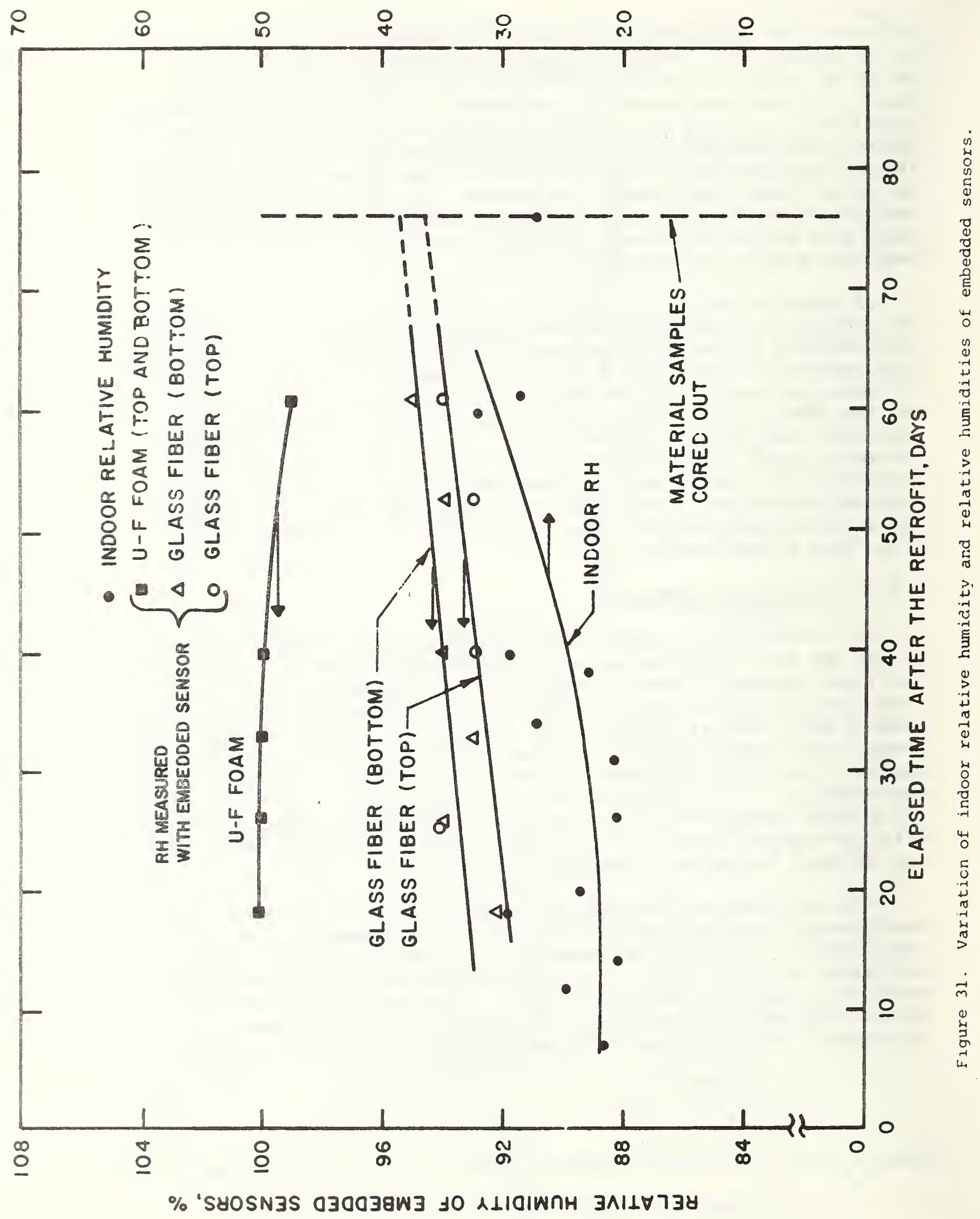
The moisture contents of the material samples removed from cellulose wall sections are shown in table 24.

TABLE 24. WINTER MOISTURE CONTENTS OF MATERIAL SAMPLS REMOVED FROM CELLULOSE WALL SECTIONS

\begin{tabular}{lcccc} 
& \multicolumn{3}{c}{ Moisture Content, $\%$ (by weight) } & $\begin{array}{c}\text { Outside } \\
\text { Location* }\end{array}$ \\
\cline { 2 - 4 } & $\begin{array}{c}\text { Wood } \\
\text { Siding }\end{array}$ & Sheathing & $\begin{array}{c}\text { Inside } \\
\text { Core }\end{array}$ & $\begin{array}{c}\text { Insulation } \\
\text { Core }\end{array}$ \\
\hline 1 Top & 11.2 & 10.9 & 13.5 & 11.9 \\
1 Bottom & 12.0 & 13.0 & 15.6 & 15.3 \\
2 Top & 10.8 & 11.3 & 13.2 & 16.0 \\
2 Bottom & 8.6 & 10.7 & 13.0 & 12.5 \\
3 Top & 11.8 & 14.1 & 16.3 & 14.1 \\
3 Bottom & 12.1 & 12.3 & 15.7 & 14.7 \\
6 Top & 15.3 & 10.5 & 13.6 & 13.2 \\
Average & 11.7 & 11.8 & 14.4 & 14.0 \\
See figure 30 for location & identification. &
\end{tabular}

The average moisture content of the insulation adjacent to the cold exterior surface is seen to be only slightly higher than the average moisture content of samples adjacent to the warm inside surface. This observation suggests that the moisture content of cellulose tends to become uniformly distributed.

The moisture contents of material samples taken from the glass-fiber wall section are shown in table 25. The moisture contents of the glassfiber insulation are seen to be clearly lower compared to values for cellulose insulation, but the moisture contents of the wood siding and the sheathing at this section are somewhat higher than corresponding samples taken from wall sections insulated with cellulose.

TABLE 25. WINTER MOISTURE CONTENTS OF MATERIAL SAMPLES TAKEN FROM THE GLASS-FIBER WALL SECTION

\begin{tabular}{lccc}
\multicolumn{3}{c}{ Moisture Content, \% (by weight) } \\
$\begin{array}{c}\text { Wood } \\
\text { Siding }\end{array}$ & Sheathing & $\begin{array}{c}\text { Outside } \\
\text { Insulation } \\
\text { Core }\end{array}$ & $\begin{array}{c}\text { Inside } \\
\text { Insulation } \\
\text { Core }\end{array}$ \\
\cline { 2 - 3 } 12.3 & 14.0 & 8.1 & 10.1 \\
16.8 & 15.5 & 11.0 & 3.2 \\
14.6 & 14.8 & 9.6 & 6.7
\end{tabular}

* See figure 30 for location identification. 
The molsture contents of material samples removed from the U-F wall section are shown in table 26.

TABLE 26. WINTER MOISTURE CONTENTS OF MATERIAL SAMPLES TAKEN FROM U-F WALL SECTION

\begin{tabular}{|c|c|c|c|c|}
\hline Location* & $\begin{array}{c}\text { Wood } \\
\text { Siding }\end{array}$ & Sheathing & $\begin{array}{c}\text { Outside } \\
\text { Insulation } \\
\text { Core }\end{array}$ & $\begin{array}{c}\text { Inside } \\
\text { Insulation } \\
\text { Core }\end{array}$ \\
\hline 4 Top & 24.8 & 28.1 & 8.0 & 9.4 \\
\hline 4 Bottom & 21.6 & 38.6 & 12.9 & 12.3 \\
\hline Average & 23.2 & 33.4 & 10.5 & 10.9 \\
\hline
\end{tabular}

* See figure 30 for location identification.

The moisture contents of the U-F foam itself are comparable with values for the other insulation material. However, the moisture contents of the sheathing and wood siding samples taken from the U-F wall section are much higher than corresponding values for the other wall sections. An explanation is given in the following:

The wet density of U-F foam when $1 \mathrm{t}$ is installed $1 \mathrm{~s} 2.51 \mathrm{~b} / \mathrm{ft}^{3}$ $\left(40.0 \mathrm{Kg} / \mathrm{m}^{3}\right)$. After the foam has cured and dried, its density is $0.7 \mathrm{lb} / \mathrm{ft}^{3}\left(11.2 \mathrm{Kg} / \mathrm{m}^{3}\right)$. The difference in these density figures is due to the original water content of the foam. This amount of water corresponds to approximately $0.47 \mathrm{lb}$ per $\mathrm{ft}^{2}$ of wall $\left(2.29 \mathrm{Kg} / \mathrm{m}^{2}\right)$.

The water originally contained in the wet foam apparently migrated from the U-F foam into the sheathing and siding and could not readily penetrate the ofl-base paint film applied to the exterior surface of the wa11. Published data indicate that three layers of o1l-base paint have a

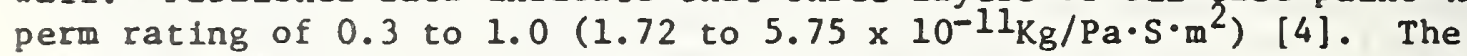
exterfor walls of the test house contained several layers of o11-base primer and top coat, which probably functioned as a vapor barrier.

At the end of the winter season, some blistering of the oll-base palint at the U-F wall section was observed. Two large blisters (one at the top and one at the bottom of the section) were present. A photograph of the water blister at the top is shown in figure 32. Many small blisters also occurred under the double-hung window at this wall section. At the end of the summer season, the small blisters disappeared, but the two large blisters remained.

The foregoing experimental results show that when U-F is blown into wood-frame cavity walls during the winter, the water originally contained in the foam will move outward into the wood siding and sheathing. When a vapor-impermeable paint system is applied to the exterior surface, this moisture may not be able to escape to the outdoor environment and 


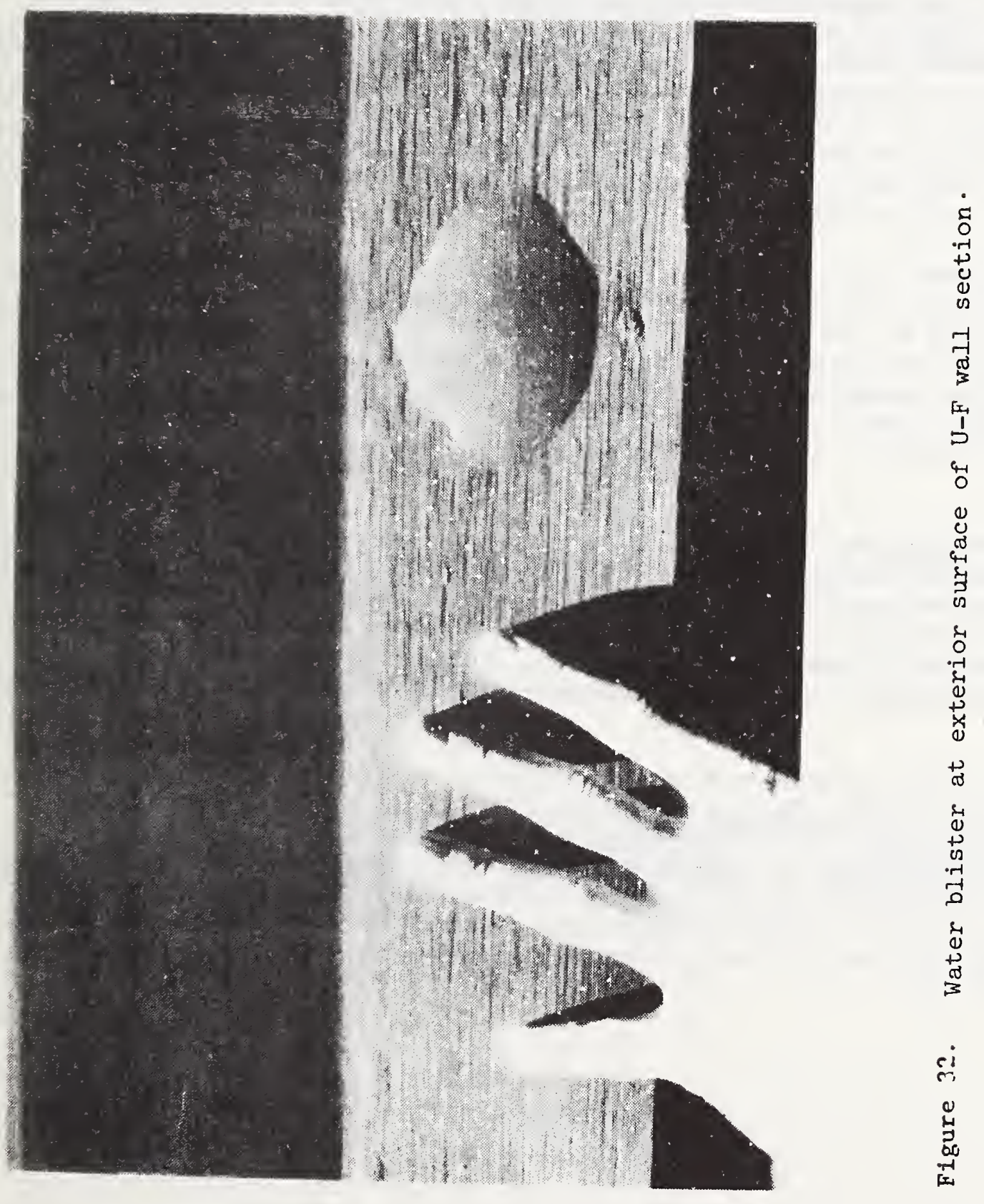


can lead to paint peeling and blistering. If a more permeable paint system (such as a latex paint system) had been applied to the exterior surface, the accumulated moisture might have escaped more readily to the outdoor environment.

At the end of the following summer season, samples of wood siding, sheathing, and insulation were again cored out at wall sections insulated with the three different materials, and the moisture contents of these samples were determined. The heat pump in the test house was operated throughout the summer and maintained the indoor temperature at approximately $74.4^{\circ} \mathrm{F}\left(23.6^{\circ} \mathrm{C}\right)$ and at a dew point of approximately $58^{\circ} \mathrm{F}$ $\left(14.4^{\circ} \mathrm{C}\right)$. Summer moisture contents of material samples are given in tables 27,28 , and 29 for the cellulose, glass-fiber, and U-F wall sections, respectively.

Comparing the moisture contents of samples cored from the cellulose wall section at the end of the winter season (table 27) to corresponding samples cored at the end of the summer (table 24), it can be seen that the moisture contents of the wood siding, sheathing, and insulation tended to be approximately the same. Note that for both the summer and winter measurements the moisture contents of the inside and outside insulation cores at the cellulose wall section were very nearly the same.

An examination of summer moisture content values taken from the glass-fiber wall section (table 28) show that the moisture contents of the inside insulation cores were considerably greater than those of outside insulation cores. During the summer season, the flow of vapor is predominantly from the outside to the inside. Moisture tends to accumulate within the insulation layer adjacent to the cooler interior surface.

The summer moisture contents of material samples cored from the U-F wall section (table 29) show that much of the original water that had become entrapped in the wood siding and sheathing was able to migrate inward and escape during the summer. However, the slightly elevated moisture contents of the wood siding and sheathing, and the fact that the outside insulation cores contained more moisture than the inside cores, would indicate that the wood siding and sheathing may still have been losing moisture. 
TABLE 27. SUMER MOISTURE CONTENTS OF MATERIAL SAMPLES REMOVED FROM CELLULOSE WALL SECTION

\begin{tabular}{|c|c|c|c|c|c|}
\hline \multirow{3}{*}{ Location* } & \multicolumn{5}{|c|}{ Mo1sture Content, $z$ (by we1ght) } \\
\hline & \multirow{2}{*}{$\begin{array}{l}\text { Wood } \\
\text { Siding } \\
\end{array}$} & \multirow[b]{2}{*}{ Sheathing } & \multicolumn{2}{|c|}{ Insulat1on Core } & Inside \\
\hline & & & outside & Inside & Wall Covering \\
\hline 1 Top & 12 & 12 & 13 & 13 & 8 \\
\hline 1 Bottom & 16 & 12 & 16 & 14 & $9(11) * *$ \\
\hline 2 Top & 10 & 10 & 14 & 16 & 10 \\
\hline 2 Bottom & 8 & 9 & 15 & 14 & 9 \\
\hline 3 Top & 11 & 13 & 17 & 18 & 8 \\
\hline 3 Bottom & 13 & 14 & 18 & 18 & 8 \\
\hline 6 Top & 11 & 12 & 25 & 14 & 9 \\
\hline Average & 11.6 & 11.7 & $15.5 * *$ & 15.3 & 8.7 \\
\hline
\end{tabular}

* See figure 30 for location identification

** Plaster (wood)

*** The moisture content for 6 Top is not included in the average..

TABLE 28. SUMMER MOISTURE CONTENTS OF MATERIAL SAMPLES TAKEN FROM THE GLASS-FIBER WALL SECTION

Molsture Content, $\%$ (by weight)

Location*

Wood

Insulation Core

Siding Sheathing Outside Inside

Inside

Wall Cover Ing

5 Top

12

14

12

14

12

14

Average

* See figure 30 for location Identification.
22

18

20
9

9

9 
TABLE 29. SUMMER MOISTURE CONTENTS OF MATERIAL SAMPLES TAKEN FROM THE U-F WALL SECTION

\begin{tabular}{|c|c|c|c|c|c|}
\hline \multicolumn{6}{|c|}{ Moisture Content, \% (by weight) } \\
\hline \multirow[b]{2}{*}{ Location* } & Wood & & Insulat & n Core & Inside \\
\hline & Siding & Sheathing & Outside & Inside & Wa11 Covering \\
\hline 4 Top & 17 & 21 & 22 & 17 & 15 \\
\hline 4 Bottom & 13 & 11 & 14 & 14 & 9 \\
\hline Average & 15 & 16 & 18 & 15.5 & 12 \\
\hline
\end{tabular}

\subsection{Other Performance Properties of Insulations}

The shrinkage, fissuring, and settling properties of in situ insulating materials were also observed on the test house.

\subsubsection{Shrinkage and Cleavage in the U-F Foam}

The U-F wall section was opened up periodically to observe the condition of the foam. On these occasions, the linear shrinkage away from the studs was measured at several locations and average shrinkage figures were calculated. Average shrinkage figures of the foam of the test house are given in table 30.

\section{TABLE 30. MEASURED LINEAR SHRINKAGE OF IN SITU U-F FOAM OF THE TEST HOUSE}

$\begin{array}{cc}\begin{array}{c}\text { Elapsed Time } \\ \text { Months }\end{array} & \begin{array}{c}\text { Linear Shrinkage } \\ \%\end{array} \\ 3.1 & 2.6 \\ 14.8 & 5.6 \\ 20.1 & 7.3 \\ 26.2 & 8.1\end{array}$

These data are plotted in figure 33. It can be seen that the percent linear shrinkage of the in situ foam of this particular house has been occurring at an approximately constant rate. After 26.2 months, there has been very little leveling off in the rate of shrinkage. Since the composition and density of the U-F foam are known to have an effect on the rate and extent of linear shrinkage, the data in table 30 may not be characteristic of all U-F foam applications.

Several small fissures (void spaces where the foam has pulled apart) were also observed in the in situ foam. They ranged from $3 / 8$ in $(.95 \mathrm{~cm})$ to 1 in $(2.54 \mathrm{~cm})$ in width. 


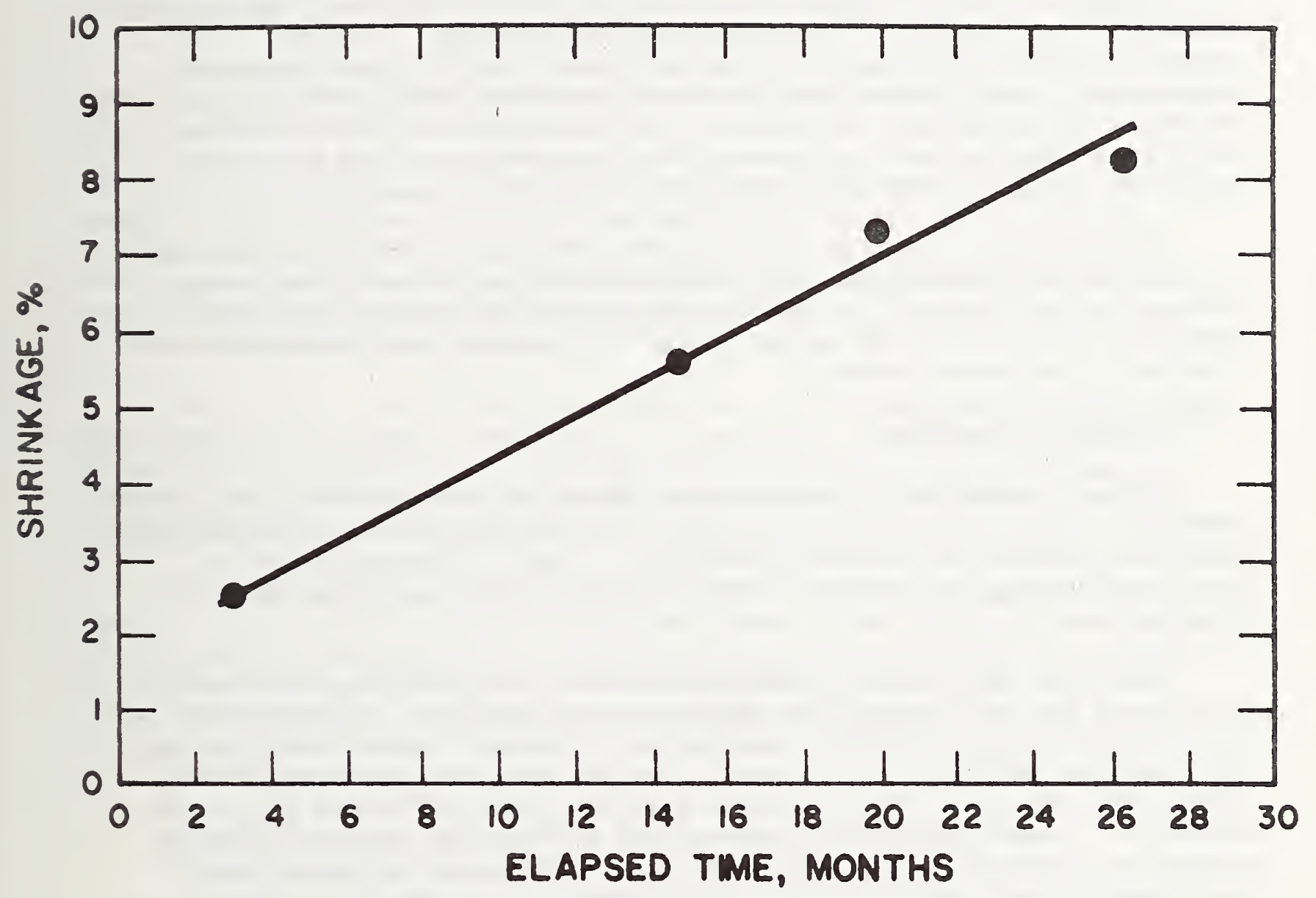

Figure 33. Percent linear shrinkage of urea-formaldehyde foam insulation as a function of elapsed time. 


\subsubsection{Settling of Loose-fill Insulation}

Settling of the loose-fill cellulose insulation installed in the celling was observed over a period of 18 months following the installation. The settling that occurred during the first 25 days was $3 / 4$ in $(1.91 \mathrm{~cm})$ or 12.5 percent, of the initial thickness of 6 in $(15.24 \mathrm{~cm})$. Eighteen months after the installation, the total measured settling was $1-1 / 2$ in $(3.82 \mathrm{~cm})$, or 25 percent out of an initial fill of 6 in $(15.24 \mathrm{~cm})$.

Part of the settling of the loose-fill cellulose may have been due to compression of the existing $3-1 / 2$ in $(8.89 \mathrm{~cm})$ of $\mathrm{glass}-\mathrm{f}$ iber blanket insulation over which the cellulose had been applied. However, it is doubtful that the glass-fiber insulation would exhibit slow long-term compression, since glass fiber is one of the most nearly perfect elastic materials which exists. In addition, the bag count for the cellulose insulation used to insulate the ceiling indicated that the loose-fill cellulose had been initially installed at too low a density.

In the case of the walls, holes were drilled at the top of the wall cavities of the glass-fiber and cellulose wall sections. These holes were sealed with plastic plugs, permitting periodic inspections for settling. No settling of either loose-fill materlal was observed over a period of eighteen months.

\subsection{Summary of Results}

Thermal conductivity measurements using the guarded-hot-plate apparatus showed that cellulosic fiber, fibrous glass wool, and U-F foam have high thermal resistances (R-values). The U-F foam was found to have somewhat higher thermal resistance values than the other two materials.

Heat-loss and moisture measurements were performed on a full-scale laboratory test wall which was exposed to a temperature of approximately $5^{\circ} \mathrm{F}\left(-15^{\circ} \mathrm{C}\right)$ at the exterior surface and a typical indoor condition at the interior surface for a two-month period. Separate sections of the laboratory test wall were insulated with the three different insulating materlals. Measured thermal conductances of the separate wall sections agreed with corresponding predicted values determined by the seriesresistance method, even though a large amount of molsture was present in the form of lce on the exterior side of the insulation.

Heat-transmission measurements were also performed on separate wall sections (insulated with the three different insulating materials) of the test house. Measured thermal conductances for the glass-fiber and cellulose wall sections agreed with corresponding predicted values determined by the series-resistance method, whereas the measured thermal conductance of the U-F wall section was considerably higher than predicted value. The higher measured thermal conductance at the U-F wall section was attributed to a $1-1 \mathrm{n}(2.54 \mathrm{~cm}$ ) fissure (or vold space), which was discovered directly in line with the heat-flow measuring station. 
At the end of the winter season, after the insulation was installed in the exterior walls of the test house, the moisture content of the wood siding and sheathing of the cellulose and glass-fiber wall sections was determined by an oven-drying technique and found to range between 12 and 15 percent (by weight).

The average moisture content observed at the end of the winter season for the wood siding and sheathing at the U-F wall section were 23 and 33 percent, respectively. These values are considerably higher than corresponding values observed at other wall sections. At the end of the winter season, paint blistering was observed at the U-F wall section.

The comparatively higher moisture contents observed at the U-F wall section were attributed to the original moisture content of the foam. When the foam was initially installed, it contained approximately 0.47 $1 \mathrm{~b}$ of water per $\mathrm{ft}^{2}$ of exterior wall $\left(2.29 \mathrm{~kg} / \mathrm{m}^{2}\right)$. The original moisture in the foam migrated into the siding and sheathing and was unable to penetrate the oil-base paint system applied to the exterior surface. 0il-base paint is known to have a low permeance for water vapor. If a more permeable paint system had been used, the original water of the foam probably might have been able to escape to the outdoor environment without blistering the paint.

The U-F wall section was opened up on several occasions and the foam was examined for linear shrinkage. The percent linear shrinkage was observed to increase at an approximately steady rate during the period of observation. Af ter 26.2 months, the average linear shrinkage was found to be approximately 8.1 percent.

Eighteen months after the cellulose and glass-fiber insulations were installed in the walls of the test house, no settling of the loosefill materials was observed. Eighteen months after cellulose was installed over the existing glass-fiber celling insulation, the height of the cellulose above the ceiling had decreased by 25 percent. The bag count of the cellulose used to insulate the ceiling indicated that it had been installed at too low a density.

\section{EFFECTIVENESS OF RECOMMENDED "GOOD PRACTICE" MEASURES FOR PREVENTING MOISTURE ACCUMULATION}

The effectiveness of recommended "good practice" measures [4] for preventing winter moisture accumulation in attics and summer moisture accumulation in crawl spaces was also investigated. 
The experimental plan for evaluating the effectiveness of recommended "good practlce" measures for preventing potentlally dangerous moisture accumulation was to employ the following measures during the third stage of the retrof 1t:
a. Vapor-barrier cover over the bare earth of the crawl space,
b. Recommended attic ventilation,
c. Recommended crawl-space ventilation,
d. A vapor barrier on the warm side of the celling and floor insulation.

Item $d$ is not a requirement for the Washington, D.C. location, but it was included as part of the retrofit, nonetheless. During the remainder of the winter season, perlodic inspections of the test house for visible condensation were performed. Materlal samples were cored from the attic at the end of the winter season and from the floor over the crawl space at the end of the summer season, and the molsture contents of these samples were determined.

\subsection{Experimenta1 Results}

At the end of the winter season, 76 days after the Insulation had been installed in the test house, samples of the glass-f iber blanket insulation and cellulose were removed at locations where the light fixtures penetrated the celling. These locations were considered to be spots where moisture-laden air could readily pass into the insulation from the living space below.

The molsture content was 1 percent for the glass-fiber specimen and 13 percent for the cellulose specimen. These moisture contents were probably related to the equilibrium molsture contents of the two materials. In addition, the underside of the roof was never observed to be wet from condensation.

At the end of the summer season, wood samples of the sill plate above the foundation wall and center pler were cored out, and the molsture contents of these samples were found to be 19 and 16 percent (by weight), respectively. This amount of accumulated moisture is much less than the fiber saturation point ( 30 percent, by weight). Usually, molsture problems such as wood rot due to fung 1 begin to occur when the molsture content approaches the fiber saturation point [21].

\subsection{Conclusions}

The recommended "good practice" measures were found to be effective in preventing damaging winter moisture accumulation in wood parts of crawl spaces for the test house and for the conditions under which it was tested. 
1. Patterns of Energy Consumption in the United States, Stanford Research Institute, 1972.

2. Anderson, D. B., Heat Loss Studies in Four Identical Buildings to Determine the Effect of Insulation, ASHRAE Transactions, Vol. 48, 1942.

3. Degelman, L. D., and Lewis, S. A., Single Family Dwelling and Natural Resource Consumption Effects and Energy Budget, Seminar paper presented at the 1975 ASHRAE annual meeting held at Boston, Massachusetts.

4. ASHRAE Handbook of Fundamentals, The American Soclety of Heating, Refrigeration, and Air Conditioning Engineers, 1972.

5. Anderson, L. D., Condensation Problems: Their Prevention and Solution, USDA Forest Service Research Paper FPL 132, Forest Products Laboratory, Madison, Wisconsin, 1972.

6. Paljak, Ivar, and Pettersson, Bert1l, Thermography of Buildings, Swedish Council of Building Research, Lund Institute of Technology, Lund, Sweden, 1972.

7. Kelly, G. E., and Bean, J. W., Dynamic Performance of a Residential Alr-to-Air Heat Pump, Bullding Sclence Series 93, National Bureau of Standards, 1977.

8. Nottage, H. B., The Thermal Properties of Building Materials Used in Heat Flow Calculations, ASHRAE Research Bulletin No. 2, Vol. 53, 1947.

9. Tye, R. P., Heat Transmission in Cellulosic Fiber Insulating Material, Journal of Testing and Evaluation, Vol. 2, No. 3, American Society of Testing and Materials, 1974.

10. Bankval1, Claus G., Natural Convection Heat Transfer in Insulated Structures, Report 38, Division of Building Technology, Lund Institute of Technology, Lund, Sweden, 1972.

11. Hunt, C., and Treado, S., A Prototype Semi-Automated System for Measuring Air Infiltration In Buildings Using Sulfur Hexafluoride as a Tracer, NBS Technical Note $898,1976$.

12. Hunt, C. M., and Burch, D. M., Air Infiltration Measurements in a Four-Bedroom Townhouse Using Sulfur Hexafluoride as a Tracer Gas, ASHRAE Transactions, Vo1. 81, Part I, 1975. 
13. Bahnfleth, D. R., Moseley, T. T., and Harris, W. S., Measurement of Infiltration in Two Residences, Part I: Technique and Measured Infiltration, Part II: Comparison of Variables Affecting Infiltration, ASHRAE Transactions 63, pp. 453-476, 1957.

14. Coblentz, C. W., and Achenbach, P. R., Field Measurements of Air Infiltration in Ten Electrically Heated Houses, ASHRAE Transactions 69, pp. 358-365, 1963.

15. Peavy, B. A., Burch, D. M., Powe11, F. J., and Hunt, C. M., Comparison of Measured and Computer-Predicted Thermal Performance of a FourBedroom Wood-Frame Townhouse, Bullding Sclence Serles 57, National Bureau of Standards, 1975.

16. Mattingly, G. F., and Peters, E. F., Wind and Trees - Air Infiltration Effects on Energy in Housing, Center for Environmental Studies Report No. 20, Princeton University, May, 1975.

17. Stricker, S., Measurement of Heat Output of Residential Furnaces, ASHRAE Transactions, Vol. 76, Part II, 1970.

18. Falson, T. K., Jr., Davis, J. C., and Achenbach, P. R., Performance of Louvered Devices as Alr Mixers, Bullding Sclence Series 27, National Bureau of Standards, 1970.

19. Jacobs, M., and Petersen, S., Making the Most of your Energy Dollars in Home Heating and Cooling, NBS Consumer Information Serles 8, National Bureau of Standards, June, 1975.

20. Petersen, S. R., Retrofitting Existing Housing for Energy Conservation: An Economic Analysis, Building Science Series 64, National Bureau of Standards, December, 1974.

21. Scheffer. T. S., and Verral1, A. F., Principles for Protecting Wood Bulldings from Decay, USDA Forest Service Research Paper FPL-190, Forest Products Laboratory, Madison, Wisconsin, 1973. 
Nomenclature

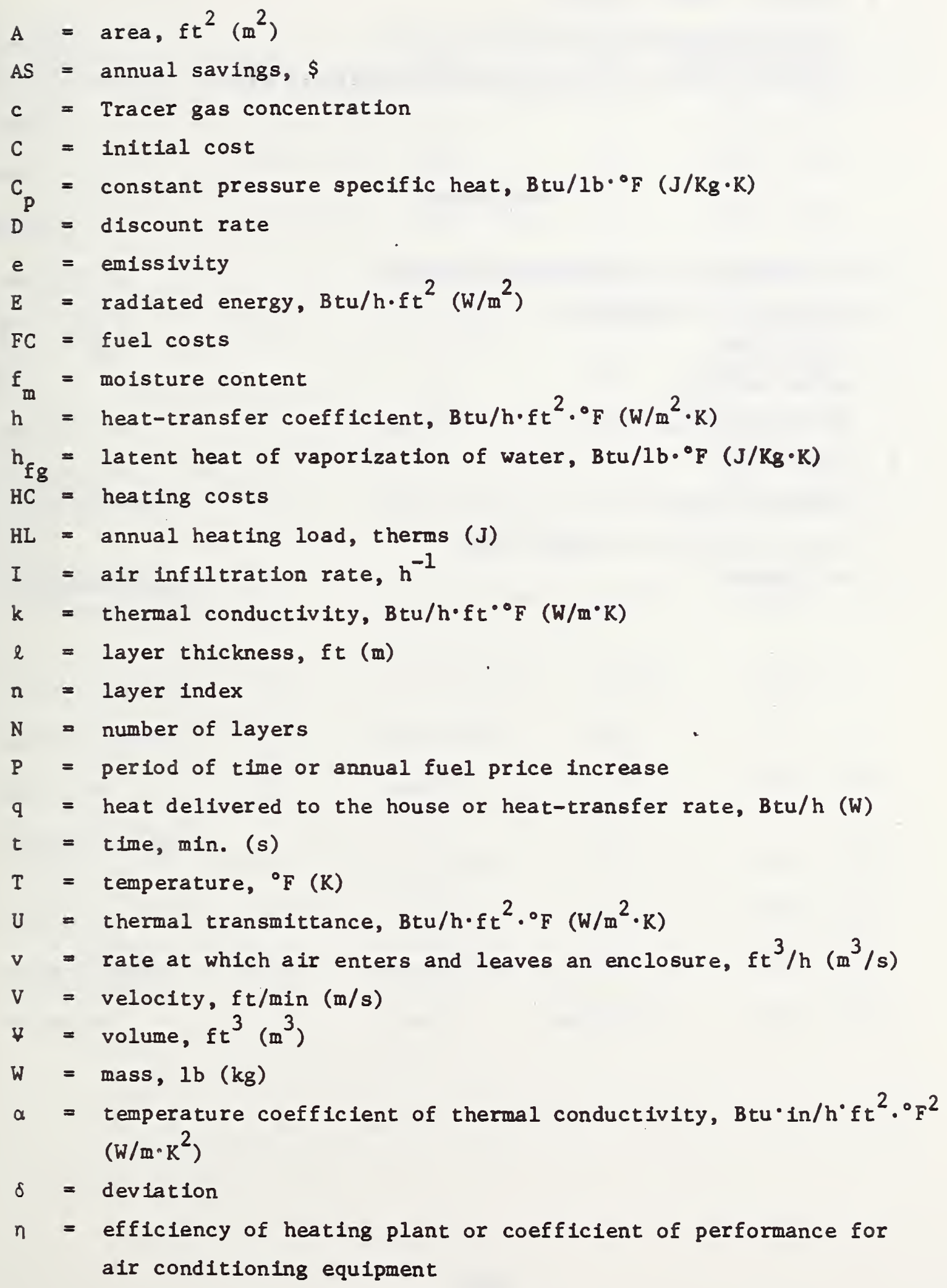




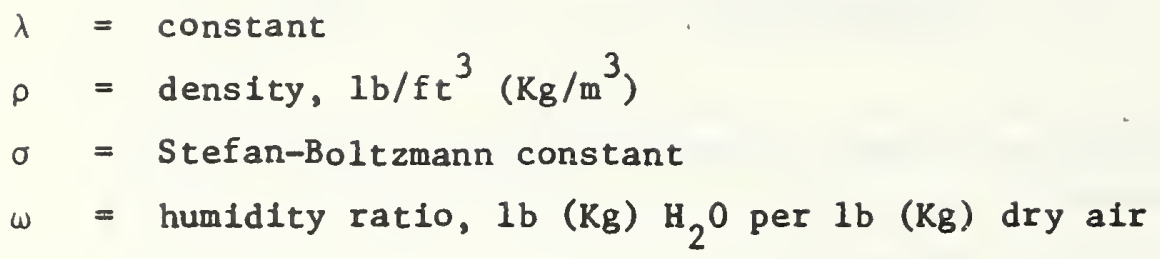

Subscr 1pts

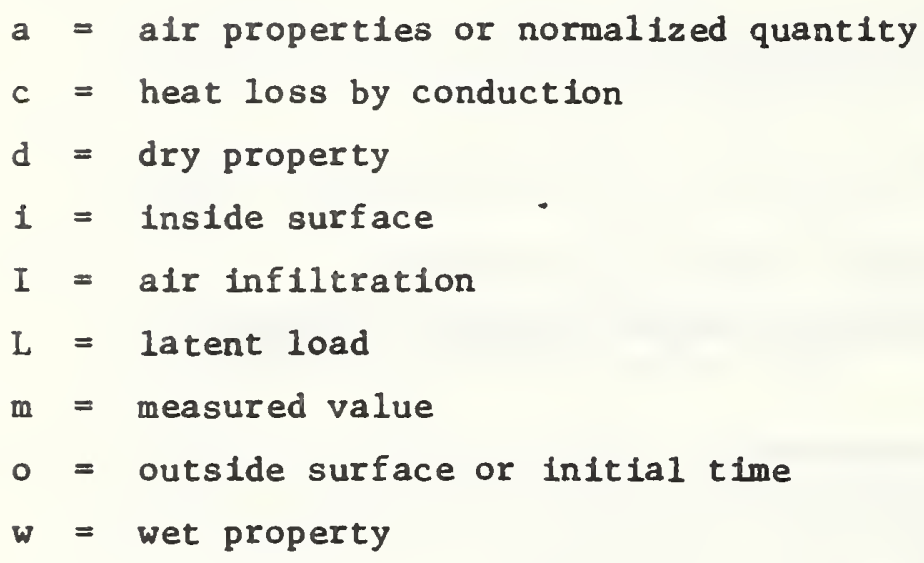




\begin{tabular}{|c|c|c|c|c|}
\hline $\begin{array}{l}\text { Physical } \\
\text { Quantity }\end{array}$ & Symbol & $\begin{array}{l}\text { To Convert } \\
\text { From }\end{array}$ & To & Multiply By \\
\hline Length & $\ell$ & ft & $\mathrm{m}$ & $3.05 \times 10^{-1}$ \\
\hline Area & $\mathbf{A}$ & $f t^{2}$ & $\mathrm{~m}^{2}$ & $9.29 \times 10^{-2}$ \\
\hline Volume & $\forall$ & $f t^{3}$ & $m^{3}$ & $2.83 \times 10^{-2}$ \\
\hline Temperature & $\mathrm{T}$ & Fahrenheit & Celsius & $t_{c}=\left(t_{f}-32\right) / 1.8$ \\
\hline Temp. Diff. & $\Delta \mathrm{T}$ & Fahrenheit & Kelvin & $\mathrm{K}=\left(\Delta \mathrm{T}_{F}\right) / 1.8$ \\
\hline Mass & & $1 \mathrm{~b}$ & $\mathrm{Kg}$ & $4.54 \times 10^{-1}$ \\
\hline Density & $\rho$ & $1 \mathrm{~b} / \mathrm{ft} \mathrm{t}^{3}$ & $\mathrm{Kg} / \mathrm{m}^{3}$ & $1.602 \times 10^{1}$ \\
\hline $\begin{array}{l}\text { Thermal } \\
\text { Conductivity }\end{array}$ & $k$ & $\mathrm{Btu} \cdot \mathrm{in} / \mathrm{h} \cdot \mathrm{ft} \mathrm{t}^{2}$ & ${ }^{\circ} \mathrm{F} \quad \mathrm{W} / \mathrm{m} \cdot \mathrm{K}$ & $1.442 \times 10^{-1}$ \\
\hline $\begin{array}{l}\text { Thermal } \\
\text { Transmittance } \\
\text { (or Conductance) }\end{array}$ & $\mathrm{U}$ & $\mathrm{Btu} / \mathrm{h} \cdot \mathrm{ft} \mathrm{t}^{2} \cdot{ }^{\circ} \mathrm{F}$ & $\mathrm{W} / \mathrm{m}^{2} \cdot \mathrm{K}$ & 5.68 \\
\hline Thermal Resistance & $\mathbf{R}$ & $h \cdot f t^{2} \cdot{ }^{\circ} \mathrm{F} / \mathrm{Btu}$ & $\mathrm{m}^{2} \cdot \mathrm{K} / \mathrm{W}$ & 0.176 \\
\hline Heat Flux Rate & $\mathrm{q} / \mathrm{A}$ & $\mathrm{Btu} / \mathrm{h} \cdot \mathrm{ft} \mathrm{t}^{2}$ & $\mathrm{~W} / \mathrm{m}^{2}$ & 3.15 \\
\hline Heat Flow & $q$ & Btu/h & W & $2.93 \times 10^{-1}$ \\
\hline $\begin{array}{l}\text { Volumetric Flow } \\
\text { Rate }\end{array}$ & $\mathbf{v}$ & $\mathrm{ft} \mathrm{t}^{3} / \mathrm{min}$ & $\mathrm{m}^{3} / \mathrm{s}$ & $4.72 \times 10^{-4}$ \\
\hline Velocity & V & $\mathrm{ft} / \mathrm{min}$ & $\mathrm{m} / \mathrm{s}$ & $5.08 \times 10^{-3}$ \\
\hline Specific Heat & $C_{p}$ & $\mathrm{Btu} / 1 \mathrm{~b} \cdot{ }^{\circ} \mathrm{F}$ & $\mathrm{J} / \mathrm{Kg} \cdot \mathrm{K}$ & $4.19 \times 10^{3}$ \\
\hline Permeance & & perm & $\mathrm{Kg} / \mathrm{Pa} \cdot \mathrm{s} \cdot \mathrm{m}^{2}$ & $5.72 \times 10^{-11}$ \\
\hline
\end{tabular}




\section{ACKNOWLEDGMENTS}

Staff members of the Building Environment Division of CBT provided much assistance and support during the period of research and preparation of this report.

The authors are grateful to Paul Achenbach, David Didion and George Kelly for their many ideas, conceptual approach, and technical suggestions prior to and during the experimental phases of the study, and to Steve Petersen for suggestions concerning the economic technique for evaluating the cost effectiveness of the retrofit measures. The authors are Indebted to Rollin Baumgardner for many helpful suggestions concerning retrofit techniques and moisture condensation in buildings. Appreciation is also expressed to $C$. Siu for conducting the guarded-hotplate measurements; to Walter Ellis for his technical assistance in the installation of the instrumentation and day-to-day operation of the experiment; to John Grimes for designing, constructing, and testing the full-scale laboratory test wall; to James Allen for carrying out the smoke and thermographic measurements; to Dee Showalter for assisting in the smoke measurements; to John Bean for reducing the energy data; to Mary Reppert for editing the manuscript; and to Tammy Mewshaw and Shirley Baile for typing this report.

Mr. Reid Hartsell, general technical representative, Federal Energy Administration, provided liaison for this report, and his patience and encouragement are appreciated by the authors. 
Appendix A

Description of the Third Stage of the Retrofit

\section{Introduction}

The third stage of the retrofit consisted of applying insulation in the walls and the floor, and installing additional insulation in the ceiling. Since NBS did not have the equipment nor the trained personnel to blow loose-fill insulation into walls and over ceilings, the thirdstage work was performed under contract.

\section{Installing Additional Insulation in the Ceiling}

Six inches $(15.24 \mathrm{~cm})$ of loose-fill cellulose insulation were blown on top of the existing $3-1 / 2$ in $(8.89 \mathrm{~cm})$ of glass-fiber blanket ceiling insulation. The cellulose insulation was poured from bags into the blowing machine shown in figure A-1. At the bottom of the blowing machine, the rotation of an agitator broke up the cellulose into smallsize particles which were subsequently fed into a blower. The blower pumped the insulating material through a $2-1 / 2$ in $(6.35 \mathrm{~cm})$ diameter hose which was used to distribute the insulating material uniformly on top of the existing ceiling insulation (see figure A-2). Loose-fill cellulose was also blown under and up to the top surface of the 6-ft $(1.83 \mathrm{~m})$ wide catwalk that ran the length of the attic.

\section{Insulating the Walls}

Loose-fill cellulose insulation was blown into the wall cavities, with the exception of the northeast bedroom where loose-fill glass fiber was blown into the north exterior wall and U-F foam was blown into the east exterior wall. The technique used to install loose-fill cellulose in most portions of the wall was to drill a $1-1 / 4$ inch $(3.18 \mathrm{~cm})$ hole through the siding and the sheathing, approximately 1 foot $(0.305 \mathrm{~m})$ above the floor and 1 foot $(0.305 \mathrm{~m})$ below the ceiling. The cellulose material was fed into the blowing machine and forced to pass through the flexible hose. A flow-reducing nozzle with a sight glass (for observing the flow of cellulose) and a flow-control lever was mounted at the end of the hose, as shown in figure A-3. The nozzle was inserted into the hole in the wall cavity and the flow of insulating material was initiated by activating the flow-control lever. Upon detecting the stoppage of flow through the sight glass, the equipment operator would de-activate the flow control lever and move the nozzle to the next hole.

Loose-fill glass-fiber insulation was blown into the north wall of the northeast bedroom. The application technique was to $\operatorname{dril1}$ a 2-9/16 in $(6.51-\mathrm{cm})$ hole through the siding and the sheathing at the bottom and top of each wall cavity. Insulating material was pumped through a 3 -in $(7.62-\mathrm{cm})$ diameter flexible hose into a $2-1 / 2$ in $(6.35 \mathrm{~cm})$ nozzle which was inserted into the hole as shown in figure A-4. Blowing loose-fill 


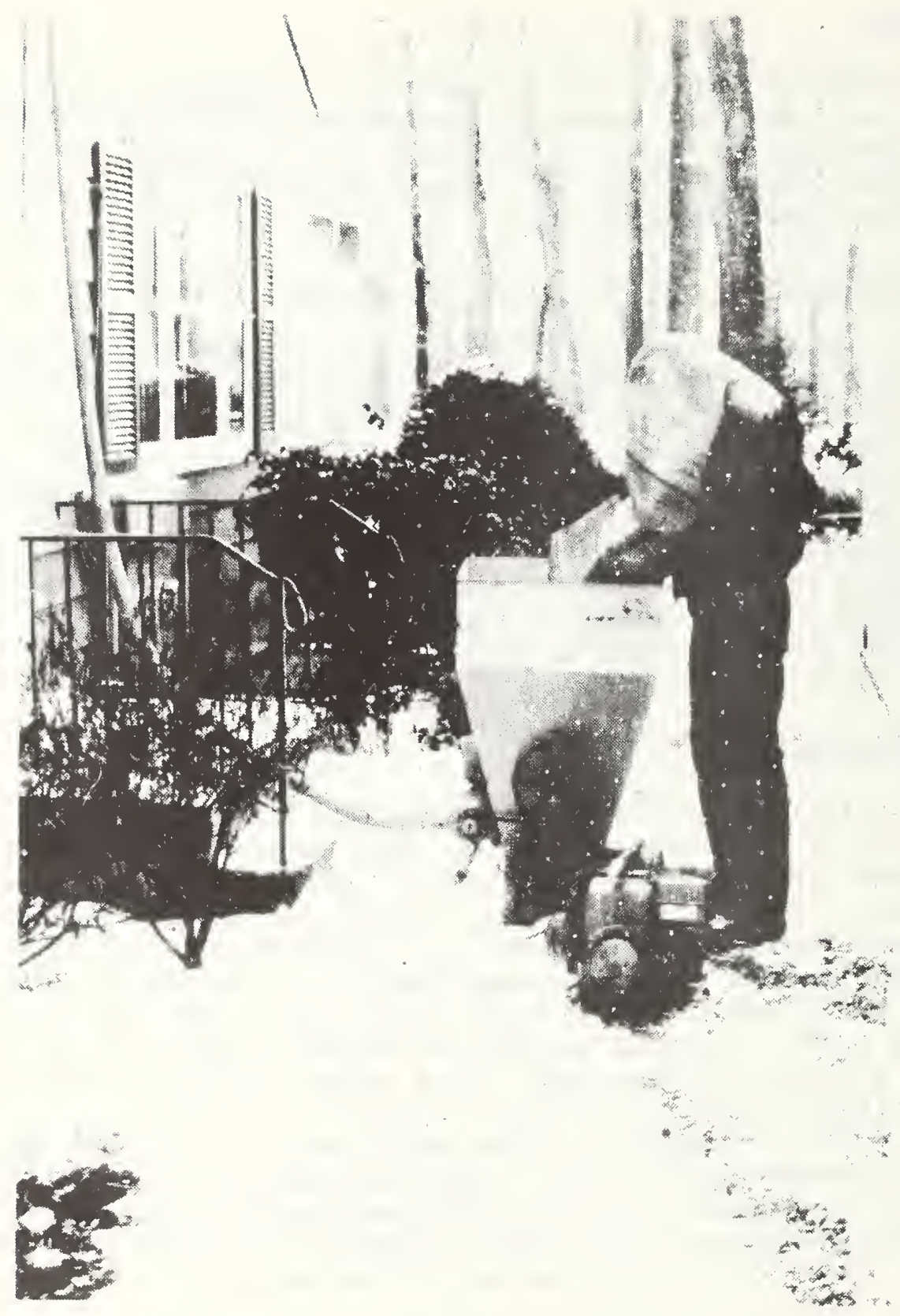

Figure A-1. Loose-fill cellulose insulation being poured into blowing machine. 


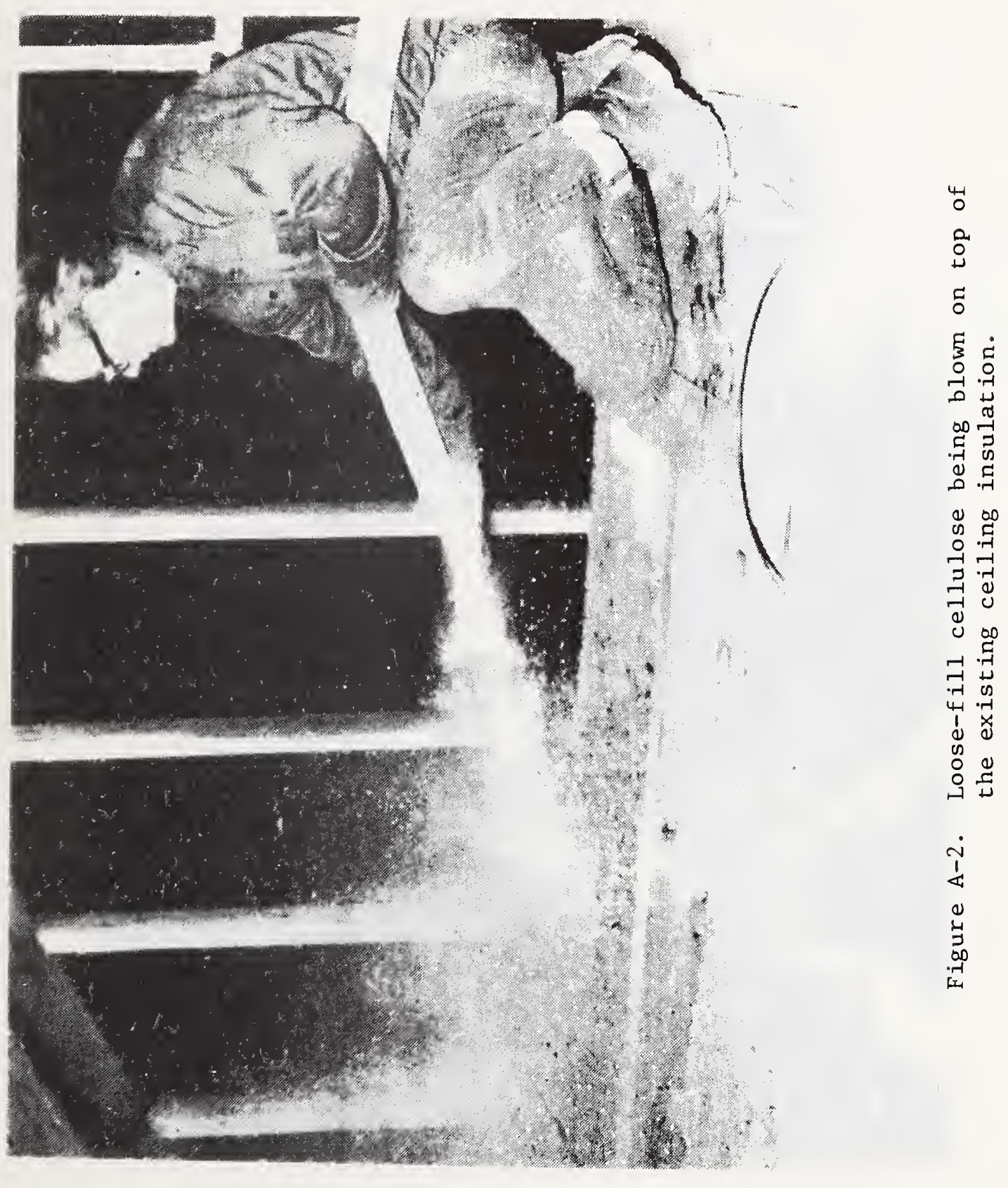

A -3 


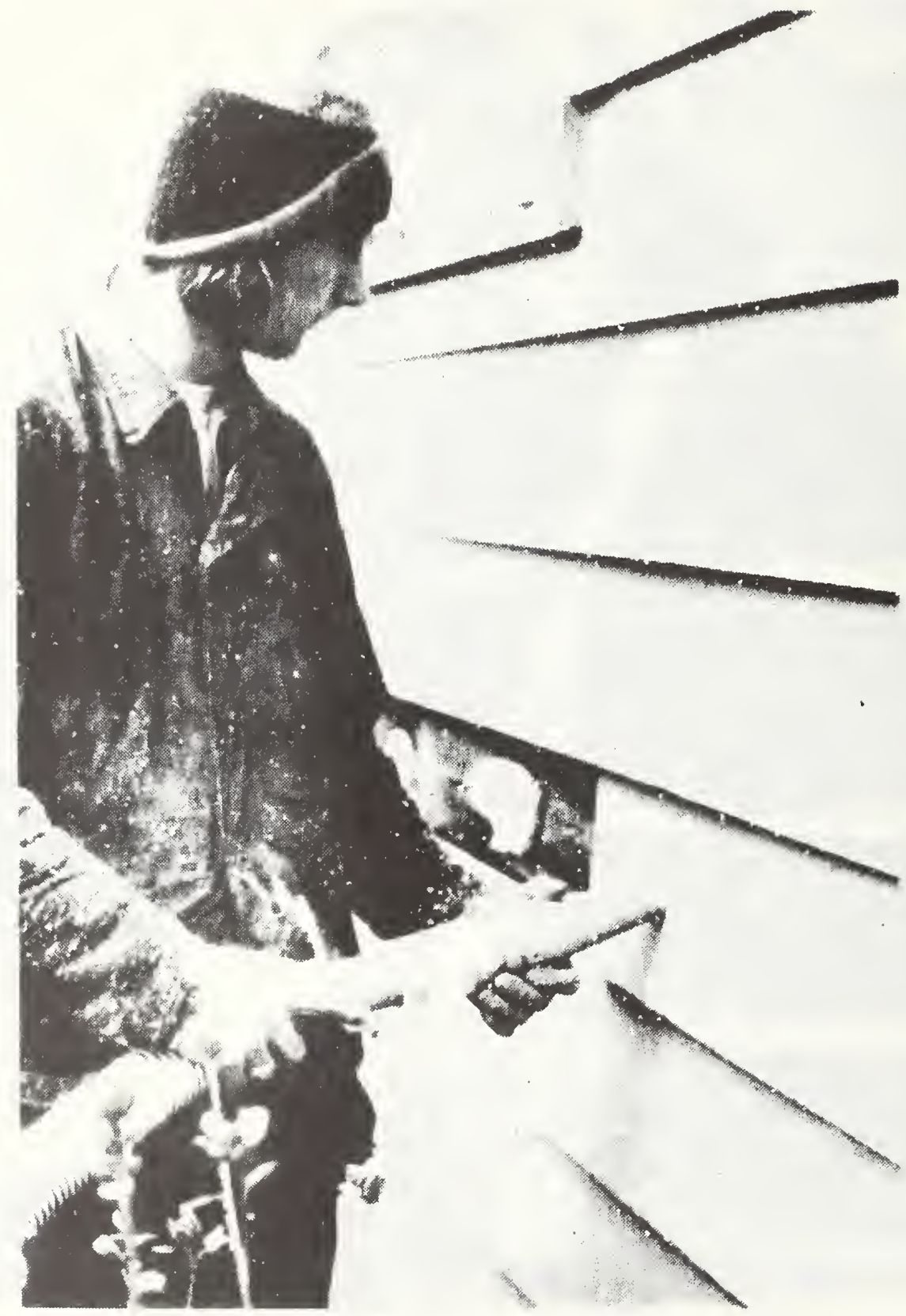

Figure A-3. Cellulosic fiber being blown into the walls of the test house. 


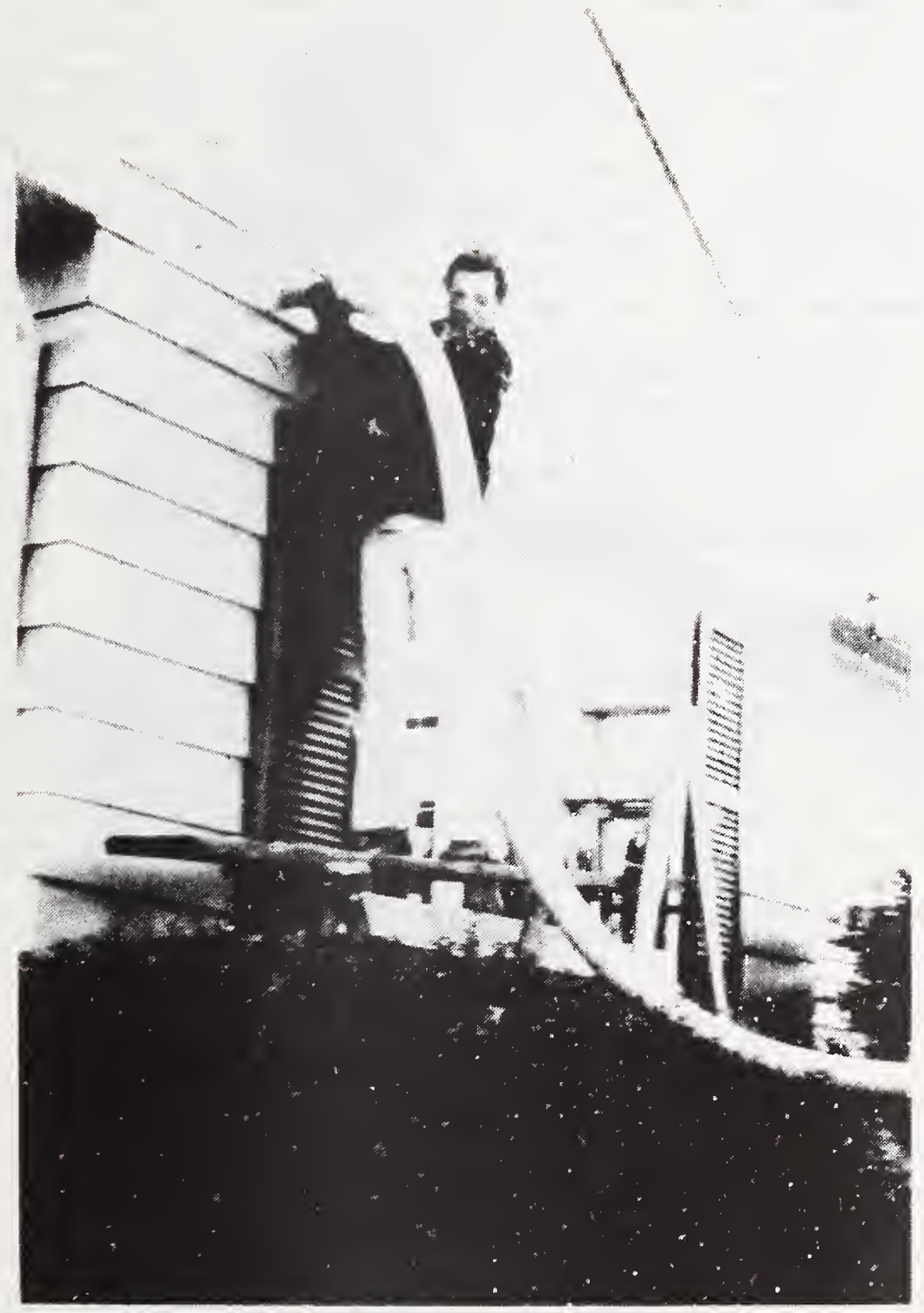

Figure A-4. Glass fiber being blown into a wall section.

$$
A-5
$$


glass fiber into walls requires larger holes, since the glass fibers are long and have a tendency to get hung up in a small reducing nozzle.

Urea-formaldehyde (U-F) foam insulation was blown into the east wall of the northeast bedroom. The application technique was to drill four 1 -inch $(2.54 \mathrm{~cm})$ holes, approximately $2 \mathrm{feet}(0.610 \mathrm{~m})$ apart vertically, in each of the wall cavities. The U-F foam was successively applied from the bottom to the top holes, completely filling the wall cavity (see figure A-5). When the foam was initially applied, its wet density was $2.51 \mathrm{~b} / \mathrm{ft}^{3}\left(40.1 \mathrm{Kg} / \mathrm{m}^{3}\right)$. Figure $\mathrm{A}-6$ is a photograph of the technical representative for the U-F foam measuring the wet density of the U-F foam material. The technical representative also determined = the setting time of the U-F foam after it left the foaming apparatus. The setting time was found to be less than 1 minute. These are very important tests which should be performed prior to blowing U-F material into the wall cavities, since they provide a good indication of the correctness of the composition of the material. After drying, its density was $0.71 \mathrm{~b} / \mathrm{ft}^{3}\left(11.21 \mathrm{Kg} / \mathrm{m}^{3}\right)$. Three hoses transporting U-F resin, a catalytic foaming agent, and compressed air were connected to the applicator gun (shown in figure $\mathrm{A}-5$ ) in which the constituents were mixed in proper proportions to produce U-F foam.

4. Insulating the Floor

Six-inch $(15.24 \mathrm{~cm})$ foil-faced $\mathrm{g}$ lass-fiber batts were installed between the floor joists over the crawl space (see figure A-7). The foil was placed in contact with the underside of the floor. The insulation was held in place with flexible thin rods called "tiger teeth." The domestic water pipes in the crawl space were also insulated to provide freeze protection. A polyethylene vapor barrier was placed over the bare earth of the crawl space to prevent moisture of the earth from migrating into the crawl space. 


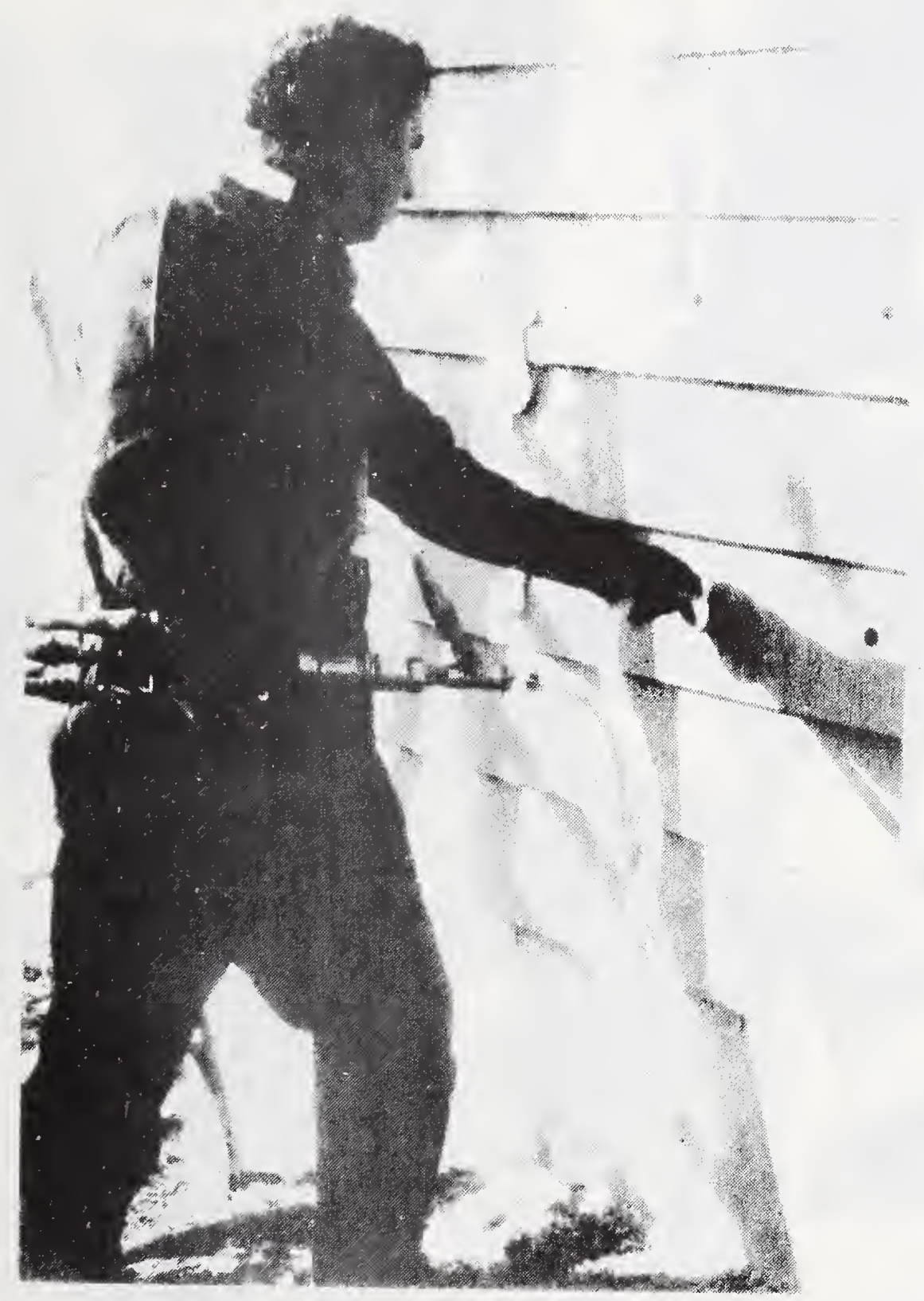

Figure A-5. Urea-formaldehyde foam being blown into a wall section. 


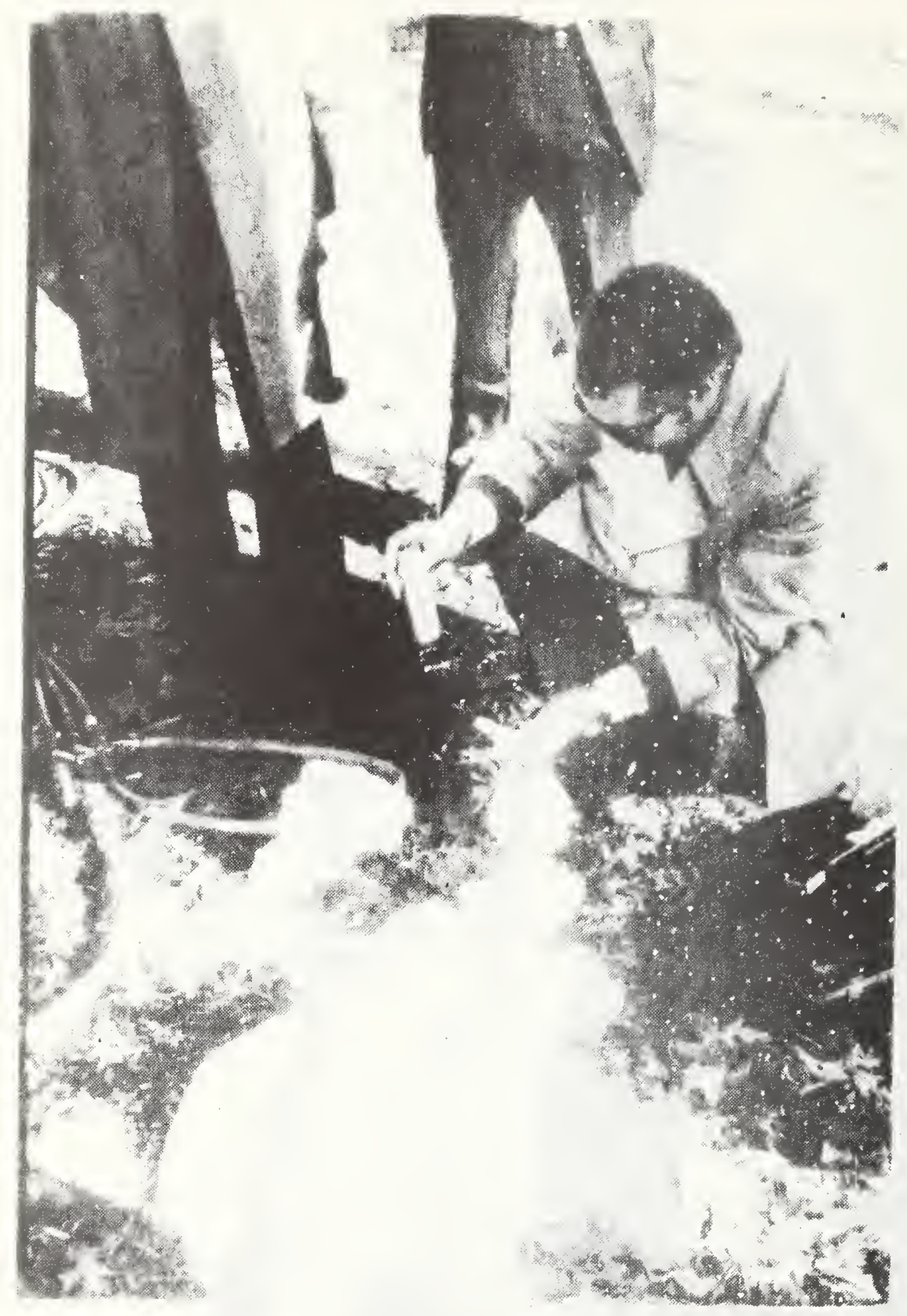

Figure A-6. Technical representative measuring wet density of the U-F foam.

$$
A-8
$$




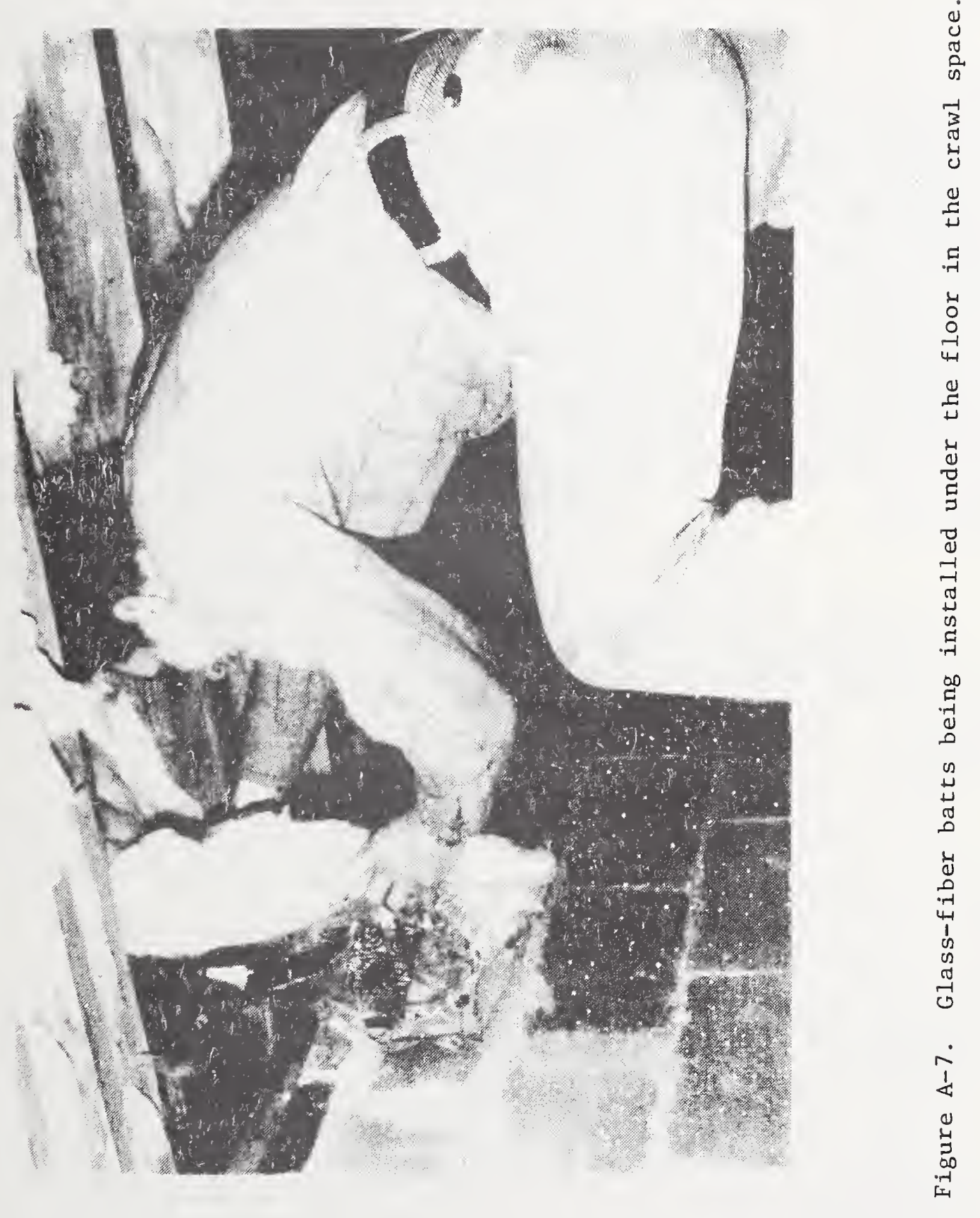

A-9 

Location of Heat Leaks in Residences

Using Infrared Thermography

\section{Introduction}

As part of the energy conservation study conducted on the test house, a thermographic survey using an infrared (IR) television system was performed before and after energy conservation measures were implemented. The purpose of the survey performed prior to the retrofit was to identify major heat leaks which could be treated as part of the retrofit. The purpose of the survey performed after the retrofit was to determine the effectiveness of the retrofit in treating these previously discovered heat leaks. A thermographic survey of the exterior walls of the test house was performed after insulation was blown into the walls to identify vold spaces where insulation was missing. Finally, another survey of the retrofitted test house was performed during the following summer to determine if the same void spaces (previously observed in the winter season) could be observed in the summer when the inside-tooutside temperature difference was much smaller.

\section{Description of Thermographic Equipment}

Infrared thermography is based on the principle that all surfaces emit energy in the form of electromagnetic radiation. The amount of self-emitted radiated energy is proportional to the emissivity of the surface and the fourth power of the absolute temperature, or

$$
E=e \cdot \sigma \cdot T^{4}
$$

where $\mathrm{E}=$ radiated energy, $\mathrm{Btu} / \mathrm{h} \cdot \mathrm{ft} \mathrm{t}^{2} \cdot\left(\mathrm{W} / \mathrm{m}^{2}\right)$

$$
\begin{aligned}
& \mathrm{e}=\text { surface emissivity } \\
& \mathrm{T}=\text { absolute temperature, }{ }^{\circ} \mathrm{R}(\mathrm{K}) \\
& \sigma=\text { Stefan-Boltzmann constant, Btu/h.ft }{ }^{2} \cdot{ }^{\circ} \mathrm{R}^{4}\left(\mathrm{~W} / \mathrm{m}^{2} \mathrm{~K}^{4}\right)
\end{aligned}
$$

A photograph of the infrared television system used for the present study is shown in figure B-1. The equipment from right to left consists of an IR television camera, black-and-white television monitor, a color television monitor, and a temperature-profile display monitor. Upon sensing the radiation emitted from a surface, the IR television camera produces a video signal. The IR camera consists of an optical scanning system with a liquid-nitrogen cooled indium-antimonide photovoltaic detector having high sensitivity in the spectral range of 2.0 to 5.6 micrometers $\left(10^{-} \sigma_{\mathrm{m}}\right)$.

The video signal from the IR camera is processed in the black-andwhite television monitor where it is converted into a thermal picture in 


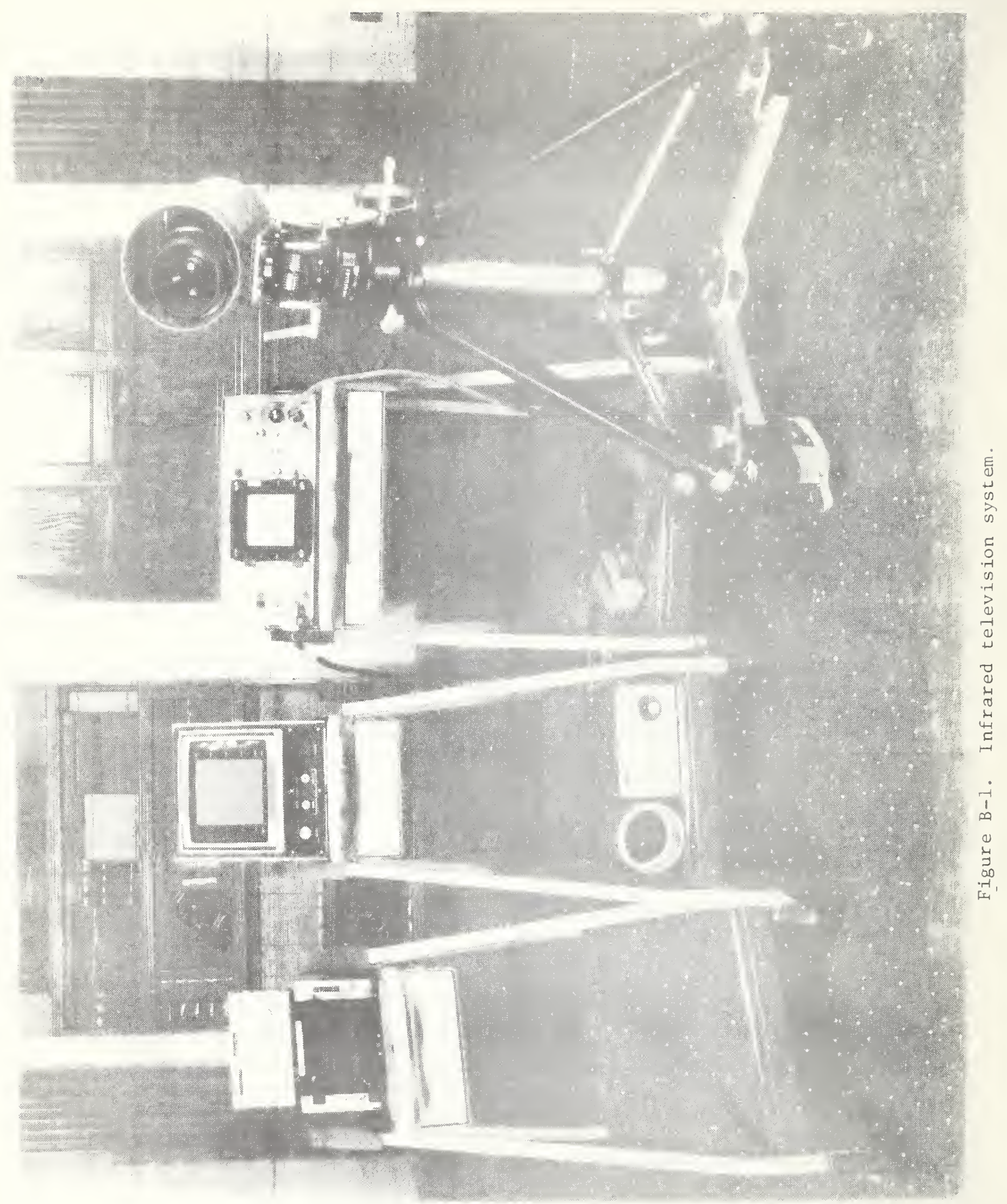


which the gray tones in the picture approximately correspond to surface temperatures. A photograph of the thermal picture is called a "thermogram." Video signals are also fed into the color television monitor where ten individually color-coded isotherms are displayed on the color television screen to produce a thermal picture in which the temperature range has been subdivided into ten regions, each coded with a separate color. The temperature profile display monitor selects a single horizontal trace line of the black-and-white television picture and displays this line such that the temperature change throughout the line is shown as a vertical displacement.

The color thermograms* of the present study were obtained by taking photographs, using conventional camera equipment, of the color television display, respectively. Ten regions of different temperatures are displayed in different colors. The temperature spectrum from the coldest region (coded black) to the warmest region (coded white) is displayed at the bottom of each color thermogram.

\section{Comparison of Thermographic Surveys Performed Before and After the Retrofit}

A thermographic survey was performed before the retrofit for the purpose of identifying specific heat leaks which could be eliminated by some retrofit procedure. After the house was retrofitted, a second survey was performed to examine the success of the retrofit. In this section, three photographs are presented in each figure. The first photograph is a conventional photograph in the visible spectrum of a surface of the house; the second photograph is a thermogram (in the IR spectrum) of the same part prior to the retrofit; and the third photograph is a thermogram (in the IR spectrum) of the same part of the test house taken after the retrofit. All thermographic pictures were taken at night to eliminate solar radiation effects.

The dates and temperature conditions for the two thermographic surveys are given in table $B-1$ :

Table B-1. Conditions for the Two Thermographic Surveys

\begin{tabular}{cccc} 
& Inside & Outside & Temp. \\
Date & Air Temp. & Air Temp. & Diff. \\
\hline
\end{tabular}

$\begin{array}{lllll}\begin{array}{l}\text { Pre-retrofit } \\ \text { survey }\end{array} & \text { March, 74 } & 81.0 & 41.0 & 40 \\ \begin{array}{l}\text { Post-retrofit } \\ \text { survey }\end{array} & \text { March, 75 } & 70.0 & 29.0 & 41\end{array}$

* This NBSIR report shows the thermograms only in black and white. A Building Science Series report covering this research will present the thermograms in color. B-3 
The indoor air temperature for the pre-retrofit thermographic survey was intentionally elevated, so that the inside-to-outside temperature difference would be approximately the same as that for the post-retrofit survey. When performing a thermographic survey, a large inside-tooutside temperature difference is desirable, so that the contrasts in the thermal picture between insulated and non-insulated regions will be as large as possible. Another important consideration necessary for a meaningful comparison between thermograms (say before and after retrofit) is that the inside-to-outside temperature differences be the same for the two cases. The wind velocities were not measured during the two surveys, but visual observations would indicate low wind velocities for both surveys, probably less than $5 \mathrm{mph}(3.61 \mathrm{~m} / \mathrm{s})$.

An overall view of the whole test house is given in figures $B-2 a$, $b, c$. Comparing the pre-retrofit thermogram (figure B-2b) to the postretrofit thermograms (figure $B-2 c$ ), it is seen that the contrast between the test house and the surroundings is much greater in the pre-retrofit thermogram than the post-retrofit thermogram. This decrease in contrast in the post-retrofit thermogram is due to comparatively colder exterior surfaces (with respect to the surroundings) for the insulated test house. Thus, we see that the contrast (temperature difference) between a bullding and its surrounding environment may be used as a qualitative indication to determine whether wood-frame cavity walls are insulated.

Thermographic surveys of the east end of the test house before and after the retrofit are presented in figures $B-3 a, b, c$. In the postretrofit thermogram the contrast (temperature difference) between the left and right parts of the wall section is due to the difference in the heat loss characteristics of wall sections insulated with different insulating materials. The wall section on the left is insulated with loose-fill cellulose, whereas the wall section on the right is insulated with urea-formaldehyde foam. It can be seen that the cellulose wall section is approximately two color-coded isotherm units colder than the U-F wall section. The lower outside surface temperature of the cellulose wall section clearly demonstrates that, at the time this particular thermogram was taken, the insulating properties of the cellulose material were better than those of the urea-formaldehyde foam. It should be pointed out that the post-retrofit thermogram was taken only 17 days after the U-F foam was installed, when the U-F material st 111 contained significant residual moisture which may have considerably reduced its insulating properties. The embedded relative humidity transducer mounted inside the wall between the U-F foam and the sheathing showed a saturated condition at the time this infrared picture was taken. The rectangularly shaped dark region between the windows on the pre-retrofit thermogram is a closet. Since the interior of the closet is an unheated space, less heat is lost through the exterfor wall where the closet is located, resulting in lower exterior surface temperatures at this location. Note, however, after insulation is added to the walls, it is no longer possible to distinguish the closet in the thermogram. This suggests that for thermograms taken at an inside-to-outside temperature difference 


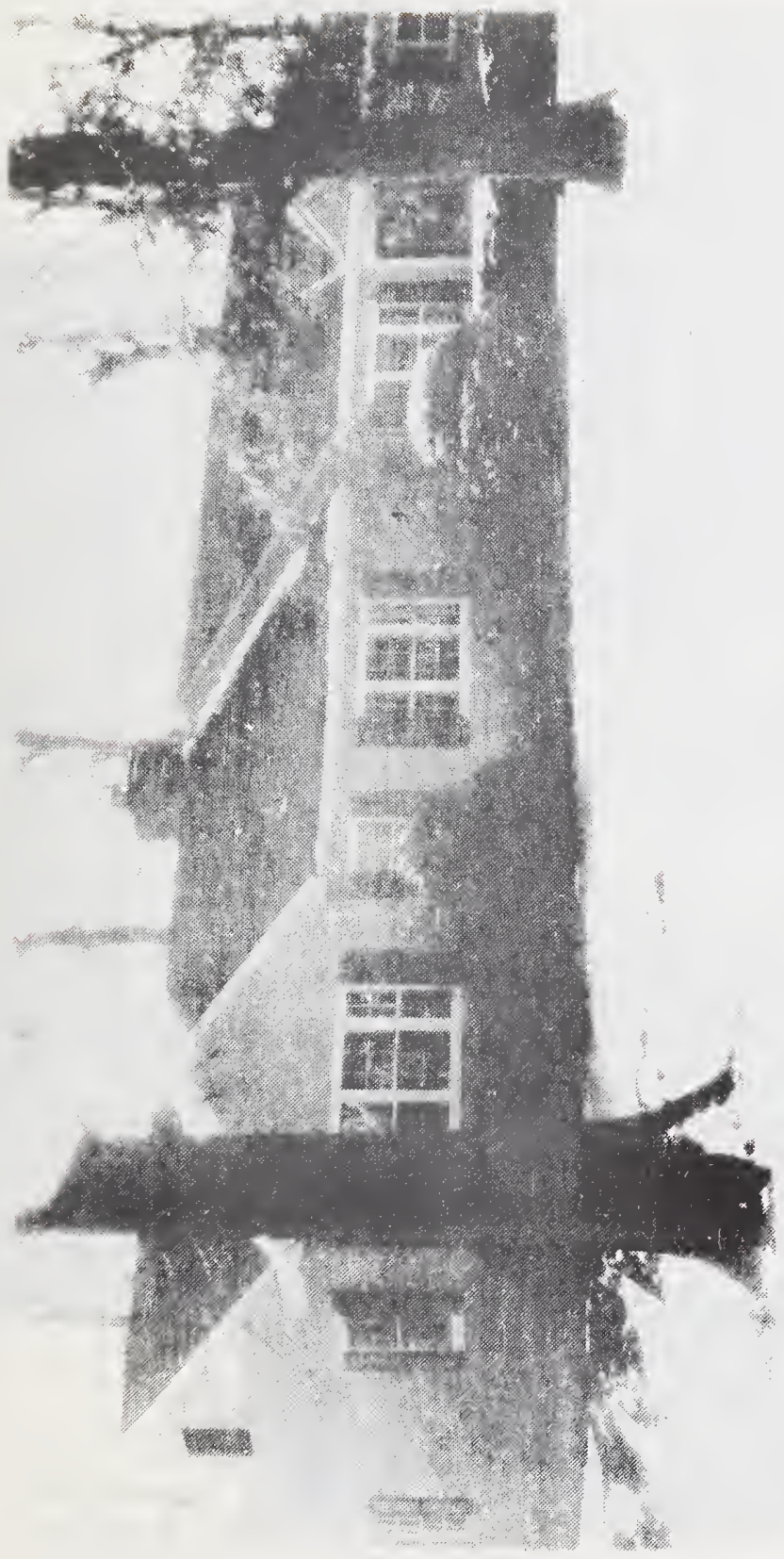

j

㟔

$\stackrel{\Xi}{L}$

岁

g

U

岁

क

4
-11
01

당 음

茂

$\begin{array}{ll}-4 & 0 \\ 0 & 0 \\ 3 & -1 \\ 0 & 0 \\ -1 & 0 \\ > & 0 \\ -1 & 0\end{array}$

尔

ì

崩

B-5 


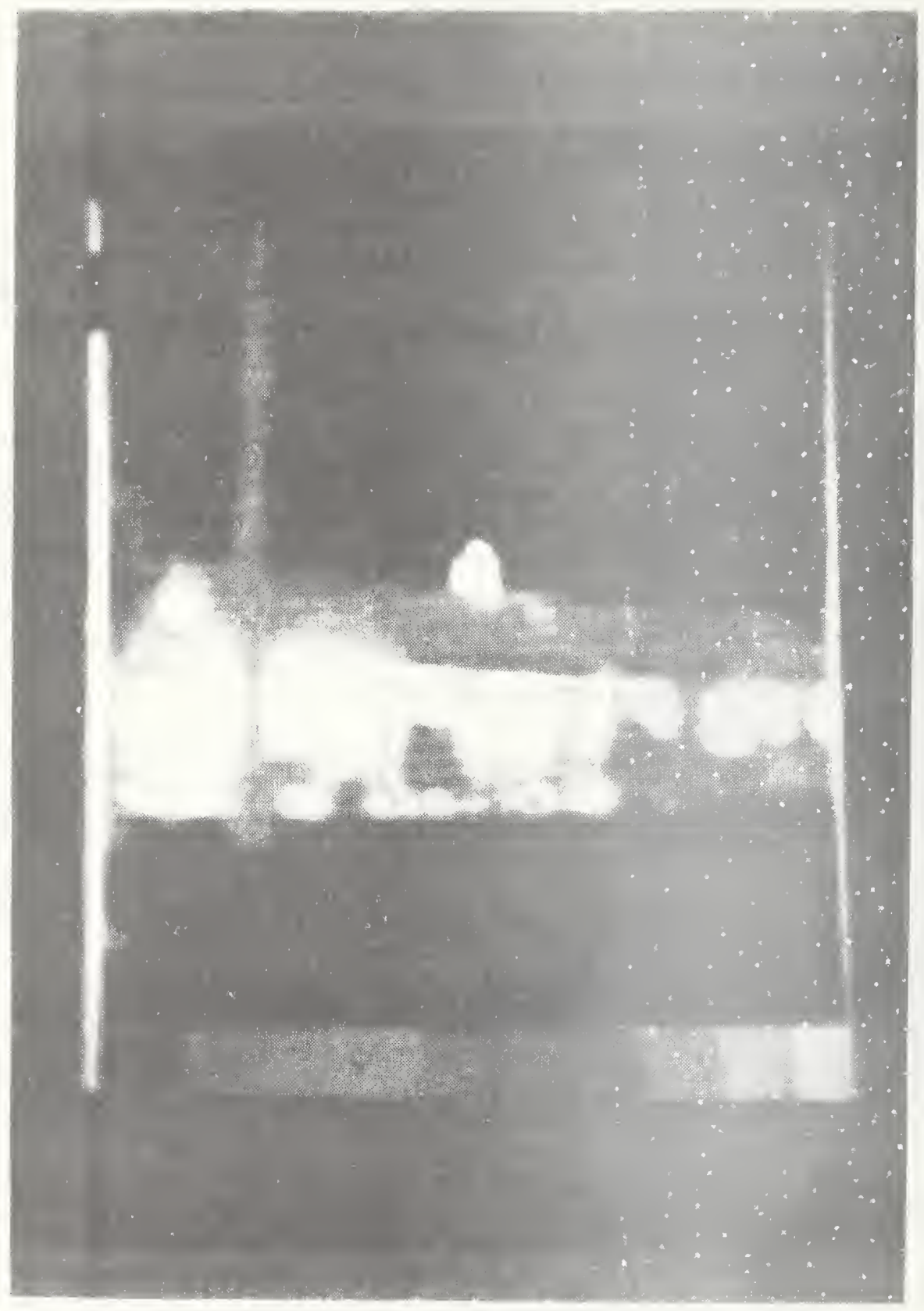

Figure B-2. Overall view of exterior surfaces of the test house.

(b) Thermogram before retrofit. 


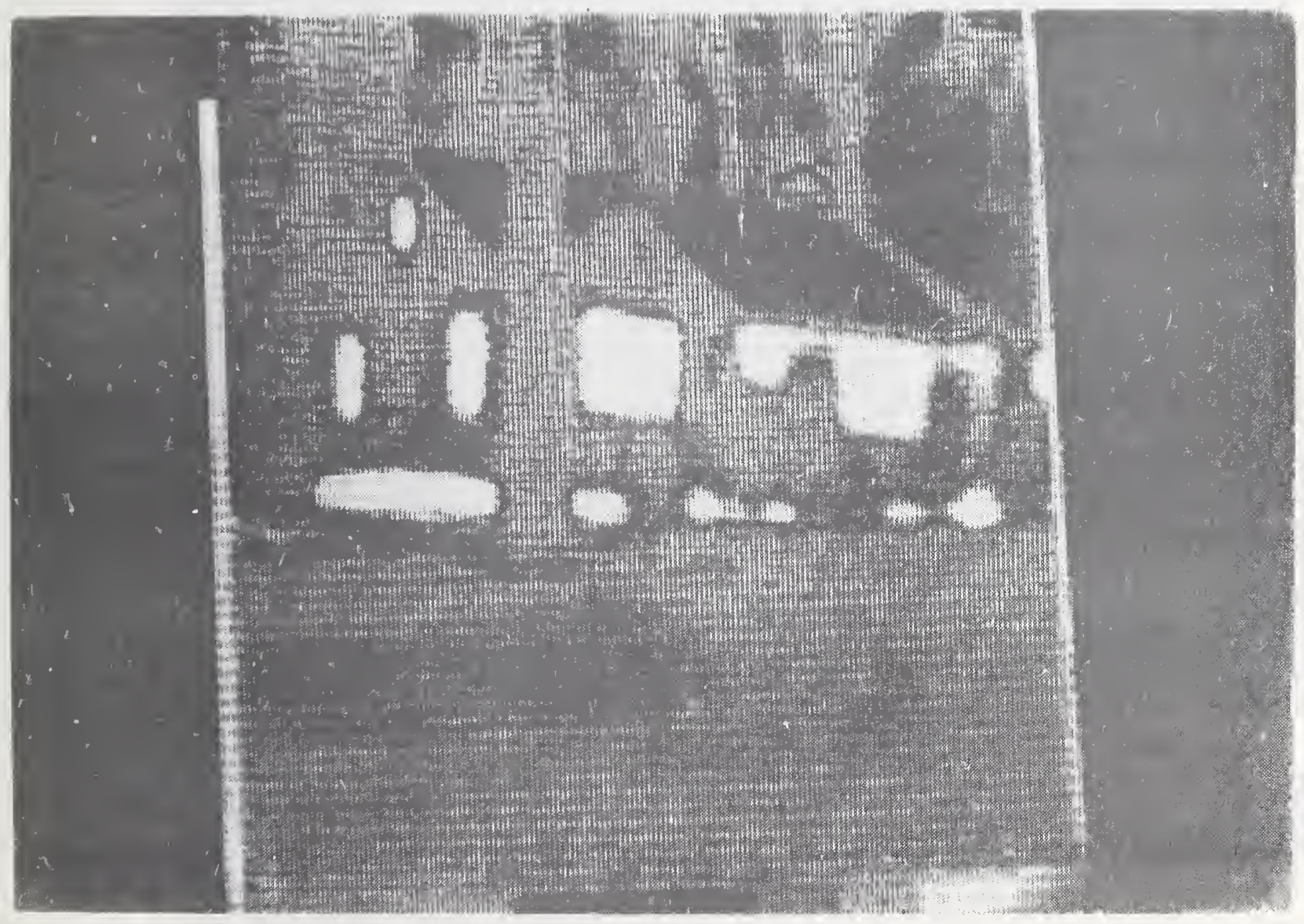

Figure B-2. Overall view of exterior surfaces of the test house. (c) Thermogram after retrofit. 


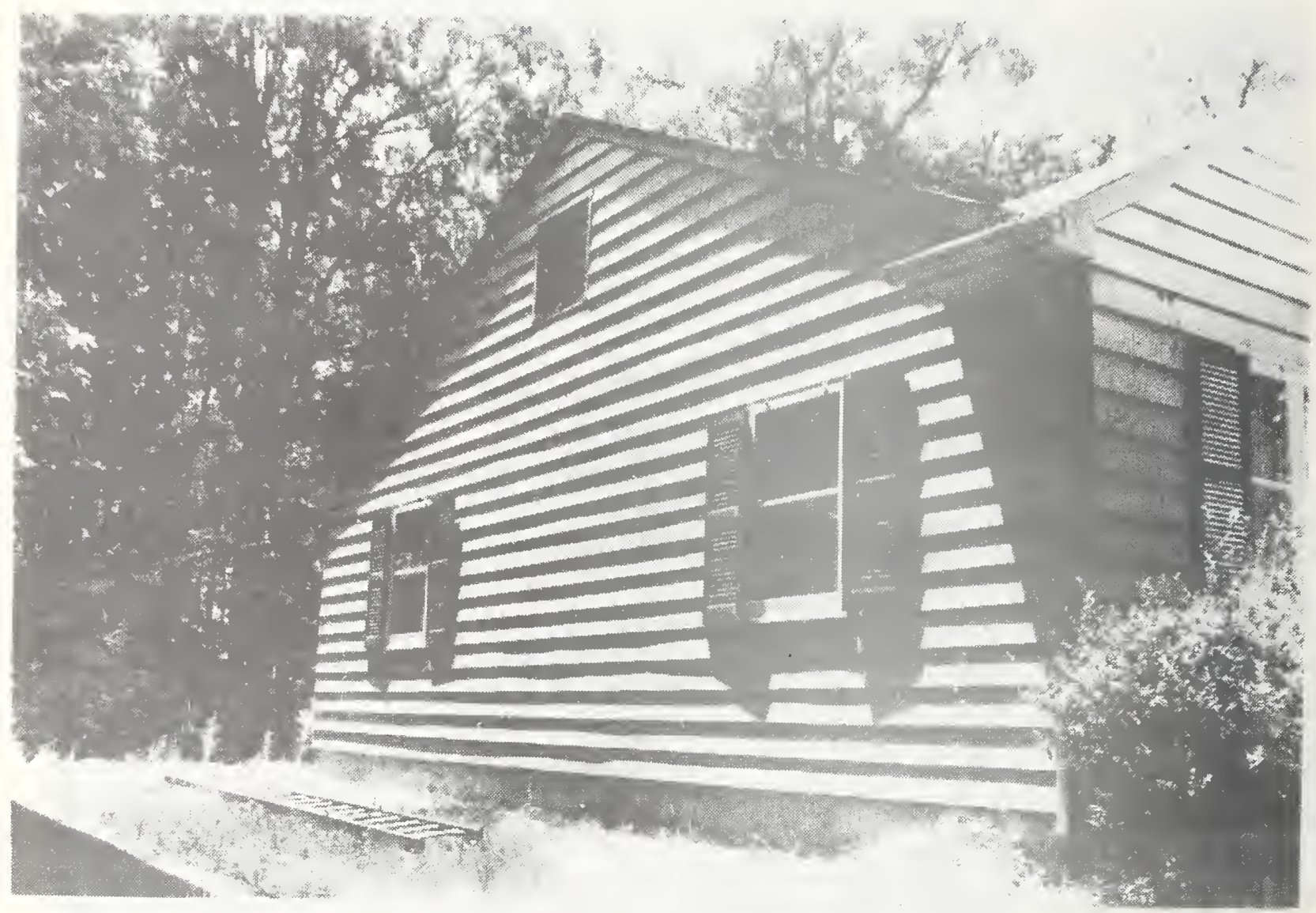

Figure B-3. East end of test house.

(a) Conventional photograph. 


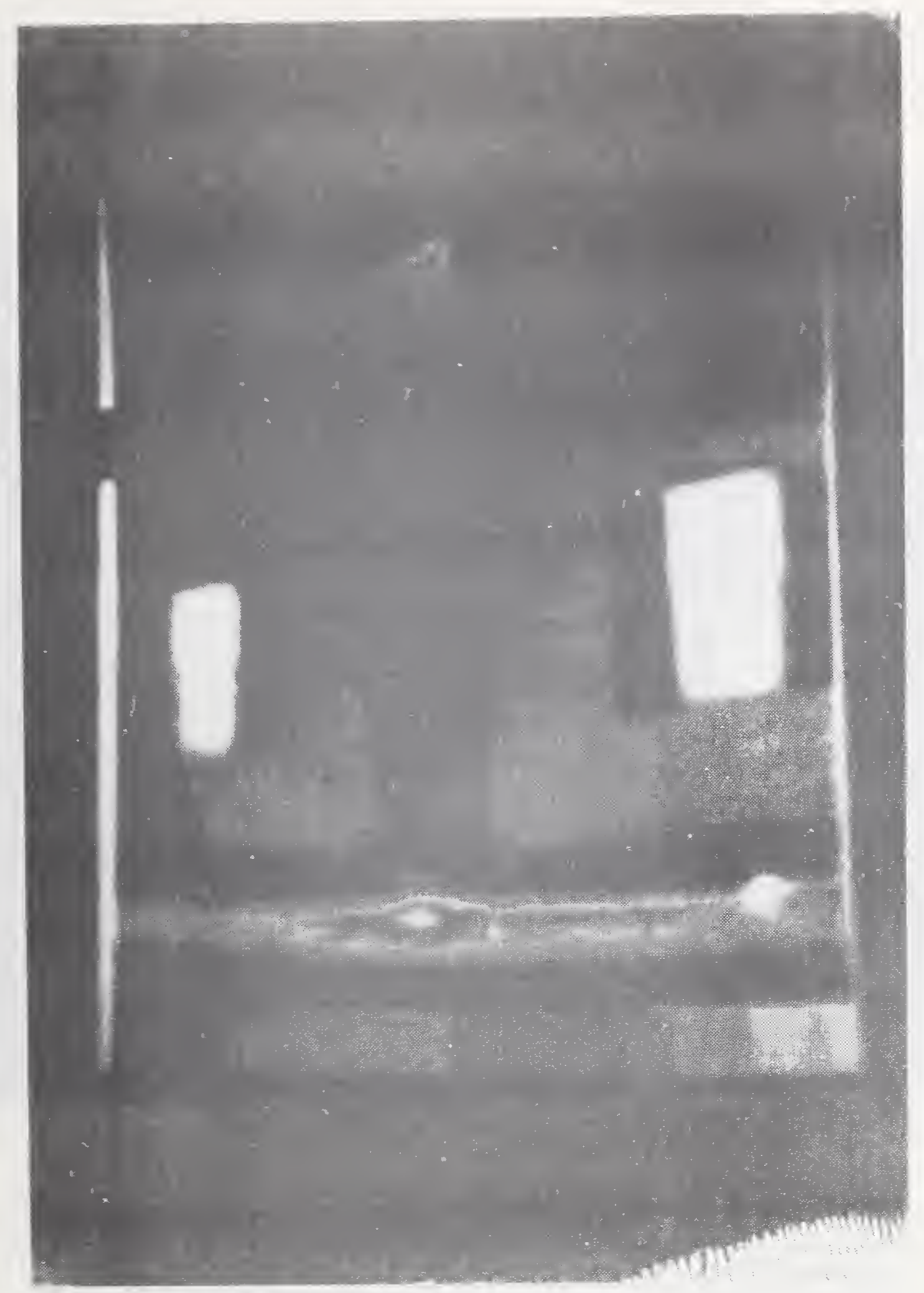

Figure B-3. East end of test house.

(b) Thermogram before retrofit. 


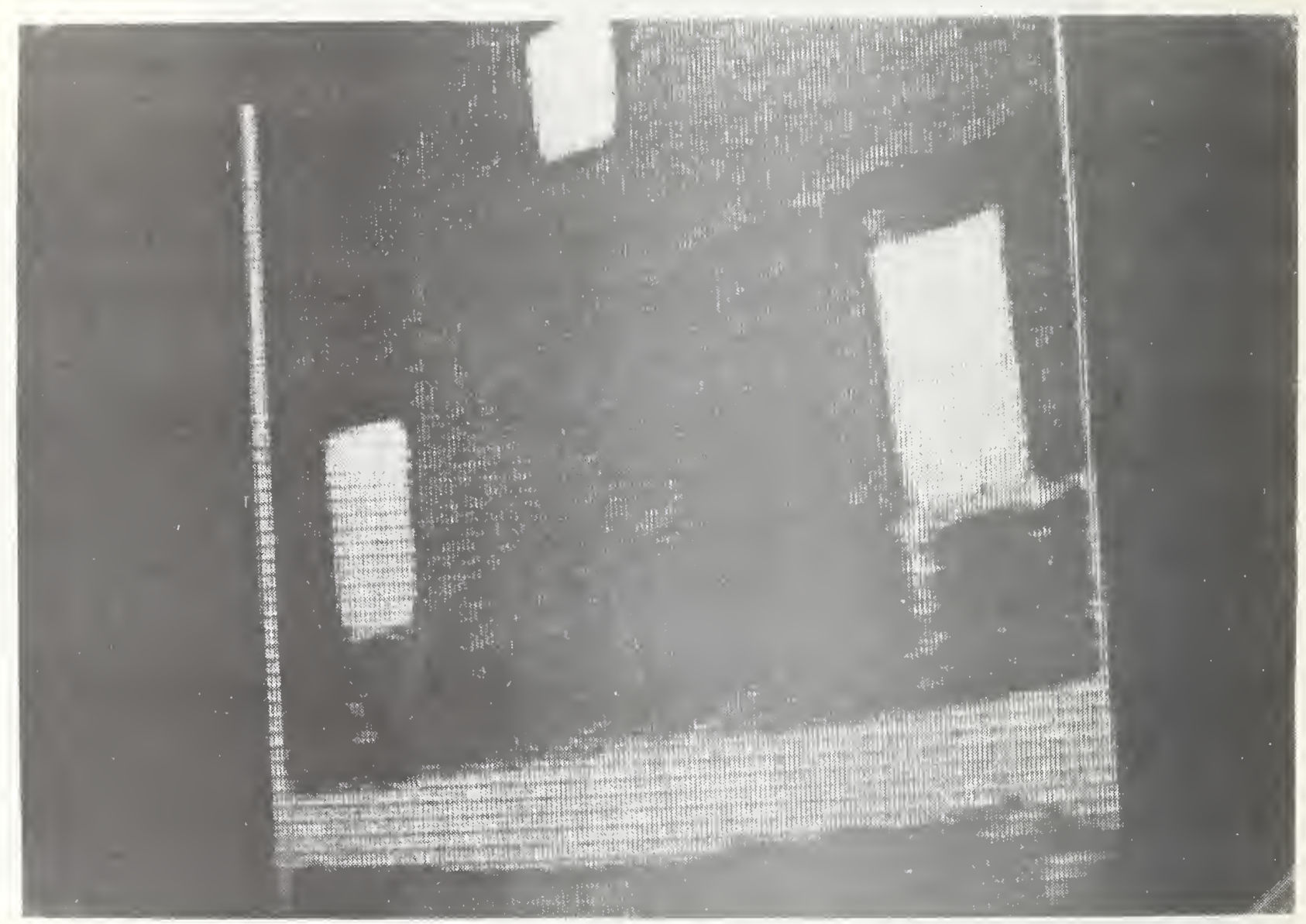

Figure B-3. East end of test house.

(c) Thermogram after retrofit. 
of approximately $40^{\circ} \mathrm{F}\left(22.2^{\circ} \mathrm{C}\right)$, the ability to see closets in thermograms of the exterior surfaces may be used as a qualitative indication to distinguish between insulated and uninsulated wood-frame cavity walls.

As a final comment on this pair of thermograms, the foundation wall of the post-retrofit thermogram appears saturated white. On the particular day that the post-retrofit thermographic survey was performed, the afternoon temperatures were comparatively warm, followed by significantly lower temperatures in the evening. It was hypothesized that the foundation wall apparently stored heat in the afternoon. It was believed that this stored heat was released in the evening, as shown in the postretrofit thermogram. It should be pointed out that, when a part of a thermal picture (such as the windows of figure B-3) is displayed in white or black, its temperature level may not be determined, since the extent of which the temperature level is into saturation is not known.

Figures $B-4 a, b$, and $c$ are a thermographic survey of the door leading from the dining room to the screened-in back porch. These pictures were taken from inside the dining room. The black region (cold spots) in the pre-retrofit thermogram (figure $B-4 b$ ) is due to an air leak under the door. The sensitivity (total temperature range display in the thermal picture) is the same for both the pre- and post-retrofit thermograms. Observed differences may therefore be regarded as being due to the differences in surface temperatures. Note that in the postretrofit thermogram (figure $B-4 c$ ) the application of improved weatherstripping at the bottom of the door is seen to be effective in eliminating the previously observed air leak.

Figures B-5a, b, and c are a thermographic survey of the interface between the ceiling and the wall above the large picture window of the living room taken before and after the retrofit. A dark line has been superimposed on these photographs to assist in identifying the interface between the wall and the ceiling. In the pre-retrofit thermogram (figure B-5b) a cold black region can be seen in the ceiling surface where it intersects the wall. An inspection of this location from the attic showed that the insulation was in place. It was believed that cold air leaking through the eaves of the attic was able to penetrate through the ends of glass-fiber blanket insulation and cause the cold spot. Note that in the post-retrofit thermogram (figure B-5c) 6 inches $(15.24 \mathrm{~cm})$ of loose-fill cellulose over the top of the existing $3-1 / 2$ inch $(8.89 \mathrm{~cm})$ glass-fiber blanket was successful in eliminating the cold spot along the ceiling.

Figures $\mathrm{B}-6 \mathrm{a}, \mathrm{b}$, and $\mathrm{c}$ are a thermographic survey of an upper corner of the northeast bedroom. A dark line has been superimposed on these photographs to assist in identifying the interface of various surfaces of the room. The red and pink regions (region 1) shown in the pre-retrofit thermogram (figure B-6b) are cold spots on the ceiling due to compressed glass-fiber ceiling insulation. When blanket insulation is compressed, it loses some of its insulating properties and allows

$$
\text { B-11 }
$$




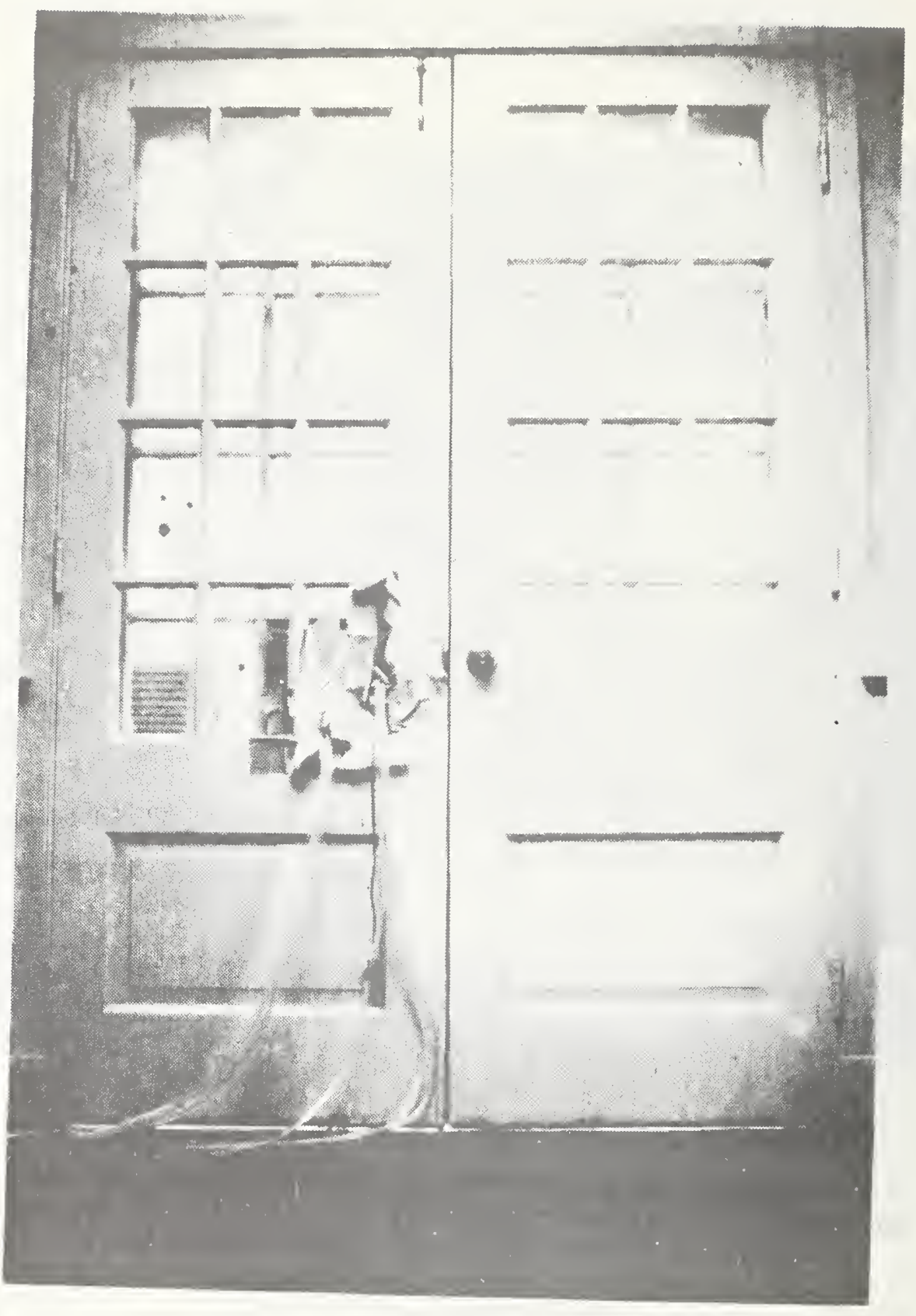

Figure B-4. Interior surface of dining room door.

(a) Conventional photograph. 


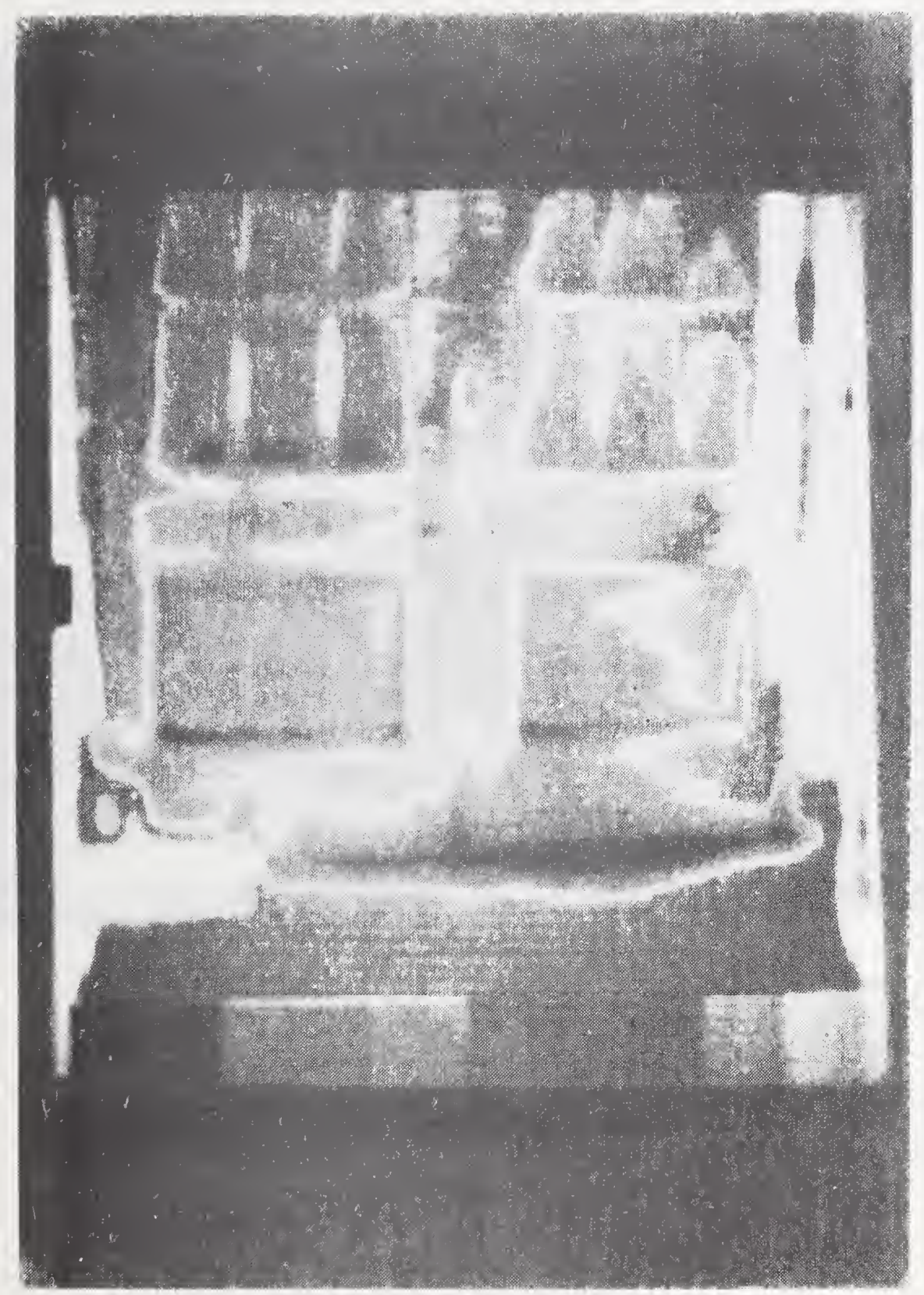

Figure B-4. Interior surface of dining room door.

(b) Thernogram after retrofit. 


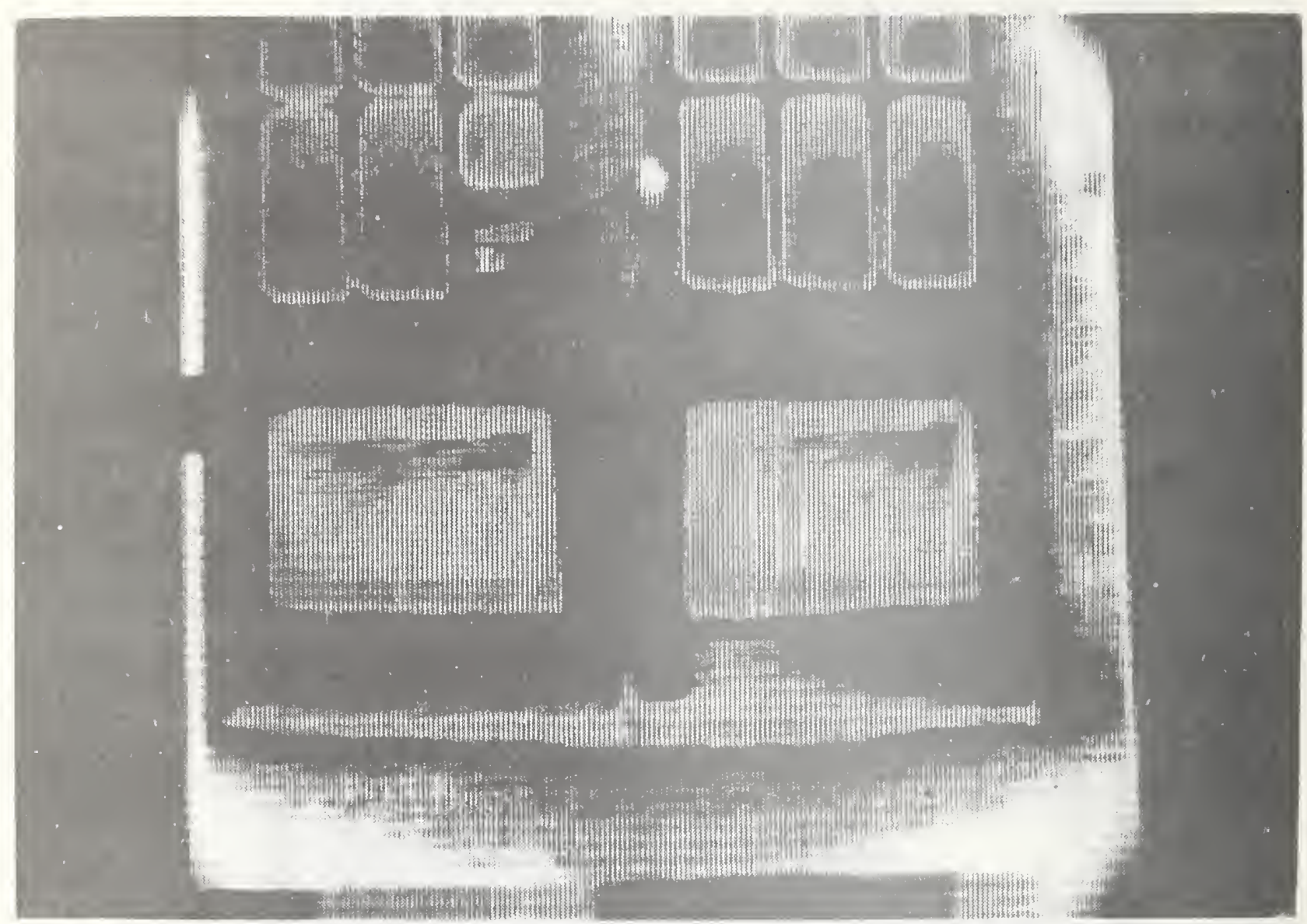

Figure B-4. Interior surface of dining room door.

(c) Thermogram after retrofit. 


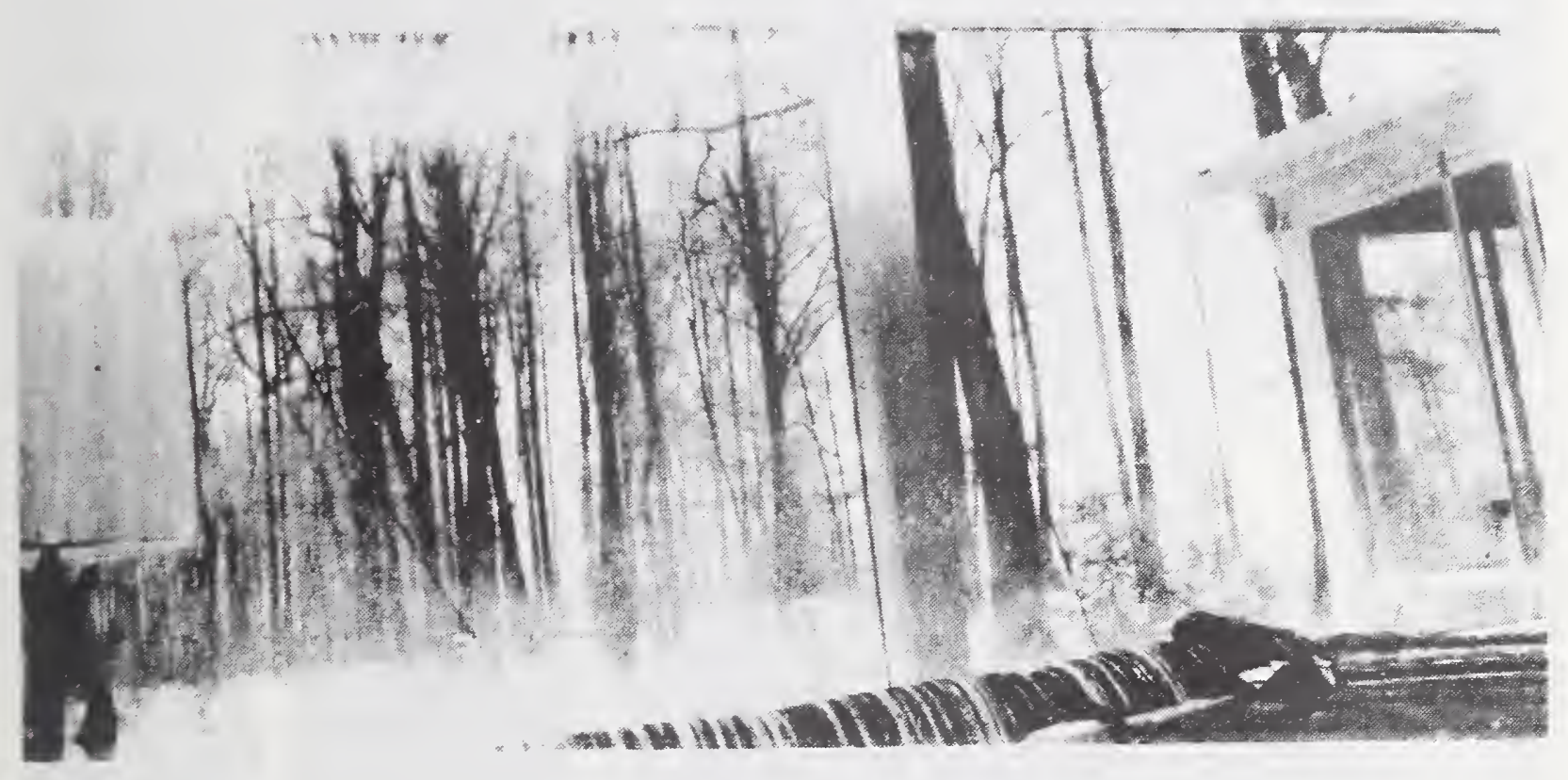

Figure B-5. Interior view of ceiling-wall interface above
the bay window in living room.

(a) Conventional photograph. 


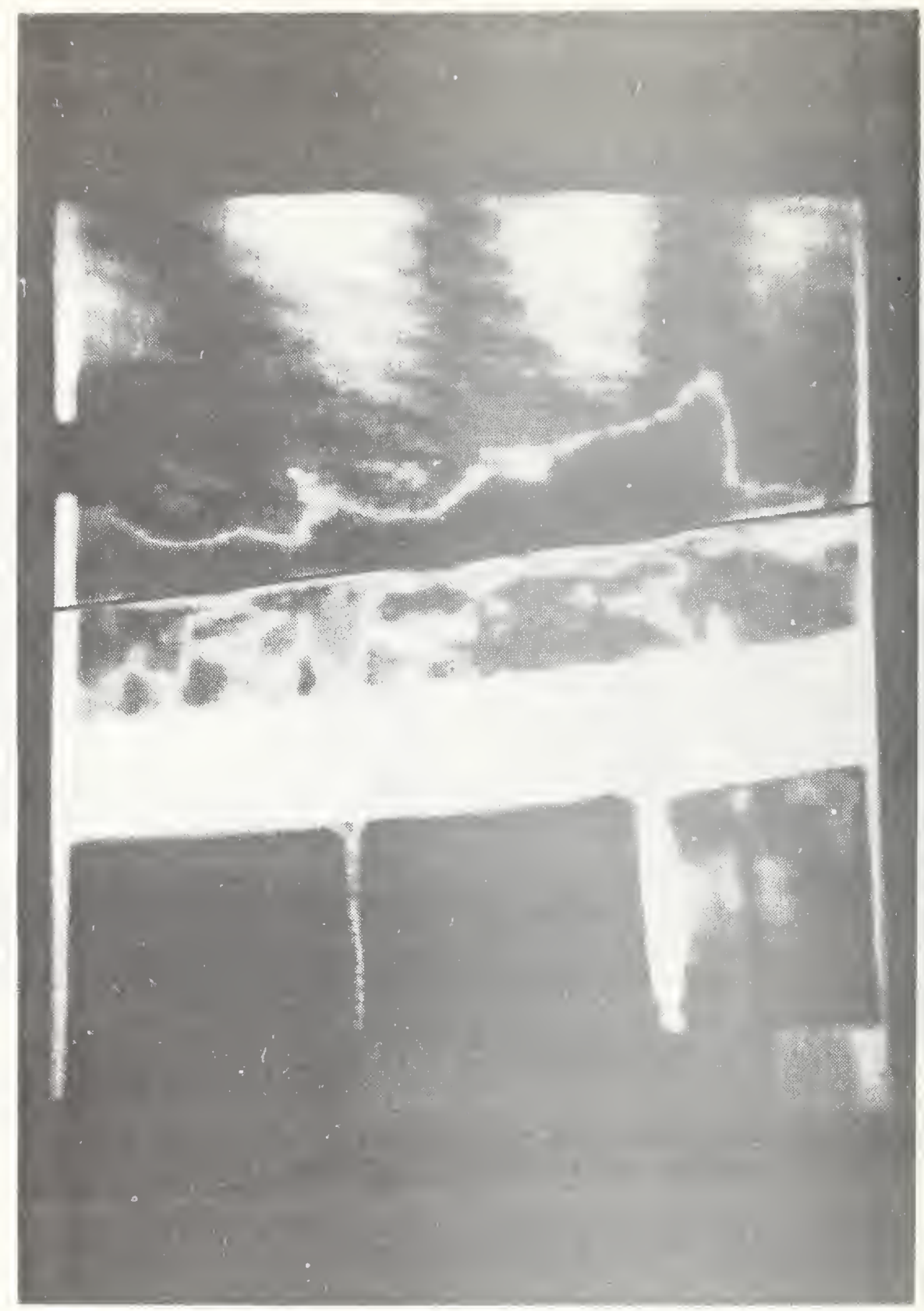

Figure B-5. Interior view of ceiling-wall interface above the bay window in living room.

(b) Thermogram before retrofit. 

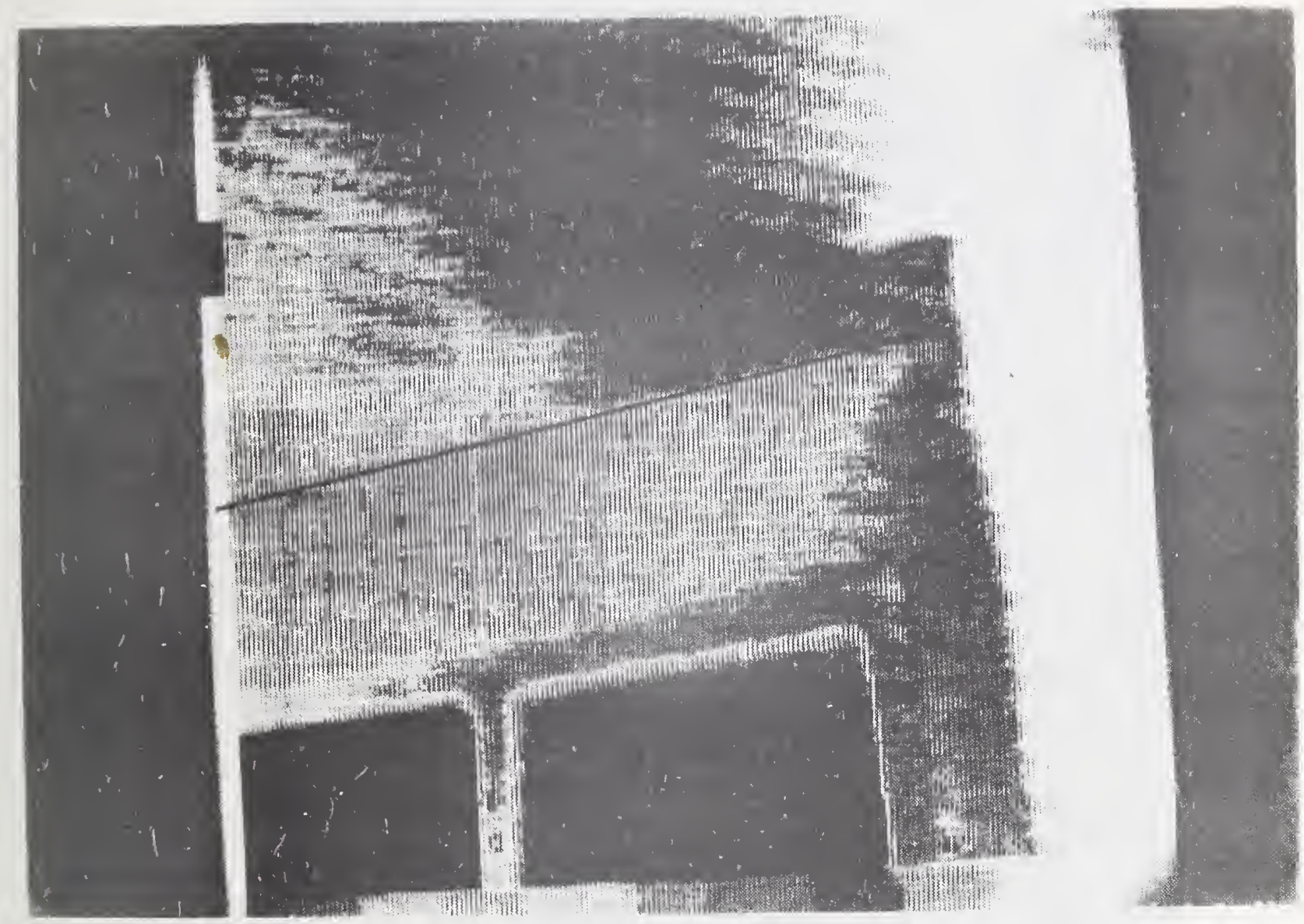
Figure B-5. Interior view of ceiling-wall interface above
the bay window in living room.

(c) Thermogram after retrofit. 


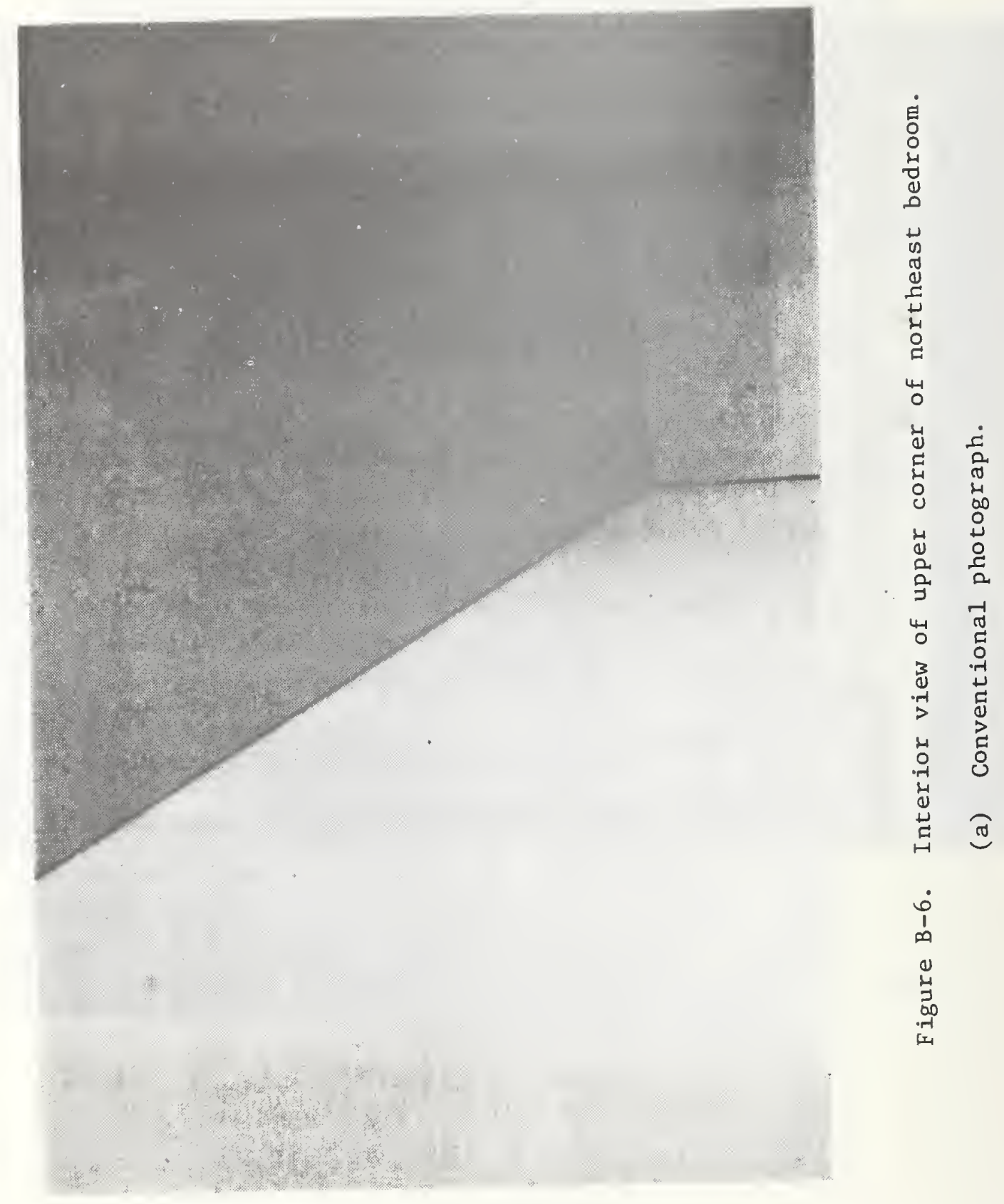




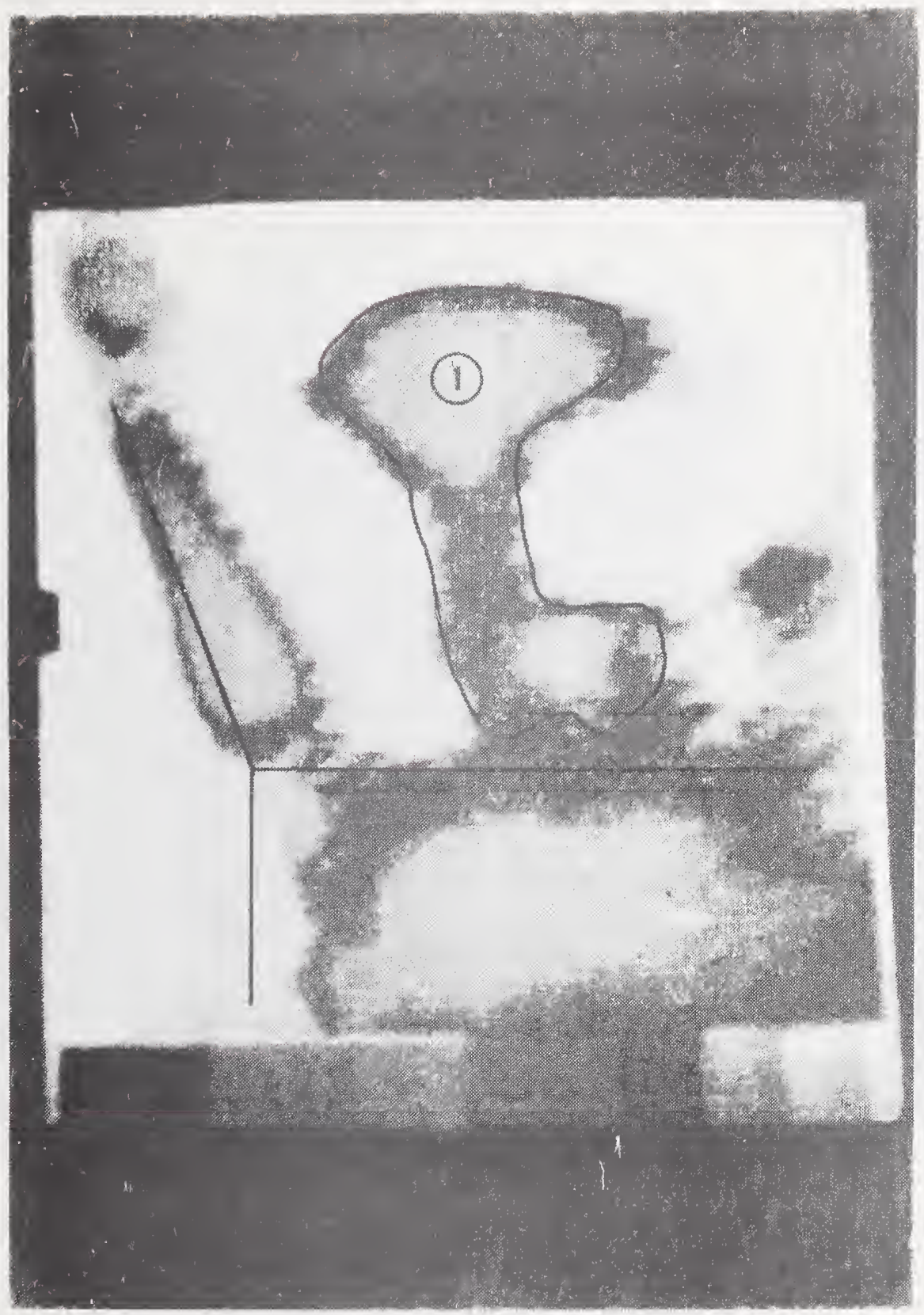

Figure B-6. Interior view of upper corner of northeast bedroom.

(b) Thermogram before retrofit. 


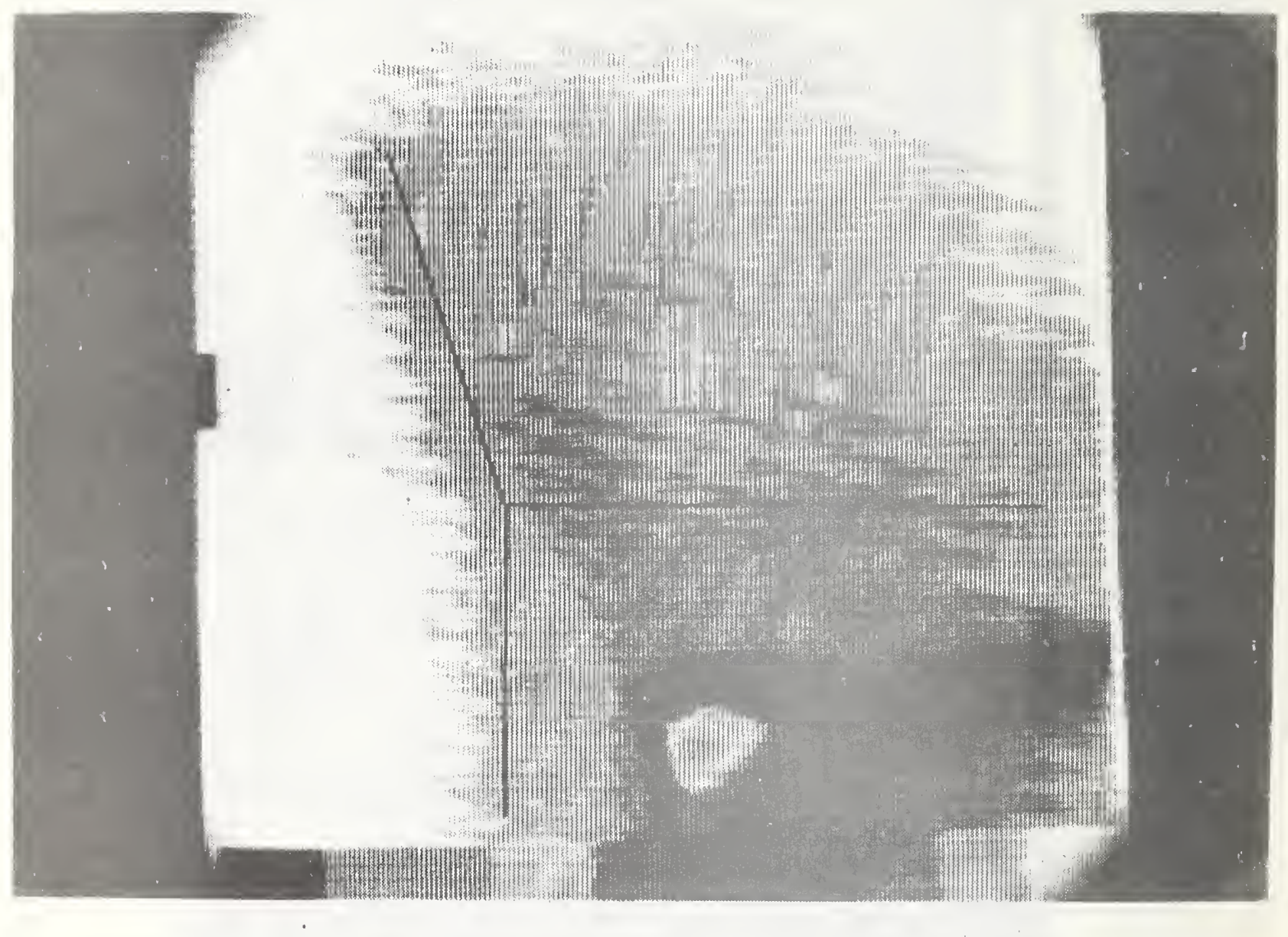

Figure B-6. Interior view of upper corner of northeast bedroom.

(c) Thermogram after retrofit. 
more heat loss. The post-retrofit thermogram (figure B-6c) indicates that the installation of loose-fill cellulose over the top of the existing glass-fiber blankets has eliminated the cold spots on the ceiling.

4. Winter Thermographic Survey of the Extermior Walls After the Retrofit

The following post-retrofit thermographic survey was taken on March 3, 1975, during the evening when the inside-to-outside temperature difference was $44^{\circ} \mathrm{F}\left(24.4^{\circ} \mathrm{C}\right)$.

Figure B-7 is a thermogram of the U-F wall section after the retrofit. The blue area above the window (region 1) is a cold spot on the inside wall due to an air space between a regular stud and a jack stud. A jack stud is an extra stud inserted in a wall to support a window frame. Notice the maroon-shaded area (region 2) depicting a cold spot, probably where U-F foam of two regions did not completely flow together. Also, note that the region where the heat-flow measuring station was placed (region 3) appears to be free of any void spaces. However, when the inside wall surface was removed at this location, a one-inch fissure was discovered at this location which caused the measured heat-loss rates to be greater than the predicted values (as indicated in section 8.3 of the report).

Figure B-8 is a thermogram of one section of the inside surface of the south wall. The dark spot is a cold spot on the inside surface due to a void space in the wall cavity which is not filled with cellulose insulating material. The diagonal member shown in the thermogram is a wind brace. The hole through which insulation was blown was drilled below the wind brace. When cellulose insulation was blown into the wall cavity, the wind brace prevented the space from being filled with insulating material.

Figure B-9 is a thermogram of the inside surface of the east wall of the southeast bedroom. Again, the diagonal member shown in the thermal picture is a wind brace. In this case, void spaces are located below the wind brace. The holes for blowing insulation into these cavity spaces were drilled below the wind brace. Insufficient cellulose insulating material was blown into these spaces, as indicated by the void spaces.

Figure B-10 is a thermogram of the inside surface of a glass-fiber wall section. Again insufficient glass fiber material was installed as indicated by the void spaces.

In the thermograms of inside surfaces shown in figures B- 8 through B-10, it can be seen that wall studs can be distinguished in the thermal picture. In the pre-retrofit thermographic survey, it was difficult to see wall studs for inside-to-outside temperature differences at approximately $40^{\circ} \mathrm{F}\left(22.7^{\circ} \mathrm{C}\right)$. Thus, the ability to see wall studs in thermograms of inside wall surfaces of a wood-frame house may be used to distinguish between insulated and uninsulated wood-frame cavity walls. 


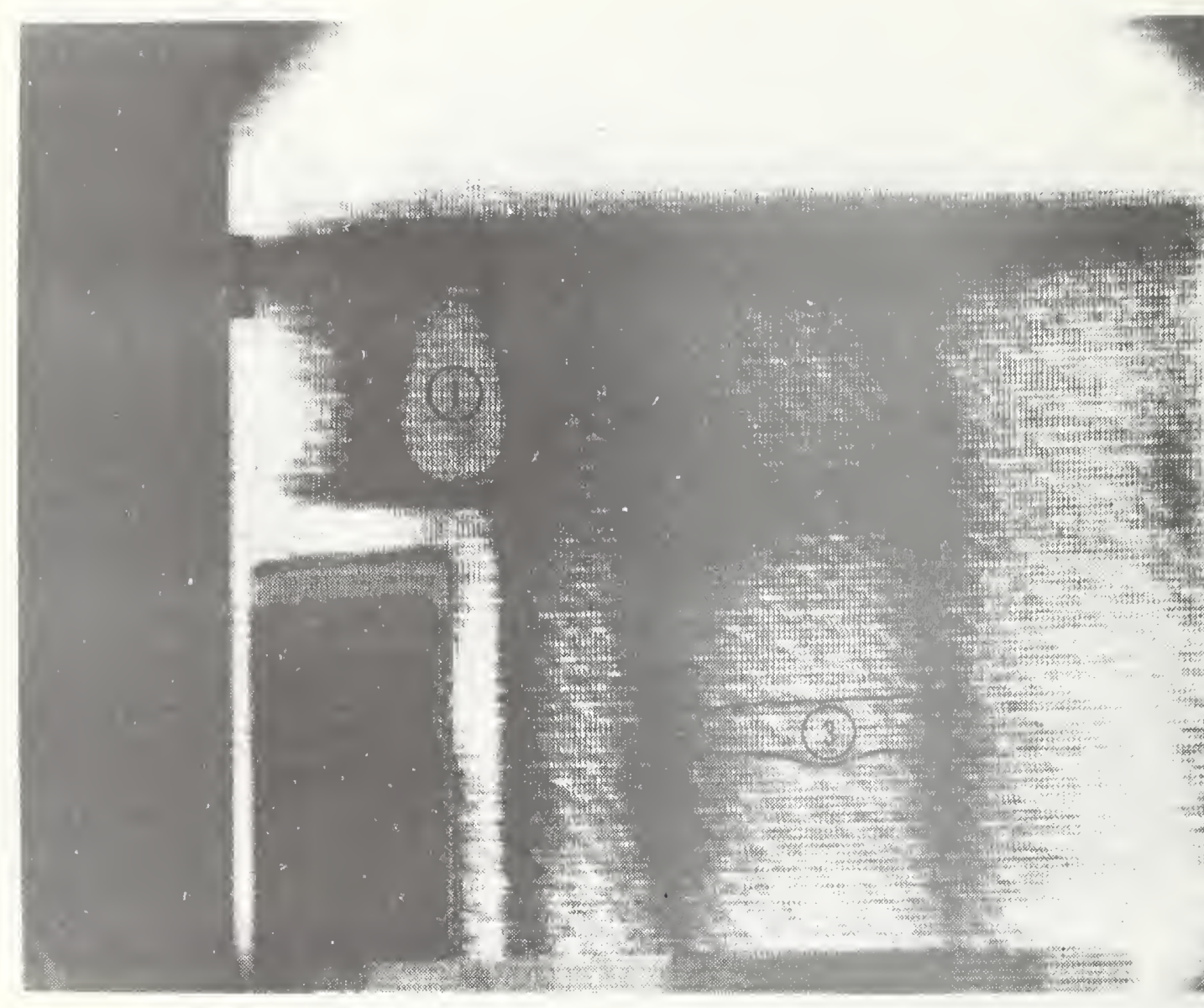

Figure B-7. Winter thermogram of inside surface of U-F wall section. 


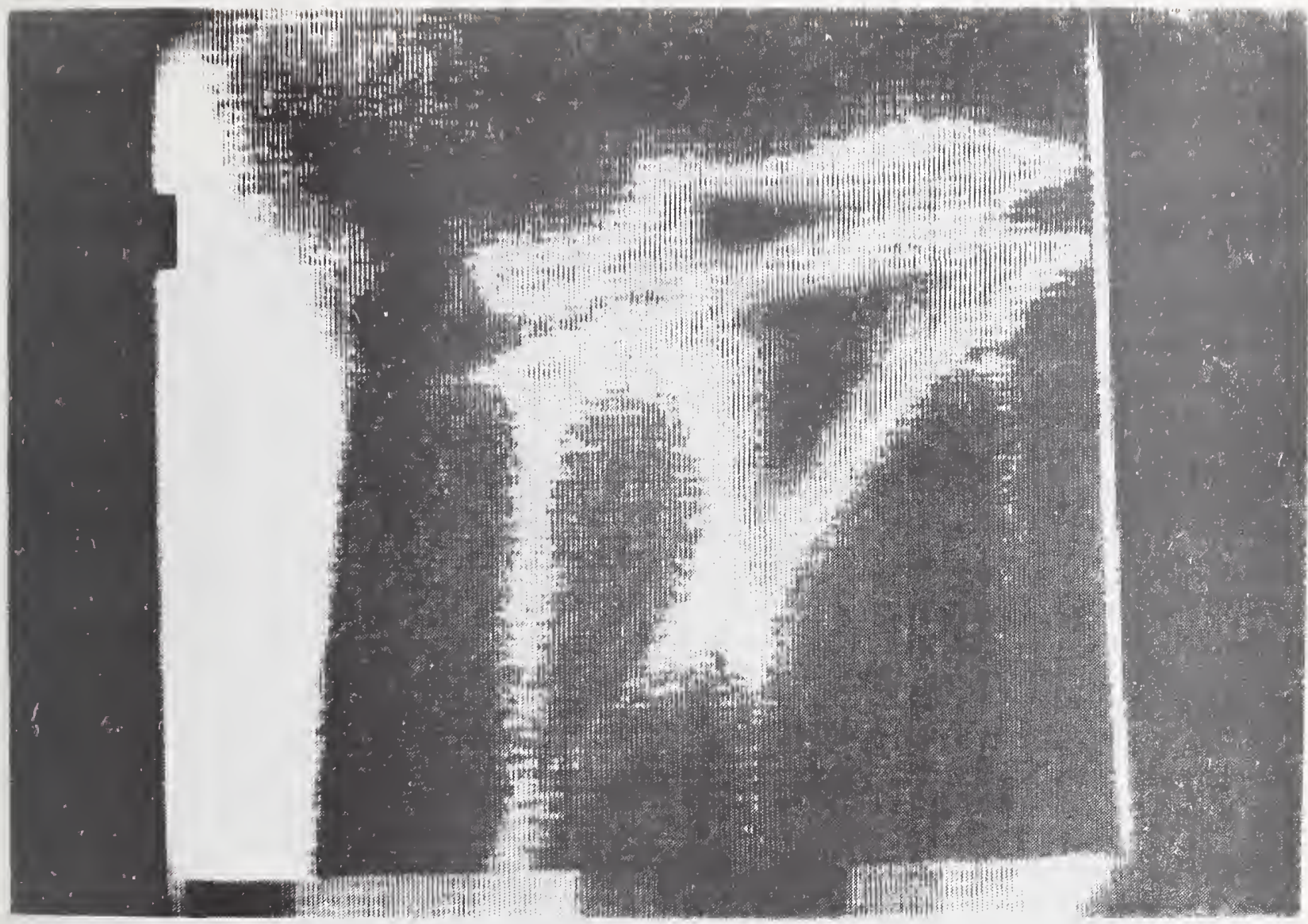

Figure B-8. Winter thermogram of inside surface of cellulose wal1 section in dining room. 


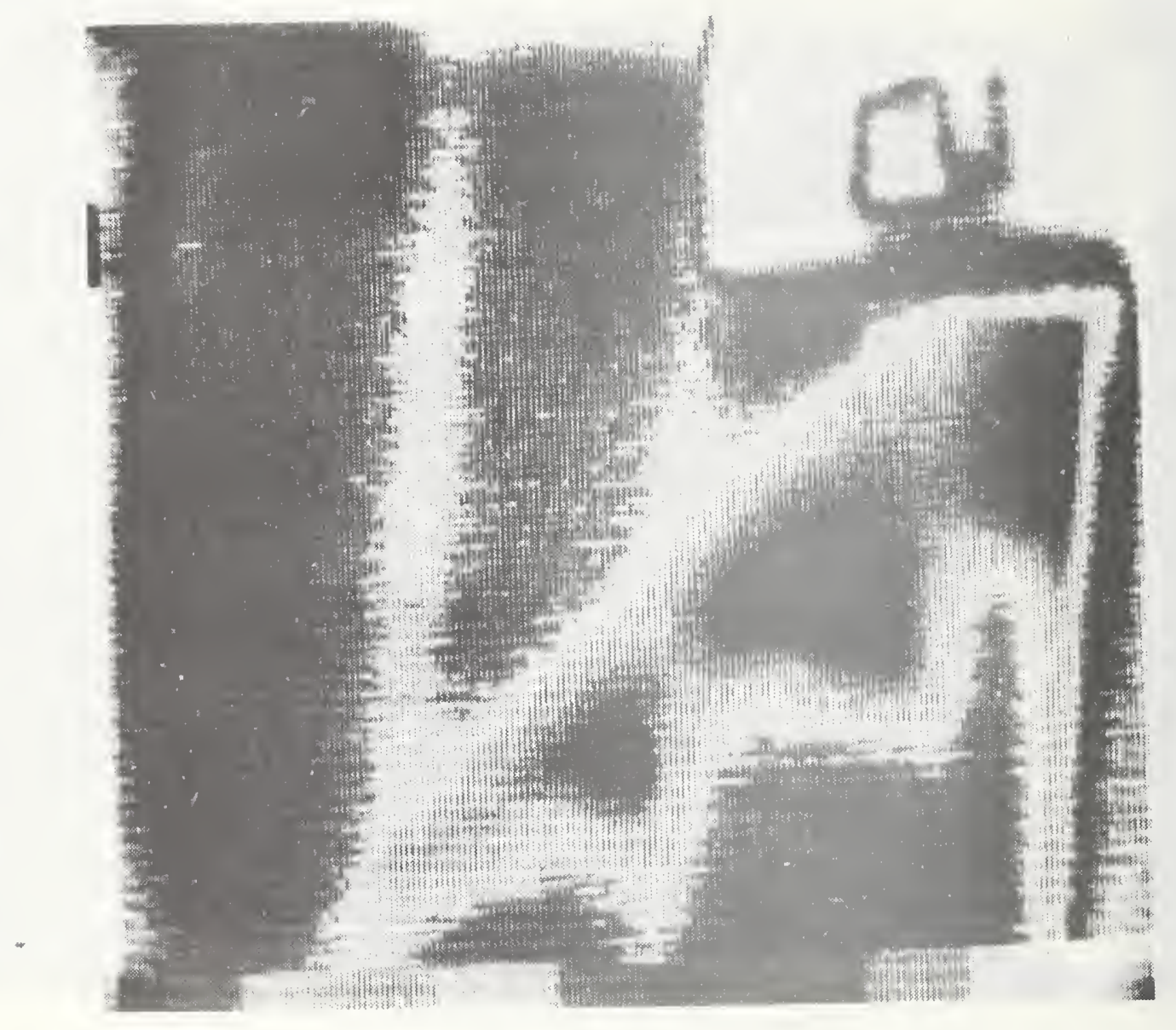

Figure B-9. Winter thermogram of inside surface of cellulose wall section in southeast bedroom. 


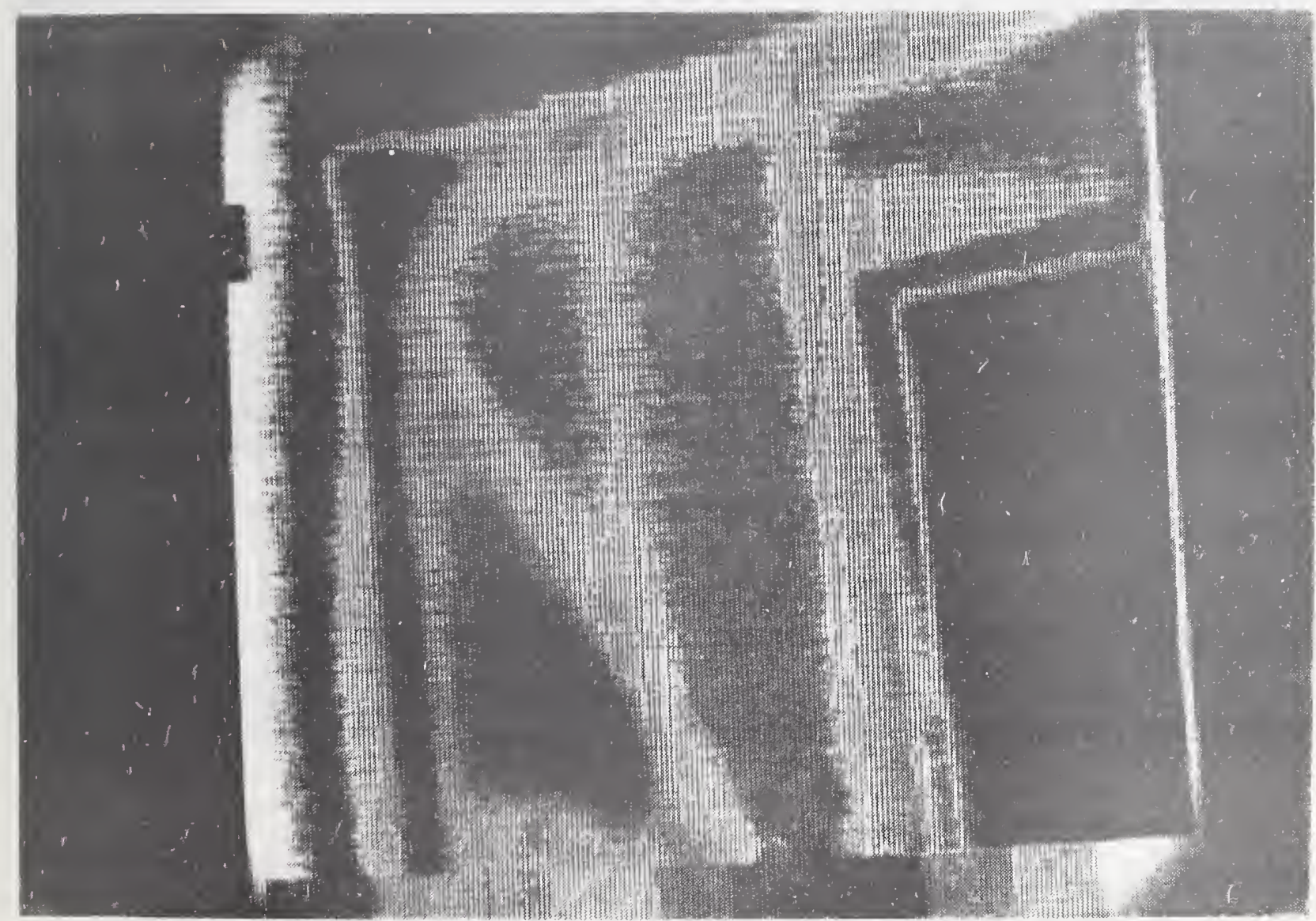

Figure B-10. Winter thermogram of inside surface of glass-fiber wall section in northeast bedroom. 


\section{Summer Thermographic Survey of the Exterior Walls \\ After the Retrofit}

Summer thermographic pictures were taken at the same location where winter heat leaks had been previously identified (see figures B-7 through B-10) to determine if uninsulated regions (void spaces) could still be detected during the summer when inside-to-outside temperature differences were much smaller. A summer thermographic survey was performed after the retrofit on September 5, 1975. For these measurements the indoor temperature was approximately $69^{\circ} \mathrm{F}\left(20.6^{\circ} \mathrm{C}\right)$, whereas the outdoor temperature ranged between $74^{\circ} \mathrm{F}\left(23.3^{\circ} \mathrm{C}\right)$ and $75^{\circ} \mathrm{F}\left(23.9^{\circ} \mathrm{C}\right)$. Thus, the inside-to-outside temperature difference was about $6^{\circ} \mathrm{F}\left(3.3^{\circ} \mathrm{C}\right)$.

Figures $B-11$ and $B-12$ are summer thermograms of cellulose and glass-fiber wall sections shown in figures $B-9$ and $B-10$, respectively, Notice that the uninsulated void spaces may still be identified. Thermograms of the wall sections shown in figures B-7 and B- 8 were not successful in identifying the void spaces seen during the winter. It is therefore concluded that summer thermographic surveys, performed when the insideto-outside temperature differences are small, may be only partially successful in identifying uninsulated void spaces in retrofitted walls.

\section{Conclusions}

Thermographic surveys were performed during the winters before and after the house was retrofitted. Thermography was shown to be an effective technique to distinquish between insulated and uninsulated wood-frame cavity walls. For instance, the following characteristics observed in the winter, when there exists at least a $40^{\circ} \mathrm{F}\left(17^{\circ} \mathrm{C}\right)$ inside-to-outside temperature difference, indicate that exterior woodframe cavity walls of a house are uninsulated:

- Studs do not stand out in contrast with respect to the insulated portion of the wall when viewed from the inside:

- Exterior walls stand out in contrast with the surroundings when viewed from the outside.

- Closets next to exterior walls appear as cold spots when viewed from the outside.

The absence of the foregoing characteristics indicates that wood-frame cavity walls are insulated.

Summer thermographic surveys, performed when the inside-to-outside temperature difference was small, were only partially successful in identifying uninsulated void spaces in insulated wood-frame cavity walls. 


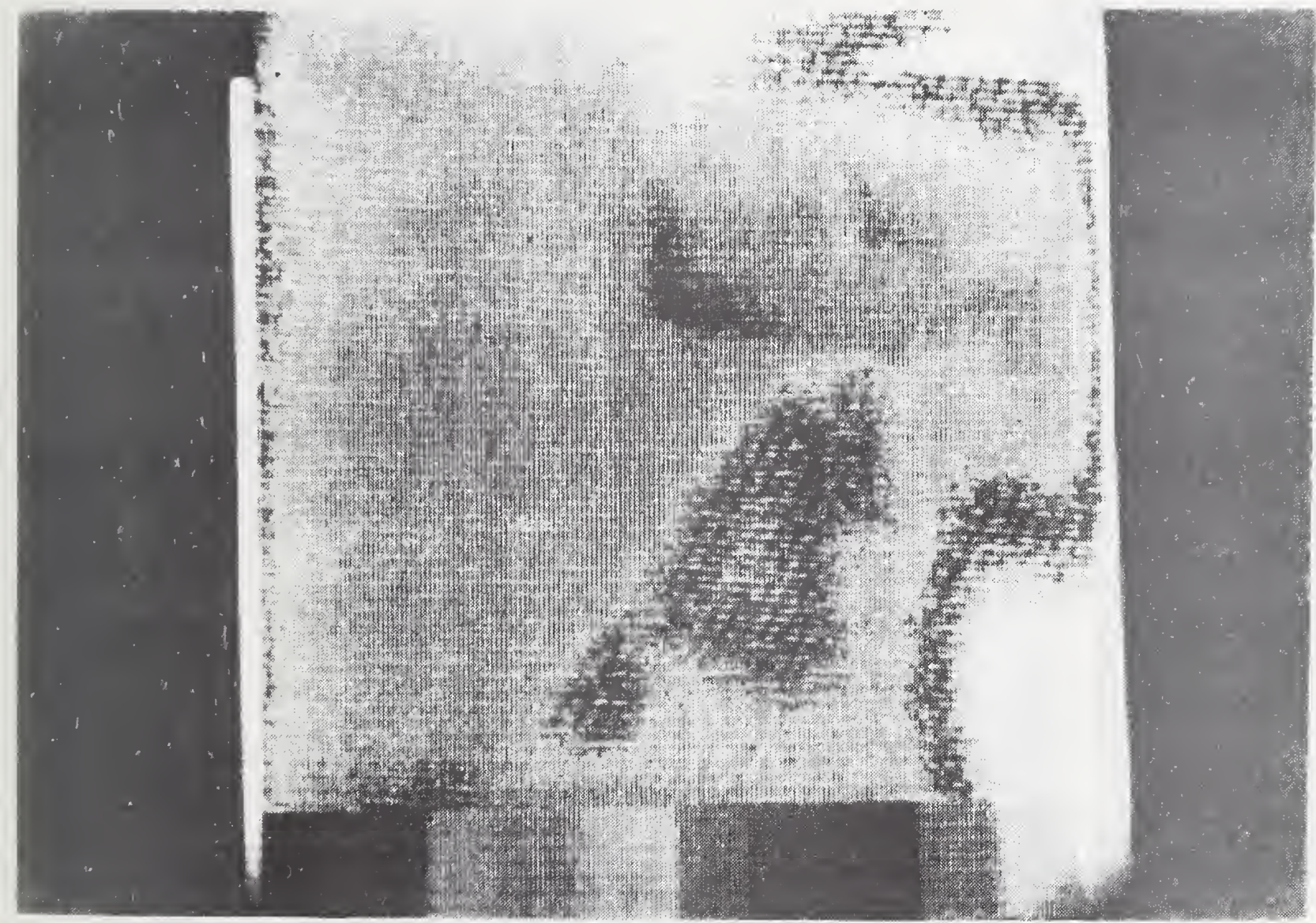

Figure B-11. Summer thermogram of the inside surface of the cellulose wall section in southeast bedroom. 


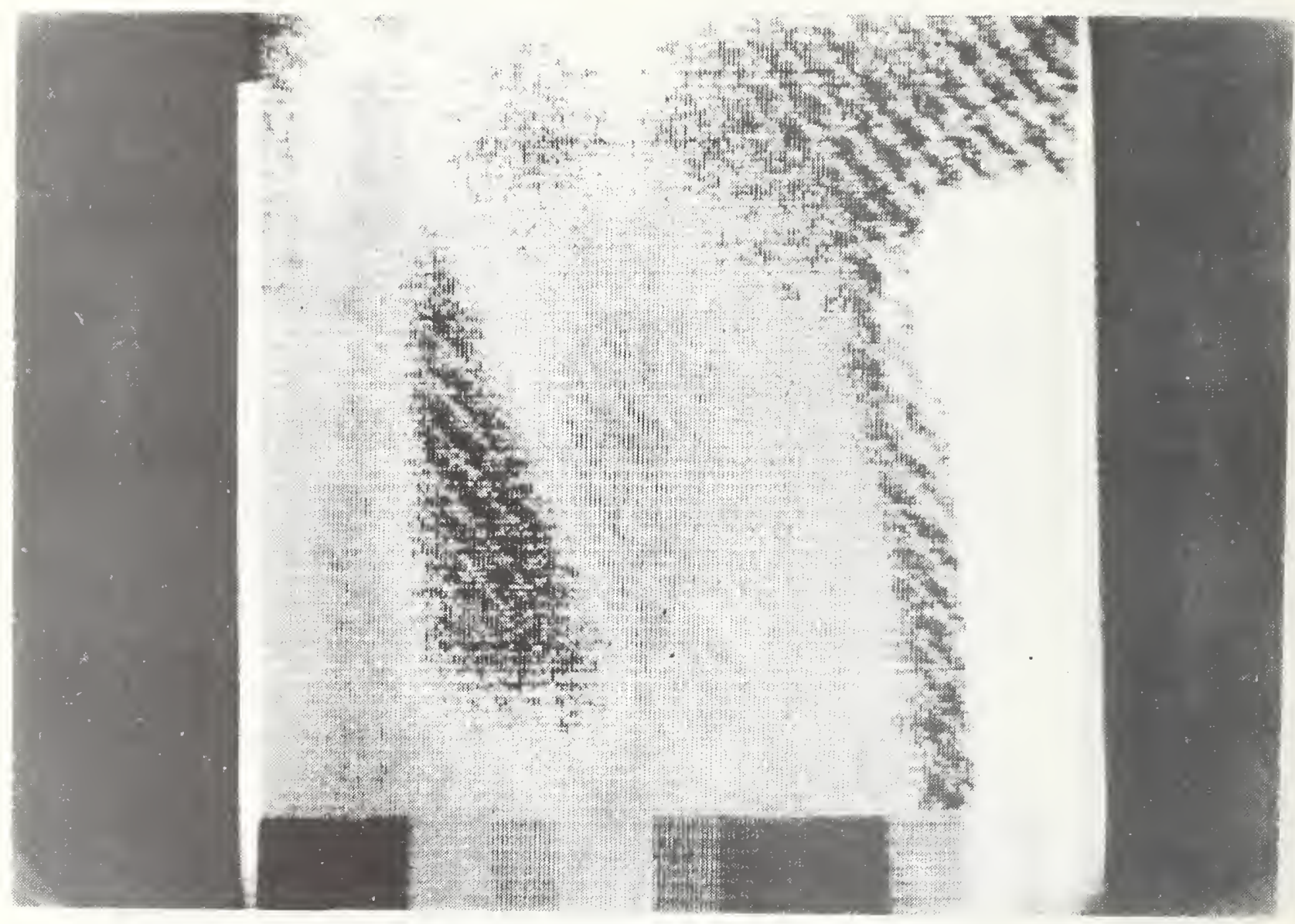

Figure B-12. Summer thermogram of the inside surface of the glass-fiber wall section in northeast bedroom. 
Appendix C

Location of Air-Leakage Paths in a Residence

Using Pyrotechnic Smoke

\section{Introduction}

Specific air-leakage paths were identified in the test house using white pyrotechnic smoke. The experimental procedure was to fill a portion of the test house with white pyrotechnic smoke, and subsequently pressurize the interior of the house. The air-leakage paths were then identified through visual observations and photographed.

\section{Instrumentation and Experimental Procedure}

White pyrotechnic smoke was released in each room of the test house using either the drum-type distributor (figure C-1) or the combination fan and metal trash basket (figure C-2).

In the case of the drum-type smoke distributor, two pyrotechnic smoke generators were ignited and placed inside the cylindrical drum. The operation of the electrically-driven blower mounted at the base of the cylindrical container caused smoke to effuse through holes at the top periphery of the drum. For the other smoke distribution system, two smoke generators were ignited and placed inside metal trash baskets. The fan blew air across the top of the container causing the smoke to mix with the indoor air.

After the smoke had filled a portion of the interior of the test house, the inside of the house was pressurized using a 1/2-horsepower (373 W) centrifugal blower connnected to a sealed window panel with a 12 -inch $(30.48 \mathrm{~cm})$ diameter flexible hose. A photograph of the centrifugal blower and flexible hose connection to the window is shown in $\mathrm{f}$ igure $\mathrm{C}-3$.

The inside-to-outside pressure difference was measured with a Hook gage. The air-delivery rate of the centrifugal blower and the wind speed were measured using a rotating vane anemometer.

Since the centrifugal blower was not of sufficient capacity to obtain an adequate inside-to-outside pressure difference for the whole house, it was decided to segment the test house into approximately equal sections by closing and taping the interior doorway in the center hallway. It should also be pointed out that performing smoke tests on segmented portions of the test house has the additional advantage of reducing the exterior surface requiring monitoring. Due to time conflicts with other aspects of the energy conservation study, smoke tests were performed only on the living quarters. 


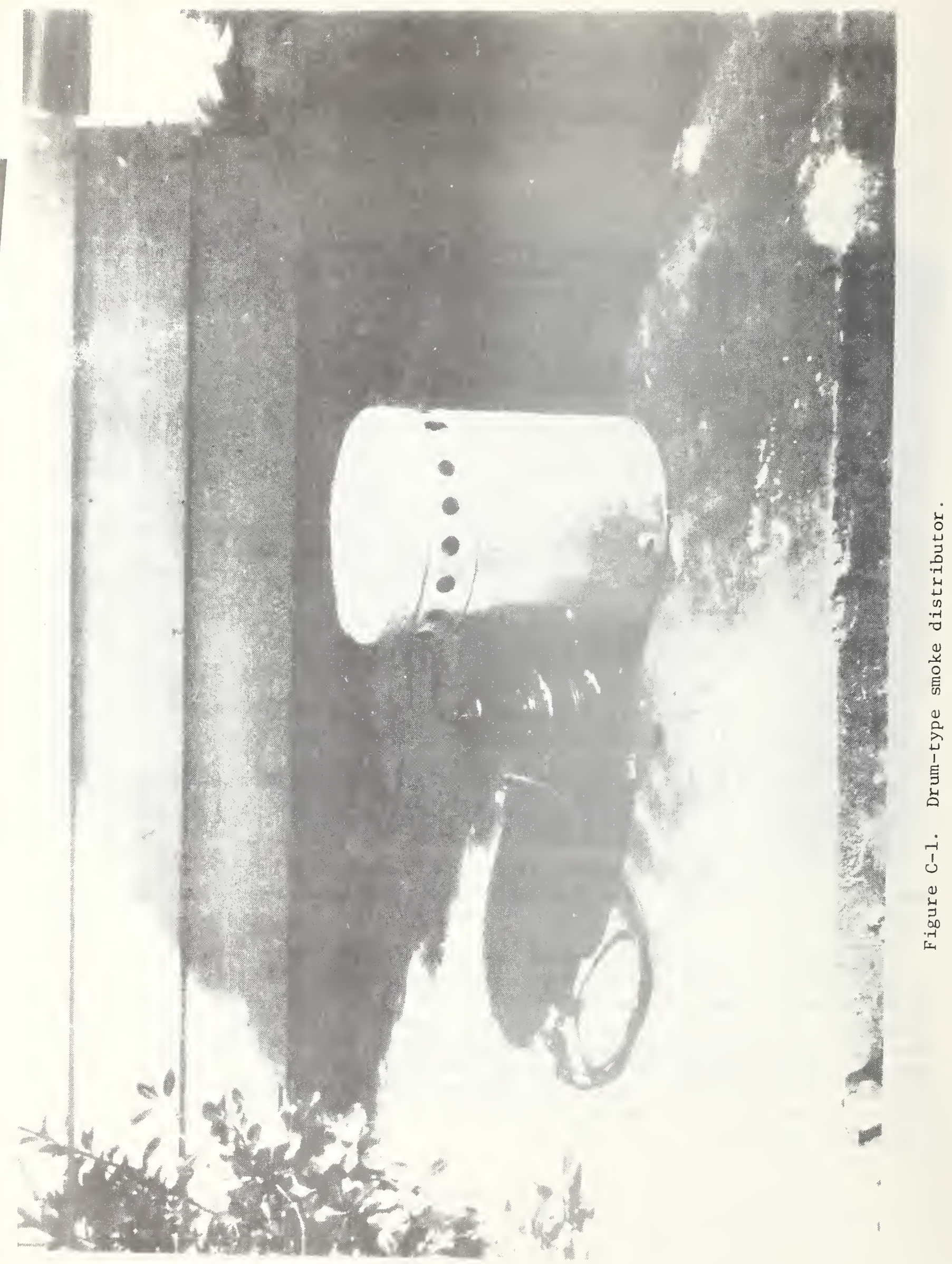




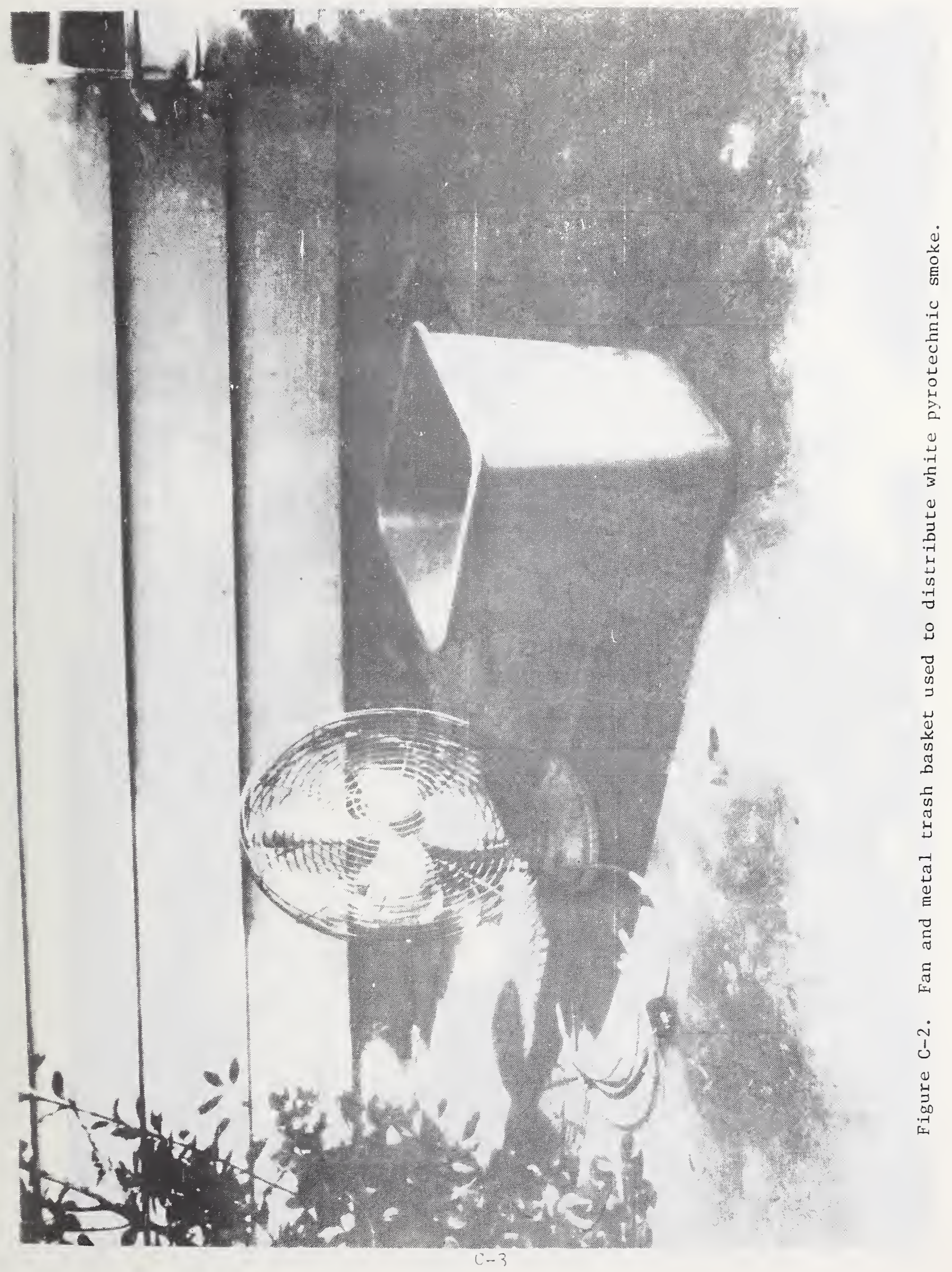




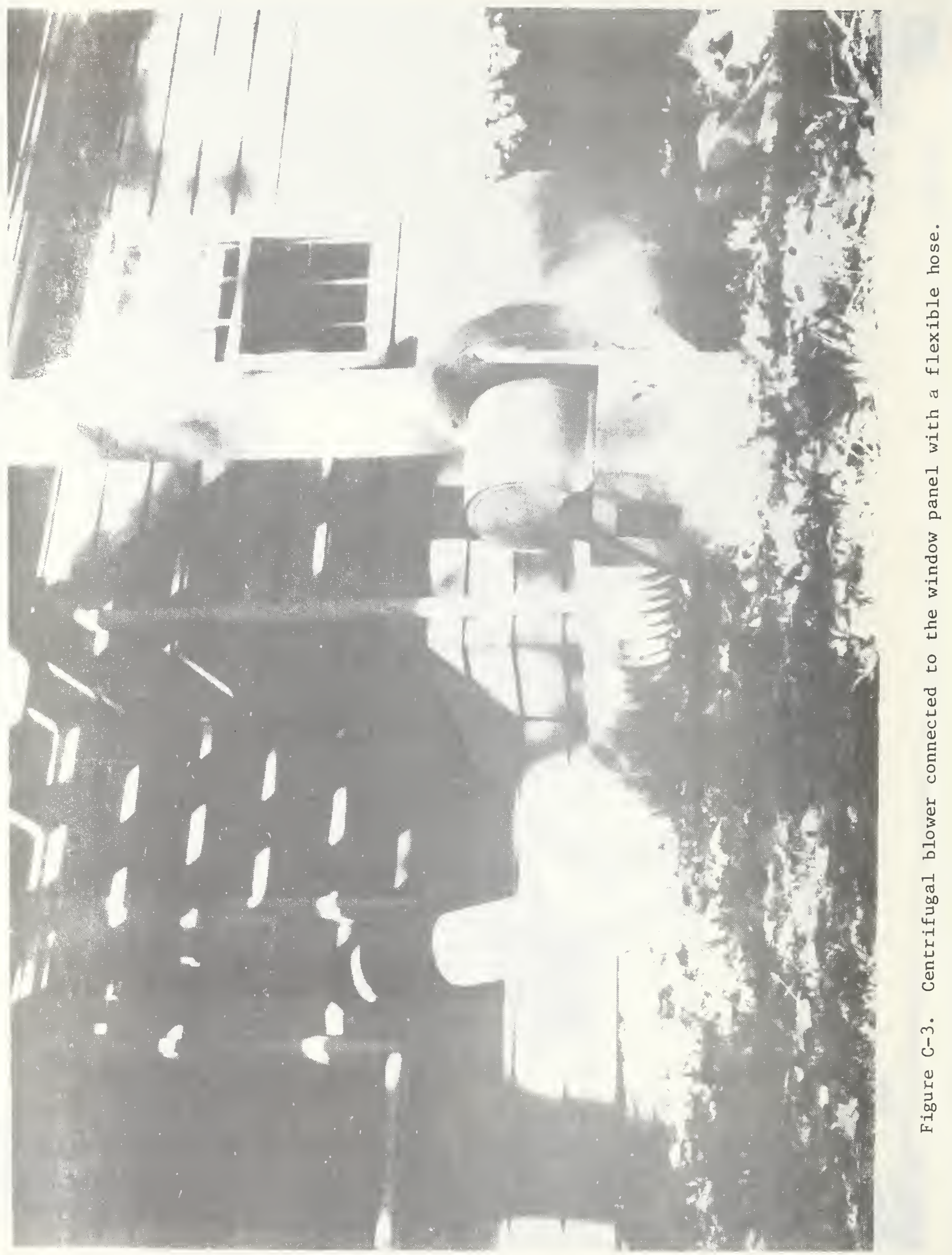


The smoke test on the living quarters was performed before any of the retrofit measures were implemented to reduce air leaks. The drain waste-water traps were filled with water, since this is the way a house would normally be operated. In addition, the return and supply air registers were sealed with aluminum duct tape, since the primary objective was to locate the major air leaks of the exterior envelope of the test house. It would have been useful to perform a separate smoke test on the duct system. However, experimental constraints did not permit such a test to be conducted.

During the smoke test, the wind speed above the test house, the air-delivery rate of the centrifugal blower, and the inside-to-outside pressure differences were measured. The smoke generators were ignited and the living space of the house was allowed to fill with smoke. Subsequently, the house was pressurized and the air-leakage paths were located by visual observations. Smoke leakage was monitored on the four faces and the roof of the test house. In addition, smoke leakage through the floor and ceiling were observed from the basement and the attic spaces, respectively. Points of smoke leakage were marked with colored chalk and photographically documented.

\section{Discussion of Test Results}

Prior to conducting the smoke test, the air-delivery rate of the centrifugal blower was measured and found to be $1970 \mathrm{ft} 3 / \mathrm{min}(0.882$ $\left.\mathrm{m}^{3} / \mathrm{s}\right)$. This air-delivery rate corresponds to approximately 13.7 induced air changes per hour, which is roughly twenty-eight times the natural rate under typical winter conditions. Inside-to-outside pressure differences measured at various locations are given in table $\mathrm{C}-1$.

Table C-I

Location

Living Room

Kitchen

Dining Room

Half Bath

Foyer

Study or Den

Average
.1034

.0920

.0917

.0919

.0913

.0958 
The inside-to-outside pressure difference remained comparatively constant and did not vary much from one room to another. An important consideration in conducting smoke tests is that the pressure difference remain approximately constant across the various exterior surfaces of the test structure.

The wind velocity was measured before and after the test and ranged between 0.5 and $3 \mathrm{mi} / \mathrm{h}(0.224$ and $1.34 \mathrm{~m} / \mathrm{s})$.

A major air-leakage path was through the chimney as shown in figure $\mathrm{C}-4$. An inspection of the fireplace damper revealed that it was not seated properly and a large crack existed between the damper frame and the damper. Another major path of air leakage was through the kitchen ventilation-exhaust opening, as shown in figure C-5. An inspection of the kitchen ventilation-exhaust opening revealed that the hinge of the damper had become seriously corroded and the damper was frozen in an open position. Another major air-leakage path was through the celling as observed from the attic space. In this case, the smoke was observed to be effusing through the large crack where the chimney penetrated the ceiling and at the eaves where the sloping roof meets the attic floor. It was postulated that the path for the smoke effusing near the eaves was through the wall cavities of the exterior walls. The smoke may have entered the wall cavity through cracks along the baseboard. Other observed air-leakage paths include cracks under the doors and around the windows. These paths were much less pronounced than the other major air-leakage paths previously noted.

\section{Conclusion}

A smoke test was shown to be an effective research technique for locating specific air leaks for a residence. As a result of the findings of the smoke test, the following specific measures were taken to seal air-leakage paths of the test house:

- The fireplace-damper system was repaired.

- A spring-activated kitchen ventilation-exhaust damper was installed.

- The window panes were reputtied as needed.

- The window frames were recaulked as needed. 

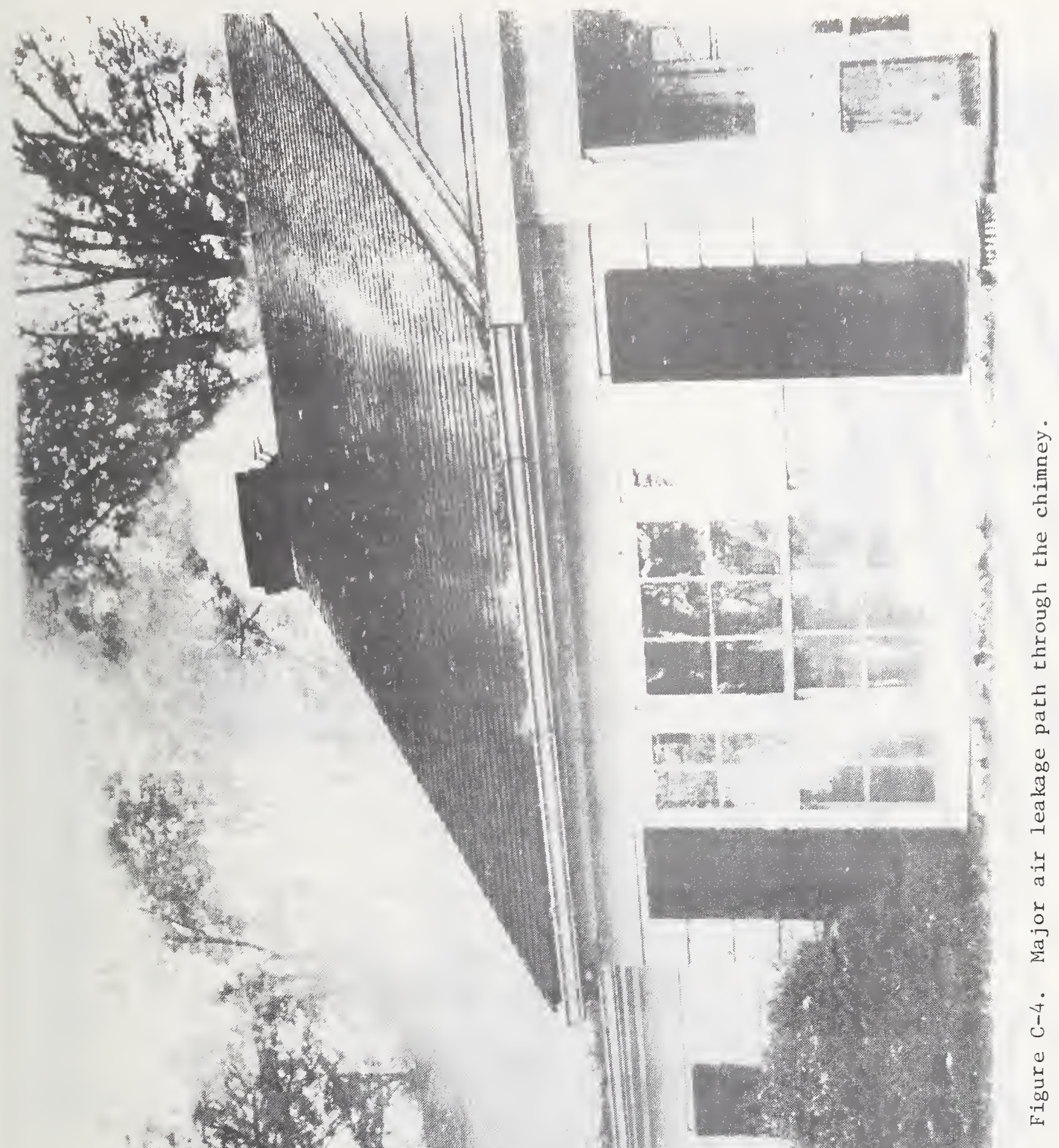

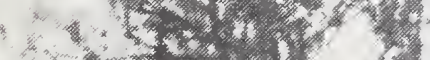

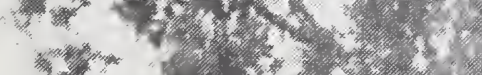

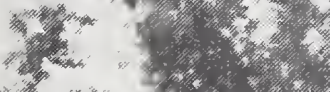

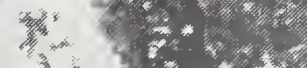

2.

(n)

\% 


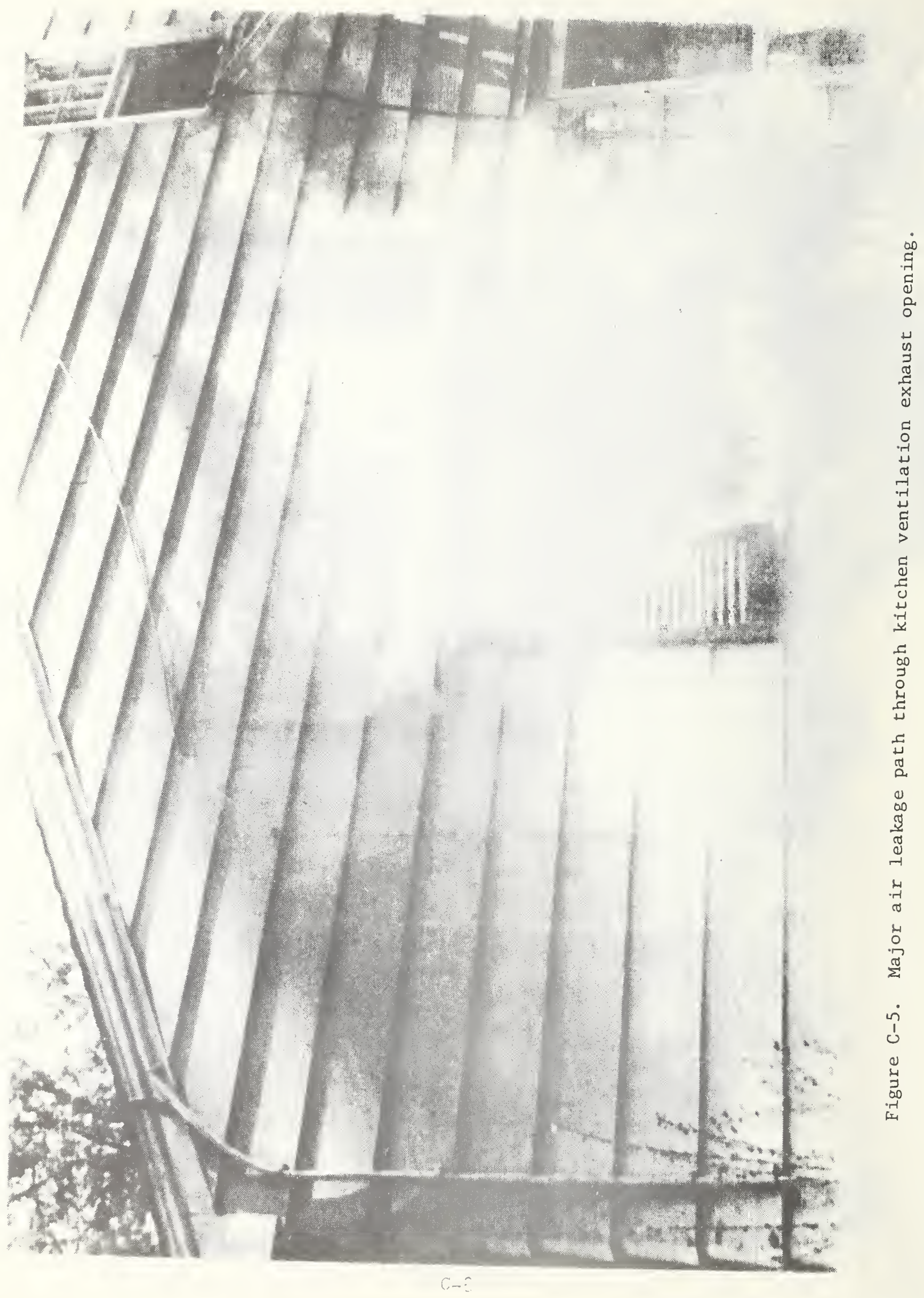


N85.116

IF ...

\begin{tabular}{|c|c|c|}
\hline $\begin{array}{c}\text { U.S. DEPT. OF COMM. } \\
\text { BISLIOGRAPHIC DATA } \\
\text { SHEET }\end{array}$ & $\begin{array}{c}\text { 1. I'IIII.IC ATION ()R RH:P(OR'T N(). } \\
\text { NBSIR } 77-1274\end{array}$ & $\begin{array}{l}\text { 2. GOV't Accession } \\
\text { No. }\end{array}$ \\
\hline
\end{tabular}

4. TITI.I: AND SIIITITI.I:

7. AUTHOR(S)

RETROFITTING AN EXISTING WOOD-FRAME

RESIDENCE FOR ENERGY CONSERVATION-AN

EXPERIMENTAL STUDY

D.M. Burch and C.M. Hunt

9. PERFORMING ORGANIZATION NAMF AND ADDRESS

NATIONAL BUREAU OF STANDARDS

DEPARTMENT OF COMMERCE

WASHINGTON, D.C. 20234

5. Publication Date

July 1977

6. P'erforming Organization Code

8. Performing Organ. Report No.

10. Projuct/Task/Work Unit No. 4626400

11. Contract/Grane No.

13. Type of Report \& Periou Covered

Final - 2-year repor

Federal Energy Administration (F'EA)

Washington, D.C. 20461

14. Sponsoring Agency Code

15. SIIPPI.EMENTARY NOTES

16. ABSTRACT (A 200-word or less factual summary of most significant information. If document includes a significant bibliobraphy of literature survey, mention it here.)

A wood-frame residence having only limited insulation in the at.tic was retrofitted in three stages to reduce its energy requirements for heating and cocling. The three retrofit stages comprised: reducing air leaks; adding storm windows; and installing insulation in the floor, ceiling, and walls. The house was extensively instrumented to evaluate energy savings and other performance factors. An economic model was used to evaluate the cost effectiveness of the retrofit options and the number of years to pay back their initial investment.

The walls of the test house were insulated with three different types of insulating material: fibrous glass wool, cellulosic fiber, and urea-formaldehyde foam. The thermal performance of these three insulating materials was measured and comparet, both in the field and laboratory.

"Recomended good practices" for moisture protection were applied when insulation was installed in the test house. The effectiveness of these measures in preventing damaginle moisture accumulation in crawl spaces and attics was evaluated.

Finally, thermographic surveys were performed before and after the retrofit. Based on the results of these surveys, criteria for distinguishing between insulated and uninsulated wood-Prame cavity walls were presented.

17. KEY WORDS (six to twelve entries; alphabetical order; capitalize only the first letter of the first key word unless a proper name; separated by semicolons)

Air infiltration; condensation in buildings; energy conservation; energy measurements; fuel savings; heat-loss reduction; insulation properties; residential heat loss; retro fitting houses; therwel conductivity; themal irsulation. themomarby

18. AVAILABILITY Unlimited

[- For Official Distribution. Do Not Release to NTIS

[7 Order From Sup. of Doc., U.S. Government Printing Office Washington, D.C. 20402, SD Cat. No. C13

[X] Order From National Technical Information Service (NTIS) Springfield, Virginia 22151
19. SECURITY CLASS

(THIS REPURT)

UNCL ASSIF IED

20. SECURITY CLASS

(THIS PAGE)

UNCLASSIFIED
21. NO. OF PAGES

\section{7}

22. Price

$\$ 7.50$ 

